Portland State University

PDXScholar

Summer 8-15-2017

\title{
The Tension between Technocratic and Social Values in Environmental Decision-making: An'Yang Stream Restoration in South Korea
}

Chang-Yu Hong

Portland State University

Follow this and additional works at: https://pdxscholar.library.pdx.edu/open_access_etds

Part of the Water Resource Management Commons

Let us know how access to this document benefits you.

Recommended Citation

Hong, Chang-Yu, "The Tension between Technocratic and Social Values in Environmental Decisionmaking: An'Yang Stream Restoration in South Korea" (2017). Dissertations and Theses. Paper 3784. https://doi.org/10.15760/etd.5668

This Dissertation is brought to you for free and open access. It has been accepted for inclusion in Dissertations and Theses by an authorized administrator of PDXScholar. Please contact us if we can make this document more accessible: pdxscholar@pdx.edu. 
The Tension between Technocratic and Social Values in Environmental Decisionmaking: An'Yang Stream Restoration in South Korea

$$
\text { by }
$$

Chang-Yu Hong

A dissertation submitted in partial fulfillment of the requirements for the degree of

\author{
Doctor of Philosophy \\ in \\ Urban Studies
}

\title{
Dissertation Committee: \\ Connie P. Ozawa, Chair Sy Adler \\ Heejun Chang \\ Sung $\mathrm{Yi}$
}

Portland State University

2017 
(C) 2017 Chang-Yu Hong 


\begin{abstract}
This dissertation examined the extent to which interests and values of diverse stakeholders were considered through participation-oriented decision-making. It covered the An'Yang Stream restoration case in South Korea, which has been judged a successful stream management endeavor led by public-private partnership governance.

This research utilized a mixed methods approach, combining qualitative and quantitative methods. It addressed the extent to which the collaborative and participatory decision-making processes incorporated diverse stakeholder values and visions. The relevant data on stream restoration was collected through nominal group technique (NGT), analytic hierarchy process (AHP), semi-structured interviews, observations at collaborative stakeholder meetings and workshops, and documentation review.

My research concluded that integration of all interests was not achieved. These interests might have potentially affected the extent to which stakeholders' values are incorporated or not in participation-oriented collaborative stakeholders' partnerships by utilizing interest-based facilitation techniques, such as joint-fact-finding or principled negotiation. At the same time, my findings expatiate the catalyzing roles of the public media within stream restoration decision-making governance.
\end{abstract}




\section{TABLE OF CONTENTS}

ABSTRACT

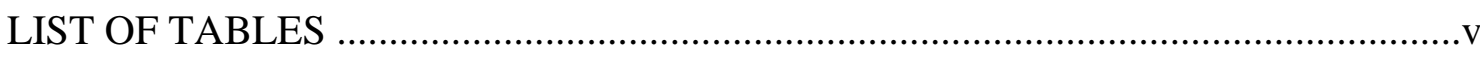

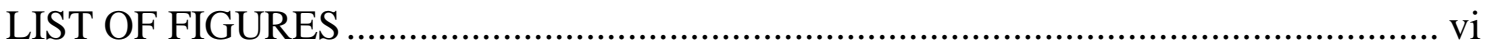

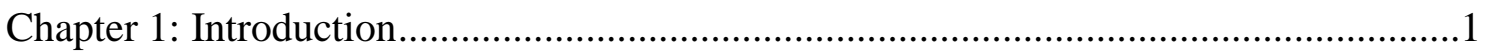

1.1 MOTIVATIONs AND THEORETICAL PERSPECTIVE …………......................

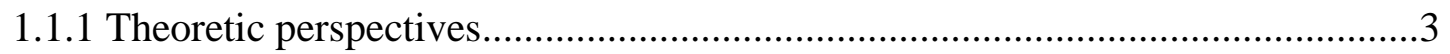

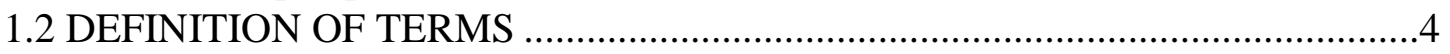

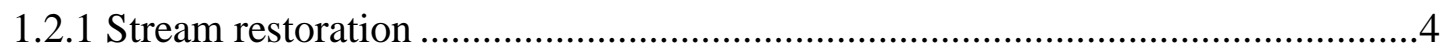

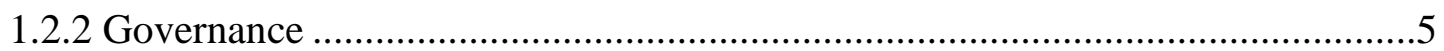

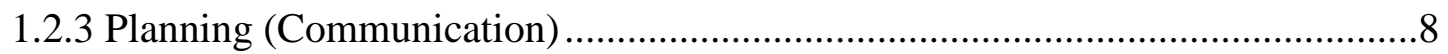

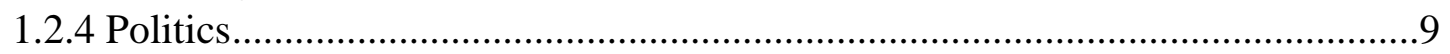

1.3 RESEARCH OBJECTIVES AND QUESTIONS ................................................10

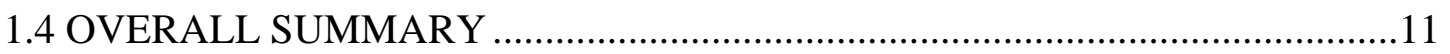

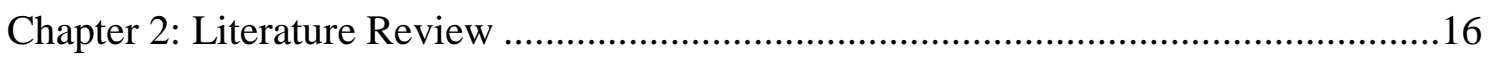

2.1 HISTORICAL DOMINATION OF TECHNOCRATIC PERSPECTIVES IN

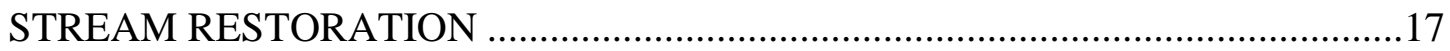

2.2 INTEGRATED WATER RESOURCE MANAGEMENT (IWRM) …..................18

2.3 TENSION RESULTING FROM NARROW PERSPECTIVES ...........................19

2.4 ELEMENTS OF INTEGRATED WATER RESOURCE MANAGEMENT .......20

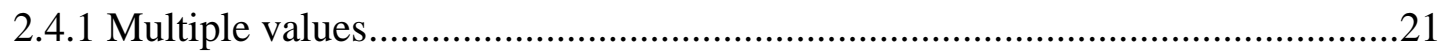

2.4.2 Decision makers' value, background and ability .............................................21

2.4.3 Uncertainty within decision-making ...............................................................22

2.5 MOVING BEYOND CONVENTIONAL TECHNOLOGY-DOMINATED

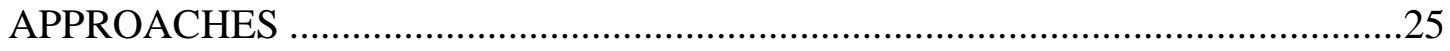

2.6 PLANNING AND STREAM RESTORATION …………………………........28

2.6.1 The role of power in making decisions about stream restoration understanding

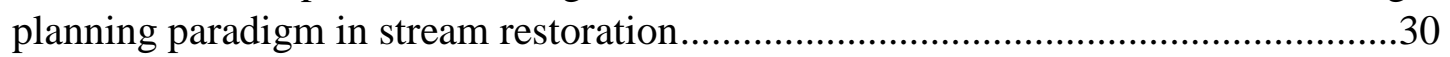

2.6.2 Power in collaborative planning ......................................................................33

2.6.3 Collaborative planning methods to mitigate conventional sources of power ....36

2.7 ENVIRONMENTAL PLANNING PARADIGM EVOLUTION OF SOUTH

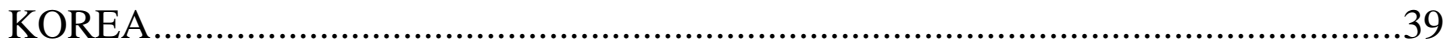

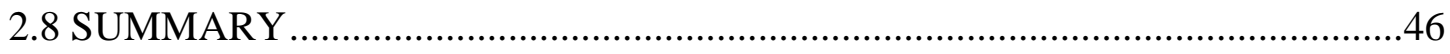

Chapter 3: Research Design ..................................................................................4

3.1 REGIONAL CONTEXTS IN THE FIELD OF STREAM RESTORATION.......48

3.2 CASE SELECTION AND INTRODUCTION TO AN'YANG STREAM ...........50

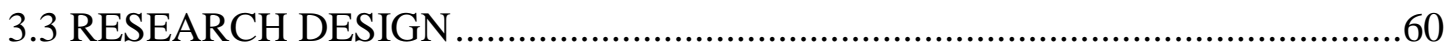

3.3.1 Questions guiding data collection (See factors to examine in Appendix 4) ..... 60 


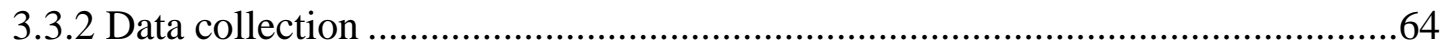

3.3.3 Phase 1: NGT and Initial document review ..................................................66

3.3.4 Phase 2: Designing and preparing semi-structured interviews ...........................67

3.3.5 Phase 3: Mixed method analysis (Content analysis + AHP) ………………........71

3.3.6 Phase 4: Grounded theory .............................................................................

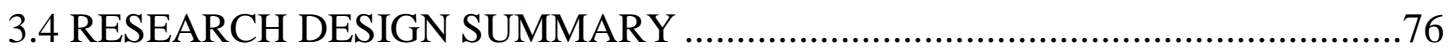

Chapter 4: Document Review of An'Yang Stream Restoration Master Plan ..................77

4.1 CONTENT ANALYSIS .............................................................................

4.1.1 Contextual background and initial agendas of the Master Plan ........................81

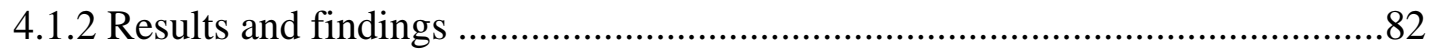

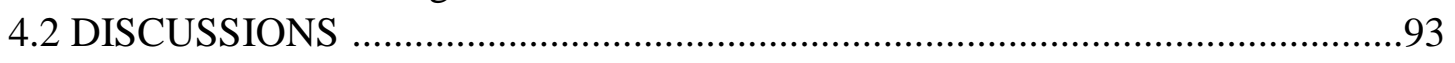

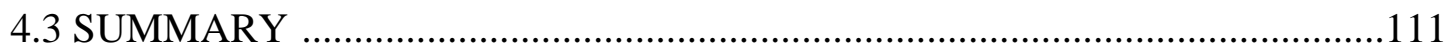

Chapter 5: Content Analysis of Interview with Stakeholders ......................................116

5.1 RESULTS FROM CONTENT ANALYSIS OF INTERVIEWS …………........116

5.2 INTERVIEW WITH STAKEHOLDERS …………………………..............122

5.2.1 Government groups (Public administrators) …………..................................123

5.2.2 Non-governmental organization (NGO) …………....................................127

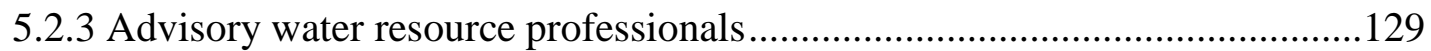

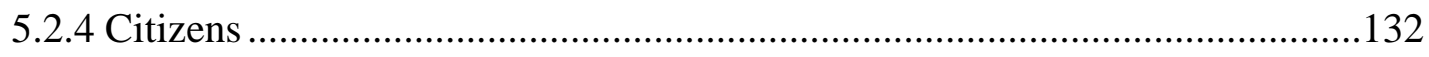

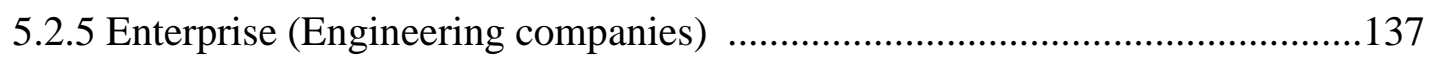

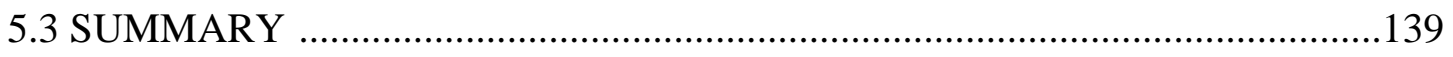

Chapter 6: Understanding Values of Stakeholders (AHP Analysis) .............................141

6.1 QUANTITATIVE ANALYSIS BY AHP ……………................................142

6.2 USING NGT TO SELECT SURVEY ITEMS FOR AHP .................................144

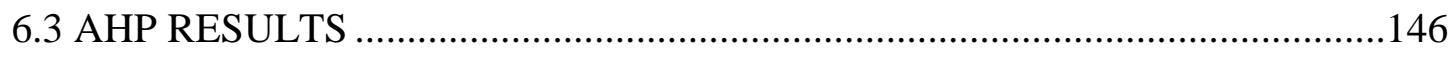

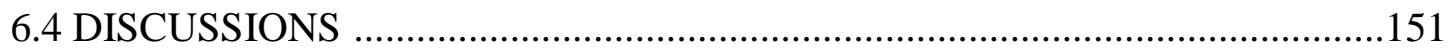

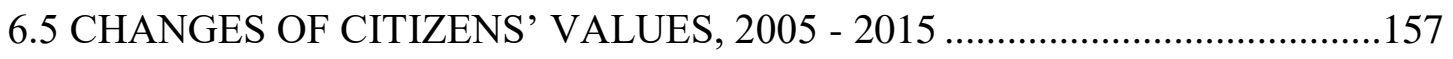

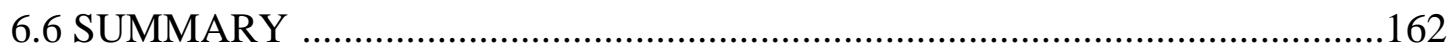

Chapter 7: Evaluating and Comparing Values of Stakeholders .....................................163

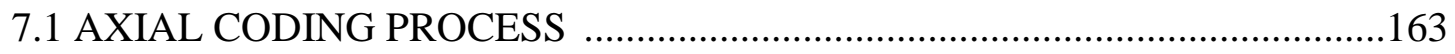

7.1.1 Main three values of stakeholders (core category) …………………………....164

7.1.2 Influential background (causal condition) ………….........................................166

7.1.3 Preconditions- public opinion and media (contextual conditions) ..................170

7.1.4 Interactive motivation (intervening conditions) ...........................................172

7.2 TACTICAL POSITIONING FOR SHORT-TERM GOALS (STRATEGIES) ..178

7.3 IMPLEMENTATION OF MASTER PLAN (CONSEQUENCES)....................183

7.4 OVERALL STORYLINE OF STREAM RESTORATION GOVERNANCE

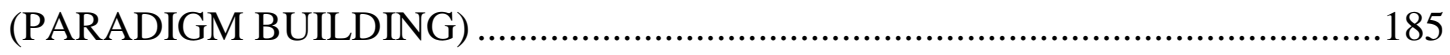

7.4.1 Leadership in decision-making ..............................................................189

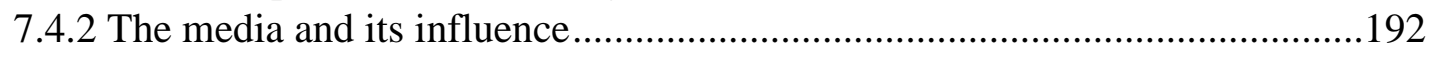

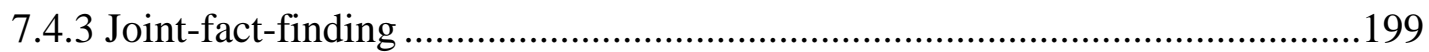




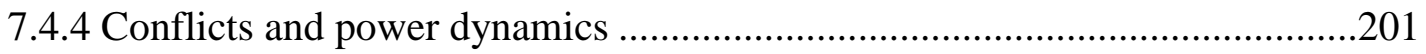

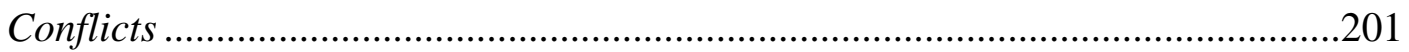

Power dynamics within decision-making ........................................................207

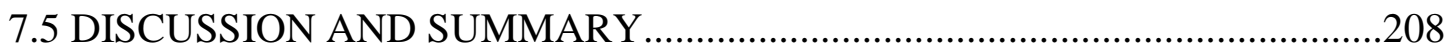

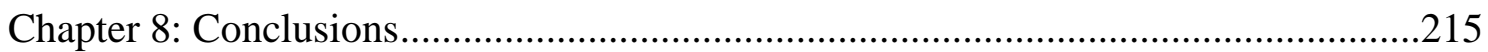

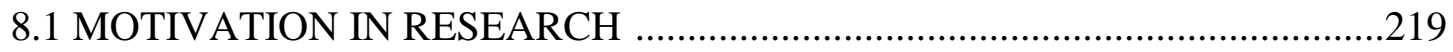

8.2 SUMMARY OF FINDINGS …...............................................................22

8.3 DISCUSSION OF FINDING 1: STRENGTHS OF TECHNOCRATIC STREAM

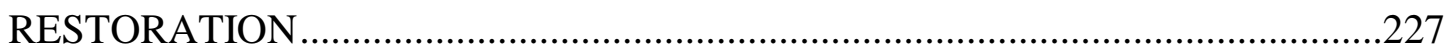

8.4 DISCUSSIONS OF FINDING 2: WEAKNESSES OF TECHNOCRATIC

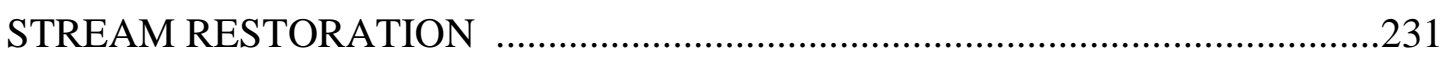

8.5 LIMITATIONS AND VALUES OF THIS RESEARCH ...............................236

8.6 GUIDELINES FOR FUTURE RESEARCH ..............................................237

8.7 SYNERGISTIC PATHWAYS FOR WATERWAY RESTORATION (SPWR)

.238

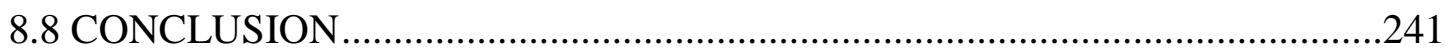

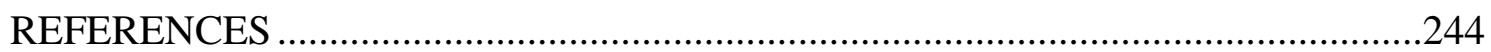

APPENDIX A Codes of the content analysis of the An'Yang Stream Restoration Master

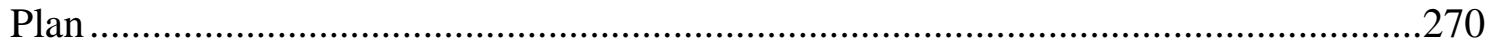

APPENDIX B Codes of the content analysis of the interview .................................271

APPENDIX C Top three values on An'Yang stream restoration of water professionals

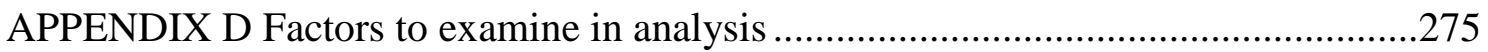

APPENDIX E Informed consent information for semi-structured interviews.............281

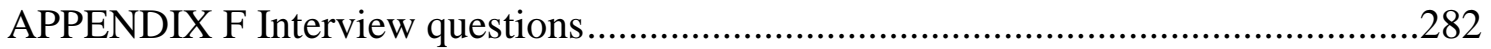

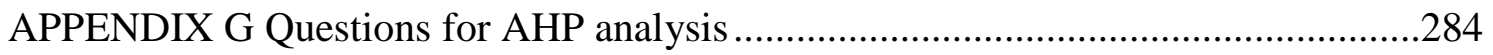

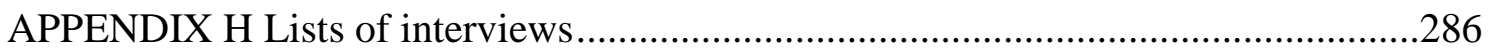




\section{LIST OF TABLES}

Table 1. Research process design 13

Table 2. Major key decision-makers in water resource management (U.S. vs.

Korea) 45

Table 3. An'Yang Stream Restoration Goals (An'Yang City, 2003) .................... 56

Table 4. Early period timeline of An'Yang Stream restoration before 2001 ......... 57

Table 5. Annual plans and strategies of An'Yang Stream Restoration ................. 59

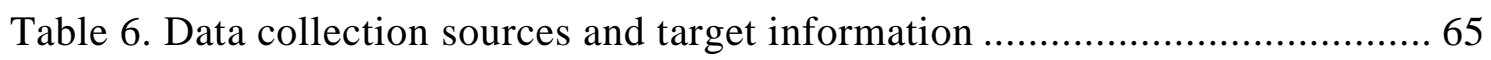

Table 7. Research process design ...................................................... 76

Table 8. Codes and results in content analysis .......................................... 79

Table 9. Value and preferred participatory ways of An'Yang citizens in $2001 \ldots . .82$

Table 10. Participants of the decision-making board ................................... 84

Table 11. Major values of stakeholders ................................................. 118

Table 12. The survey results of NGT: priorities among diverse values .............. 146

Table 13. The relative importance test results of AHP with stakeholders' value .. 147

Table 14. Core categories (main values of stakeholders) ............................. 165

Table 15. Causal conditions (influential background) ................................ 168

Table 16. Contextual condition (preconditions of decision-making)................. 170

Table 17. Intervening conditions (solutions for interactive situation) ............... 174

Table 18. Strategies (tactical positioning for short-term goals) ...................... 178

Table 19. Consequence (Implementation of Master Plan) ........................... 183 


\section{LIST OF FIGURES}

Figure 1. Conventional water management governance

Figure 2. Conventional water governance with three vertexes of discipline,

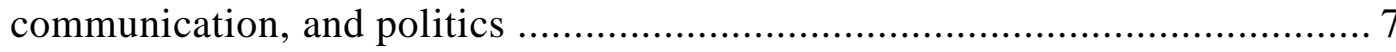

Figure 3. Research flow-map of dissertation ........................................... 14

Figure 4. Paradigm shift under conceptual model of eco-hydrology ................... 27

Figure 5 An'Yang Stream River basin .................................................... 51

Figure 6 An'Yang Stream Restoration Governance (City of An'Yang, 2001) ....... 55

Figure 7 Flowing-chart of interview and AHP survey process ......................... 71

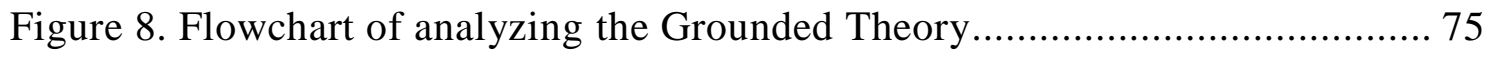

Figure 9. Flowing map of research for An'Yang Stream Restoration Master Plan

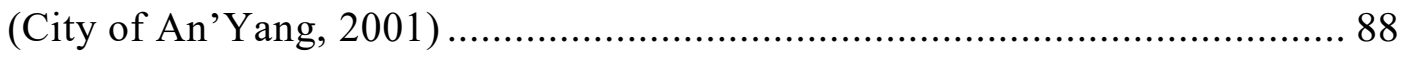

Figure 10. Organization chart of An'Yang Stream Restoration task force and advisory committee (City of An'Yang, 2001) ................................... 108

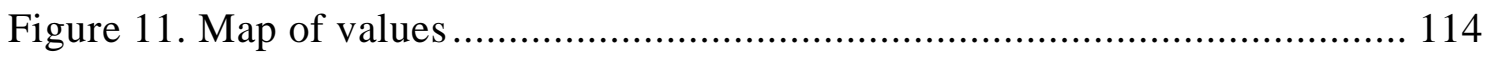

Figure 12. AHP process flowchart ................................................ 144

Figure 13. Distribution diagrams of the stakeholders' preferences in agenda setting of stream restoration

Figure 14. Weighted value of relative importance and CVs of the criteria on

An'Yang Stream Restoration .......................................................... 154

Figure 15. Paradigm building of An'Yang Stream case ................................ 188

Figure 16. An'Yang Stream Restoration Story Hall (Visitor Center) Facebook (1): communicating with citizens and announcing their events 198 
Figure 17. An'Yang Stream Visitor Center Facebook (2): updating on An'Yang Stream on the social media 198

Figure 18. Hierarchical structure of stream restoration ............................... 209

Figure 19. Various definitions of stream restoration ............................... 219

Figure 20. Synergetic pathways for waterway restoration (SPWR) ................... 241 


\section{Chapter 1}

\section{Introduction}

Assuring healthy water and efficient water distribution systems is a goal for scientists, urban planners, and localities around the globe. One strategy to meet this goal is the restoration of existing contaminated water sources, such as streams.

For South Korea, water issues are serious concerns. Many streams require restoration efforts to provide safe water to society and maintain a well-conserved ecological system for nature.

Even though there is agreement on the importance of water resource management, and restoring existing streams is a promising strategy, there is less agreement about how to meet this goal. An important question in this regard is, What are the conditions, consequences, and processes of identifying and engaging stakeholders?

Prior research offers alternative perspectives on this question. On the one hand, stream restoration studies commonly apply technological and natural science-oriented standards (Nakamura et al., 2006). In fact, prevailing definitions of stream restoration focus on acts of scientists and engineers to improve water environments through the application of hydraulic modeling and structures, ecological revitalization and fluvial

geomorphic approaches to watersheds (Wohl et al., 2005; Woolsey et al., 2007; Simon, 2011).

However, these technocratic and natural science-oriented standards, while based on scientific methods and led by engineering technologies, address non-scientific interests held by stakeholders in only a limited way. This approach has led to conflicts among stakeholders (Burger et al., 2005). 
Other researchers apply an interdisciplinary lens in which the human element weighs equally with technical expertise (MacDonald et al., 2004; and Henriksen et al., 2009). Comin et al. (2005) note that every case has unique characteristics, and the desired restoration outcomes tend to be subjective. Accordingly, such an approach recommends a review of social factors, as well as ecological enhancement, when planning and implementing stream restoration.

This research analyzes the role of alternative perspectives in the An'Yang Stream Restoration Project in South Korea. The Restoration Project has been heralded as an effective example of establishing citizen-oriented water governance (Hong and Chung, 2016). While there is much description of the technical aspects of restoration, there has been little discussion of how multiple perspectives were incorporated when making decisions were made about this project.

\subsection{MOTIVATIONS AND THEORETICAL PERSPECTIVE}

Motivation for this study is both professional and personal. From a personal perspective, water management in South Korea is important to me because the stream provided wonderful memories for my grandmother a century ago. My grandmother, Soon-Im, was born in An'Yang in 1905. When I was a child, she talked about her distant memories of the clean and beautiful watershed. I would like to repay her love with this dissertation.

From a professional perspective, as water supplies throughout the world are threatened, global leaders are called upon to plan and implement strategies. They must improve the quality and expand the quantity of water so the populace can sustain itself. 
My academic and career goals are to advise water resource management and environmental decision-makers.

\subsubsection{Theoretic perspectives}

To analyze how decision-making took place for the An' Yang Stream Restoration Project, this research is informed by theoretical perspectives from water resource management as well as from planning.

Theories about how to improve water quantity and quality through stream restoration are evolving. Historically, research has focused on theories from natural science, advancing rational planning processes and efficient decision-making. Scientific and engineering information has played the primary role in water resource planning (Winterfeldt, 2012). Successful water management has been measured by technical criteria from natural sciences, such as return to the natural state, water flow and reduction of pollution (Allan and Castillo, 2007). Technological water management theories identify the scientists themselves as primary stakeholders in decision-making (Winterfeldt, 2012). Further, engineering-oriented decisions tend to be made through top-down governance (Park and Grigg, 2004).

However, reliance on engineering technologies has led to conflicts between engineers and natural scientists on the one hand, and social scientists who incorporate the human element in water restoration. Community, lifestyle, cultural and historical elements impact the sustainability of water management. Contemporary research utilizes continuous assessment of community support from multiple sectors, including 
political, historical, engineering, natural science, and culture (Palmer et al, 2005; Lave et al, 2012).

While this research acknowledges technical contributions from natural science and engineering to build a foundation of knowledge, this study also examines interdisciplinary elements.

\subsection{DEFINITIONS OF TERMS}

A foundation for this research rests on the key terminologies. First, the concept of governance is reviewed as a form of the directivity and structure of decision-making. The second set of terms are definitions specific to stream restoration (discipline). The disciplines of stream restoration involve standards guided by scientific and technological concepts. The last set of terms pertains to change processes, including communications and power. Conventional water governance clearly shows an imbalanced relationship between natural scientific factors and social values (Figure 1). This research will describe a stream restoration case from three perspectives: governance, communication tools, and power dynamics.

\subsubsection{Governance}

Governance occurs on a continuum, from top-down approaches such as technocratic governance systems, to social coordination with a public purpose (Pierre and Peters, 2000). In any case, governance represents the means of integration and consolidation to promote social order and stability by enforced power and control under an agreement among decision-makers (Priscoli, 2001 and Cvitanovic et al., 2015). As 
noted by Tuladhar (2005), governance provides a structure for decision-making by a group of stakeholders. This decision-making process can be the most important element of forming successful governance. Science-centric governance leads to an unbalanced decision-making process (Figure 1).

\subsubsection{Stream restoration}

Stream restoration can be distinguished by two approaches: technical definition and interdisciplinary definition. "From a technological and engineering perspective, stream restoration is defined as a process of returning river sections from conditions adversely influenced by humans to a near-natural state through improved hydrologic, geomorphic and ecological processes by scientists and engineers." (Wohl et al., 2005; Wolsey et al., 2007) Under a technological definition, stream restoration improves according to indicators that can be objectively measured using scientific standards. These indicators include: improved water quality, or Bio-chemical Oxygen Demand (BOD) and Dissolved Oxygen (DO) value, controlled and explained by technocratic concepts, such as hydraulic modeling, fluvial geomorphology, etc. (Purcell et al, 2002; Phillips, 2003) Conventional stream restoration indicates predominance of natural scientific oriented stream restoration factors, and social restoration, such as social integrity and stakeholder involvement is not properly considered (Figure 1 and 2). Technocratic disciplines and politics weigh heavily in stakeholder involvement (Figure 2).

From an interdisciplinary perspective, the definition of stream restoration incorporates input from broad swaths of society. Ostrom (2009) has applied the term 


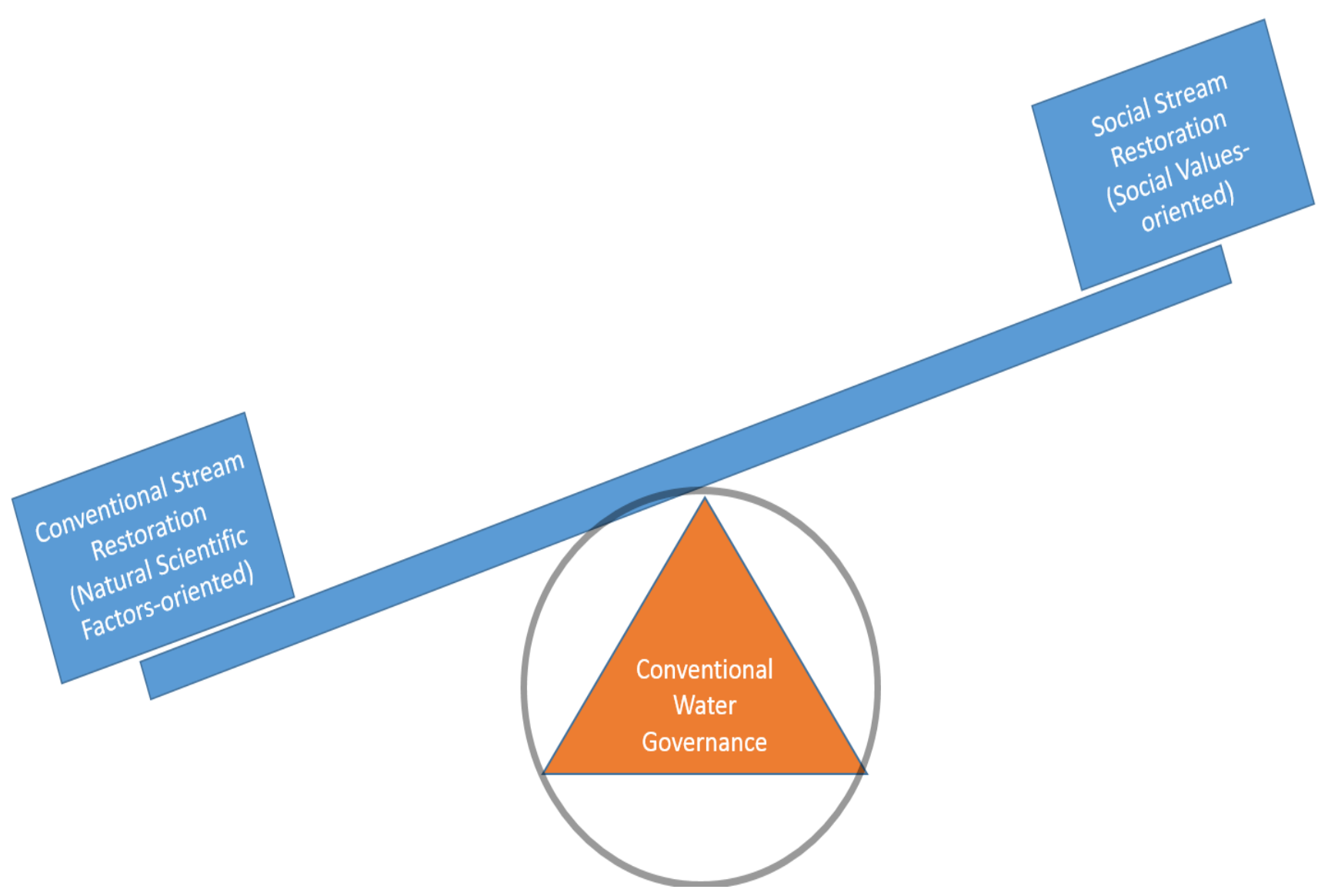

Figure 1. Conventional water management governance 


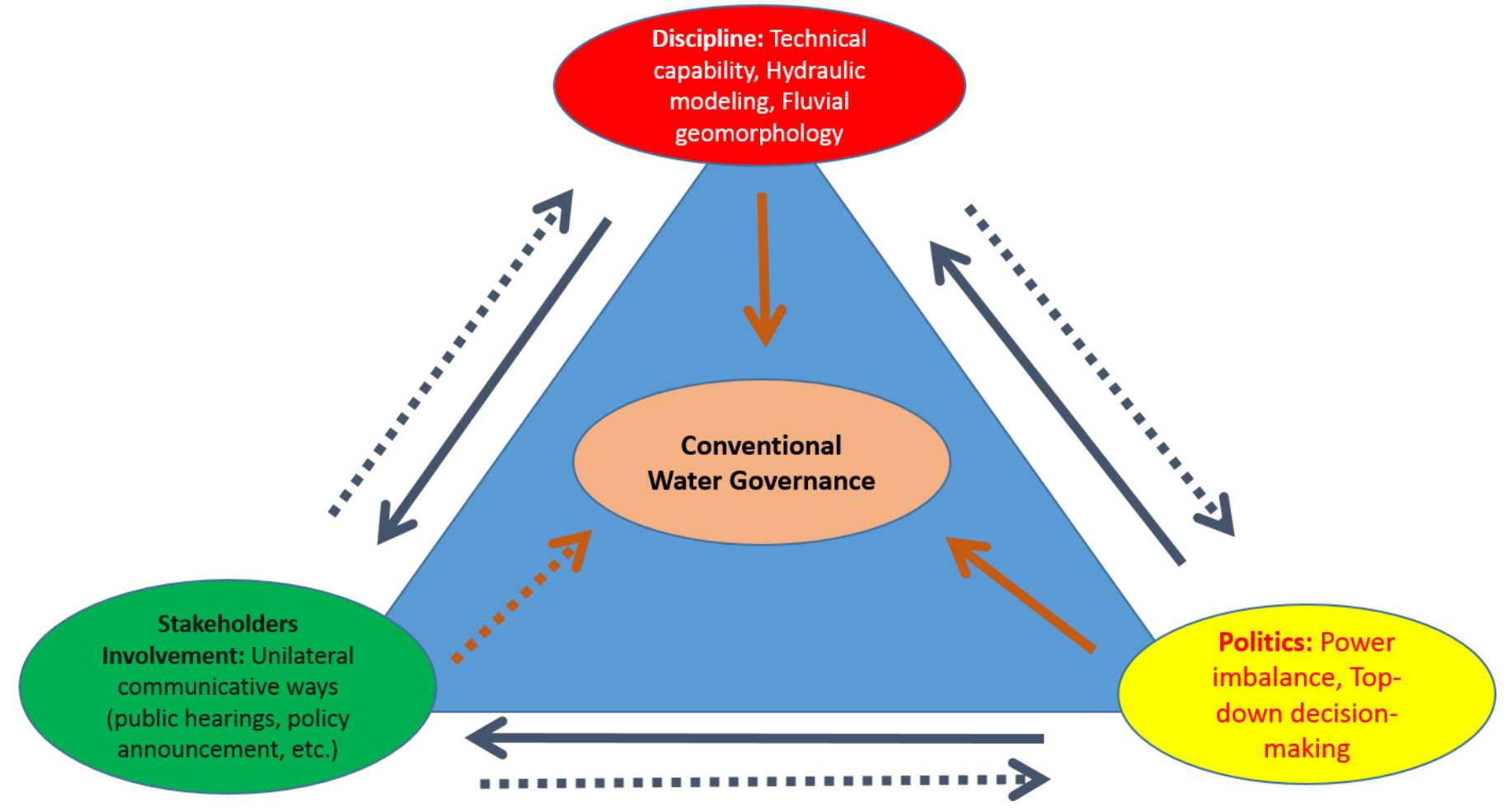

Figure 2. Conventional water governance with three vertexes of discipline, communication, and politics 
"Socio-Hydrology (SH)" to connote the interdependent and communicative feedback between social/human and ecological technical systems. Following Ostrom, SH embraces communication patterns in which information is widely shared and the balance of political power allows for democratic consensus building. In this way, the interdisciplinary approach of SH is adaptive and dynamic, melding technical expertise with social factors.

\subsubsection{Stakeholder involvement}

The concept of collaborative planning provides a theoretical background to understand the structure of stakeholder involvement and institutional rules for participatory decision-making (Booher and Innes, 2003). In terms of communication and interaction between actors, collaborative planning can sometimes function as communicative planning. Collaborative planning tends to focus on collective communicative processes in public relations (Ansell, 2008).

The concept of collaboration is used as an integrated term in this paper because the notion of collaborative planning has been analyzed and explained as part of the communicative interaction process. In terms of communicative interaction, the traditional rational planning model has been criticized for how it addresses social dynamics in the public domain. This is reflected in cases of significant public interest where information and knowledge must be shared among stakeholders. With respect to understanding, the role of the planner is to ensure that communication between actors and stakeholders is not distorted. The conventional, comprehensive rational model does not provide equal and deliberative conditions for stakeholders (Wilson, 2001). 
Conventional planning models tend to involve a public hearing or policy announcement (Figure 2). These are passive and unilateral communication methods and often occur late in the decision-making process (Berner, 2001) (Figure 2).

Since the 1980s, there has been tension in terms of working toward democracy and an equitable planning process while simultaneously increasing public participation and civic engagement among individuals, stakeholders, and governments (Innes and Booher, 2004). Progressive planning practitioners have introduced civic participation as a communicative action and a deliberatively democratic performance within planning practices (Foster, 1989).

\subsubsection{Politics}

This research explains the patterns and paradigms of the power and control of decision-makers and stakeholders in one case. Power is a significant element in stream restoration decision-making (Anderson et al., 2003). Irazabal (2009) asserts that power makes things happen ('power to'), makes others do things ('power over'), or prevents things from happening (preemptive power). These shapes of power in networks or relationships have been explained in the classic writing of Machiavelli's The Prince. Machiavelli views power as a means to an end, not a resource, such as in military relationships between princes and others (Sadan, 2004).

On the other hand, Hobbes (in his writing, 'Leviathan' 1651) proposes that power is centralized and focused on sovereignty as hegemony over others. In the midtwentieth century, it appeared that Hobbes's viewpoint on power dynamics dominated. That's because his approach, based on scientific and technological societal structure, 
was more appropriate in explaining modernism than was Machiavelli's military image (Sadan, 2004). In stream restoration subjects, scientific and technological superiority constitutes power. Consequently, stream restoration projects based on conventional planning models tend to frequently take a top-down decision-making pattern that only aims for goal-oriented efficiency controlled by scientific and technological power.

In collaborative decision-making, power can be shaped within a structure. In other words, the power action is consistent within the network structure (Giddens, 1984; Bryson and Crosby, 1992; Innes and Booher, 2000). Anthony Giddens (1982) discusses power as part of a social theory in his writings. Giddens and Foucault are similar in that they viewed power as an essential component in social structures. Foucault (1979) argues that power is an inseparable part of social structure. He agreed with Nietzsche's concept that the connection between knowledge and power causes inequality. Also, French and Raven (1959) proposed that power based on knowledge or expertise is expert power, which can cause power imbalance. Amy (1987) argues that this power imbalance of expertise or knowledge is frequently seen in environmental conflicts.

\subsection{RESEARCH OBJECTIVES AND QUESTIONS}

This research analyzed decision-making processes utilized in the An'Yang Stream Restoration Project in South Korea from 2001 to 2015. Documents and local news media reported considerable conflicts between hydraulic engineers and natural scientists and stakeholders who lacked professional knowledge and were uncertain about their position on certain aspects of revitalization (Park, 2009). 
This research was organized around the following questions that guided field research conducted in South Korea in 2015. Each research question contains an associated hypothesis (attached in Appendix), concentrates on addressing related factors, and presents subjects for elucidation in the research. The broad research question for supporting the research aims to address:

(1) To what extent are non-technocratic values integrated into stream restoration cases in governance processes of stream restoration in South Korea?

(2) What was achieved and why were social factors not more heavily considered?

(3) In what ways does a participatory governance process in a stream restoration project in South Korea enable the consideration of non-scientific factors into the decision-making process?

In stream restoration, conflicts occur when stakeholders with different viewpoints attempt to work together. Social and scientific factors are often disharmonious in stream restoration. Generally, conflicts occur between stakeholders when involved parties fail to listen to one another. These research questions are interconnected. By addressing these questions, this research provides a refined view of governance participants' values and sharing of their visions across disciplines in South Korean context.

\subsection{OVERALL SUMMARY}

To achieve successful management of stream restoration, appropriate institutions should establish collaboration between decision-makers and stakeholders living in the community, as well as improve environmental elements in the stream (Maathai, 2004). Also, effective stream restoration can contribute to a sustainable and more livable earth, 
so we should clearly identify which elements should be assessed and considered in defining the success of stream restoration. The answer would arguably emerge from an interdisciplinary examination of feedback exchanges through participatory decisionmaking, with emphasis on operationalizing systemic restoration objectives. The feedback is recorded and marked through analyzing interests and values of decisionmakers in the Korean case of stream restoration.

This dissertation explains a complex and critical systems-based framework for sustainable stream restoration by describing and illuminating the impacts of a participatory process in the collaboration between associated stakeholders. In addition, an interdisciplinary literature review is included to explore the implications of complex stream restoration systems. The literature review chapter helps elucidate critical social and ecological epistemologies and relevant methodologies. These methodologies include a qualitative analysis with a descriptive case study by Grounded Theory and the Analytic Hierarchy Process model (AHP) based on in-depth interviews for comprehending sustainable management, the planning process, governance and the power structure between the stakeholders (Table 1). In other words, each stakeholder represents different social and scientific interests. So this research focuses on understanding the roles, interests, and positions of each stakeholder in the case of the An'Yang stream restoration work in South Korea.

The conceptual model based on Grounded Theory for describing and refining the interactions, as well as the roles and interests of each stakeholder, was explained in the context of sustainable and collaborative governance-building within the conceptual 
boundary of the interdisciplinary theories like socio-hydrology and Socio-Ecological Systems (SESs).

Table 1. Research process design

\begin{tabular}{lll}
\hline & \multicolumn{1}{c}{ Qualitative Process } & \multicolumn{1}{c}{ Quantitative Process } \\
\hline Data Collection & 1) Documents review & 1) Water quality data \\
& 2) Semi-structured & 2) Ranking of preferences \\
interview & of decision-makers in \\
& 3) Observation at & stream restoration \\
& $\begin{array}{ll}\text { stakeholder meetings } \\
\text { 4) Social media and DVDs }\end{array}$ & \\
\hline Data Analysis & 1) Content analysis & 1) Analytic Hierarchic \\
& 2) Grounded Theory & Process \\
\hline
\end{tabular}

The next chapter provides a comprehensive overview of an integrated and interdisciplinary literature, which helps understand complex and critical stream restoration, environmental decision-making and power dynamics in stream restoration governance. Chapter 3 introduces the outline of this research approach and specific field-work processes and shows the primary goal and designed research plan of this dissertation. Based on Chapter 3, Chapters 4, 5 and 6 address the research process step by step. Chapter 4 analyzes the goals of the early stage prior to 2001 of one primary document, the An'Yang Stream Restoration Master Plan (2001), through content analysis. Chapter 5 discusses findings and the implications of interviews to recognize and analyze the values and goals of each participant within the An'Yang Stream Restoration decision-making and governance process of implementation after the Master Plan (from 2001 to 2015). Chapter 6 includes discussion of findings and the implications of Analytic Hierarchy Process (AHP) analysis in order to recognize and analyze the priorities among the values of each decision-maker within an entire 
storyline and implementation process of the agendas and strategies established in the Master Plan (2001). Chapter 7 includes comprehensive discussion of findings and the implication of content analysis after interviews and AHP analysis of the comparative preference survey to integratedly understand and recognize the various values and goals of each decision-maker within the An'Yang Stream Restoration governance, along with the conceptual map of Grounded Theory. This last chapter, Chapter 8, covers conclusions after discussions of overall findings and proposals of available solutions that are found through this dissertation research.

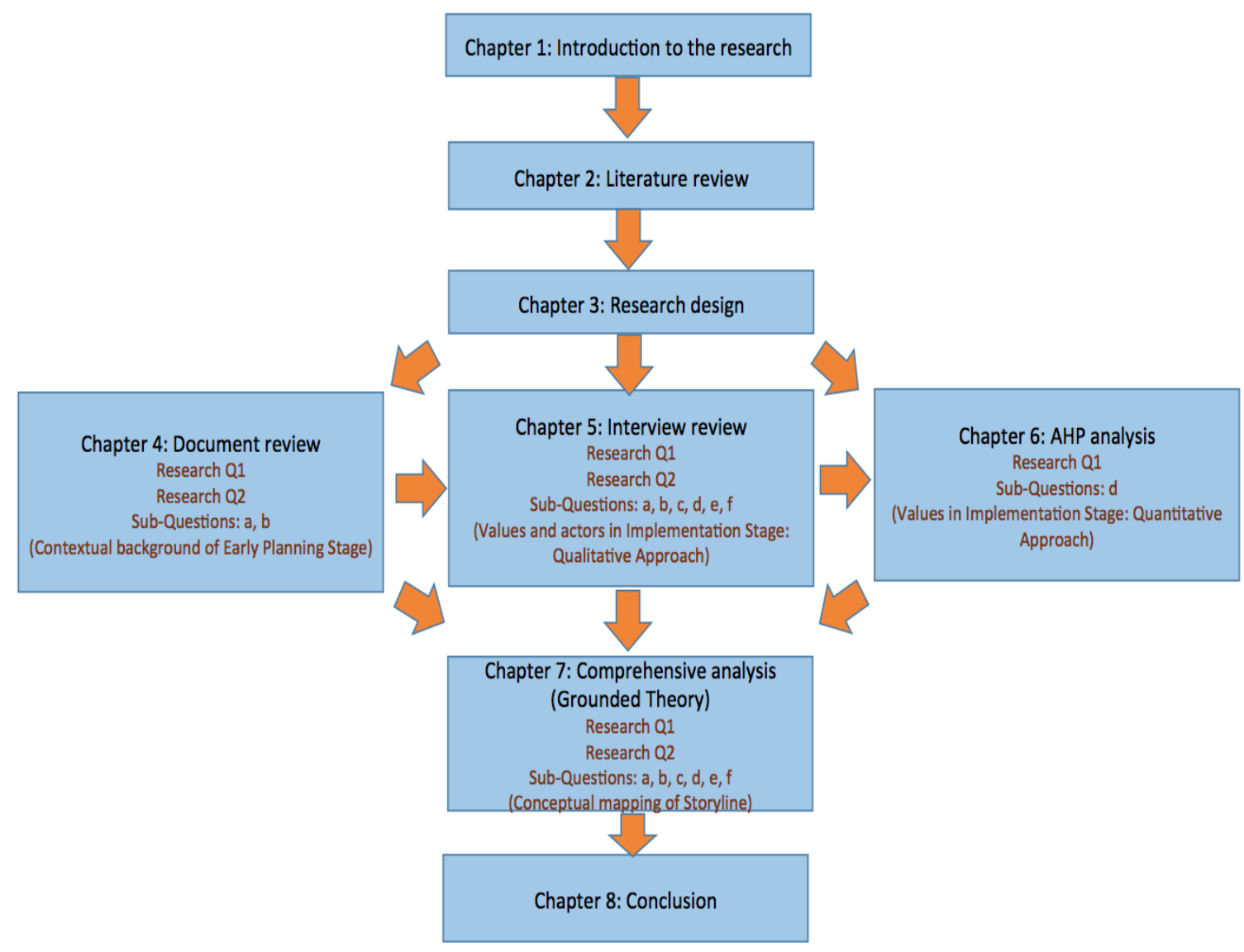

Figure 3. Research flow-map of dissertation 
To sum up, this research analyzed a decision making processes in a project to restore An'Yang Stream in South Korea between 2001 and 2015. The study integrates perspectives from environmental water resource management with theories about participatory decision making. 


\section{Chapter 2}

\section{Literature Review}

How are decisions on stream restoration made in South Korea? This chapter presents literature that has helped to formulate this dissertation work which is designed to answer the question on the decision-making process in Korean stream restoration. First of all, this work needs to recognize what extent the Korean stream restoration case follows Western environmental decision-making models. Thus, key concepts and factors of environmental decision-making will be discussed to build a theoretical foundation in this chapter. According to Hammond and Keeney (1999), Slovic and Gregory (1999), and Moran (2010), good environmental decision-making can result from the balanced embracing of different stakeholders as well as their values and interests.

Environmental managers consider conditions before anthropogenic influences and aim to return the stream to those conditions. Their focus has been almost exclusively on the biophysical elements of the system. One might assume that it would be important to address additional items such as the interests, values, scientific information, and related constraints of diverse stakeholders involved in the restoration process, including current stream users. Therefore, balanced interaction and coordination between scientific knowledge and societal contexts are crucial to achieving positive outcomes in stream restoration for resource management.

This literature review section presents key works in the broad and changing field of stream restoration that provides the foundation for this study. This researcher first notes that, while technical perspectives of the engineering field in particular have historically 
dominated stream restoration, current thinking recognizes the much greater complexity of stream restoration. In particular, three inter-related approaches are of particular relevance: socio-hydrology (SH), Integrated Water Resource Management (IWRM), and Socio-Ecological System (SES). After reviewing the literature in those areas, this chapter considers the interface between human and natural systems, and what the planning field has to offer.

\subsection{HISTORICAL DOMINATION OF TECHNOCRATIC PERSPECTIVES OF STREAM RESTORATION}

In traditional water planning processes, natural science and engineering technologies are paramount in decision-making. In this paradigm, stream restoration is conceived as scientific and environmental modification to existing streams and adjacent basins (Simon, 2011). Water planning involves hydraulic modeling and structures, ecological revitalization, and fluvial geomorphic approaches to watersheds (Simon; Allan and Castillo, 2007).

In the United States, scientists seek stream restoration to enhance water quality, to manage riparian zones, to improve in-stream habitat, to improve fish passage and to stabilize banks of waterways (Wohl et al., 2005). To assist the recovery of an ecosystem that has been degraded, damaged, and destroyed, engineers and natural scientists intentionally alter a site to reestablish an indigenous and original ecosystem (SER International Science \& Policy Working Group, 2004; Comin, 2010). Ecological restoration is a process to return degraded streams to healthy streams (Palmer et al., 2005). In the process of rebuilding streams into healthy ecosystems, engineers and 
natural scientists apply biological, hydrological, and geomorphic approaches (Palmer).

While an engineering model of stream restoration remains common, recent scholarship has acknowledged a more complex interdisciplinary system including ecohydrology. The term eco-hydrology is a compound word of ecology and hydrology, indicating an interdisciplinary field that studies the interaction of water and ecosystems (Cho et al., 2011). Eco-hydrology is often situated in water resource management, such as the quantification of the hydrological cycle, integrative understanding of biological processes, the influence and function of the river-flow of vegetation, and feedback between ecological and hydrologic effects (Kim and Woo, 2004).

\subsection{INTEGRATED WATER RESOURCE MANAGEMENT (IWRM)}

Although the accumulation of science-oriented knowledge is necessary for stream restoration, it has not been shown to be sufficient in creating sustainable long-term outcomes (Ostrom, 2009). Integrated perspectives note interactions of humans and water. Under an integrated perspective of stream restoration, IWRM incorporates diverse stakeholders and relevant actors (Sivapalan et al., 2012). IWRM emphasizes capacity building through the interactions and feedback exchange among stakeholders and collaboration between scientific and non-scientific values (Brunner et al., 2005; Nelson et al., 2008; Giebels et al., 2015). The feedback and interactions can be precisely realized and described in participatory decision-making process based on the governance structure of collaborative planning (Falkenmark, 1979). 


\subsection{TENSIONS RESULTING FROM NARROW PERSPECTIVES}

Researchers have noted critical friction among actors who rely on a single perspective to make decisions, evaluate outcomes, and implement planning for stream restoration. One aspect of this friction occurs from disparities between technological and integrated processes. Technological approaches value rationality, with predetermined stages, certainty in implementation, and clearly defined outcomes. Early rational planning models reflect technocratic goal-oriented and effectiveness-oriented top-down decision-making. Under rational planning theory, technocratic scientific information is the most important factor in decision-making because it is believed that the effectiveness and efficiency of decision-making results based on positivist and epistemological evidence can set people at ease from complicated and confusing uncertainty (Altshuler, 2004).

Rational planners are considered to be technically trained experts who cope with the uncertainty in their specific subjects. Therefore, in the rational planning model, the planner's primary role is to guide professional deliberations to implement various aspects of the planning (Altshuler, 2004). In fact, under powerful political regimes, the rational planning model can be viewed as an ideal approach because planners can accomplish implementation quickly after deciding on their plans. Many other Asian societies, such as China and other Communist societies controlled by powerful regimes, can be considered as one of the best examples of the use of traditional rational planning (Haferkamp and Smelser, 1992). This type of rational planning, with a top-down decision-making system, has been popular in developing societies such as Korea whose 
environmental decision-making is prone to be formulated under top-down administrative structure (Lee et al., 2014).

However, the concept of a rational planning model has faced many criticisms. Critics have argued that the rational model applies a narrow focus to the objects of the planning process due to rational planners' professionalism-oriented approaches (Reese and Rosenfield, 2004). For example, planners of the traditional rational model hold professional knowledge on engineering technology to support the stakeholders to make better decisions justified by instrumental rationality among many alternatives in cases of environmental issues. They believe the instrumental rationality with professional scientific knowledge can convince the public (Benveniste, 1994 and Altshuler, 2004).

Conversely, more integrated perspectives embrace uncertainty, resulting from actors using ecological systems in their daily lives. Planning and implementing dynamic ecosystems adapts to disturbances and changed in the watershed environment caused by human actions (Holling, 1986). The integration of technocratic and social perspectives is termed "socio-ecological systems" (SES) that link changes in local water systems and changes in the wider social context (Diaz et al, 2011). SES incorporates the full range of existing values and perspectives across all stakeholders of watershed management (Savenije and Van der Zaag, 2008; Svapalan et al, 2012).

\subsection{ELEMENTS OF INTEGRATED WATER RESOURCE MANAGEMENT}

Research has identified essential — though challenging — factors in integrated water resource management. Moran (2010) adds key factors such as multiple values, 
challengeable uncertainty issues, and decision makers' values, background and ability to be dealt with to the environmental decision-making process.

\subsubsection{Multiple values}

One important task is to clarify values and preferences of both stakeholders and decision-makers in environmental issues because there are different kinds of parties who hold various values and preferences (Keeny, 1992; Moran, 2010). For successful decision-making in environmental management cases, the various values and preferences need to be appropriately and collaboratively shared and communicated among the parties who will face potential risks of conflicts and disputes in the decisionmaking (Moran, 2010). Accepting and understanding diverse values and preferences recognizes that there is no single best or most primary value and preference among many different options (Moran, 2010).

\subsubsection{Decision makers' value, background, and ability}

The activities and characteristics of individuals and groups in environmental decision-making have a profound impact on the environment (NRC, 2005; Moran, 2010). In environmental decision-making, it would be important to appropriately select participants of the decision-making process for successfully choosing the best alternative (Gregory and Keeney, 2002). Environmental scientists, civil engineers, and ecologists have been playing a major role in environmental decision-making (Folke et al., 2005).

In environmental planning, scientific knowledge and engineering information are 
used to help characterize and mitigate risky uncertainties (Gregory and Keeney, 2002 and Morgan and Henrion, 1990; Cullen and Frey, 1999; Moran, 2010). Because decision-makers are required to have certain credentials or knowledge in order to understand the scientific data, they may tend to neglect non-scientific values and data when finding the best alternative solution to the environmental issues (Bazerman, 2002).

Decision-makers' backgrounds are also significant factors in the decision-making process. Individuals and groups involved in the decision-making hold different academic and professional backgrounds that can impact their values, as well as preferences and interests within the process. Some environmental decision-makers may have earned their training before advanced education incorporated social factors and non-scientific values supported by other decision-makers (Gregory and Keeney, 2002). Gregory and Keeney (2002) state that experts in the natural sciences may not usually apply and consider factors of social sciences. In addition, the environmental decisionmakers may have the misperception that social science approaches are easy to understand as the common sense of everyone (Gregory and Keeney, 2002), which can delegitimize the contributions of many stakeholders.

\subsubsection{Uncertainty within decision-making}

Within environmental decision-making, the participants and stakeholders inevitably face and have to handle issues of uncertainty due to miscommunication between and a mismatch of scientific efficiency and social values (Howarth and Monasterolo, 2016). Scientists and engineers need to continually reduce and mitigate the risks of uncertainty 
caused by non-scientific factors (Harding et al., 2013). Beierle and Cayford (2003) and Howarth and Monasterolo (2016) argue for dealing with mixed issues and incorporated various values, such as both social factors and scientific knowledge, which can give rise to potential uncertain risk. In this sense, it is significant to manage and mitigate the uncertain risks (Harding et al., 2013). In addition, the authors (2013) suggest that stakeholders or decision-makers pay attention to communicative networks and participatory culture so as to better control the risks of uncertainty, such as social conflicts and disharmony resulting from a lopsided decision-making culture led by scientists (Gregory, 2000, Harding et al., 2013, and Howarth and Monasterolo, 2016). Hence, it is important to perceive that communication among the participants within environmental decision-making processes may decrease the level of uncertain risks when handling differing perceptions about the issues (Harding et al., 2013).

The concept of "muddling through" was developed to cope with the intractability of decision-making within a rational model oriented around scientific information by Lindblom (1959) (Gregory and Keeney, 2002). The present science-oriented system of environmental decision-making has been mostly evaluated by a cost-benefit analysis that the natural scientists prefer. However, this cost-benefit analysis does not and cannot always control and manage the unintended grappling relationship among the decisionmakers (Gregory and Keeney, 2002). These authors (2002) suggest building a structure of decision-making in which the various values of decision-makers can be combined and integrated to identify both scientific and non-scientific objectives with a wide range of knowledge sources considered by different stakeholders, as well as decision-makers. In addition, environmental decision-makers are frequently prone to strongly insist 
upon their individual interests and values, based on efficiency and effectiveness, in applying various types of information and data in the decision-making process. This is because the groups of stakeholders, as well as the decision-maker group, are often composed of natural scientists and environmental engineers in order to reduce risks (Gough, 1997).

In environmental decision-making, individuals within a specific group often compromise their own values in favor of those pursued by the group (Chmielewski, 200 4). In terms of ethical decision-making, the participants often seek both the right value and the value of efficiency. Because of this, individuals in the group consider whether their organizational decisions are ethical or rational. When group dynamics are an increasingly vital measure of organizational success, and regulations or standards regarding decisions are meticulously considered with regard to the context of profit and integrity, it is imperative that the group conceptualizes the impact of their decisions (Chmielewski, 2004). However, the efficiency issue may be a priority in fields such as stream restoration, which is occupied and controlled by scientists or engineers (Chmielewski, 2004).

Ostrom (1990) argues for participatory strategies that can embrace these both natural and social scientific factors. Environmental decision-making is certain to face complex ongoing issues resulting from a lack of democratic procedural rationality even though they may find more effective alternatives and mitigate environmental uncertainties with scientific improvement. The complex ongoing issues cannot always be expected, estimated, or prevented by the scientific knowledge held by the decision- 
makers.

\subsection{MOVING BEYOND CONVENTIONAL TECHNOLOGY-DOMINATED}

\section{APPROACHES}

Recently, researchers in multiple disciplines have found that some governmental policies based on decisions by engineers and scientists may accelerate resource destruction without appropriately integrating other diverse knowledge disciplines, while resource users who understand the other diverse knowledge disciplines through their cultural and social experiences make an effort to accomplish sustainable natural resource management (Giebels et al, 2015). In other words, lay users might have more sustainable thoughts on natural resource management, but governmental policies might not accept the idea of individuals challenging governmental regulations. Hence, it can cause unbalanced management of natural resources and social fragmentation due to conflicts among stakeholders.

To establish a better decision-making process for stream restoration, definitions of stream restoration should be identified before considering how one designs frameworks to link scientific information to social contexts as the SES aims to do. Some researchers have been studying the concept of stream restoration to reduce stresses and uncertainty in rebuilding a healthier water environment and a more efficient water distribution system.

Also, the wide range of vaguely defined goals and interests make it difficult to define a successful model of efficient stream restoration because of different goals, values, and interests to the streams. Due to these issues, the stream restoration 
movement has become a broad grassroots movement and a key agenda for local ecological restoration integrating and embracing social mechanisms (Reed, 2008; Lave et al., 2012; Morandi et al., 2014; Wohl et al., 2014). Those researchers also argue for highlighting the functions of connectivity, feedback, and resiliency between social and ecological mechanisms of the stream for sustainable and long-lasting decision-making. Gregory and Wellman (2001) argue for wisely using scientific ecological knowledge, reflecting social values of various stakeholders, and accepting precise economic valuation of stream restoration into the policy decision-making as key elements for establishing successful stream restoration governance. More simply, responsible stewardship of resources in streams can be managed from the bottom-up according to local social values in addition to strictly ecological ones. The grassroots movements in resource management could be an indicator of ecological values as well as social values in stream restoration (Lee and Choi, 2001). Thus, restoring streams means aligning conservation interests with those of the community, including individuals in the stream's revitalization, and revitalizing polluted and declined ecological systems; at the same time, this stream restoration provides a method for how to conserve and utilize social elements for efficient water resource management in our neighborhoods at the local scale. In particular, streams in urban areas have been contaminated due to human activities in the stream-edge space and in the streams themselves (Lee and Choi, 2011). Interactive methods of stream restoration can be a primary resource to continually assess the quality of the community support for the stream in good shape and quality in various sections (such as policies, history, engineering, science, culture, etc.) and as well as the natural environment itself because interactive stream restoration can 
motivate various agendas and topics in the processes of regional developments (Lave et al., 2012). The main concepts from interactive disciplines, such as the Eco-hydrology (Figure 4) are future-oriented potential keys for this integrated framework of stream restoration.

Ecological restoration-oriented projects have had various social and cultural elements, as well as cultural problems even though they have achieved successful ecological conservation on stream system.

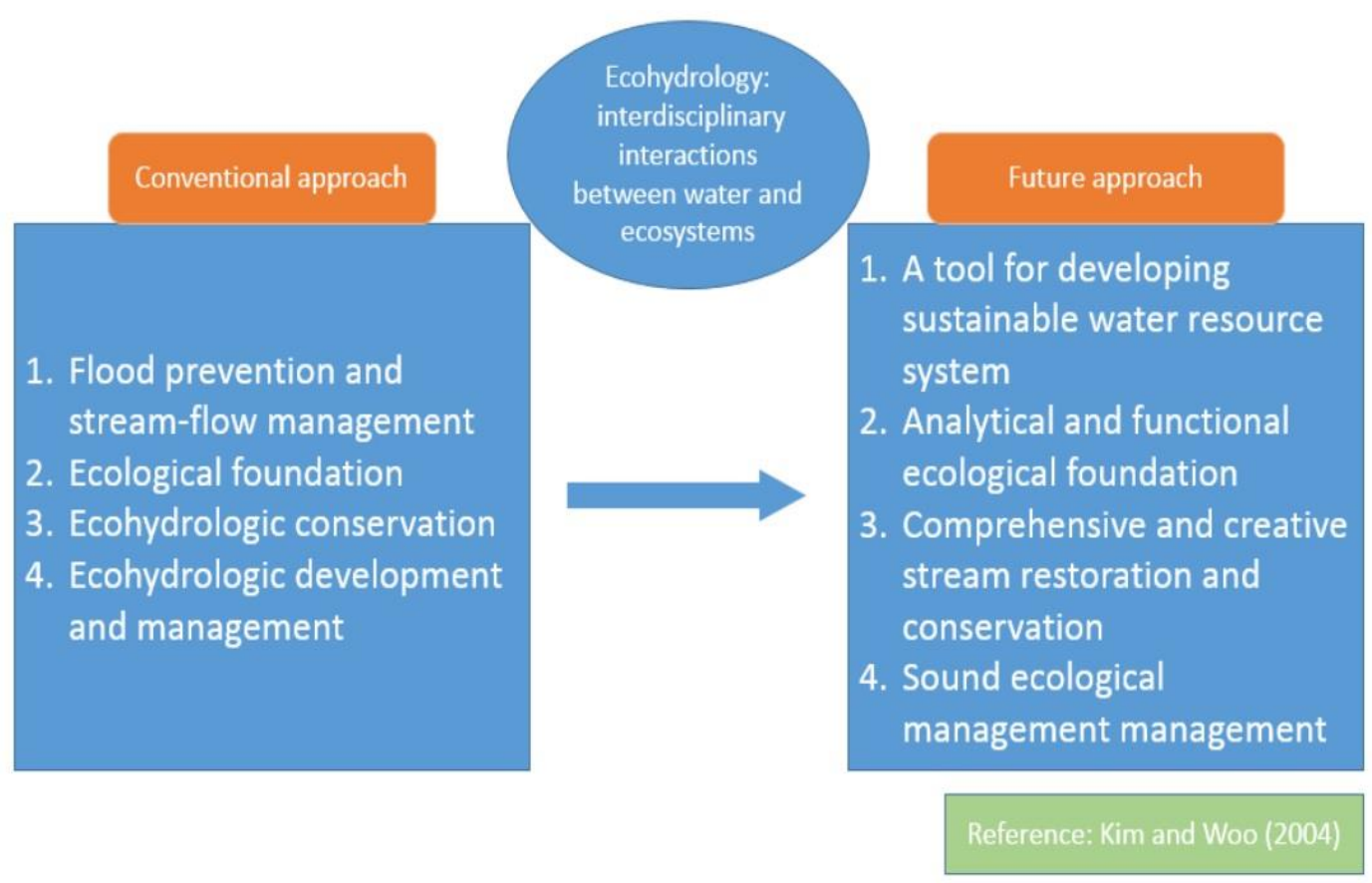

Figure 4. Paradigm shift under conceptual model of eco-hydrology 


\subsection{PLANNING AND STREAM RESTORATION}

Planning is a professional field that not only seeks to manage, but also to set up a framework for managing the longer term stream restoration strategy. In addition, planning addresses both biophysical imperatives as well as the social structures and relationships needed to make and sustain change. Planning theory includes a strong theoretical foundation of more practical and available principles about the social systems established by human activities.

Hoch (1994) argues that understanding and adopting various planning models help to seek possible solutions in dealing with and anticipating uncertainties. In particular, as he mentions, comparing characteristics of the different planning models is significant to reduce social, political, and scientific miscalculations in recognizing uncertainty in technical analysis, the value of including non-scientific information, and participation of non-expert stakeholders and the underrepresented within decision-making.

Sevaly (2000) defines planning as the process of making places better or making decisions through listening to underrepresented voices, compensating for market failures, and adapting to economic, social, and political changes. In this interactive and complicated planning paradigm, many planners and planning scholars have studied various approaches in their efforts to cope with, anticipate, and reduce uncertainties.

In contrast, collaborative planning gives equal voice, rights, and influence to those groups who have not historically been able to affect the process (Habermas, 1984); (Burby, 2003). Communicative action theory is invested in the process of cognitive exchange through social learning (Friedmann, 1987; Irazabal, 2009). Collaborative 
planning, a more inclusive decision-making approach, embraces various values including socio-cultural importance in stream restoration. That is, the inclusive decisionmaking sets forth procedural legitimacy and justification for handling uncertainty.

Innes and Booher (2010) explain that due to the complexity and rapid changes in decision-making, there is a need for increased shared awareness within the existing structure of decision-making governance. This rising awareness may contribute to motivating new attentions to the need to consider and react to future uncertainties. The authors (2010) compare collaborative rationality with existing instrumental rationality. In a society which has become more culturally and politically diverse, decision makers are prone to be called to deal with a wide range of different values, interests, and perspectives of the public to meet both rationalities (Innes and Booher, 2010; Susskind, 2010).

In environmental planning, collaborative rationality rebuts the reliance on instrumental rationality as coping with uncertainty in any issues and assumes that all decisions are justified by procedure-oriented multiparty negotiation (Innes and Booher, 2010 and Susskind, 2010). During the decision-making process justified by the collaborative rationality, efficiency and effectiveness of the solution are not the most primary conditions to consider and evaluate the possible alternatives. It can offset risks resulting from the uncertainty issues in selecting better alternatives through interdependent engagement among the stakeholders. According to Innes and Booher (2010) and Susskind (2010), such decision-making processes based on collaborative rationality helps not only to seek new and better ways to move forward, but also to stimulate collective decision-making capacity when facing inevitable new challenges. 
Complexity in environmental decision-making can be deflected when individual stakeholders interact dynamically in sharing and exchanging relevant information for mutually agreed outcomes (Susskind, 2010). In negotiation among the stakeholders, the condition of interdependence may be used and considered before the stakeholders collaborate for sustainable resolution beyond risks from accepting and reflecting diverse interests. The complex interplay of different interests held by the stakeholders can amplify the possibility of deterministic collaboration in terms of procedural rationality.

The field of planning theory has played the role of a bridge between social systems and engineering technologies in many environmental decision-making processes (Bilec et al., 2007). In addition, Reed (2008) notes that participatory processes and interdependence emphasized in collaborative planning can lead to strong and durable decisions in matching common interests of the interplay cohesion and embracing different values from both social and ecological systems in environmental planning cases. Consequently, a collaborative approach is one of the most useful and workable models for sustainable decision-making in environmental issues (Zaki et al., 2000).

2.6.1 The role of power in making decisions about stream restoration understanding planning paradigm in stream restoration

Power in rational planning is assumed to be centralized in agencies placed at high levels where decisions are made, a top-down paradigm because the power can serve as a stumbling block to democratic consensus building (Dryzek, 1990). To overcome inequitable power, Smith (2012) urges the use of professionally trained mediators. 
Under a structure of the collaborative planning model, the concept of power is quite less concentrated. In this respect, collaborative planning can be an alternative to top-down centralized decision-making in favor of consensus-building among diverse stakeholders with varying degrees and types of power. Healey (2003) notes the benefits of communicative action between competing actors so the actors can understand other interests through discussions.

This collaborative planning is a discourse-oriented model based on a communicative action model, as well as on communicative rationality (Healey, 2006). The collaborative planning model has become a frequently mentioned concept among urban planning researchers in the attempt to reduce uncertainties in both practice and ideology by building diverse institutional relationships around environmental issues (Healey, 2006; Upton et al., 2009). In other words, the discourse based on communicative rationality exists to maximize deliberation in the process of resolving conflicts as well as uncertainty issues. There is a thread of connections between this communicative rationality and inter-subject reasoning. The collaborative planning model can be reflected with discursive democracy (Dryzek, 1990) and emancipatory communicative rationality (Habermas, 1984) in building interdependence among individuals. As stakeholders from varying backgrounds engage in negotiation and share information, conflicts can be minimized.

Collaborative planning is strongly associated with negotiation theory because through successful interest-based or principled negotiation (Fisher and Ury, 1991, Burgess and Burgess, 1994), stakeholders in the planning process can find clear solutions based on mutual consent. It is a valuable tool in reaching solutions in 
environmental debates among the stakeholders, which can solve and cope with environmental uncertainty in decision-making over the disputes (Ruskin, 1993).

As stakeholders in stream restoration share their own interests, collaborators can discuss issues of fairness and efficiency (Susskind and Cruikshank, 1987). Open discussions among stakeholders can overcome differences between technocratic and social factors (values) so that all participants can concentrate on feasibility. The successful and wise resolution with various opinions requires collaborative inquiry to avoid a manipulation and distortion by some experts and to emphasize procedural fairness, efficiency and feasibility (Susskind and Cruikshank, 1987).

Collaborative planning is treated as a structure based on the equal opportunity that aims to neutralize power among actors (Healey, 2003). However, power relations are not neutralized simply by virtue of the process being labeled "collaborative" (Flyvbjerg, 1998), and planners are called upon to facilitate communication and interaction with diverse interest groups and stakeholders (Forester, 1994; Healey, 2006). Interaction or discussions can resolve and mediate conflicts by an analysis regarding the distribution of power (Fainstein \& Campbell, 2012). Moreover, planners have the duties of mediators to help disputants find solutions for conflicts (Moore, 1996). Planners think that the mediators do not have the power to make a decision in planning. As a matter of fact, they do have power in the decision-making process because they are involved in communicative actions and they influence the stakeholders in their duty of mediator in democratic deliberation. Hence, planners as mediators do possess power in mediating conflicts, although whether they use it or not, is an open question. 


\subsubsection{Power in collaborative planning}

The definition of power may be elusive because power has different meanings depending on the context and the people involved (Innes \& Booher, 2010). Bryson and Crosby (1993) argue that power is a leveraging and exercising tool that can enable individuals and groups at the margins to engage in the decision-making process. This suggests the existence of a tacit power in the background, having an economic and political dimension or an institutionalized religious structure (Innes \& Booher, 2010).

According to Galbraith (1983), secular power is of three types - condign, compensatory, and conditioned power. Galbraith (1983) states that individuals and groups seek power to advance their own pecuniary interests and values, such as budget allocation and financial compensation in social relationships. "Condign power wins submission by inflicting or threatening appropriately adverse consequences. Compensatory power, in contrast, wins submission by the offer of affirmative reward -by giving something of value to the individual so submitting. In addition, conditioned power, contrastively, is exercised by changing belief." (Galbraith, 1983) In this research, both conditioned power and compensatory power are typical concepts used to address power relations among stakeholders in environmental decision-making processes.

In environmental decision-making processes, decision-makers need to deal with power distribution influenced by their backgrounds, such as individual personality, property, and affiliated group. Galbraith (1983) depicts three sources of power: personality, property, and organization. Some organizations can exert condign power; for example, the government can exert legal punishments. As factors influencing the 
power of organization, Galbraith addressed the number and diversity of its purposes. In other words, if the purposes of an organization are many and varied, the power of the organization will be greater. For instance, corporations are organizations primarily possessing property and hence of compensatory power, but they extend this power to conditioned power through public relations, advertising, and political lobbying. Expertise or knowledge of planners influences negotiations and decision-making under an instrument of conditioned power described by Galbraith (1983).

Innes and Booher (2002) argue that power in a network is a jointly held resource, enabling networked organizations or individuals to accomplish things they could not achieve individually (and that the responsibility of a planner or mediator is to facilitate this information sharing). Giddens (1984) contributes to this network power by understanding the structure as a boundary of power. Addressing the function of the structure, he argues three types of power: the power of action, the power of ideas, and the power of deep structure. These types of power shape network power overall, because the ideas and actions of each stakeholder influence the network (the structure) (Innes \& Booher, 2002). In Galbraith's perspective, this power can be defined as conditioned power through exchanging information (1983). For example, environmental negotiation cases such as water resource management often include structured, shared, and agreed upon information on water data as the power of ideas in a conditioned format within the mutual interactions like the negotiations. In this conditioned format of water data, the hydrologists and engineers examine the water pollution standards that can control the human activities in the river basin. 
The most important aspect of network power is the ability of networked organizations to improve the choices available to all stakeholders as a result of collectively developed innovative ideas (Booher \& Innes, 2002). Network power among cooperative stakeholders can be considered the most democratic and equitable form of power, requiring the inclusion of all stakeholders and openness to social learning and cognitive politics (Booher \& Innes, 2002). The strengthening of network power through trust-building may both inspire and provide the motivation for networking coalitions to engage in more complex governing and planning agendas, as civic capacity and social capital grow. The network power can create governance in a practical way. This governance is about fostering inclusiveness and open dialogue with various stakeholders (Irazabal, 2009).

There are sometimes preconditions for network power: diversity and interdependence (Booher \& Innes, 2002). Diversity is a mandatory element of network structure because it provides various resources for building network-creating conditions and solutions. For instance, the wide range of life experiences, interests, values, knowledge, and resources in society creates a challenge for planning and the effort to produce agreements and collective action (Booher \& Innes, 2002). However, diversity is a prerequisite for organizational strength, by enabling consensus building regarding common perspectives and resource allocation (Susskind, 2011). (Ostrom, 1990).

Interdependence based on self-interest and reciprocity among diverse participants fuels network power (Booher \& Innes, 2002). Interdependence means that each organization needs something from the others. According to Innes and Booher (2009), the condition of interdependence holds that agents must depend, to a significant degree, 
on the other organization, in a reciprocal way. Reciprocity is the basis of trust (Innes and Booher, 2009). The existence of trust and reciprocity, in turn, means organizations will have a reason to continue to work together. This helps assure that participants will maintain the interest and energy to engage with each other throughout the process, and have an incentive to reach an agreement. Negotiation theory notes that interdependence among diverse interests is key to creative mutual gain (Innes \& Booher, 2009). This interdependence means that stakeholders cannot reach their objectives alone. Interdependence makes this dynamic possible, and keeps the stakeholders at the table.

\subsubsection{Collaborative planning methods to mitigate conventional sources of power} As noted earlier, multiple forms of power are wielded in a collaborative planning process. Stakeholders of environmental conflicts can vary considerably in terms of the power they exercise; advocacy groups with limited resources are often opposing corporate interests with nearly unlimited resources (Dredge, 2006). Amy (1987) explains how these power imbalances can result in systematic biases that threaten the fairness of the procedure and outcomes. For instance, unequal access, sweetheart deals, lack of technical expertise, and quasi-forced participation all can defy collaboration, achieving consensus, and forging lasting agreements (Rosenthal and Brandt-Rauf, 2006). Reed (2008) states that stakeholder participation can promote empowerment, equity, trust, knowledge distribution, and social learning in the environmental issues.

Planners as a convener or mediator also exercise power through the administration of rules, utilizing the legitimate discretionary power and creating a political culture surrounding planning. This legitimate discretionary power and the culture of planning 
influence how power relations are defined and shaped (Forsyth, 1999). Benveniste (1972) argues that professional planners are obliged to play a political role in the planning process by modifying and justifying political power relations among the stakeholders, as well as fairly sharing technical information. Thus, planners must appropriately consider political realities while addressing technical information.

Although mediators cannot be perfect protectors, they can design procedures and techniques to address some of these power imbalances (Rosenthal and Brandt-Rauf, 2006). One such technique is "joint fact-finding," which aims to transform the use of scientific and technical expertise from a weapon in an adversarial setting into a tool for consensus (Ozawa, 1993). Joint-fact-finding may provide a venue to share sound scientific information in a power-neutral manner for the stakeholders (Herman et al., 2007). In particular, power imbalance due to gaps in technical information and scientific uncertainty may be balanced by offering joint-fact-finding (Susskind et al., 1999). However, in cases with severe power imbalances and disparities in access to relevant expertise among the stakeholders, joint-fact-finding may not be appropriate if the conditions cannot be easily adjusted, due to some powerful parties' oligopolistic occupation (Ehrmann and Stinson, 1999).

Joint-fact-finding can often assist both professional and non-professional stakeholders to craft agreements about scientific issues through joint determination and a well-organized information gathering and analysis process (Ehrmann and Stinson, 1999). In this joint-fact-finding, roles of a mediator (Ozawa, 1993) merge technocratic and social knowledge in the decision-making process of stream restoration. In stream restoration, the joint-fact-finding could include a convener (trained mediators) to assist 
in the identification of the stakeholders and to enhance consensus-building dialogue among the stakeholders (Herman et al., 2007).

According to Schultz (2003) and Herman et al. (2007), there are several principles to meet for a joint-fact-finding process to be effective. First, representation is essential in forming the decision-making system. All of the stakeholders have to be included in framing and sharing the issue of the decision-making process as well as work together to discuss, debate, and research the facts by strategic communications (Schultz 2003; Herman et al., 2007). Second, the neutral professional expert is selected and invited to the decision-making process through ongoing conversations about the implications by the participants (Herman et al., 2007). Lastly, the convener agrees to accept a written statement from the participants and pledges to be responsible (Herman et al., 2007). In other words, the convener ties the participants under the written agreement to follow the mutual consensus in evaluating and analyzing specific scientific information and knowledge. In addition, professional expertise should be able to be shared with all parties in the planning process, through ongoing monitoring and data collection led by trained experts (Ozawa, 1991). These three characteristics can test if the stream restoration case includes an appropriate format of joint-fact-finding.

McCreary et al. (2001) explain common points of success in joint-fact-finding. First, the mediation team has to aim to produce a new synthesis of findings. Second, it has to distinguish goals of joint-fact-finding process from other efforts. Third, experts in the team have to evaluate consequences of policy choices regarding scientific issues. Lastly, when dealing with technology, experts should present the findings and jointly agree on the synthesis of scientific information in public. 
Ozawa (2006) has found that uncontrolled scientific uncertainty, complexity, and disagreement can aggravate conflicts among the stakeholders. Thus, technocratic environmental planning cases should be approached with a careful negotiation tactic and well-organized facilitation plan in dealing with and using the scientific data.

\subsection{ENVIRONMENTAL PLANNING PARADIGM EVOLUTION OF SOUTH} KOREA

The planning theories of Western society have influenced South Korean planners, both theoretically and in practice (Jung, 2014). Since the 1960s, after the devastation of the Korean War, South Korea's planning has focused on economic development (Kang, 2014). President Jeong-Hee Park implemented strong policies on regional development, based on conventional rational planning concepts, and most Korean public officials studied engineering and other applied sciences (ADB, 2012). In South Korea, planning is directed toward improving industrial exports, which creates disputes across urban and rural settings, managers and workers, and income levels (Kang, 2014).

South Korea has a different planning background than the United States, and has carried out radical changes based on globalization in rational planning (Kang, 2014). In 1962, President Park's regime established the Law of Urban Planning, which originated in the Japanese Urban Planning System under the Japanese Government-General of Korea (Graham, 2003 and Watanabe, 2007). Many urban planners and engineers went to Japanese institutions to learn about and experience engineering-oriented urban development and regional planning, and the Tokyo Urban Comprehensive Development Plan acted as a textbook for urban engineers in the Department of Construction at the 
time (Jung, 2004). Thus, most Korean cities built during the 1960s and 1970s are similar to those built under the Japanese urban system (Graham, 2003 and Jung, 2004).

During the 1960s, the urban concentration of populations and lack of infrastructure systems were major focuses of Korean urban planners (Jung, 2004). To carry out zoning, land-use reform, construct transportation, and new highways for dealing with these issues, the Korean government then amended the Law of Urban Planning in 1972 (Bae, 1998). With the Sae-Mah-Eul movement, urban and regional planning was designed to cope with the issues of uneven national development, which focused on major cities, Seoul and Busan under a national master plan. The radical industrialization-oriented uneven development patterns initiated by South Korean leadership involved a top-down regional development plan that was a typical example of a rational planning model, and was based on Korea's need for rapid industrialization like that in Japan (Douglass, 2000 and ADB, 2012). Most urban planners were urban engineers or civil engineers, and this trend noticeably influenced the watershed planning of Korea (Jung, 2004).

In 1971, President Park established the Plan of Four Major Rivers Comprehensive Development. Under this Plan, new multipurpose dams in river basins were constructed (Han'guk Haengjŏng Yŏn'guwŏn, 2015). In 1972, the Korean government created the Green Belt outskirts of Seoul, which is similar to the Urban Growth Boundary of Portland, Oregon. During the 1970s and 1980s, the Korean Central Government planned many new towns and cities to redistribute the congested populations of urban areas because of loosening the functions and the restrictions of the Green Belt (Han'guk Haengjŏng Yŏn'guwŏn, 2015). As part of this trend, the Korean Water Resources 
Corporation planned dams and reservoirs to provide affordable water for the cities (Han'guk Haengjŏng Yŏn'guwŏn, 2015). The civil engineers of the government and the Korean Water Resources Corporation designed most of the plans for dam construction, which were based on a top-down, centralized, and rational model. Unfortunately, this model brought about environmental disputes and social conflicts during the 1990s (Bae, 1998 and Han'guk Haengjŏng Yŏn'guwŏn, 2015).

In the 1990s, as Korean institutional changes moved toward more localized political decision-making, changes were implemented that allowed public participation in planning through government reforms. Local economies began experiencing turbulence, and these changes increased citizen awareness, causing people to begin considering democratic decision-making processes in urban and regional planning (Han'guk Haengjŏng Yŏn'guwŏn, 2015). Citizen awareness and social circumstances thus came to determine the evolution of the planning field. Today, collaborative planning models are commonly adopted among public administrators in South Korea (Lee et al., 2010).

Environmental laws like the Law of Urban Planning were amended to incorporate collaborative and participatory decision-making processes on environmental and green regional development (Park and Lee, 2016). In 2003, President Roh established regulations including participatory and bottom-up planning for effective river basin management (Lee, 2012). These new regulations stated that river basin management committees should involve local residents and local governments, as well as NGOs (Lee et al., 2010). However, there continues to be dissonance among stakeholders, because urban engineers design most watershed plans (Lee, 2012). 
In addressing the similarities and differences between the planning institutions and practices of South Korea and the United States, it is meaningful to compare the degree of public participation and centralization to functional rationality based on scientific efficiency and effectiveness in environmental planning. Understanding the flow of information and resources in planning practices helps us to determine whether the planning is goal- or process-oriented or not, as Mannheim (1940) distinguishes functional rationality with substantial rationality. Korean environmental planning relies on functional rationality more than the United States.

However, in the environmental planning of the United States and South Korea, there are many similarities in regulation structure and citizen awareness due to wellorganized social capital (networks).

As is the case in most of the world, what is legislated often differs from implementation (Benveniste, 1994). Even though South Korean laws and regulations require participatory decision making, water management strategies continue to be designed and planned by civil engineers and hydrologists. (Lee et al., 2010). These technological scholars and professionals rely on centralization, and use jargon when they communicate with ordinary stakeholders. For instance, this can be seen in the use of Integrated Water Resource Management (IWRM) with four major rivers of Korea.

South Korea is reforming its water policy by adopting a new water paradigm, which is required by changes in political, economic, and social environments since the 1960s. The reforms were also influenced by global opinions about water management and the environment. The water development ideology of South Korea must be adapted to sustainable development and reflect the changing paradigm from water development to water management. The new water paradigm must support needs for water supply, pollution control, flood control, and other purposes of water management, and be characterized by best practices in the basinwide approach, integrated management, and sustainable development. (Park and 
Grigg, 2004)

According to Park and Grigg (2004), a model of Korean IWRM is mostly designed by the central organization, Korea Water Resources Corporation. Many citizens recognize the importance of both environmental conservation and political democratization in Korea (Hong and Chung, 2016). Meanwhile, the IWRM represents a typical Korean styled approach to stream renovation using only modern technologies against the interests of the people. The announcement of IWRM by the Korean Water Resource Corporation included a statement about the importance of public participation and cooperation with stakeholders (Chung, 2007). However, in reality, civil engineers have been at the forefront of IWRM, and have tended to use technology to plan and implement most stream restoration projects (Lee et al., 2012 and Hong and Chung, 2016). This has skewed the stream restoration process in favor of engineering technologies (Hong and Chung, 2016).

The engineer-oriented structure drove centralized decision-making processes from the top down (Park and Grigg, 2004 and Lee et al., 2012). In addition, the Water Resources Corporation is the only organization in charge of water resources in Korea. The citizen stakeholders could not have appropriate information and participation in the stream restoration process under the Korean IWRM because the key participants were scientists or engineers (Lee et al., 2012). In Korean context, engineers and economists have been playing the most important decision-maker role until now (Park and Griggs, 2004). Social scientists and NGOs began to participate in the decision-making of water resources management to meet the condition of "public acceptance" since the late 
1990s (Table 2). However, the Korean water resources management mechanism is still evaluated as a rational model reliant on scientific information (Wang et al., 2003).

In the United States, water resource planning cases based upon both top-down and bottom-up models have often been discussed and examined in its history. Regional development and transportation masterplan projects in the United States were actively designed and planned under rational planning models from the 1930s until the 1950s. In this period, Integrated River Basin Management was introduced under the supervision of the Federal Government (Heathcote, 1998).

However, due to water contamination issues, planners and engineers changed the water resource management model to local watershed planning based upon localized governance (Heathcote, 1998 and Hooper, 2006). "Multi-disciplinary participation in water policy has been common in the United States since the late 1960s because public acceptance became the main factor to justify the water resource management project." (Park and Grigg, 2004) IWRM has also been used in the United States; however, this IWRM is completely planned and designed through local collaborative governance (Hooper, 2006).

Many different stakeholders participate in a local institutional system, collaborative governance in the cases of the United States (Warner, 2007). Many water resource management strategies have been maintained and monitored by local people who want to improve the water from their rivers (Hooper, 2006). Although conflicts may arise among them, they are willing to accept preconditions to enjoy decentralized and participatory water resource planning with their neighbors (Bourget, 2011). Moreover, 
various methods of public meetings can be arranged, designed and planned to provide appropriate information and resources to the stakeholders.

Table 2. Major key decision-makers in water resource management (U.S. vs. Korea)

\begin{tabular}{|c|c|c|}
\hline Period & United States & South Korea \\
\hline Before 1970s & Engineers, economists & Engineers \\
\hline 1970s & $\begin{array}{l}\text { Engineers, economics + } \\
\text { Environmentalists }\end{array}$ & \\
\hline 1980s & $\begin{array}{c}\text { Engineers, economics, } \\
\text { Environmentalists + social } \\
\text { scientists }\end{array}$ & Engineers + Economists \\
\hline Early 1990s & $\begin{array}{c}\text { Engineers, economics, } \\
\text { Environmentalists, social } \\
\text { scientists + affected stakeholders }\end{array}$ & $\begin{array}{l}\text { Engineers, economists + } \\
\text { Environmental scientists }\end{array}$ \\
\hline Mid 1990s & \multirow{2}{*}{$\begin{array}{c}\text { Engineers, economics, } \\
\text { Environmentalists, social } \\
\text { scientists, affected stakeholders + } \\
N G O s\end{array}$} & $\begin{array}{l}\text { Engineers, economists, } \\
\text { Environmental scientists + } \\
\text { affected stakeholders }\end{array}$ \\
\hline Late $1990 \mathrm{~s}$ & & $\begin{array}{c}\text { Engineers, economists, } \\
\text { Environmental scientists, } \\
\text { affected stakeholders + } \\
\text { NGOs and social } \\
\text { scientists }\end{array}$ \\
\hline Early 2000s & $\begin{array}{c}\text { Engineers, economics, } \\
\text { Environmentalists, social } \\
\text { scientists, affected stakeholders, } \\
\text { NGOs + Public "acceptance" }\end{array}$ & $\begin{array}{l}\text { Engineers, economists, } \\
\text { Environmental scientists, } \\
\text { affected stakeholders, } \\
\text { NGOs and social } \\
\text { scientists + Public } \\
\text { "acceptance" }\end{array}$ \\
\hline
\end{tabular}

Source: Goodland (1997); Park and Grigg (2004)

Note: Newly added participants are denoted in italic font.

More recently, in South Korea many have become familiar with a bottom-up, participatory, and decentralized method, but in practice their management of water resources still indicate the typical traits of conventional planning (Wang et al., 2003 and Lee et al., 2010). The Cheong-Gye stream in Seoul is a good Korean example of this top-down method of stream restoration without appropriate and sustainable partnerships 
with stakeholders (Cho, 2010). Also, local politicians in Korea are prone to use this issue for their political purposes. These issues hinder solutions to Korea's water management challenges. There are not many studies on reflecting the relationships between democratic decision-making processes and stream restoration in Korean cases (Lee et al., 2010).

\subsection{SUMMARY}

The literature review in this chapter establishes a theoretical foundation for linking the systems of social and ecological factors to the study of stream restoration. Changing perspectives on stream restoration are demonstrated by a trend from bio-physical focus to the roles of human users and institutional factors. Moreover, this researcher reviewed the planning literature to suggest how planners, as the bridge between public agencies and residents, between experts and laypersons, and between the present and the future, can potentially help shape the dynamics of interactions in cases such as urban stream restoration.

In addition, this chapter discussed the Korean planning literature to understand how planners (urban engineers and public administrators) typically view the dynamics of decision-making processes in environmental management.

This review chapter addressed how the political evolution of government towards more citizen participation in public policies established the context for this research. 


\section{Chapter 3}

\section{Research Design}

The primary goal of this dissertation is to analyze the decision-making processes and conflicts among primary values of the stakeholders in one stream restoration process in Korea. More specifically, using qualitative and quantitative methods, this dissertation aims to address the research questions: (1) To what extent are nontechnocratic values integrated into stream restoration cases in governance processes of stream restoration in South Korea? Also, what was achieved and why were social factors not more heavily considered? (2) In what ways does a participatory governance process in a stream restoration project in South Korea enable the consideration of nonscientific factors into the decision-making process?

This chapter explains the research design used in the investigation. First, the case selection is explained and background information provided. The time frame for this examination extends over both the plan-making phase as well as its implementation. Then, four steps in data collection and analysis for the stream restoration case are presented: (1) initial document review and Nominal Group Technique (NGT), (2) designing interviews and Analytic Hierarchic Process (AHP) survey with governance participants, (3) a mixed method analysis with content analysis and AHP, and (4) Grounded Theory. Content analysis and grounded theory are utilized to observe, evaluate, and trace power relations, stakeholders' values, and roles of technocratic information, as well as outcomes and initial agendas of the stream restoration, which are accounted for through field research. The qualitative analysis results informed and facilitated the subsequent quantitative analysis, AHP. Each step is described in greater 
detail, after a brief discussion of the status of stream restoration in Korea, case study selection and relevant background and other contextual information.

\subsection{REGIONAL CONTEXTS IN THE FIELD OF STREAM RESTORATION}

Local governments in Korea face various challenges in balancing the tension between engineering and civic engagement in water management. Rivers in Korea have long been regarded as a major resource system in the country, and water resources have been utilized strategically for economic growth since the 1960s (Lee and Choi, 2012). Korean communities focused on the value of rivers and streams for inland transportation and agrarian use during the 1960s. In the 1970s, irrigation and flood control were the top priorities, with the value of water regarded as a complementary resource for national economic development. Rapid industrialization initiated by

Korea's central government between 1960 and 1980 led to contamination, so that by the 1980s the ill effects of pollution led governmental and local Korean leaders to prioritize the enhancement of water quality. Since the late 1990s, Korean society has recognized the separate but connected roles of environmental conservation and political democratization based on citizen participation. Hence, stream restoration has become a popular construction project, in which revitalization of environmental systems has become both an end in itself as well as a means for democratization of decision-making.

For example, during the transition period of 1962 to the present under the new President Park regime, the Korean Municipal Water Maintenance Plan and the Water Resource Long-term Plan were flagship strategies of the Ministry of Construction and Transportation (Lee and Choi, 2012). These plans sanctioned the dual roles of water 
policy by conserving river water resources as well as regional management. However, these plans by the Korean government did not address long-term sustainable resource management of the river basins in Korea, and there were still many ongoing conflicts often grounded in issues of legitimacy of regional plans — about regional river basin management between citizen groups and governmental organizations.1

In Korean cases, the first step in the water management process is usually shaped and guided by engineers and local governments (Lee and Choi, 2012), who concentrate on the improvement of water quality through new technologies. In fact, local Korean inhabitants are also interested in participating in the decision-making forum to share their ideas due to their growing awareness of the importance of stream restoration from an environmental perspective. Their preference is to engage in the restoration process through democratic communication, rather than be forced to accept unilateral stream renovation based on technocratic efficiency and innovative engineering technologies implemented by the government officials. This social pressure for participation in the process of decision-making for stream restoration ultimately resulted in an integrated water resource management system, as well as an integrated administrative system which the Korean government adopted in 2006 (City of An'Yang, 2006).

Integrated water resource management (IWRM) has played a remarkable role in Korea. In particular, IWRM systems in Korea have facilitated many successful examples of stream restoration, which include advantages of citizen participation (Lee and Choi, 2012). Ko (2008) states that IWRM for streams in Korea has helped to

1 Two cases in point are the Sanji Stream restoration in Jeju Island and the Cheonggye Stream restoration in Seoul. (Koh, 2005; Hong, 2009) 
overcome weaknesses in terms of natural disasters and improve water quality and ecological systems. Further, participatory decision-making allows for a balance across scientific factors of the ecological systems and factors of the social systems (Lee and Choi, 2012). They note that integrating scientific improvements and citizen participation improved the long-term success of the restoration project because the citizens became interested in their participation as well as stream ecological management and usage of water-front spaces by technological innovation (City of An'Yang, 2001 and Daejeon Daily, 2011).

This research examined one stream restoration project, a flagship case of the Korean IWRM, to uncover the extent to which societal factors as well as ecological and scientific factors were embraced within the decision-making process (Heathcote, 1998). The findings of this research will provide a potential direction to promote policy implications for Korean stream restoration authorities that face the need to address the significance of social restoration such as public participation as well as ecological preservation.

\subsection{CASE SELECTION AND INTRODUCTION TO AN'YANG STREAM}

An'Yang Stream flows into the Han River through the downtown of the city An'Yang, located approximately $21 \mathrm{~km}$ south of Seoul. The An'Yang Stream is 32.2 $\mathrm{km}$ long with a basin area of $275 \mathrm{~km}^{2}$ (Yu et al., 2003). An’Yang Stream includes tributary streams An’Yang Stream (11.85 km), Hak-ui Stream (4.5 km), Sooam Stream $(5.5 \mathrm{~km})$, Sammack Stream $(3.5 \mathrm{~km})$, and Samsung Stream $(5.3 \mathrm{~km})$. In the river basin 
of An'Yang Stream, 14 local governments oversee the 3.5 million persons who live along this stream (City of An'Yang, 2001).

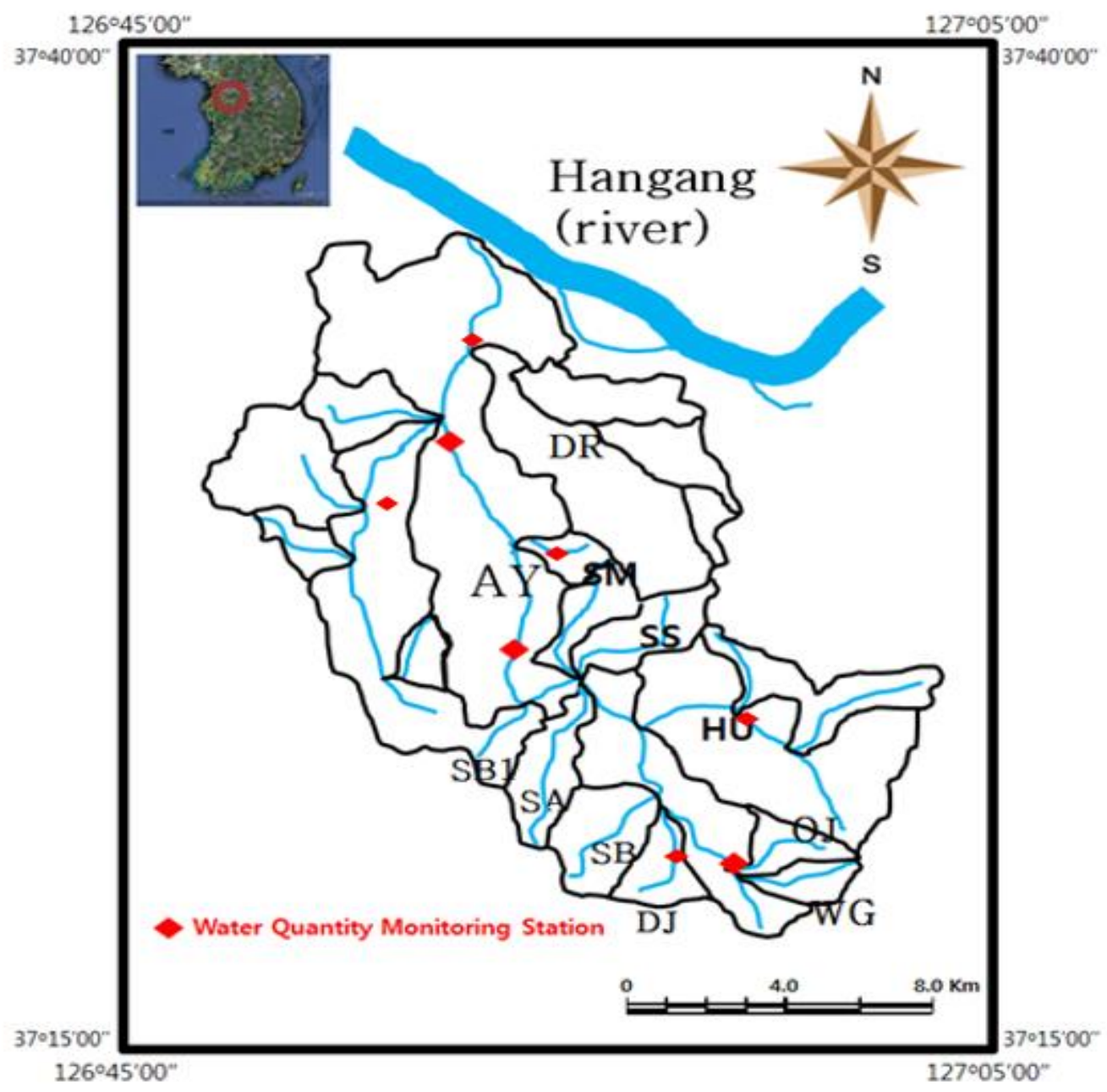

Figure 5. An'Yang Stream River basin

Due to the geographical proximity to the political and economic capital of Korea, Seoul, the City of An'Yang experienced rapid urbanization and industrialization after the Korean War (1950-53). Social and industrial changes in An'Yang negatively influenced the water quality and the eco-system of the An'Yang Stream (Chang, 2008). 
Ultimately, the severe contamination of An'Yang Stream induced ordinary citizen groups to work together for stream restoration (Lee et al., 2005).

Prior to 1999, the An'Yang city government undertook several engineering projects aimed at cleaning up polluted local streams further downstream. However, those projects were unsuccessful due to continuous dumping by local residents and wastewater flowing into the streams from nearby industry. Since the late 1990s, diverse efforts from the citizen movement and governmental collaboration have improved water quality. According to the An'Yang Stream Governments Water Quality Improvement Council (AGCWQ), the BOD level was $66.7 \mathrm{mg} / \mathrm{L}$ in 1992 but dropped dramatically to $5 \mathrm{mg} / \mathrm{L}$ in 2008 (Min et al., 2014).

One of these efforts was the formation of the An'Yang Stream Governments Water Quality Improvement Council (AGCWQ) established by 13 local governments in order to support citizens' collaboration regarding integrative watershed management. The council leaders were elected politicians who sought expert advice from engineers and hydrologists who could evaluate water quality changes and provide solutions for improving water quality (i.e., BOD, DO, COD, and T-N). As the first step, the leaders suppressed illegal wastewater discharge human and industrial into the An'Yang Stream and conducted a river corridor survey (RCS) to investigate precise water quality and ecological indicators in 2001. During these processes, the AGCWQ professional advisory consultants (mostly scientists and civil engineers) actively participated in the fieldwork and citizen surveys (Daily Daejeon, 2011). The AGCWQ established the system of collaborating with the private sector: NGOs, citizens, and environmental organizations. As a result, they formed a strong partnership, 'The People Loving 
An'Yang Stream,' with 2,817 members from the private and public sectors (Joo, 2004) and opened a proposal bidding process for installing an underwater wire net to prevent fish from perishing during heavy rains. Lastly and most importantly, the AGCWQ strengthened the basics of the An'Yang Stream Restoration Master Plan in 2001.

The AGCWQ was comprised of actors that were both interdependent on one another as well as independent in their own localities. When the AGCWQ (11 governments) was initiated, the city government of An'Yang officially began to play a key role in this governmental partnership. This was the first governmental collective association for stream restoration. By extension, local knowledge based on the citizens' collaborative partnership from the grassroots gathering was handed down to the extended AGCWQ (13 governments). Seven local districts of the city of Seoul and six counties of the Gyeonggi province joined this committee as the main leading actors. This AGCWQ relied on engineering methods to deal with water quality issues, regional environmental conservation and stream restoration. As an umbrella organization with broad financial resources, the AGCWQ could fund conferences to share information among stakeholders, conduct periodic watershed joint research, investigate water ecology and provide sponsorship for environmental monitoring by citizen watchdog programs. In other words, this sponsorship resulted from their financial executive powers, as each stakeholder and local governments of the AGCWQ had the authority to allocate the budget only for water quality improvement (Min et al., 2014).

In addition to a consensus on financial decisions, the divided nature of stakeholders resulted in different viewpoints regarding priorities and values of stream restoration. Local citizen groups often had views that conflicted with those of public administrators 
and urban engineers. The citizens held different priorities than those of governmental officials and defined ecological restoration in terms of short-term achievements such as river cleanup, waterfront beautification, and landscape gardening (Min et al., 2014). However, public administrators and engineers measured ecological restoration by scientific indicators of ecological systems.

A third major player in this case was the An'Yang Stream Protection Network (ASPN). The An'Yang Stream Protection Network was initiated through the collaboration of private sector members and organizations in 1999 (Figure 6). This integrative organization — based upon citizen movement — operated to improve water quality, watershed research, ecological education, monitoring, and participation in the policy-making processes. According to publications from the City of An'Yang (2001) the four major goals of the ASPN were: 1) stream ecological restoration motivated by public engagement and community movement, 2) cultural and historic preservation in the river basin, 3) collaborative partnership building amongst stakeholders, and 4) establishing a comprehensive master plan for stream restoration. ASPN was composed of citizen groups, NGOs, and environmental groups, and later contributed to the formation of 'The People Loving An'Yang Stream,' which shaped the decision-making committee shown in Figure 6 (City of An'Yang, 2001).

According to the Daily Daejeon, a daily newspaper with high readership, (2011), the ASPN experienced financial hardship, conflicts among citizen groups, and a vacuum of executive power in 2000. Even so, ASPN communicated with citizens about the seriousness of ecological changes and pollution through social media such as Facebook and Twitter. In addition to public media methods, the ASPN took the lead in 
the ecological conservation of the An'Yang Stream by emphasizing activities valued by local citizens, such as spatial efficiency and landscaping beautification. For example, ASPN led efforts to relocate the parking space in the waterfront area to provide a better aesthetic landscape for the community (Daily Daejeon, 2011)

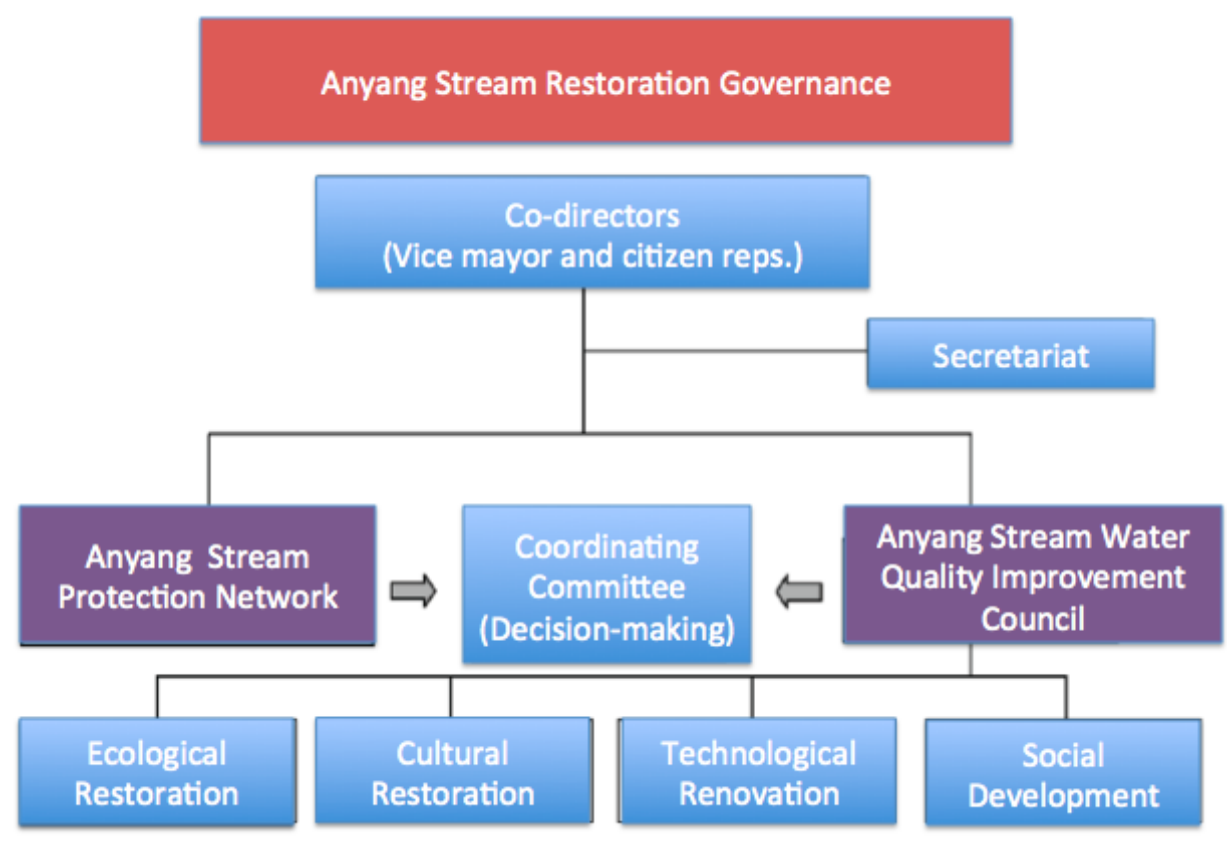

Figure 6. An'Yang Stream Restoration Governance (City of An'Yang, 2001)

As a result, the ASPN played the role of an ignition agent in at least two ways. ASPN not only focused on observable improvements for citizens' lives with beautification, but it also was the first group to contribute to building environmental governance in the City of An'Yang. This governance network proclaimed the Always Green An'Yang 21's agenda, which aimed to organize and lead diverse groups for sustainable urban planning in the region of An'Yang City. The decontamination of the An'Yang Stream was one of the major projects on the agenda (City of An'Yang, 2009). 
Thus, the ASPN based on the cooperation of both citizen groups and governmental associations initiated a local stream restoration movement by soliciting public attention and active collaboration. ASPN stakeholders sought advice from the An'Yang Stream Water Quality Improvement Council, which was composed of environmental scientists, civil engineers, and ecologists, in supporting the decision-making (see Table 3) and to set the following goals, 1) restoring biological function, 2) enhancing water quality, 3) improving flood prevention functions, and 4) constructing recreational facilities. Also, this An'Yang Stream Restoration Plan shared the goals with the An'Yang City Master Plan, An'Yang Vision 21, An'Yang Environmental Conservation Plan to create a synergy effect.

Table 3. An’Yang Stream Restoration Goals (An’Yang City, 2003)

\begin{tabular}{cl}
\hline Ecological goals & \multicolumn{1}{c}{ An'Yang Stream Restoration Goals } \\
& $\begin{array}{l}\text { Water quality improvement, Nature-friendly stream restoration, } \\
\text { Improving functional diversity, etc. }\end{array}$ \\
\hline Cultural goals & $\begin{array}{l}\text { Recreational waterfront space for citizens, Forest park and } \\
\text { landscaping, River basin beautification, Historic preservation, } \\
\text { Educational programs for students, etc. }\end{array}$ \\
\hline Technological & $\begin{array}{l}\text { Hydro-Engineering development, Water flow control, Adaptive } \\
\text { goals }\end{array}$ \\
systems for flood control, Supplying in-stream flow, etc. \\
\hline Social goals & $\begin{array}{l}\text { Public participation, Governance building, Partnerships with } \\
\text { citizens, Economic development in the An'Yang city region, }\end{array}$ \\
& $\begin{array}{l}\text { Long-term monitoring based on collaboration among stakeholders, } \\
\text { etc. }\end{array}$
\end{tabular}

The water quality of the An'Yang Stream has improved since 2001 because of various governance efforts guided by the An'Yang Stream Restoration Master Plan (Hong and Chung, 2016). These governance efforts are a collaborative partnership consisting of engineers, GOs, NGOs, and stakeholders or citizens. In the An'Yang Stream Restoration Project, governance contributed to the water quantity and quality 
improvement, which were accomplished by utilizing the advanced engineering technologies and collective governmental efforts such as sewage treatment plants, heavy metal control, non-point pollutants control, and stream sewage treatment facilities, initiated in 1999 (Hong and Chung, 2016).

In the mid-2000s, the An'Yang Watershed had many construction projects for both river channel management and spatial renovation. Ecological habitat composition and conservation projects were conducted between 2003 and 2005. In the upper stream, this habitat composition and conservation project is an extension of the existing water quality improvement strategies. After the parking lot demolition near the watershed, waterfront renovation construction projects went on from 2003 until 2009 (Tables 4 and $5)$.

Table 4. Early period timeline of An'Yang Stream restoration before 2001

\begin{tabular}{cl}
\hline Year & \multicolumn{1}{c}{ Timeline of An'Yang Stream restoration } \\
\hline $1960-1990$ & Polluted due to effluent from nearby urbanized and industrialized areas \\
\hline 1999 & $\begin{array}{l}\text { Established An'Yang Stream Protection Network (ASPN) (An'Yang } \\
\text { vision 21 project) }\end{array}$ \\
\hline 1999 & Organized the An'Yang Stream restoration task-force \\
\hline 2000 & Formed partnerships between institutes and goverments \\
\cline { 2 - 2 } & Launched governmental committee for water quality improvement \\
\cline { 2 - 2 } & Set the implementation strategies and plans \\
\cline { 2 - 2 } & Published inception reports \\
\cline { 2 - 2 } & Held public administrative meeting led by City of An'Yang \\
\cline { 2 - 2 } 2001 & Held public hearings \\
\hline 2001 & $\begin{array}{l}\text { Published determined stream restoration construction plan (An'Yang } \\
\text { Stream Restoration Master Plan) }\end{array}$ \\
\hline & $\begin{array}{l}\text { Televised SBS Documentary TV Show 'Water is Life', and the SBS } \\
\text { team filmed, joined and participated in the An'Yang Stream Restoration } \\
\text { Project }\end{array}$ \\
\hline $2001-2010$ & Began major construction and renovation of An'Yang Stream \\
\hline 2001 & $\begin{array}{l}\text { Set An'Yang Stream Protection Network's new goals } \\
\text { 1) restoring biological function }\end{array}$ \\
2) enhancing water quality
\end{tabular}




\section{3) improving flood prevention functions}

4) constructing leisure facilities

However, many citizen groups and NGOs were also active in private sectororiented stream restoration activities and establishing programs, such as cultural and educational events about stream restoration, to create public sentiment in favor of advanced participatory decision-making based on bottom-up civic engagement structure, but they could not directly convey and lobby for their values and interests in the decision-making process because the government systems showed far too many limitations to accept the citizen-oriented bottom-up structure (Hong and Chung, 2016). In general, the governmentt administrators still valued technocratic decision-making systems based on scientific efficiency as many documents and public reports have tended to pay attention only to the roles and contributions of science to water quality improvement in the An'Yang Stream (Hong and Chung, 2016). 
Table 5. Annual plans and strategies of An'Yang Stream Restoration

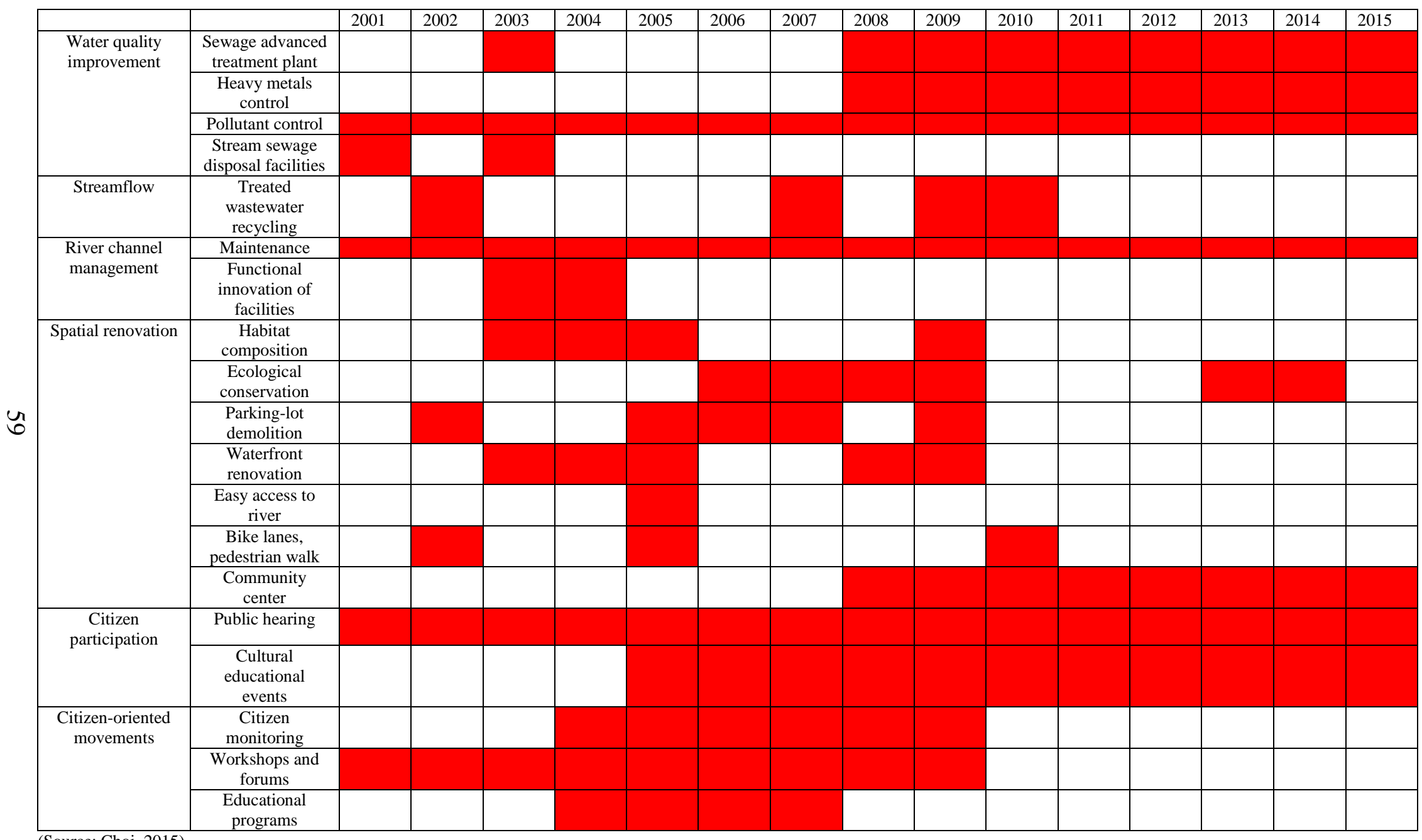

(Source: Choi, 2015) 


\subsection{RESEACH DESIGN}

The main objective of this research is to examine whether stream restoration governance incorporates different values and visions of various stakeholders within the context of a top-down decision-making structure. This research studies the An'Yang Stream Restoration Project in South Korea to analyze decision-making processes. In particular, the research sought to answer: (1) To what extent are non-technocratic values integrated into stream restoration cases in governance processes of stream restoration in South Korea? (2) In what ways, does a participatory governance process enable the consideration of non-scientific factors into the decision-making process?

This research conducted a content analysis of the Master Plan, interviews and survey participants, applying Analytic Hierarchy Process to establish their priorities, and a comprehensive analysis by Axial Coding of Grounded Theory.

\subsubsection{Questions guiding data collection (See factors to examine in Appendix 4)}

The following questions guided the field research conducted in 2015. Each research question contained an associated hypothesis, concentrated on analyzing related factors in the research. Next to each question, a code indicates how the anticipated data will be used in the analysis of the final documents (QA = qualitative analysis; $\mathrm{AHP}=$ analytic hierarchy process).

This section helps to expand the research questions of this work. For the first question, "To what extent are non-technocratic values integrated into stream restoration cases in governance processes of stream restoration in South Korea? Also, what was achieved and why were social factors not more heavily considered?", the 
results of document review and content analysis provide a frame and a contextual structure by reviewing and evaluating the agendas and values in the early stage's strategies and plans guided in the Master Plan. To answer the second question, "In what ways does a participatory governance process in a stream restoration project in South Korea enable the consideration of non-scientific factors into the decision-making process?", the contents regarding civic participation described in the An'Yang Stream Restoration Master Plan are reviewed and analyzed in conclusions of the citizen survey conducted in advance.

To answer the main research questions, subordinate questions are given and those questions scoped each hypothesis. (CA: Content Analysis. AC: Axial Coding, AHP: Analytic Hierarchy Process)

a. Who are the stakeholders in this collaborative stream restoration process? (CA)

Hypothesis 1: Decision-making groups that include non-engineers/planners incorporate social values into the decision-making (stream restoration) process.

Hypothesis 2: When information is shared more widely in the participatory decision-making process, social values on the stream restoration are incorporated. b. How does the context of the water planning affect the problem definitions and the goal setting in stream restoration? (CA)

Stream restoration processes are influenced by water resource planning organized by governments. The stream restoration processes engage planning processes and their decision-making culture in scoping goals and specific agendas.

Hypothesis 1: Decision-making of stream restoration processes in South Korea tends to be shaped in a top-down structure. 
Hypothesis 2: Stream restoration strategies with concentrated social and cultural factors are more likely to draw the attention and participation of the citizens. Also, planning activities where the objectives are to achieve cultural and historical preservation on the stream will result in a positive tone for participatory stream restoration including communities.

c. To what extent do the stakeholders use scientific knowledge in stream restoration collaborative decision-making? (CA, AC)

Hypothesis 1: The decision makers use scientific knowledge as the most important and primary factor in the decision-making process of stream restoration collaborative governance. Engineering technology provided by professionals and experts is considered to be a more important factor than the socio-cultural factors that citizens consider important in the stream restoration decision-making process.

Hypothesis 2: Engineers and public administrators who understand scientific measurements and evaluations in stream restoration have more powerful positions than do citizen groups who do not understand the professional jargon without assistance and who do not directly participate in the decision-making process. Each stakeholder has a different level of power based on the degree to which the stakeholder can access and analyze relevant information, such as scientific sources.

d. What factors are considered to be the most important by the stakeholders? (AHP, CA, and $\mathrm{AC})$

e. What factors are excluded in the decision-making processes and why? (Water quality, water culture, historic preservation, regional economic development, ecological conservation, landscaping, political issues, etc.) (AHP, CA and AC) 
In stream restoration, conflicts among the stakeholders occur when different frames attempt to work together (Conley and Moote, 2003). Social and scientific factors are often disharmonious in stream restoration goal setting. In particular, conflicts among stakeholders representing both social and scientific elements cause intractable conflicts in the decision-making process. Collaborative governance allows stakeholders and participants to embrace and understand one another's needs and concerns. The collaborative adaptive governance theory facilitates conflict resolution through methods such as paraphrasing professional language, thereby allowing ordinary citizen groups to take part in the decision-making process.

Hypothesis 1: Conflicts in stream restoration emerge from contradictions among diverse interests. The stakeholders in stream restoration collaborative groups argue with other groups who interpret professional/scientific knowledge from different perspectives.

Hypothesis 2: Participants state that water quality evaluated by scientific indicators will be the most important factor in decision-making.

f. What is the contribution of media in building citizen partnerships? (CA and AC)

The case of An'Yang Stream restoration has been well-known for successful and effective water resource management in Korea (Hong and Chung, 2016). There was the contribution of mass communications (Houston et al., 2015). Hong and Chung (2016) argue that the mass communications influenced sharing scientific knowledge as well as information on the stream systems with citizens and inducing more citizens to various stream restoration programs and citizen-oriented movements. 
Hypothesis 1: Public mass communications such as TV programs, newspapers, and social media will contribute to sharing scientific information among citizens on the stream system.

Hypothesis 2: Public mass communications can draw public attention from the citizens concerning the stream restoration process.

\subsubsection{Data collection}

Data collection and case analyses took place in three steps: 1) Nominal Group Technique (NGT) and initial document review, 2) interviews (online and in-person) + AHP survey, and 3) Analytic Hierarchic Process (AHP) analysis and 4) comprehensive analysis through Axial Coding of Grounded Theory-based upon the results from surveys and interviews. Each sequential step built upon previous analyses and research documents provided by the City of An'Yang. At each step, the data sources are outlined and methodologies for the data collection processes and individual analyses were identified in advance.

Document retrieval and analysis:

In June of 2015, the researcher went to South Korea to collect relevant data and conduct interviews. During the field research work, Dr. Jinkyu Chung of the Korea Research Institute of Human Settlements (KRIHS) and Professor Eunsung Chung of the Seoul National University of Science and Technology assisted the researcher in conducting interviews and accessing relevant information on An'Yang Stream Restoration. Archival research was completed with public documents held at KRIHS, and the AHP survey design and analytic process were conducted at Seoul National 
University of Science and Technology with the cooperation of Professor Chung, Eunsung. The researcher also visited the National Assembly Library and the Archive of the City of Seoul to find and collect public documents. Content analysis of archival documents identified conflict-causing events and values, as well as identified the decision-making structure in stream restoration. After these archival visits, the An'Yang Stream Restoration Master Plan (2001) was selected as an appropriate public document for the document review process. Accordingly, data from both document review and interviews were collected and gathered from the following sources regarding An'Yang Stream in this research (Table 6).

Table 6. Data collection sources and target information

\begin{tabular}{cl}
\hline Sources & \multicolumn{1}{c}{ Target Information } \\
\hline An'Yang Stream & 1) Original values reflected in the master plan making \\
Restoration Master & process up to 2001 \\
Plan (City of & $\begin{array}{l}\text { 2) Stream restoration strategy documents and policy } \\
\text { proposals }\end{array}$ \\
An'Yang, 2001) & 3) Annually recorded water quality data \\
\hline Semi-structured & 1) Implementation of the master plan (2001) \\
interviews and AHP & 2) 33 participants (stakeholders) of the An'Yang Stream \\
survey with & restoration governance \\
stakeholder groups & $\begin{array}{l}\text { 3) The semi-structured interviews with questions designed } \\
\text { on the subject of stream restoration. }\end{array}$ \\
& $\begin{array}{l}\text { 4) Both qualitative analysis and AHP analysis } \\
\text { 5) Axial Coding of Grounded Theory }\end{array}$ \\
\hline
\end{tabular}

Semi-structured interviews:

Semi-structured personal interviews with participants of the collaborative process representing each stakeholder group, as well as with scholars in the field of stream restoration, were conducted in South Korea from June through August 2015. The interviews were recorded and scripted verbatim in both English and Korean. Most 
importantly, the official long-term master plan document issued by the local governments, as well as interview scripts, underwent qualitative (content) analyses.

During summer of 2015, I attended and observed public meetings (two times in Gwangmyong and An'Yang) and collaborative council gatherings (three times in Seoul (Guro and Yangcheon) and An'Yang) on stream restoration in South Korea for content analysis and survey.

\subsubsection{Phase 1: NGT and initial document review}

In the first phase, the researcher conducted the nominal group technique (NGT) with sixteen water resource professionals who worked for and participated in the An'Yang Stream restoration project. These sixteen NGT participants, who requested anonymity, were asked to rank their top three values prior to AHP. Generally speaking, the NGT helps to find the ranking of the values and the top-ranked three values are used in survey questions of the AHP survey questionnaire. This NGT result will be described later in the following section on AHP.

Also, the first phase aimed at understanding the contextual background of the early stage of An'Yang Stream Restoration Project, including the stream restoration goals, processes, and planning exercises, and to construct a map of the stakeholders' interests through content analysis. To select the appropriate document describing the long-term master plan of the stream restoration, relevant data included plans and strategies prior to the initiation of the stream restoration with governmental documents, media/newspaper archive search for background information, published articles, and internal documents recording stakeholder meetings and the agenda for each meeting. This in-depth study of 
reviewing the relevant documents guided this work to select the available document to understand the original values reflected in the stream restoration agendas. As a result of this process, the An'Yang Stream Restoration Master Plan (City of An'Yang, 2001) was finally selected as the document for document review which can guide to recognize the values reflected in the early stage of stream restoration.

After the relevant documents were reviewed and studied, content analysis with one document, the An'Yang Stream Restoration Master Plan (City of An'Yang) was accomplished by analysis of coded and collected texts with Dedoose software. The collected data was open-coded by hand. In addition to retaining the hand-coded data from the document, this analytical memo was added to document summary, containing diverse interests and stakeholders, roles of scientific information on stream management, power dynamics among stakeholders, agenda settings as well as initial researcher reflections. All analytical memoranda were integrated into a larger draft conceptually summarizing the initial document.

3.3.4 Phase 2: designing and preparing semi-structured interview and AHP survey Interviewee Sample selection:

The participants and their key values were identified after the first phase. The interview candidates were stakeholders who were directly involved in the stream restoration process. Also, with snowball sampling, additional interviewees were identified, as recommended by other stakeholder groups or individuals. These interviews focused on the themes of goals and agendas of stream restoration, participatory process with relevant stakeholders, stream restoration governance 
structure, understanding diverse interests, power dynamics, influential social factors in the stream restoration, and treatment and sharing of the scientific information. Before conducting each interview, the researcher investigated and learned about the interviewees' educational and professional experiences. The interview questions and informed consent are attached in the Appendix in English and Korean.

Interviews were sought with five groups of stakeholders: 1) stream restoration experts, 2) public administrators (sometimes planners), 3) engineering consultants from the private engineering corporations (construction contractors), 4) non-governmental organizations, and 5) citizens. Interviews with public administrators guided this researcher to understand the stream restoration governance and how it was shaped beyond conflicting interests. Interviews with participants from the private sector helped to define the roles of the private sector and their interests in the stream restoration. Interviews with spokespersons or leaders of NGOs involved in the process provided an understanding of both macroscopic and microscopic values of stream restoration. Lastly, interviews with citizens addressed how feedback issues and public communications work in stream restoration governance, as well as why stream restoration needs a balanced decision-making process in considering social and scientific factors under collaborative adaptive management with public participation including many citizens' ideas.

This interview process was designed to ask about implementation and what occurred after the An'Yang Stream Restoration Master Plan was published in 2001. Some public administrators and stream restoration experts helped to enlist and contact stakeholders for the interviews. In this stage of research planning, it was anticipated and 
intended that this field research should equate to approximately 33 interviews divided across five types of stakeholder groups: 6 stream restoration experts, 9 public administrators (planners), 5 private engineers working at engineering corporations (enterprise), 6 representatives of non-governmental organizations, and 7 local citizens, who were recruited from the groups of local residents who attended public hearings.

For processing interviews, each interviewee was initially contacted by email or phone to request a formal one-hour interview and ten-minute Analytic Hierarchy Process (AHP) survey. In order to schedule an interview appointment, a confirmation email or text was sent with the human subjects consent form attached or the consent form was shared in hard copy. Both in-person interviews (about an hour) and Skype interviews were conducted. If longer interviews were needed, interviewees were asked for their consent in advance.

The interview content was recorded and saved into electronic voice files (MP3 and WMA), a memo written immediately following the interview, and transcribed using voice recognition software Dragon Dictate for Mac in Korean. Also, the summary documents will be shared with the interviewees with transcripts available upon their request (see Table 6).

Right after the semi-structured interview, AHP survey was administered to each interviewee. First of all, the AHP tool is appropriate to find the most significant value or interest for the stakeholders in establishing a complicated IWRM. According to Ko (2007), for IWRM to lead to successful stream restoration, it must be participatory, adaptive, and experimental, integrating all the relevant scientific knowledge/ data and user-supplied information regarding the social, economic, and environmental processes 
affecting water issues in the watershed. A tool that permits explicit presentation of evaluation criteria and thus possibly improves IWRM plan selection is the Analytic Hierarchy Process (AHP) (DeSteiguer, 2003), which is a Multi-Attribute Decision Method (MADM). MADM refers to a host of quantitative techniques used to facilitate decisions that involve many competing criteria (Alonso and Lamata, 2006). MADMs use multiple criteria rather than relying on a single criterion to make a decision, for example, as in cost-benefit analysis or efficiency feasibility test (maximum net present value) (Thengane et al., 2014). AHP was a useful method of quantitative analysis for analyzing which factors were most influential in decision-making for stream restoration and resolving water conflicts in the face of diverse interests, because it treats decisioncriteria and criteria-weighing in an open and explicit manner (DeSteiguer, 2003). In this research, the Nominal Group Technique (NGT) and Analytic Hierarchy Process (AHP) method were used to support and assist in analyzing the decision-making process; it is particularly suited to integrating water systems taking into account multiple interests and goals.

\section{AHP Analysis:}

AHP analysis included three steps during the process of research design. First, the criteria were selected from a set of values that stood for the interests of the stakeholders through the Nominal Group Technique (NGT) during field research preparation before the field trip to Korea. This step identified and chose three criteria for calculating the relative weights through pairwise comparisons between the criteria (values in content analysis or core categories in Grounded Theory). Before leaving for Korea to process 
field research, the water resource professionals who had participated in the An'Yang Stream restoration project were contacted by email to ask their availability to answer a short NGT survey ranking top three important criteria (values) of stream restoration. Sixteen water professionals answered to opt into this NGT survey after a brief introduction of this research to them by Skype calls or emails.

Second, this research modeled the hierarchy structure to set a goal of three criteria of the An'Yang Stream restoration before the field survey to Korea. The third step, the AHP survey was held in Korea.

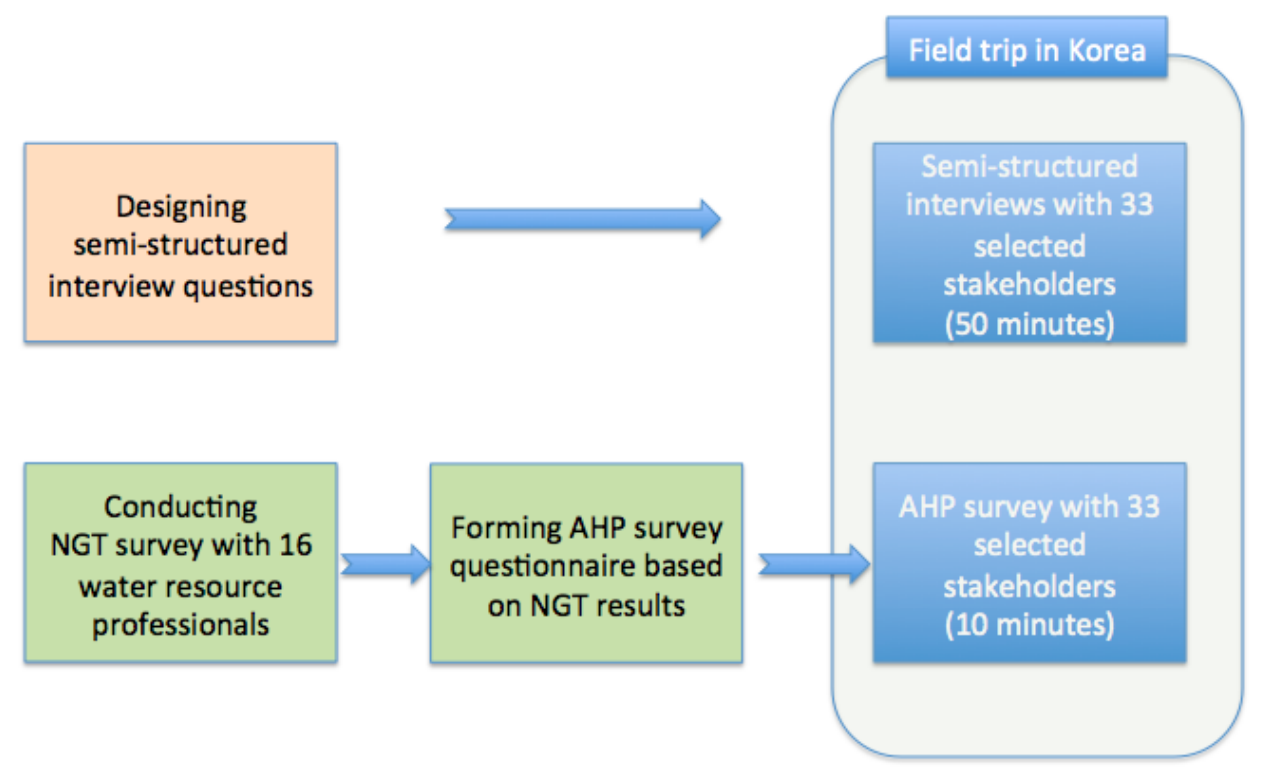

Figure 7. Flowing-chart of interview and AHP survey process

3.3.5 Phase 3: Mixed method analysis (Content analysis + AHP)

After identifying the interests and values of the stakeholders for stream restoration through the two previous phases of document review and interviews, the third phase 
involved a computer-based qualitative content analysis of the final documents published by the governmental authority in charge of the overall stream restoration process. In this phase, the researcher examined what factors were included in measuring and evaluating the success of their stream restoration. Also, this research tries to answer the question, "Was scientific information still more important than social factors in stream restoration?"

With the summarized documents from phases one and two, this research compared the results of a qualitative analysis of interview transcripts by Dedoose with results of AHP surveys, which is a computer-based program to confirm (or not) the extent to which interests of the stakeholders was accepted and reflected. Also, this qualitative analysis with Dedoose assisted to identify any newly emerging interests on stream management, and to understand how much scientific knowledge was shared with other stakeholders, and how participants in the Stream Restoration Project perceived scientific knowledge in this particular decision-making process. Through this analysis, a potential pattern of stakeholders' values and interests could be displayed on a chart created by the Dedoose software program (see Appendix 2 and 3). This information contributed to understanding potential conflicts due to different values and interests within the decision-making process of stream restoration. At the same time, the results from Nominal Group Technique Analysis (NGT) and Analytic Hierarchy Process (AHP) were used to trace rankings of individual and collective interests, representing each stakeholder group (Schmoldt et al., 1994 and Hiligsmann et al., 2013). The AHP survey result was calculated to indicate the rates of the relative importance among more than two criteria through the pairwise comparisons (Song and Kang, 2016). 
This research examined how much of the interaction among the stakeholders on the stream restoration committee was associated with participants' individual priorities within the decision-making process, i.e., to what extent diverse values in decisionmaking processes influenced the decision-making process. During the research plan and proposal, it was assumed that the more active interaction the stakeholders had with one another, the more unified the outcome of the AHP would be with regard to their preferences on policy priority for stream restoration.

The AHP survey result was based on calculating and understanding relative weighted importance between the values through pairwise comparison. If the survey has three values (ex. A, B, C) in the AHP survey, first A is compared to B, second, A is compared to C, and lastly, B is compared to C. During the comparing processes, the results show us how much A (or B) is more or less important than B or C. Also, consistency index (CI) was calculated because some respondents' answers indicated an illogical pattern (Song and Kang, 2016).

This research assumed that the individual values and goals of the interviewees reflect the social and natural scientific (ecological) priorities of stakeholders in the process of restoring An'Yang Stream in Korea from 2001-2015. The content analysis of one public document and interview transcripts delved into the extent the stakeholders put on a technocratic performance, which is based on improvement by adopting scientific knowledge. Hence, my research will show how this work analyzed the interview transcripts, and quantitative data of an AHP survey in a new way: by evaluating the agenda setting in terms of concepts. In particular, the content analysis of interview transcripts addressed who the key participants and leading stakeholders were, 
and how their values were drawn. In addition, the results of the AHP and content analysis indicated which values were discussed more frequently and valued more highly than others within the An'Yang Stream decision-making process.

\subsubsection{Phase 4: Grounded Theory}

Finally, this work conducted one test using 'Grounded Theory.' The leading scholars of the Grounded Theory field, Corbin and Strauss (2015) argue that the strength of the methods of research analysis and data analysis can be mutually interactive and interrelated in the analytic process. This benefit makes the comprehensive analysis of this dissertation successful in conceptual mapping among the major factors of the capacity-building and decision-making activities of stream restoration (including social and ecological perspectives) based on a pragmatic viewpoint (Corbin and Strauss, 2015).

This research uses open, axial, and selective coding guided and designed by Strauss and Corbin (1967) (Gorra and Kornikali, 2007). Also, this work perceives the qualitative analysis software Dedoose to be a valuable device that can help us to sort codes and make it easier to extract the transcripts for discussion. At the same time, this analysis with the concept of Grounded Theory examines if it is an appropriate methodology to use in the qualitative analysis about the topic of stream restoration. 


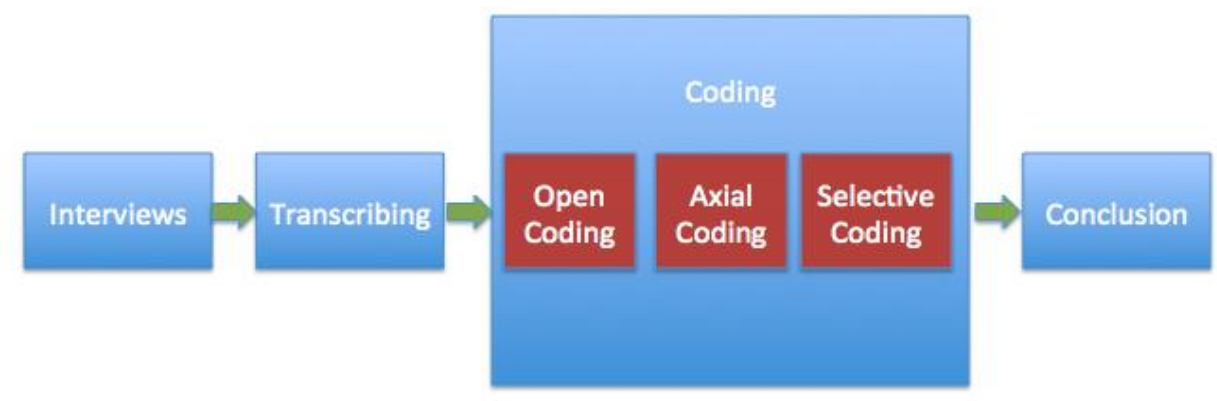

Figure 8. Flowchart of analyzing the Grounded Theory

Chen and Chan (2013) introduce the coding processes guided by Grounded Theory. As the authors (2013) test, the research will conduct content analysis by open coding, axial coding, and selective coding. The open coding is a bottom-up and data-driven approach with the computer based program, Dedoose. The second process of coding is the axial coding which is composed of causal conditions, contextual conditions, core categories, intervening conditions, and consequences. Finally, selective coding guided to outline and shape the implications and potentials of developing the qualitative analysis. To sum, the Grounded Theory methodology is an inductive and systematic qualitative process in many disciplinary fields with a positivistic viewpoint (Gorra and Kornikali, 2007). In particular, the Grounded Theory provided a clear way of adopting various codes and coding processes, which reflect the interview transcripts of the specific social phenomenon (See the figure 8 above). Consequently, this research by applying the coding processes grounded on the Grounded Theory tested what factors influence the An'Yang Stream restoration decision-making process. 


\subsection{RESEARCH DESIGN SUMMARY}

The research design integrates qualitative and quantitative methods, as noted below. The following three chapters report the findings from each step in the research design, beginning with Chapter 4, a content analysis of the Master Plan to look at the values reflected in the plan making process up to 2001.

Table 7. Research process design

\begin{tabular}{lll}
\hline & \multicolumn{1}{c}{ Qualitative Process } & \multicolumn{1}{c}{ Quantitative Process } \\
\hline Data Collection & 1) Semi-structured intervie & 1) Survey with key stakeh \\
& w & olders in stream restoratio \\
& 2) Documents review & $\mathrm{n}$ \\
& 3) Observation at stakehol & \\
& der meetings & \\
\hline Data Analysis & 1)Content analysis & 1)Analytic Hierarchic Proc \\
& 2)Axial Coding & ess \\
\hline
\end{tabular}




\section{Chapter 4}

\section{Document Review of An'Yang Stream Restoration Master Plan}

The purpose of this chapter is to understand the original plans for the decisionmaking structure of the restoration process as presented in the An'Yang Stream Restoration Master Plan published in 2001. While other documents have been published subsequent to the Master Plan — An'Yang Urban Planning Strategy (City of An'Yang, 2003), An'Yang Stream Restoration White Paper (the An'Yang Gunpo Euiwang Federation of Environmental Movement, 2005), the An'Yang City Environmental Master Plan (City of An'Yang, 2009) — the Stream Restoration Master Plan depicts the inception of the Restoration Project. The Master Plan includes agendas and goals of the stream restoration plan and describes the strategies of citizen participation in decision-making systems used in its development. The Master Plan was published by the City of An'Yang (2001) and written by an advisory committee that was comprised of professionals, including engineers, hydrologists, geo-morphologists, environmental scientists, and ecological scientists.

This chapter reports the results of a content analysis of the Master Plan. By examining the Master Plan, we can gain insights about the dynamics among the various stakeholders involved, and what issues were most salient. The quoted paragraph below briefly tells us the primary values and intentions of the authors of the An'Yang Stream Restoration Master Plan.

During the urbanization process, the An'Yang Stream had problems because the shape of the urban streams was prone to show a pattern of channel strengthening and low fluvial diversity in the watershed resulting in water quality deterioration... This An'Yang Stream restoration will provide a better urban 
lifestyle for citizens and nature. Also, this stream restoration aims social integrity of the An'Yang Stream region. P.31 (City of An'Yang, 2001)

\subsection{CONTENT ANALYSIS}

The Master Plan is a 530-page document, divided into three sections related to long-term An'Yang Stream management. The researcher conducted a content analysis of the Master Plan by reviewing and tagging key words and phrases that reflected the dual goals of the bio-physical elements and the socio-cultural elements of sustainable stream restoration. In the Master Plan, frequently mentioned ecological restoration, social restoration, and landscape revitalization as well as public participation (participation or civic participation) as sub-elements that structured the broad value of the social restoration.

For the content analysis, open coding was applied to sentences and paragraphs in the Master Plan document by reading them and tagging codes utilizing the web-based qualitative analysis software, Dedoose. These open coding processes included three steps: 1) reading and tagging codes, 2) reading and grouping codes, and 3) reading and categorizing the codes as shown in Table 8.

During the coding process, the Dedoose software categorized and grouped topics under the three key values seen in Table 8. Based on the values (criteria) and subcriteria of ecological restoration, social restoration and landscape revitalization found in the Master Plan, a variety of codes were applied and analyzed. Based on text grouping, three key values were revealed:

Ecological stream restoration (ER) was identified 130 times, composed of concerns about water quality (82 mentions) and ecological systems (42) times. The second most 
frequently mentioned goal was social restoration (SR), with 72 items of text.

Landscape revitalization was the third most mentioned goal of the Master Plan, with 42 separate statements divided into 34 instances related to stream-flow control and another 8 mentioning landscaping. Water quality improvement was by far the phrase of greatest frequency.

Table 8. Codes and results in content analysis2

\begin{tabular}{ccc}
\hline \multicolumn{2}{c}{ Values } & Codes \\
\hline $\begin{array}{c}\text { Ecological } \\
\text { restoration } \\
(130 \text { times })\end{array}$ & $\begin{array}{c}\text { Water quality } \\
\text { (82 times) }\end{array}$ & $\begin{array}{c}\text { Water quality improvement (48), Scientific } \\
\text { restoration (20), Urban stream (1), Monitoring (1), } \\
\text { IWRM (1), Sewage treatment (6), An'Yang } \\
\text { Stream restoration (5) }\end{array}$ \\
\cline { 2 - 3 } & $\begin{array}{c}\text { Ecological } \\
\text { systems } \\
\text { (42 times) }\end{array}$ & $\begin{array}{c}\text { Ecological city planning (28), National stream } \\
\text { restoration (5), Environmental conservation (9), }\end{array}$ \\
\hline $\begin{array}{c}\text { Landscape } \\
\text { revitalization } \\
\text { (42 times) }\end{array}$ & $\begin{array}{c}\text { Stream-flow } \\
\text { control }\end{array}$ & $\begin{array}{c}\text { Potential flood damage (20), Stream-flow } \\
\text { depletion (11), Technology (3) }\end{array}$ \\
\cline { 2 - 3 } $\begin{array}{c}\text { Social } \\
\text { restoration } \\
\text { (72 times) }\end{array}$ & $\begin{array}{c}\text { Landscaping } \\
\text { Social systems } \\
\text { (72 times) }\end{array}$ & $\begin{array}{c}\text { Landscaping (2), Water friendly space (2), Land } \\
\text { use (2), Transportation (2) }\end{array}$ \\
& & $\begin{array}{c}\text { Culture (13), Social restoration (2), Collaborative } \\
\text { governance (10), Blue-Green network (5), Policy- } \\
\text { making (3), Participation (13), Regional } \\
\text { development (1), History (10), Historic }\end{array}$ \\
& & $\begin{array}{r}\text { preservation (6), Citizen (6), Local community } \\
\text { partnership (2), Social integration (1) }\end{array}$ \\
\hline
\end{tabular}

Let us review the processes in establishing an agenda and evaluating priorities for the An'Yang Stream restoration project by means of the master plan. The master plan written by City of An'Yang (2001) addressed the direction of the An'Yang Stream restoration project. Its slogan was, “Let's restore the An'Yang Stream so a Chinese minnow can live here.” According to City of An'Yang (2001), the Chinese minnow inhabits only clear water. This master plan addressed specific levels of fluvial diversity

2 See the content analysis results of Dedoose in the Appendix 2 
and water ecological indicators in describing water quality changes and annual water quality data. The master plan described potential solutions for water quality improvement. According to the City of An'Yang (2001), the potential solutions included sewage advanced treatment technology, sewage pipelines and maintenance, sewage interceptors, heavy metal control devices, and other items. Urban streams typically have diminished water quality and have to find solutions to control contamination and prevent it from increasing. Industrial facilities and the large population near the urban stream were serious hazardous factors. In particular, the An'Yang Stream was struggling because of the serious contamination of domestic sewage inflow. The participating groups of the An'Yang Stream Water Quality Improvement Committee that wrote the Master Plan faced the challenges of domestic sewage pipeline maintenance and the need to improve the processes and augment the deficient urban sewage treatment facility. Because of this, water quality improvement became the most important and primary concern during the search for solutions. To address potential solutions to improve water quality, the Master Plan included more or only technology and engineering methods of restoration.

The Ecological Restoration (ER) codes were tagged at the paragraphs regarding the agenda of water quality improvement. This ER code generally symbolized sustainable development of the Korean society as well as the An'Yang Watershed region. For instance, the ER code was tagged in the paragraphs, "An'Yang Stream was famous for water quality contamination for a long time after fast urbanization and industrialization in Korea.” (City of An'Yang, 2001) 
Also, scientific engineering technology was in the ER code. This code related to scientific engineering technology was frequently tagged in the document when the researcher found any description of water resource data and applied technologies, as well as ecological and environmental issues. For instance, in the Master Plan, scientific innovation (Qual2e model) was utilized in water quality improvement and soil quality improvement. The code was tagged in the parts, "Qual2e model is a BOD and DO management system based on experimental research by using mathematical and engineering models for estimating and analyzing the factors in the cases of water contamination and ecological devastation phenomenon." (City of An'Yang, 2001) As stated in these examples the open coding was processed through the three coding steps.

\subsubsection{Contextual background and initial agendas of the Master Plan}

As explained in the Master Plan (2001), during the plan-making process, the An’Yang Stream Restoration Advisory Council conducted a citizen survey. Planning and conducting a citizen survey was a remarkable challenge and a great achievement for the An'Yang Stream governance because methods like surveys or interviews with citizens had previously not been common initiatives of environmental cases in the society. At the same time, the citizen survey results reflected a recognition of the values and interests of the citizens in the early stage. The 2000 survey targeted 1,240 randomly sampled citizens based on demographic data from 1998 (City of An'Yang, 2001). The survey was designed to have a balanced gender distribution to reflect the population which had a 50/50 gender rate and to seek out citizens who had lived in the An'Yang watershed area for at least ten years (54.8\% of the respondents). As a result of the 
citizen survey (Table 9), the planners identified citizens' feelings about water quality improvement, natural stream restoration, waterfront space, landscaping, and other items.

Table 9. Value and preferred participatory ways of An'Yang citizens in 2001

\begin{tabular}{|c|c|c|}
\hline Rank & Values & Preferred Participatory Ways \\
\hline 1 & $\begin{array}{l}\text { Water Quality Improvement } \\
\qquad(32.2 \%)\end{array}$ & $\begin{array}{c}\text { Citizen Watchdog Program } \\
(30.3 \%)\end{array}$ \\
\hline 2 & Ecological Restoration (29.5\%) & $\begin{array}{c}\text { Purification Activities in } \\
\text { Watershed }\end{array}$ \\
\hline 3 & $\begin{array}{l}\text { Water-friendly Space for } \\
\text { Citizens }(15.3 \%)\end{array}$ & $\begin{array}{c}\text { Reducing Domestic Sewage in } \\
\text { Households }(20.3 \%)\end{array}$ \\
\hline 4 & Stream Flow Control (11.3\%) & \\
\hline
\end{tabular}

Since a pilot project for the stream restoration was going to take place before the major restoration work began, the citizens wanted the pilot project to occur in the central area of the City of An'Yang, near the Bisan Bridge, because most people wanted to spend recreational time in that area (City of An'Yang, 2001). Again, according to City of An'Yang (2001), the project included civic participation as one major agenda in the An'Yang Stream restoration project as a mere formality. In reviewing the results of the 2000 citizen survey, one can understand the diverse values of respondents about the An'Yang Stream restoration.

\subsubsection{Results and findings of document review}

The An'Yang Stream restoration Master Plan was initiated so that the City of An'Yang could become a more livable and green city (City of An'Yang, 2001). The City of An'Yang was the key stakeholder and led this enormous and comprehensive urban planning and environmental management project. The An'Yang Stream project 
was also composed of sub-categories related to the An'Yang City Planning Master Plan, An'Yang Vision 21, An'Yang Environmental Protection Long-Term Plan, and others. Those plans for the City of An'Yang propelled the An'Yang Stream into becoming a sustainable and ecological space (City of An’Yang, 2001). The Master Plan also aimed to accomplish integrative water management by paying attention to scientific factors and social well-being.

In particular, the Master Plan described collaborative governance (tagged 10 times in content analysis, Table 10) and the way it was to be applied throughout the An'Yang Stream project. Building innovative and sustainable collaborative governance was an important feature. Valuing the governance building process differed from other previous South Korean stream restoration projects in that, "The Master Plan should enhance the historical preservation of the An'Yang and cultural restoration, and community participation and collaborative watershed governance system that encourages citizens to participate." (p. 5)

As noted earlier, a survey was administered as part of the planning process. The content analysis of the survey indicated the values of the stakeholders in the An'Yang Stream restoration (Table 10). The values listed in the table included sub-categories of each value and codes used in the open coding process. The Master Plan described the expectations and potential value of governance building and agreed with the core values of collaborative governance stated by Ansell and Gash (2007), because the Master Plan valued trust building among stakeholders and development of commitment. The decision-making structure system of the An'Yang Stream Protection Network (ASPN) 
and the An'Yang Stream Governmental Council for Water Quality Improvement (AGCWQ) was observed and described through the document review of this research.

Table 10. Participants of the decision-making board

\begin{tabular}{cc}
\hline & Participants \\
\hline AGCWQ & City of An'Yang, City of Gunpo, City of Euiwang, City of \\
(13) & Gwangmyong, City of Bucheon, City of Shiheung, Guro District \\
& (Seoul), Gwanak District (Seoul), Geumcheon District (Seoul), \\
& Dongjak District (Seoul), Yongdeumpo District (Seoul), Yangcheon \\
& District (Seoul), Kangseo District (Seoul) \\
\hline ASPN & An'Yang YMCA, Gunpo YMCA, Federation of Environmental \\
(12) & Movement of An'Yang Gunpo Euiwang, Gunpo Agenda 21, \\
& Gwangmyong Agenda 21, Gunpo Environmental Governing Citizen \\
& Association, Euiwang Agenda 21, An'Yang Agenda 21, Dorim \\
& Stream Protection Citizen Association, Open Society Citizen \\
& Federation, Citizens' Solidarity of An'Yang, Shihwanet, Federation of \\
Environmental Movement of Seoul \\
Professional & National Institute of Environmental Research, University of Seoul, \\
Advisory & Kyonggi University, KICT, Kumho Engineering, Hankyung \\
Group & University, Seoul Institute, Kyonggi Research Institute, Seoul \\
(12) & National University, An'Yang Technology College, Gacheon \\
& University, KRIHS \\
\hline
\end{tabular}

During the establishing baseline conditions, the Master Plan aimed to establish an integrative multi-party decision-making system for long-lasting and sustainable An'Yang Stream management, as well as its ecological restoration. Various local governments and citizen groups formed the AGCWQ and the ASPN, respectively (Table 10). Although the groups often reached a consensus agreement through monthly meetings and conferences, the agreement was not legally enforceable (City of An'Yang, 2001). The government groups supported the decisions formed by the AGCWQ (Daejeon Daily, 2011).

The Master Plan addressed the difficulty of sharing and handling the relevant information on the stream restoration during the early period (City of An'Yang, 2001). 
Understanding the scientific indicators of water quality and its ecological parameters was one of the biggest challenges as well as the first goal, because each group interpreted the same data from a different point of view (Hong and Chung, 2016). In the Master Plan, there was no indication about how to apply non-scientific factors like local knowledge because the decisions primarily focused on water quality improvement. The opportunities for public involvement seemed to be perfunctory as a pattern of tokenism (Arnstein, 1969) due to the limited budget and lack of awareness of citizen participation. This Master Plan document showed that the writers preferred using these scientific parameters when trying to advertise efficiently the implementation of the Master Plan.

The Master Plan includes various agenda items in the An'Yang Stream restoration (Figure 9). The goals of the An'Yang Stream Restoration Master Plan were to improve water quality, prevent the stream from drying out, stabilize the river channel, restore the ecological balance, increase citizen participation, and improve the GIS system (City of An'Yang, 2001).

The citizen survey respondents considered water quality damage, as the most important issue and the An'Yang Stream Restoration Master Plan should address any solution that would improve the water quality. They also felt that the Master Plan should include ecological restoration, as well as waterfront space renovation for recreational use and aesthetic landscaping. ... Many citizens wanted to have a natural stream restoration, which could provide high fluvial diversity. At the same time, the respondents wanted to use the waterfront space for recreational activities in a well-organized landscape. (City of An'Yang, 2001; p. 466)

First, the An'Yang Government Council for Water Quality Improvement (AGCWQ) considered how to raise the level of scientific indicators of $\mathrm{pH}, \mathrm{DO}, \mathrm{BOD}$, SS, COD, T-N, and T-P. The results of a field evaluation showed that the concentration rate of cadmium $(1.2 \mathrm{mg} / \mathrm{kg})$ and zinc $(37.64 \mathrm{mg} / \mathrm{kg}$ ) was particularly high (City of 
An'Yang, 2001). The scientists and engineers undertook frequent field investigations and conducted in-depth discussions with the AGCWQ council.

During the 1970s, the water quality was intensively getting worse. The upstream of the An'Yang Stream indicates serious water contamination because of high urbanization in the upper stream regions. To improve the water quality, the KICT and the KRIHS joined the advisory committee. (City of An'Yang, 2001; p. 18)

According to the City of An'Yang (2001), the first and most important process for the improvement of water quality was to diminish the stream channel deposit and to decrease the concentration of water sediment. The goal of improving water quality advocated for and justified the establishment of the AGCWQ. This led to a collaborative partnership for water quality improvement with research-oriented institutes, such as the Korea Institute of Civil Engineering and Building Technology (KICT) and the Korea Research Institute of Human Settlements (KRIHS). Also, the local governmental network was based on a common goal regarding water quality issues. Once it formed a solid body of governance through strong networks, the other ecological goals of stream flow control and prevention of potential flood damage in the watershed would not be difficult to meet due to the confidence from the diverse achievements of previous stream restoration experiments, such as Yang-Jae Stream (City of An'Yang, 2001).

Second, the An'Yang Watershed had a goal of stream flow control by new technocratic management.

For revitalizing the function of a natural stream, the An'Yang Stream restoration project included one key agenda of the stream-flow control strategy as an engineering technological innovation. An'Yang Stream watershed has an issue of large levels of stream flow changes between dry season and flood season..... Also, increased population and fast urbanization caused water shortage problem in the An'Yang region. (City of An'Yang, 2001; p. 249) 
Since the watershed surrounding the An'Yang Stream had experienced rapid urbanization and population growth, there was a serious issue of stream-flow depletion during the dry (low water) season. This was caused by the base runoff reduction that came from the increase in impermeability layers, in combination with the sewer system, the reduction of agricultural water release, and the increase in groundwater usage. In particular, one small catchment in the An'Yang Watershed, the Sooahm Stream, had a serious problem with severe low water, having an average water flow of 0.11367 CMS (City of An'Yang, 2001). Stream-flow increase was of significant interest to the participants of the An'Yang Stream decision-making process, including the AGCWQ, because the An'Yang Stream historically showed the impact of stream-flow depletion on agricultural and ecological destruction. Private networks, including The People Loving the An'Yang Stream, invited diverse professional consultants to discuss maintaining the stream-flow of the An'Yang Stream. After an in-depth study, the consultants involved in the network suggested various solutions for the An'Yang Stream Restoration Master Plan. For example, The Always Green An'Yang 21 proposed an education program for citizens to provide useful resources for agricultural use and household living (City of An'Yang, 2001). These efforts to mitigate the stream depletion by both private and public sectors contributed to the establishment of the An'Yang Stream Environmental College, which could provide ecological education courses. 


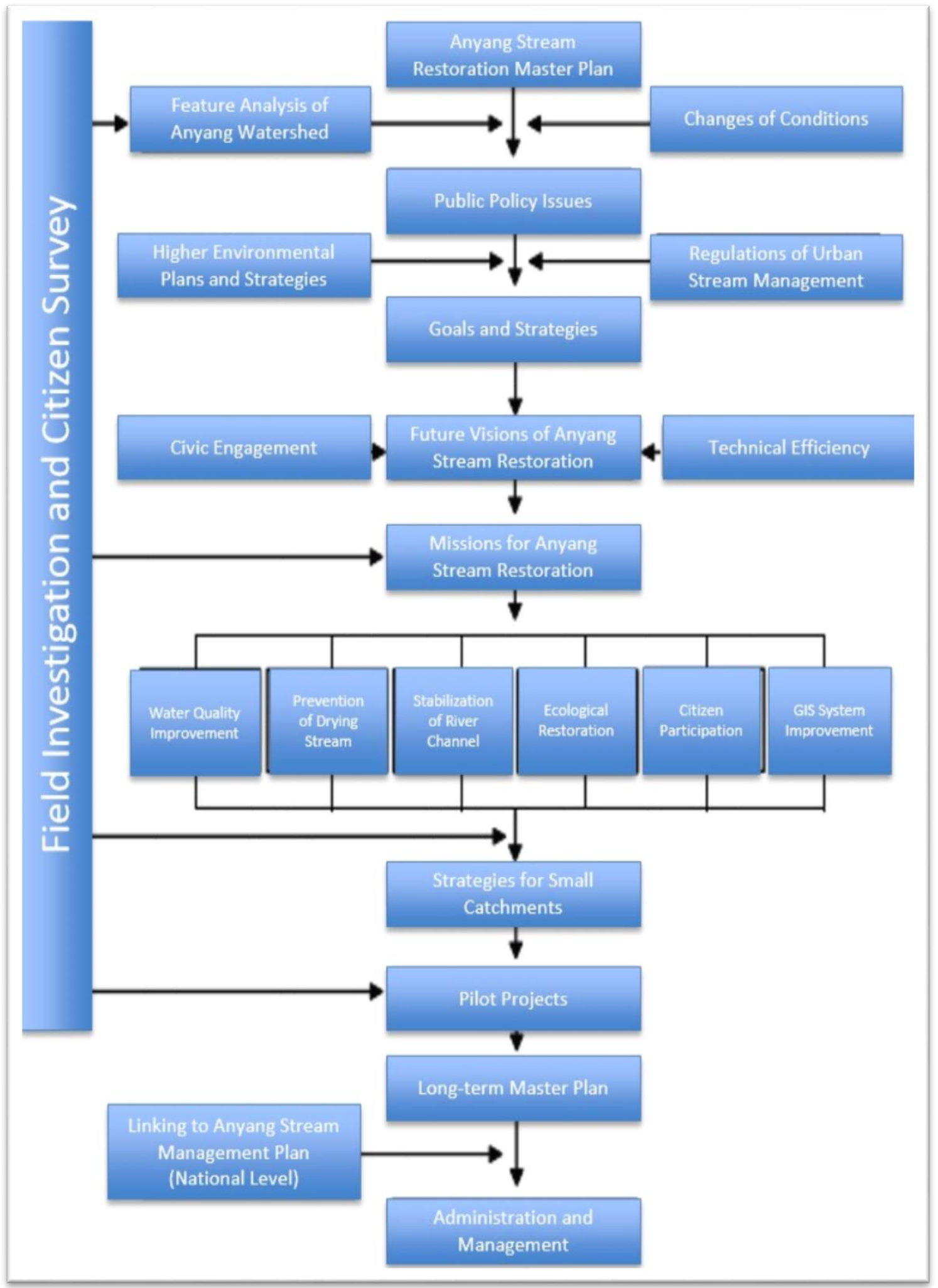

Figure 9. Flowing map of research for An'Yang Stream Restoration Master Plan (City of An'Yang, 2001) 
Third, the Master Plan addressed a goal for efficient and successful flood management.

Long-term strategies to prevent drying stream phenomenon increase the flow-rate of the groundwater to keep the minimum flow rate of the river. Also, this long-term stream-flow strategies can prevent flood risk by reducing the outstanding runoff during flood season. Flood prevention is another key agenda and goal of the An'Yang Stream restoration project because the 67 percent of Korea's annual rainfall is intensive during the flood season. (City of An'Yang, 2001; p. 303)

The research for this Master Plan that included the result of the River Corridor Survey (RCS) provided in the early stage of the stream restoration, could guide proper stream maintenance technologies (City of An'Yang, 2001). According to the City of An'Yang (2001), the RCS helped find solutions for flood management and ecological restoration. In particular, it included a tool to evaluate priorities in the watershed's Master Plan. After the RCS, the research team could develop a long-term plan by estimating the flood plain and transforming new engineering concepts with various sources of information. The RCS included mapping and recording collected data for water velocity, streamflow, watershed topography, revetment, bank, vegetation, land use, wild animals, and artificial structures. Potential flood control was important in planning a water-friendly space for citizens. According to the citizen survey, a sizable number of citizens of the An'Yang Watershed region were concerned about the flood issue, and wanted to have an efficient governance management policy (City of An'Yang, 2001). Thus, the professional advisory committee, who was writing the Master Plan, focused on addressing a flood management program that would ensure nature-friendly riverfront spaces through the use of diverse and innovative engineering technologies. 
Lastly, the advisory council focused on ecological restoration as much as water quality improvement in writing the Master Plan (City of An'Yang, 2001). In fact, the ecological restoration included the process and factors of the water quality improvement. "The An'Yang Stream was straightened during the urbanization. Water quality pollution damaged the ecological functions of the stream" (p. 315). The An'Yang Watershed had faced great challenges of ecological devastation due to river bund strengthening and water contamination. The fluvial diversity of the An'Yang Stream had decreased. Urban engineers, the public administrators who are in charge of water resource management, began to pay attention to this issue by implementing a framework for engineering innovation. As a result of this effort, the AGCWQ initiated the RCS mentioned above.

Renovated riverside and water-front park will provide the citizens with various amenities and recreational benefits as well as increased ecological diversity. (City of An'Yang, 2001; p. 113).

The AGCWQ discussed why it had to protect the riverside and determine if levee construction was needed to conserve ecological diversity (City of An'Yang, 2001). The Master Plan called for efficient ecological land use for the riverside after parking lots had been removed. This ecological use of the land resulted in planting a natural reed field to increase the ecological diversity. It was a big step for the An'Yang Stream and the community, and this became a win-win strategy. However, was the strategy for the ecological restoration of the An'Yang Stream riverside skewed because of the lack of appropriate citizen participation in the ecological management process? The governance system under the AGCWQ continued to demonstrate a typical top-down decisionmaking process based on technocratic authority. 
The An'Yang Stream restoration project aims at the multiple goals of cultural, historical, and waterfront space revitalization, civic participation as well as ecological restoration. (City of An'Yang, 2001; p. 5)

The An'Yang Stream Master Plan included multiple technocratic and social factors, to achieve successful scientific restoration and civic participation as quoted in the Master Plan above. The Master Plan described the importance of synergy, building collaborative governance, and conducting citizen surveys to identify feelings about the An'Yang Stream restoration. During the stream restoration process, social, educational, cultural, and historical factors were planned to be discussed through supporting the governance network. However, it continued to focus on the technocratic restoration plan.

The advisory consultants were specialists in civil and environmental engineering and only two advisory members, who represented the NGOs, addressed the importance of social integration through participatory processes. The remaining participants of the advisory group did not show any evidence that they considered the values of social integration and sound collaborative-governance building. However, all agreed that this Master Plan had played an important role in guiding the direction and goals of the An'Yang Stream restoration.

It was noteworthy that the Master Plan tried to include the results of the citizens' opinions and priorities for the restoration of the An'Yang Stream. This survey indicated diverse values and ways in which collaborative governance should consider the various values concerning the An'Yang Stream. (City of An'Yang, 2001; p. 5)

The An'Yang Stream Restoration Master Plan addressed the importance of creating participatory and democratic decision-making established under collaborative governance in the early stage of the stream restoration project. It included a 
participatory process to achieve water quality improvement and ecological restoration in the short term. It described a concept of civic participation and governmental collaboration, which were designed to accomplish the main goal of water quality improvement. Also, the Master Plan painted a broad picture of participatory and collaborative governance for the An'Yang Civic Cultural Revitalization through a civic movement that could support the interests of ordinary citizens. Regarding geography, the An'Yang Stream needed governmental collaboration and the citizens' participation because it passed through the central area of the City of An'Yang and other local districts. As a result, this geographical condition motivated the establishment of the AGWQC. The primary project of water quality restoration of the An'Yang watershed had to be mandatory for regional management and natural resource conservation to succeed. In the 1990s, the concepts of collaborative governance building and participatory regional planning were unfamiliar and disturbing to the Korean people (Lee and Choi, 2011) and it was hard for environmental decision-making of South Korea to accept diverse interests and ideas on the issue, in spite of the agenda regarding citizen participation written in the introduction.

According to the Master Plan (City of An'Yang, 2001), the stance on civic participation was added;

For the An'Yang Stream restoration, citizen real-time monitoring, aqua-ecological system restoration, and hydrophile advancement can be achieved by citizen participation.... The potential risk factors can be eliminated through accepting various values. (City of An'Yang, 2001;p. 477)

The Master Plan simply lists various participatory citizen events (which seemed to have been created as propaganda) that had not occurred before in the An'Yang 
watershed region. The Master Plan researchers (writers) did not seem to value participatory decision-making. It is noteworthy that most of the researchers who wrote the Master Plan were engineers. For them, the only available participatory way seemed to be public hearings led by the governments involved in the Master Plan. Readers of the Master Plan might have misunderstood that the public hearings are the most important and reliable participatory process for the An'Yang Stream restoration governance.

The citizen survey conducted in 2000 of the Master Plan showed that the citizen respondents had interest in participating in a citizen watchdog program and water quality monitoring programs; some citizens did join a citizen watchdog program to make the stream clean.

The An'Yang Stream watchdog program of citizens and collaborative activities of the AGCWQ and ASPN mainly encourage ecological revitalization and water quality improvement as a basic agenda. (City of An'Yang, 2001; p. 71)

The Master Plan's aims were mainly water quality improvement and ecological restoration. The plan included some participatory ways to reach these goals, but it did so through limited methods. A sustainable and systematic stream restoration process would address diverse social values, including participatory decision-making, culture, and history, as well as the scientific factors of water quality, ecological restoration, and engineering technology.

\subsection{DISCUSSION}

The primary goal of the An'Yang Stream Restoration Master Plan was water quality improvement. This goal could be accomplished by analyzing and adopting 
scientific and engineering innovations. The stakeholders' individual values on setting the goals of the scientific and engineering factors within the early stage of the stream restoration decision-making need to be reviewed in the context of how they were regarded within the Master Plan.

For this point, the Master Plan might have obscurely described the importance of balancing diverse values. As a result, additional survey results within the Master Plan indicated that most citizen respondents did not consider the An'Yang Stream restoration to be a mega project for the long-term social integration through participatory decisionmaking building, but an engineering-oriented technology (City of An'Yang, 2001). Also, this participatory process would not be reasonable and available to reflect diverse values because the networking system within the decision-making focused on scientific values and not social values.

The Master Plan included three sub-major practical projects of stream restoration: 1) National policy projects, 2) Investment projects, and 3) Watershed maintenance projects (City of An'Yang, 2001). First, the national policy project covered capacity building and the operation of the An'Yang Watershed and civic participation.

Second, investment projects included construction of more sewage treatment facilities, natural stream restoration, and river channel maintenance projects. Partially and briefly, the investment project discussed cultural revitalization and historical preservation in local contexts, but the researchers of the Master Plan did not view those factors as a key and preferred value. Through this content analysis, the Master Plan did not include any detailed plans or budget allocations for specific programs. Also, it did not include whom or what they would introduce into these cultural and historical 
preservation projects. This investment project also aimed for technocratic success in the project. In fact, governance building might be less difficult and more important than technical improvement based on scientific indicators. Most researchers and a great portion of the budget were allocated for this investment project.

Third, the maintenance and management project covered watershed environmental maintenance, facilities maintenance, and landscape planning, etc. as the goals to be set after improving water quality. Nominally, the physical renovation could be a bureaucratic and institutional catalyst, which would maximize the results of the scientific stream restoration. Also, the political value, tended to encourage a place-based renovation which could be shown to the public. Citizens could evaluate the success of the stream restoration when they used the waterfront space and recreational facilities that resulted from physical renovation.

The Master Plan addressed the potential risks and solutions in terms of landscape elements. Participants were interested in ecological landscape and spatial restoration. The existing structures at the waterfront space of the An'Yang Stream basin were unattractive and adversely affected the ecological system. Landscape renovation would achieve common benefits for both people and nature. Landscaping by utilizing efficient land-use planning concepts would contribute to establishing sustainable watershed management. The Master Plan included a strong justification to restore the An'Yang Stream to provide a more affluent lifestyle for citizens.

In order to reestablish the use of existing facilities and provide recreation for residents, such as sports facilities, the waterfront space needs to be renovated by using appropriate construction and listening to the opinion of the citizens...Through the access redevelopment of sports facilities, aesthetic events, 
and ecosystem protection, the An'Yang Stream governance will attempt to have new and renovated recreational amenities features for the citizens (p. 425).

The Master Plan addressed spatial renovation based on an ecological restoration concept that could provide a buffer zone between the urban and natural spaces, as well as ensure the flow of the stream. Specifically, citizen participation was sometimes requested for ideas on waterfront spatial maintenance and civic space operating management.

The sub-projects in the An'Yang Stream Restoration Master Plan let us understand the major value about the regeneration of An'Yang Stream. The fundamental goal was to award water quality restoration through technocratic knowledge. The Master Plan described some efforts to embrace diverse values. In terms of institutional aspects, the An'Yang Stream Restoration Master Plan had to be approved and guided by the River Act Article 15, which valued and prioritized integrated water resource management of potential flood control, stream-flow control, water quality, and ecological protection. The regulations also had this Master Plan aimed toward scientific stream restoration; scientific methods and information were used to support and justify their values in stream restoration.

Also, we can better recognize how this Master Plan accepted concepts of nonscientific engineering values during the governance establishment, and how these nonscientific engineering values were integrated into the agenda-setting governance process with scientific engineering values.

Water quality improvement was the most important value for the An'Yang Stream. The water quality level in the An'Yang Stream is currently associated with the water quality levels of the sewage treatment facilities located in the middle of the 
An'Yang Stream, except for the raw sewage near the Mokgam tributary. (City of An'Yang, 2001; p. 478)

The Master Plan attempted to address and represent common values that citizen groups continued to request and suggest during the decision-making processes. The An'Yang Stream first needed innovative measures for water quality improvement.

The An'Yang Stream Restoration Network, which included some citizen groups and NGO groups, believed that water quality improvement was the most important goal (City of An'Yang, 2001). In particular, the decision-makers wanted to have more sewage treatment facilities. NGOs were either professional or political in their agenda setting within the An'Yang Stream restoration governance. They invited many professional hydrologists into their group in order to participate in the decision-making board of water quality improvement for the An'Yang Stream.

The Master Plan (City of An'Yang, 2001; p. 5) notes, "Saving and protecting the urban stream should contribute to the citizens' lifestyle." Specifically, it was intended to show value from the point of view of the efficient and comfortable use of space and ecosystem restoration. Since the An'Yang Stream watershed restoration project would be a mega development project with a large-scale budget, sufficient justification for a scientific approach and engineering technology had to be given. In terms of the project, gaining strong citizen support for the An'Yang Stream project was very important. If there were miscommunications and differences of opinion between the citizens and the An'Yang Stream governance, it would not have been possible to establish a strong governance, and the restoration project would not have progressed. 
According to the Master Plan, "The An'Yang Stream has a mission of taking measures for a wildlife sanctuary plan and ecological space" (City of An'Yang, 2001; p.317). The urban stream in An'Yang was almost the only ecological passage in a city surrounded by concrete. In order to protect the migratory birds that came to the An'Yang watershed, a preliminary evaluation was needed to protect the public space and provide a relaxing space for the citizens. Using certain sections for ecological parks could limit public access, and certain sections near the downtown region had been designed as civic spaces for public activities.

“The An'Yang Stream requires a master plan of watershed protection and conservation such as a strategy of natural stream restoration for all sectors" (City of An'Yang, 2001; p.315). The An'Yang Stream restoration was carried out under the Master Plan of comprehensive watershed management strategy because it could not be done by having individual plans for each region (City of An'Yang, 2001). The An'Yang Stream needed a strategic plan to create an ecological passage to allow for the interaction between the public and nature. The aim was to penetrate each tributary and mainstream, from the upstream to the downstream of the An'Yang Stream. This Master Plan aimed to integrate values, such as the restoration of the river, the maintenance of the confluence sewage pipes, and the establishment of facilities for groundwater recharge.

The Master Plan states, “The An'Yang Stream must actively build collaborative governance in order for watershed restoration to be a long-term success" (City of An'Yang, 2001; p.39). The An'Yang Stream needed consistent goals and plans that would cover the entire watershed. Specifically, the differences between the upstream 
and the downstream regions were significant in terms of stream-flow management, flood prevention management, and water quality.

Also, “The An’Yang Stream encouraged cooperation among the stakeholders, collaboration with other governmental groups, and governance building for civic participation" (City of An'Yang, 2001; p.484). In order for such a cooperative relationship to succeed, each entity needed to participate in the basin consultation committee within the decision-making system.

"The establishment of a watershed consultative committee would need to be based on the legal foundation of the River Act of Korea." (City of An'Yang, 2001; p.5) The An'Yang Stream governance decision-making board began to reflect the citizens' values through a consultation process that asked for their opinions. As a result of these efforts, the An'Yang Stream Restoration Project was able to establish the AGCWQ and the ASPN. Compared to other river basin management plans, the An'Yang Stream was more effective in creating an advantageous collaboration with the public and private sectors of the AGCWQ and the ASPN.

The citizen participation was aimed to be one of the major values of the project, but it is difficult to find evidence of practical and pragmatic methods in which this was applied. While the citizen survey results were described in the Master Plan, they were limited and cursory.

Although it was limited, the contribution of the An'Yang Stream Restoration Master Plan (2001) had a great impact on the concept of participation in the field of stream restoration of Korean society in the 2000s. According to the City of An'Yang (2001), citizens were still not as sensitive to changes in citizen participation as in the 
past. Stream restoration was not the primary value when the citizens considered economic development, rapid urbanization, and industrialization. However, the community movements for the improvement of the recent living standards motivated the citizens to participate in the governance of the An'Yang Stream restoration because they wanted to change the ecological systems through the An'Yang Stream restoration. Thus, the citizens were becoming interested in a participatory process of decisionmaking. This demand showed the increased interests in democratic governance's activities very well. The An'Yang Stream governance, when compared to other South Korean river restoration governances, had a great deal of voluntary participation from the citizens and demonstrated democratic development:

The 11 governmental heads of the AGWQC planned a periodic event to provide a vision and a strategy for effective governance building and partnership for fundamental collaborative consultations on water resource management issues (City of An'Yang, 2001; p.481).

The goal is to build a foundation of co-participation and cooperation to take advantage of the An'Yang Stream through the direct and indirect support to the basin administrative consultation body to improve the integrity and efficiency of the restoration work (City of An'Yang, 2001; p.466).

The governance establishes the An'Yang Watershed Agenda 21 through the participation of citizens, entrepreneurs, NGOs, and governmental representatives to provide a practical way for efficient restoration based on mutual communication and information exchange (City of An'Yang, 2001; p.482).

Associations of People Loving the An'Yang Stream have been formed in order to ensure successful citizen participation based on local frameworks (City of An'Yang, 2001; p.484).

In the Master Plan, attempts to establish an An'Yang Watershed association based on a partnership which was composed of and established by citizen groups and NGOs, such as the Association of People Loving the An'Yang Stream, emerged many times 
but did not address or describe any practical and specific situations, such as specific dates, actors, and places. For example, what came out of the Master Plan was only a concept that established the An'Yangchon Basin Agenda 21. The Master Plan did not reflect the reality and condition of existing levels of civic participation and social factors regarding the An'Yang Stream. Unfortunately, it included mostly popular plans such as sidewalk renovation and bicycle lane expansion.

Again, the An'Yang Stream task-force team established by the City of An'Yang wanted to settle scientific restoration for water quality improvement, so civic participation was just one means of attaining the goal of water quality improvement. To achieve water quality improvement in a short amount of time, the Master Plan focused on citizen-led water monitoring programs to control contamination and pollutants and did not use an interactive system to gain feedback from the stakeholders. The technocratic stream restoration process was often followed by disagreements and misunderstandings of the scientific indicators and professional knowledge, but the Master Plan did not mention any process for building ground rules, facilitation, arbitration program or conflict resolution processes.

The City of An'Yang (2001) stated that the members invited engineering consultants who could assist the citizen groups in understanding and analyzing the scientific information during the decision-making process. The experts were sometimes appointed to a role of negotiator, mediator, and advocate, but the contents of the Master Plan did not clearly define and include relevant detailed outcomes of their consulting activities shaped by public officials or third-party consultants. The document only described the strategies on establishing a professional advisory board for the decision- 
makers and stakeholders. Also, the Master Plan did not provide evidence that their activities should support or build an active civic participation system. In other words, the activities of the consultants might only have been for technocratic updates regarding ecological restoration and spatial renovation. As a result, civic participation was not fully realized in the decision-making process, and was not prioritized in the agenda setting because the stakeholders in the governance considered it as only one tool to use in attaining ecological restoration.

During the urbanization process, the An'Yang Stream had problems because the shape of the urban streams was prone to show a pattern of channel strengthening and low fluvial diversity in the watershed resulted from water quality deterioration (City of An'Yang, 2001; p. 315).

Revitalization of the ecological system was an important component of the An’Yang Stream restoration. The Master Plan included a concrete strategy that addressed the function and application of constructing a natural type of shore bank and focused on the ecological ecotone in terms of stream restoration (City of An'Yang, 2001).

The Master Plan addressed the importance of fluvial and aqua vegetation diversity as well as wild animals as a long-term strategy of ecological restoration. In particular, seasonal changes and regional conditions of the ecological systems were evaluated and reviewed through the river corridor survey (RCS) from the upstream to the downstream. In the upstream region, urbanization due to a large population caused ecological devastation, while the downstream region had an issue of haphazard land use in the waterfront space because of space shortages. These issues were the major challenges of the ecological restoration of the An'Yang Stream for a long time. 
The new zoning systems are planned to address the development goals and the regional characteristics as well as the ecological restoration in terms of spatial renovation, natural stream restoration, water quality improvement, and recreational functions for citizens (City of An'Yang, 2001; p. 423).

The City of An'Yang established a zoning system to protect the ecological system from the regional development and expanded urbanization. Under the zoning, facilities built for the citizen activities had been relocated to meet the agenda of the ecological restoration. Social systems set by humans work to benefit the ecological systems as Ostrom (2011) states. In particular, the Master Plan introduced the field research process conducted by the ecological scientists and biologists, which collected samples of wild fish and wild birds in the An'Yang Watershed.

The An'Yang Stream restoration governance aims at a collaborative decisionmaking system.... This Master Plan reflects the various agendas of citizens, public administrators, and advisory committee participants. 'Value (benefit) transfer method' is conducted to evaluate each value in agenda setting of the decisionmaking. Building water governance in the An'Yang Stream restoration project is the first attempt in South Korea. (City of An'Yang, 2001;p. 86)

When setting the agenda, the An'Yang Stream Restoration Master Plan tried to establish a collaborative and democratic process to explore broader objectives of the stakeholders. The Master Plan did not address a satisfactory approach to settling disagreements and conflicts among the stakeholders. Pursuant to this Master Plan, holding frequent public hearings was the only available way of communicating with ordinary citizens.

As outlined in the previous chapter, this research aimed to examine to what extent joint-fact-finding occurred in the process of handling scientific information during the An'Yang Stream restoration decision-making process through document review. Joint fact-finding was a new and unfamiliar term in South Korea and the Master Plan never 
mentioned this concept. The Master Plan did not include any detailed process related to the concept of joint-fact-finding.

The monthly meetings of the AGCWQ and the ASPN could not be an entire and perfect substitute for joint-fact-finding. Ehrmann and Stinson (1999) state that the participants in the decision-making need to determine how professional consultants or experts have to report back to them and the public. This confidentiality issue was not considered by the decision-makers nor by the key participants in the stream restoration governance because the Master Plan (2001) ambiguously described the scope of public knowledge and policies about the stream.

In addition, the frequently held public hearings can provide stakeholders with any update such as relevant policies, scientific information and spatial changes about the An’Yang Stream. As defined and suggested by Herman et al. (2007), joint-fact-finding is a method to be able to provide a deliberative process to properly share sound scientific information and to cope with scientific uncertainty issues in a more powerneutral manner for the stakeholders. Information gaps among the stakeholders could not be addressed and reflected in the Master Plan.

The decision-making committee of An'Yang Stream restoration considered the importance of communication with the stakeholders in order for technocratic stream restoration based on scientific innovation. A good example was the collaborative partnership between governments (key decision-makers) and private stakeholders. The decision-makers and stakeholders made field trips to other river basins in Japan and Europe to find the best and most efficient solutions to achieve water quality improvement and ecological restoration (City of An’Yang, 2001). 
Also, within the decision-making systems, the decision-makers made an effort to build an open channel to communicate well with the stakeholders including ordinary citizens through 'Open Administration' the internet public service and complaint center. However, after reviewing and analyzing the Master Plan (City of An’Yang, 2001), it was hard to find an available, realistic and concrete tool that could make the governments and research institutes share their professional knowledge so that the public could easily understand it and knowledge could be distributed through an effective partnership network. The citizens could not properly share the citizens' monitoring results and local culture about this watershed area with the An'Yang Stream decision-makers. The Master Plan (City of An’Yang, 2001) addressed the monitoring results and local culture described through the open participatory events (public hearings) and citizen survey (perfunctory data collection from citizens) about the related scientific knowledge based on the collaborative partnership, but it was hard for the researcher to fully understand the function of partnership as a participatory method because the Master Plan did not include any specific strategic action plan.

Again, the Master Plan (City of An'Yang, 2001) exposed some limitations in terms of implementing the concept, neutral facilitation hosted by third party, such as jointfact-finding in dealing with scientific information because it did not include any professional conveners who rely on professional neutrals and hold trained skills and experience as mentioned by Karl et al. (2007).

The public administrators of local and central governments determined the list of most stakeholders who participated in the monthly decision-making board meetings. Thus, the Master Plan did not consider any tool or institutional program of joint-fact- 
finding that could handle and resolve scientific conflicts and disagreements among the stakeholders.

To achieve the fundamental goal of water quality improvement and ecological restoration, the Master Plan described the potential function and contribution of having public meetings to introduce programs and evaluate other alternatives before making decisions about the An'Yang Stream restoration (City of An'Yang, 2001). The participants brought various engineering technologies into the collaborative decisionmaking system and introduced the strengths and the weaknesses of their scientific solutions with the public. The Master Plan showed the budget annually allocated for these public events. In addition, one special advisory organization and the task force of the An'Yang Stream under the Mayor of the City of An'Yang were in charge of organizing and facilitating these events. Consequently, the An'Yang Stream restoration governance which included institutions, human power, and decision-making board as drafted in the Master Plan could be regarded as a type of collaborative partnership because it fulfilled sufficient conditions for it.

The professional advisory board included environmental scientists who valued ecological restoration of An'Yang Stream. In large, the Master Plan described the value of the ecological restoration after achieving water quality improvement as the following step. In this process, the environmental scientists made an effort to strengthen the foundation of ecological restoration by analyzing scientific water quality data and ecological indicators.

The advisory committee included Dr. Lee, Dr. Choi and Dr. Kim who were the prestigious scholars in the field of urban stream management and environmental hydraulic engineering. The water quality improvement and stream flow 
management strategies were designed based on engineering modeling results of WASP5 and RMA2. (City of An'Yang, 2001; Appendix P.3).

The special advisory committee included well-known professionals from the Korea Institute of Civil Engineering and Building Technology (KICT) and the Korea Research Institute for Human Settlements (KRIHS). The Master Plan written by the public administrators and the special advisory organization indicated their efforts to include diverse social values, as well as scientific opinions about the An'Yang Stream, even though most members of the special advisory organization and the public administrators were engineers or engineering knowledge-retained professionals. KICT was in charge of the river basin corridor survey, channel management, and hydrological approaches to water quality improvement, while KRIHS conducted projects that researched diverse principles and addressed appropriate methodologies in long-term planning paradigms. Kyungwon University (now Gachon University) had designed ecological and spatial planning for the waterfront space since 2000 (Figure 10). 


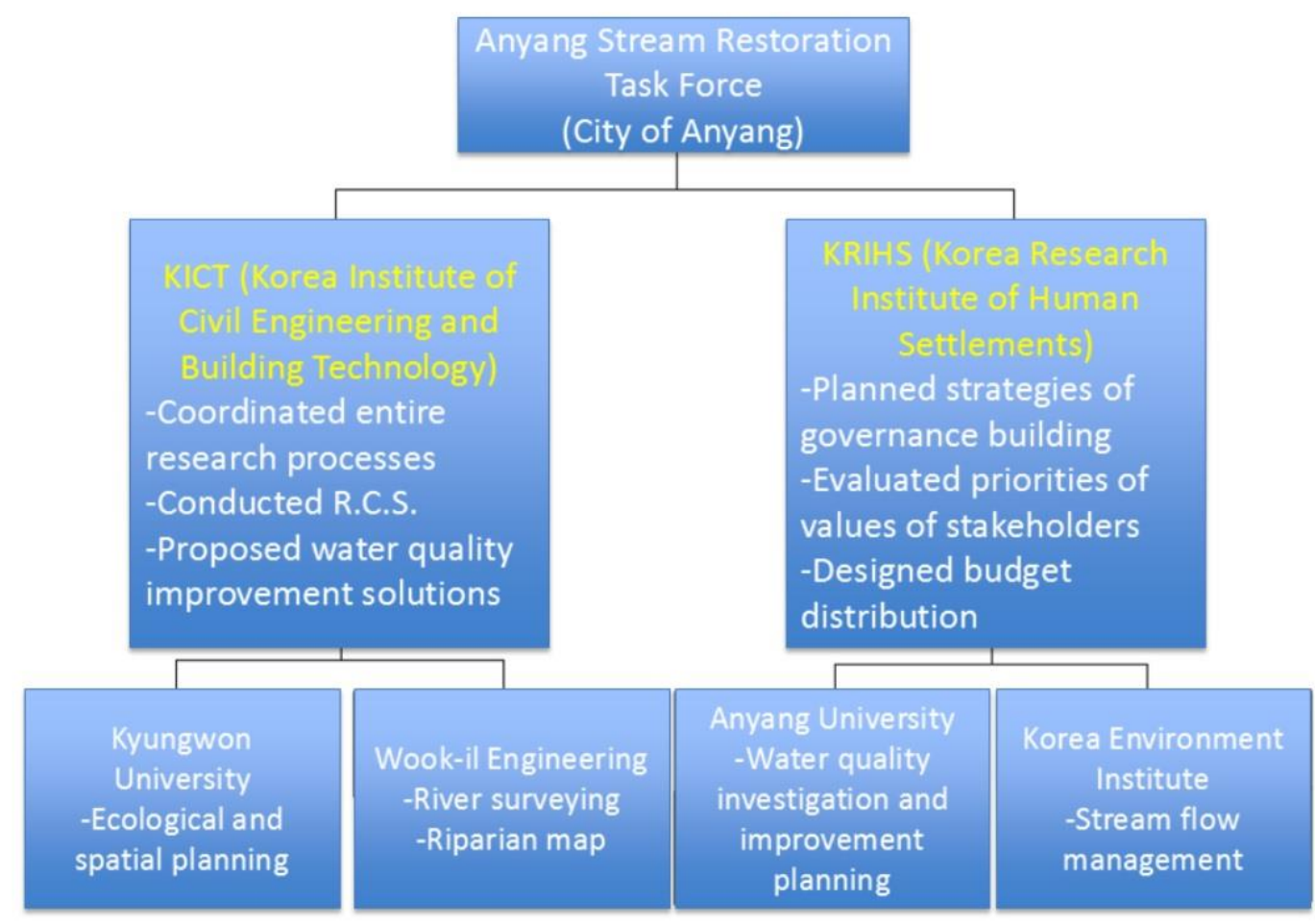

Figure 10. Organization chart of An'Yang Stream Restoration task force and advisory committee (City of An'Yang, 2001)

The values of potential flood prevention and stream-flow management were major issues in the agenda-setting process led by this special advisory committee because the An'Yang Stream had to overcome flood damage mitigation and drought. For flood control, the An'Yang Stream governance recommended that more water sewage retreatment facilities and artificial recharge systems in the region be constructed (City of An'Yang, 2001). According to the Master Plan (City of An'Yang, 2001), stream restoration was based on flood prevention and stream-flow control, as well as water quality management, by taking a conventional civil engineering approach. In other words, the stream restoration was accomplished by quantitative approaches that analyzed scientific principles. 
In some regions of the An'Yang watershed, the An'Yang Stream had a serious issue of low-stream-flow during the dry season due to rapid urbanization. This resulted from an increase in ground water usage of combined sewer treatment systems in the upstream region and discharge flow decrease of water for agriculture usage in the upstream reservoir... Thus, decision-makers and policymakers within the governance of the An'Yang Stream restoration need to contend with the stream-flow devastation as a major goal... The river beds and river channels should be maintained for potential flood damage.... and citizens in the An'Yang watershed have been concerned about the flood control issue and regard it as crucial (p.467).

The hydrologists and civil engineers who participated in the An'Yang Stream governance considered stream-flow management and flood control to be their major goals and relied on scientific findings for their work. As we observed above, the survey results addressed in the Master Plan showed how influential these concerns were during the planning of the An'Yang Stream restoration, as well as building the governance network with diverse citizen groups and NGOs.

Above all things, this Master Plan had a great driver, the task force of the City of An'Yang. This team made an effort to work closely with the stakeholders within the governance structure. The consensus building by the network contributed for easily reaching a mutual agreement over conflicts with regard to analyzing scientific indicators, because this task force team was composed of teammates from various departments: department of sewage management, department of environmental affairs, department of urban engineering, department of civil engineering, and department of financial planning, etc. In terms of inter-departmental collaboration, this formation of a special task force was exemplary. Hence, cooperating with other participants held better flexibility in decision-making. The collaborative partnership of An'Yang Stream governance was evaluated as an exemplary model of open administration guided and defined by Giorgos and Stratigea (2014). 
Again, let us review the processes in establishing an agenda and evaluating the priorities of the An'Yang Stream restoration project by means of the Master Plan. The Master Plan written by City of An'Yang (2001) addressed the direction of the An'Yang Stream restoration project. Its slogan was, 'Let's restore the An'Yang Stream so a Chinese minnow can live here." According to City of An'Yang (2001), the Chinese minnow inhabits only clear water. It addressed specific levels of fluvial diversity and water ecological indicators in describing water quality changes and annual water quality data. The Master Plan described potential solutions for water quality improvement. According to the City of An'Yang (2001), the potential solutions included sewage advanced treatment technology, sewage pipelines and maintenance, sewage interceptors, heavy metal control devices, and other items. Urban streams typically have decreased water quality and have to find solutions to control contamination and prevent it from increasing. Industrial facilities and the large population near the urban stream were serious hazardous factors. In particular, the An'Yang Stream was struggling because of the serious contamination of domestic sewage inflow. The governance that wrote the Master Plan faced the challenges of domestic sewage pipeline maintenance and the need to improve the processes and augment the deficient urban sewage treatment facility. Because of this, water quality improvement became the most important and primary concern during the quest for solutions.

In the field of water quality improvement, in 2000, this collaboration led by the task force established democratic and participatory partnerships through a citizen watchdog monitoring program and ecological education programs for citizens, which were great milestones. When we evaluate the potentiality of this Master Plan, it can be a 
great strategy for science and technology-oriented water quality restoration, but it still has challenges to overcome, such as the side effects of technocratic natural resource management with less regard to non-scientific values. In particular, the stakeholders seemed to aim participatory stream restoration to embrace diverse social values, but in practice, the participatory process pursued only specific topics such as water quality improvement, potential flood control, and stream-flow management. Thus, this was not always an ideal way of having governance of river basin management.

Hence, we can conclude that the Master Plan was designed mainly for technocratic stream management rather than stream restoration pursuing social integration, educational application, cultural prosperity, and historic preservation on An'Yang Stream.

\subsection{SUMMARY}

According to the City of An'Yang (2001), the early stage of the planning process of the stream restoration was constructed to make an exceptional effort at outreach and collaboration with other bodies and organizations and the general public. The expectations of citizens with respect to this Master Plan was huge, as they wanted to have the An'Yang Stream restored in the short term. This was the reason why citizens participated in the decision-making process as supporters, as well as colleagues and partners of other stakeholders. Their non-scientific values such as socio-cultural factors were not well reflected, guided, and addressed in the Master Plan. Remarkably, however, the AGWQC considered establishing a system of citizen participation in partnership and mutual collaboration with the decision-making board, aimed at one 
common goal: comprehensive ecological and water quality in the watershed and stream restoration.

Pursuant to the results and findings of the content analysis, it would seem that the process of reaching the goal of civic participation was limited because the Master Plan focused on achieving the technocratic stream restoration that was led by engineers. Also, the non-scientific values were not considered as the major agenda in the stream restoration process driven in the Master Plan.

The Master Plan of the An'Yang Stream decision-making system undoubtedly played a large and important role in initiating and forming the foundation for the governance activities of the An'Yang Stream restoration that followed. To accomplish the goal of water quality improvement, the Master Plan addressed major visions of the decision-making agenda (Figure 10). The professional advisory committee conducted an in-depth investigation into scientific revitalization, regarding interpreting diverse scientific and engineering professional theories. Anyone could understand the primary value: water quality enhancement using innovative scientific engineering technologies, which could be applied to the conditions of An'Yang Stream in the stream restoration project. Thus, the Master Plan did not reflect the incorporation of the various interests and values into their strategies very well. The Master Plan still prioritized the scientific restoration for water quality improvement in terms of innovative engineering technologies. The research design was more perfunctory and superficial than the public expected.

According to the Master Plan (City of An'Yang, 2001), the activities of the AGCWC might have been a sort of deliberative and collaborative attempt when 
evaluating the initial period's various values and agendas of the An'Yang Stream restoration. Glancing over the Master Plan, the described decision-making process looked well-organized and it seemed that the collaborative network got along well with the private network, ASPN during the early period. Although the members focused on ecological restoration and water quality improvement as the major and most important part of the Master Plan, this research can regard it as a groundbreaking result because of the potential contribution to decision-making process for the future.

After reviewing and analyzing the document the An'Yang Stream Restoration published in 2001, the researcher could address what values were mentioned and considered during the decision-making processes and set agendas at the early period of the An'Yang Stream restoration governance. From this analysis, it is apparent that the An'Yang Stream restoration task-force aimed to accomplish major values such as water quality enhancement, ecological revitalization, and waterfront space renovation and landscaping after the water resource experts scrutinized the monitoring process. Also, it valued citizen participation and social integrity in its stream restoration process as additional interests. 


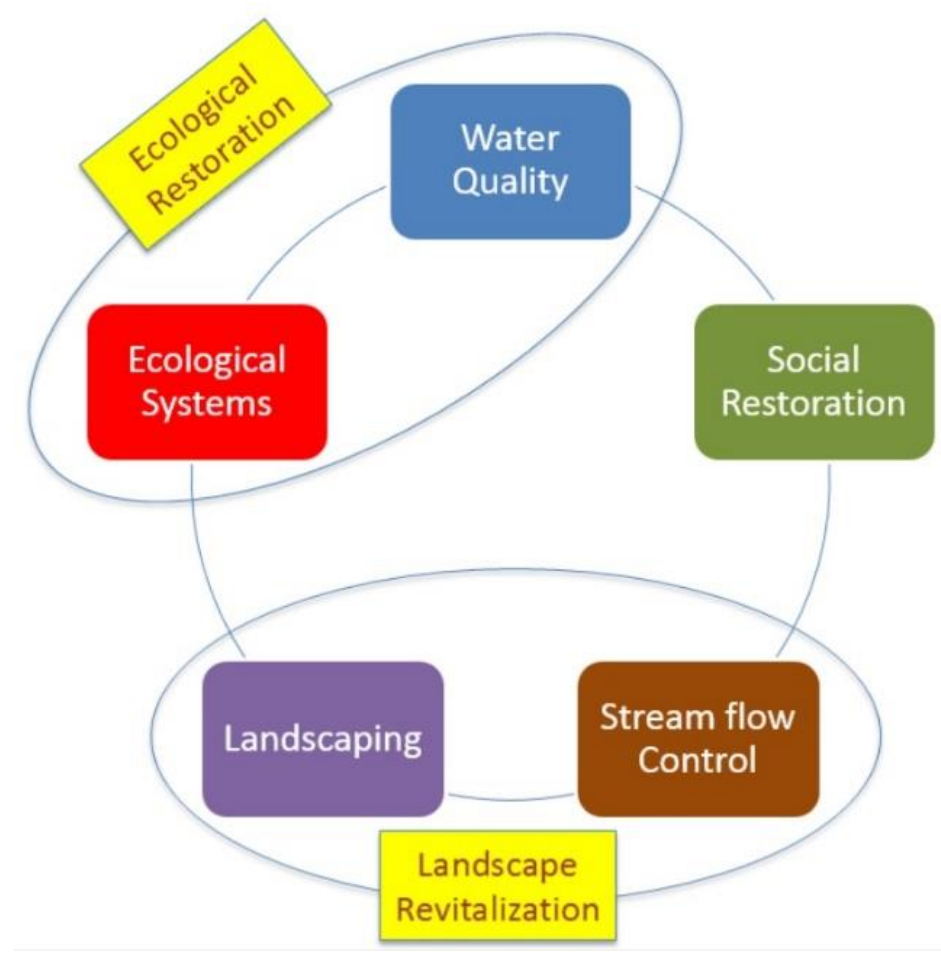

Figure 11. Map of values

However, the Master Plan could not take non-scientific interests without bias because engineers and scientists were prone to underestimate values such as society, culture, education, and history. Hence, these social values were prone to be neglected in the decision-making processes described in the Master Plan because most participants in the decision-making had backgrounds in engineering technology, which value scientific renovation as the primary agenda. Consequently, social values like citizen participation, cultural regeneration, and social integrity were not reflected in the proper way, but might provide potential spaces for a new assessment of the An'Yang Stream restoration, in spite of the limitations resulted from an unskilled citizen participation system. 
Although it was not ideal to accept different values such as social values, the An'Yang Stream decision-making was able to introduce the concept of political and administrative application of citizen participation in the An'Yang Stream, and partially influenced and motivated the reactions of its citizens (Figure 11). Furthermore, we can assume that it was also able to ignite politicians to support their political interests and values in the restoration work, which in turn induced citizen participation.

To sum up this chapter, through content analysis of the Master Plan document, this research could understand and recognize the priorities of the initial stage of the An'Yang Stream restoration project. The next step in this project was to analyze the implementation of the Master Plan. Thus, this research adds interviews with stakeholders and AHP surveys to understand how implementations of the Master Plan were held in the stream restoration process, as well as what occurred in agenda setting of the project after 2001 until 2015 in the next chapter. 


\section{Chapter 5}

\section{Content Analysis of Interview with Stakeholders}

This research was undertaken to better understand why non-scientific values of the An'Yang Stream were prioritized less than scientific values, during and after policy implementation based upon the guidance of the Master Plan analyzed in Chapter 4. The previous chapter reported a content analysis of the An'Yang Stream Restoration Master Plan, which identified the values of the stakeholders and their stream restoration strategies in the initial stage of this project (City of An'Yang, 2001).

Public administrators $(n=9)$, advisory scholars $(n=6)$, NGO representatives $(n=$ 6), and local citizens $(n=7)$ were interviewed using a semi-structured protocol in which all interviewees were asked standardized questions, followed by opportunities to make additional comments (See Appendix 8). All interviews were recorded and transcribed verbatim in Korean and English. In the interviews, participants shared backstories that were not addressed in public documents or published news articles.

\subsection{RESULTS FROM CONTENT ANALYSIS OF INTERVIEWS}

Of the three primary values outlined by the Master Plan, ecological restoration was the most frequently stated, followed by social restoration. Landscape revitalization was lowest. Some public administrators interviewed in this research stated that the reason most government groups tried to revitalize ecological factors: stakeholders and politicians looked at the strengths of ecological revitalization in urban spaces because most citizens who held voting power cared about their environment and ecological systems for their health. 
Interviewees of NGOs and citizen groups pointed to the function of ecological restoration to revitalize the environment through the citizen participation program within the stream restoration project. However, water experts did not consider holding citizen programs regarding ecological issues in the stream restoration project because they only valued technical and engineering aspects of the ecological improvement, and did not agree with the participatory strategies of other stakeholders concerned.

Although citizens' interests should be paid attention to, the various interests of the citizens were not directly related or helpful to achieve water quality improvement and ecological restoration in the An'Yang Stream. Citizens' interests were necessary for efficient use of the stream resource, but professional scientific methods would be more important to accomplish successful restoration. (NGO 03)

These interview transcripts showed a concrete vision that addressed the practical function and application of constructing a natural type of shore bank and focused on the ecological ecotone regarding stream restoration.

By coding the interview transcripts within the Dedoose $e^{R}$ software, which is a webbased mixed method research software, to indicate qualitative and quantitative analysis results of interview transcripts, this research found that the interviewees mentioned water quality improvement (ecological restoration) more frequently than other values (166 times). Also, ecological restoration supported by scientific information allowed participants to apply knowledge in decision-making debates to offer rationality for effectiveness and efficiency (Wyant et. al, 1995). Meanwhile, non-scientific values such as Social Restoration were less frequently quoted in the interviews (69 times). In addition, the stakeholders mentioned the value of Landscape Revitalization 79 times. The results are displayed in Table 11 below. 
Table 11. Major values of stakeholders

\begin{tabular}{|c|c|c|c|}
\hline Major value & Sub-value & Subjects & Content from Interviews \\
\hline \multirow[t]{3}{*}{$\begin{array}{l}\text { Ecological } \\
\text { restoration } \\
\text { (166 times) }\end{array}$} & $\begin{array}{l}\text { Improvement of } \\
\text { ecosystem and } \\
\text { increase in } \\
\text { resilience } \\
\text { (61 times) }\end{array}$ & $\begin{array}{l}\text { Ecological } \\
\text { resilience } \\
\text { improvement } \\
\text { and species } \\
\text { diversity } \\
\text { increase }\end{array}$ & $\begin{array}{l}\text { "An'Yang Stream } \\
\text { restoration should get fry, } \\
\text { water snails, snakes, } \\
\text { crawfishes, king crabs back } \\
\text { to the stream and BOD and } \\
\text { DO level control, } \\
\text { 'Protection and restoration } \\
\text { of native species,' } \\
\text { 'Endangered species, } \\
\text { ecosystem health recovery' } \\
\text { through the restored } \\
\text { protection." }\end{array}$ \\
\hline & $\begin{array}{c}\text { Water quality } \\
\text { enhancement } \\
\text { (63 times) }\end{array}$ & $\begin{array}{l}\text { Pollutants } \\
\text { removing and } \\
\text { purifying }\end{array}$ & $\begin{array}{c}\text { "Stable supply of clean } \\
\text { water } \\
\text { and increasing sewage } \\
\text { treatment capacity - } 2009 \\
\text { sewer penetration objective } \\
\text { criterion An'Yang is } 100 \% \text {. } \\
\text { Since the } 2003 \text { sewer } \\
\text { penetration has been } \\
\text { continued, locations could } \\
\text { successfully achieve the } \\
\text { target of } 100 \% \text { in } 2009 . "\end{array}$ \\
\hline & $\begin{array}{l}\text { Innovative } \\
\text { engineering } \\
\text { system (42 } \\
\text { times) }\end{array}$ & $\begin{array}{l}\text { Real-time } \\
\text { hydraulic } \\
\text { monitoring } \\
\text { system }\end{array}$ & $\begin{array}{l}\text { "Through eco-friendly } \\
\text { maintenance, primer } \\
\text { formulations, and the } \\
\text { introduction of state-of-the- } \\
\text { art techniques can enable a } \\
\text { return to optimal conditions } \\
\text { of water quality and wetland } \\
\text { area." }\end{array}$ \\
\hline $\begin{array}{c}\text { Social } \\
\text { Restoration } \\
\text { (69 times) }\end{array}$ & $\begin{array}{l}\text { Social integrity } \\
\text { (59 times) }\end{array}$ & $\begin{array}{l}\text { Sustainable } \\
\text { leadership, } \\
\text { utilizing the } \\
\text { stream } \\
\text { restoration with } \\
\text { a sustainable } \\
\text { governance } \\
\text { building }\end{array}$ & $\begin{array}{c}\text { "To maximize citizen } \\
\text { participation and } \\
\text { cooperation, to constitute an } \\
\text { An'Yang Stream basin } \\
\text { environmental } \\
\text { administration council, we } \\
\text { must be able to pursue social } \\
\text { integration." }\end{array}$ \\
\hline
\end{tabular}




\begin{tabular}{|c|c|c|c|}
\hline & $\begin{array}{l}\text { Social } \\
\text { revitalization } \\
(10 \text { times })\end{array}$ & $\begin{array}{l}\text { Cultural, } \\
\text { educational, } \\
\text { historical, and } \\
\text { social } \\
\text { revitalization of } \\
\text { the community }\end{array}$ & $\begin{array}{l}\text { "An'Yang Stream will need } \\
\text { to be restored to develop in } \\
\text { the near civil favorite } \\
\text { historical, cultural, and } \\
\text { hydrophilic space." }\end{array}$ \\
\hline \multirow[t]{3}{*}{$\begin{array}{l}\text { Spatial } \\
\text { renovation } \\
\text { (Landscape } \\
\text { Revitalization) } \\
\text { (79 times) }\end{array}$} & $\begin{array}{l}\text { Flood } \\
\text { prevention and } \\
\text { stream flow } \\
\text { management } \\
\text { (35 times) }\end{array}$ & $\begin{array}{l}\text { Wastewater } \\
\text { control facility }\end{array}$ & $\begin{array}{c}\text { "Natural stream restoration } \\
\text { should be aimed for to } \\
\text { prevent floods and } \\
\text { droughts." }\end{array}$ \\
\hline & $\begin{array}{l}\text { Economic } \\
\text { development } \\
\text { and property } \\
\text { value increase } \\
\text { (17 times) }\end{array}$ & $\begin{array}{l}\text { Local economic } \\
\text { vitalization } \\
\text { through } \\
\text { environmental } \\
\text { improvement } \\
\text { near the } \\
\text { waterfront areas }\end{array}$ & $\begin{array}{l}\text { "You want citizens to live in } \\
\text { the town, and set a target of } \\
\text { An'Yang Stream to restore a } \\
\text { livable city; also, you can } \\
\text { activate the sluggish } \\
\text { regional economy and real } \\
\text { estate market." }\end{array}$ \\
\hline & $\begin{array}{l}\text { Recreational } \\
\text { amenities } \\
\text { (27 times) }\end{array}$ & $\begin{array}{l}\text { Places for } \\
\text { leisure and civic } \\
\text { activities for the } \\
\text { community }\end{array}$ & $\begin{array}{c}\text { "Local culture must also be } \\
\text { activated to create a space in } \\
\text { which citizens enjoy a } \\
\text { nearby in the waterfront } \\
\text { space of the An'Yang } \\
\text { Stream." }\end{array}$ \\
\hline
\end{tabular}


As the Master Plan addressed the potential risks and solutions in terms of landscape elements, the interviewees also held various opinions regarding landscaping and gardening in the waterfront spaces of An'Yang Stream. The interviewees showed their interests in ecological regeneration, scenic landscape, and spatial restoration. The interviewees of government groups shared their experience when citizens filed a civil complaint to request renovation construction along the trail in the waterfront area.

Generally speaking, the interviewees tended to think that the existing conditions of the waterfront space of the An'Yang Stream basin were unattractive and difficult to access, as well as adversely affected the ecological system. Landscape renovation would achieve common benefits for both people and nature. Some interviewees representing the citizen group wanted renovated landscape for recreational use and the aesthetic function of urban gardens. Interviewees representing the professional advisory groups strongly stated that well-organized landscaping created by utilizing efficient land-use planning concepts would contribute to establishing sustainable watershed management.

The interviewees representing engineers working at corporations (private sector engineers) and environmental scientists showed strong motivations to restore the landscape of the An'Yang Stream. The private sector engineers, who worked for the engineering construction companies, wanted to receive orders for more contracts and participate in more spatial renovation construction projects, which could make them more financial profit. 
Meanwhile, the environmental scientists (PS 03) wanted to provide a more affluent lifestyle for the citizens and more diversity to the ecological systems through the landscaping update.

In order to reestablish the use of existing facilities and provide recreation for residents, such as sports facilities, the waterfront space needs to be renovated by using appropriate construction and listening to the opinion of the citizens...Through the access redevelopment of sports facilities, aesthetic events, and ecosystem protection, the An'Yang Stream governance will attempt to have new and renovated recreational amenities features for the citizens. (PS 03)

The interviewed public administrators also discussed how spatial renovation and beautification based on a concept of ecological restoration and water quality improvement could provide a buffer zone between the urbanized and ecological spaces, as well as provide the healthy flow of the stream. These interviewees stated the importance of seeking possible solutions to gratify citizens' diverse demands in landscaping within the agenda setting of the An'Yang Stream restoration project. In particular, the citizen interviewees argued that citizen participation could be one solution to gather ideas for innovative landscaping in waterfront spatial maintenance and civic space operating management.

I want the governments to build many facilities for recreational activities and beautiful waterfront parks. Also, they have to listen to and pay attention to people's various opinions in these changes of spatial modification...... I don't think the government and the public administrators took appropriate participatory processes in this spatial landscaping renovation. (CO 06)

Some citizen interviewees wanted the governments to renovate the waterfront landscape for recreational facilities. The waterfront space has been used as bike lanes, pedestrian paths, and water parks for residents. Some senior citizens held a substantial value regarding planting flowers and trees in the waterfront space for scenery. There 
were different interests between the senior and young generations. Young citizens desired value regarding spatial efficiency through the landscape renovation, rather than gardening in the waterfront space.

One interviewee of a participant NGO strictly opposed and did not agree to landscape renewal and waterfront beautification plans without careful consideration of environmental impacts and negative ramifications into the ecological systems. Some of the interviewees argued for the importance of building eco-friendly banks and making an original natural-type ecological park in the waterfront space.

The interviewed groups believed that ecological restoration was the most important agenda item. In particular, the interviewed stakeholders agreed to build more sewage treatment facilities. Some NGOs were technology and engineering focused in their agenda setting within the An'Yang Stream restoration decision-making. To capture an advantageous position during negotiation, they invited many professional hydrologists into their group to participate in the decision-making processes which were held from 2001 on. In other words, the stakeholders were primarily concerned about ecological restoration issues by technocratic approaches. In the following paragraphs, this content analysis process addressed the influential stakeholders and the prioritized values by the stakeholders. Also, the relationships and power dynamics among the stakeholders were explained and described through their interview scripts.

\subsection{INTERVIEW WITH STAKEHOLDERS}

This work identified key stakeholders of the governance, their key values, and which values were pursued during the mid-period of the An'Yang Stream restoration. 
The interviewees were selected based on the previously conducted document review.

However, most initial interview candidates did not want to participate in the interview, or were unreachable. The participants who were willing to join the interviews were later asked to share their colleagues' contact information for future interviews. Thus, the researcher used a snowball-sampling method to identify interviewees in the stakeholders' network. Regarding a socially accepted South Korean etiquette, it is acceptable to ask for an interview and survey through a referral.

\subsubsection{Government groups (Public administrators)}

The interview process with public administrators from government organizations was not easy because they did not want to share personal opinions nor their documents and internal information with the public, making this segment of stakeholders the most difficult to interview. These government groups could dominate the decision-making processes within the participatory process based on controlling the institutional systems.

These public administrators reported a solid understanding and easy access to the scientific professional information about hydrological engineering technologies, water quality evaluation, and ecological factors such as fluvial diversity and riparian vegetation of An'Yang Stream. They held professional backgrounds in civil engineering or environmental science from education and professional experiences performing their duties.

As one engineer stated

My major was civil engineering in college, and I began work in the government as an environmental administrator. As usual, most public administrators in the team that is in charge of stream management hold majors related to science or engineering because the human resource department is prone to appoint that manpower in the water resource management team. (PA 08) 
According to PA 05 and 08 , the public administrators were usually expected to play the role of urban planner and work within a rigidly top-down administrative organization. The public administrators held the administrative power of policy-making and allocation of financial resources for operating the relevant projects of An'Yang Stream restoration under the guidance and supervision of the central government. None of the public administrators nor engineers reported training or preparation for serving the roles of professional conveners or mediators. Public administrators noted they were rotated to other positions every three to four years, so that there was little consistency of professional participants. As one administrator said

Korean administrative systems are prone to be technocratic in water resource management because Korea has been experiencing fast industrialization and economic development based on scientific innovation with advanced engineering technology. And, the system did not have enough room to accept the functions of specialists, such as urban planners or professional negotiators as well as conflict mediators. Moreover, the central government tends to hold more power, so most decision-making comes from a top-down process. (PA 05)

Public administrators reported a primary goal as to collaborate and compete to receive more grants from the central government. Each local government managed one sector of the An'Yang Stream based on grant money from the Ministry of Land and Transportation (the central government). The public administrators played a significant role and saw their role (and that of other employees) as leading water quality improvement in the short term.

The group of professionals prioritized improved water quality because the An'Yang Stream was contaminated. Professionals offered the slogan, “Let's restore the An'Yang Stream so a Chinese minnow can live here." 
Water resource professionals (hydrologists) on the advisory committee and public administrators reported a deep understanding of water quality control in stream management, and their expertise allowed them to compare the annual water quality changes of An'Yang Stream. They valued their specialized role when the governance was built in 2001, and they paid particular attention to conditions that relied on their knowledge, such as building a system of hydrological monitoring of daily changes in water quality, such as the levels of biochemical oxygen demand (BOD), dissolved oxygen (DO), T-P, and T-N.

Professionals identified goals for specific technological improvements achieving specific levels of fluvial diversity, water ecological indicators, and annual water quality data — for pollution and unbalanced urbanization and industrialization. They worried that factories and industrial facilities, as well as the large population near the river basin of An'Yang Stream, were serious hazardous factors.

The interviewees argued for potential technological solutions, including advanced sewage treatment technology, sewage pipelines and maintenance, sewage interceptors, and heavy metal control devices. However, professionals reported conflicts in selecting appropriate solutions for water quality improvement because their definitions of stream restoration, relying on technocratic goals and skills, differed from other groups who had less technical knowledge. Public administrators who had backgrounds as scientists or civil engineers aimed to have water quality improvement through sustainable policymaking processes based on technological advancements of collaborative intergovernmental networks and administrative efficiency. However, water resource professionals and hydrologists wanted to see direct achievements in the stream 
restoration project, so they focused on searching for more efficient scientific

information and useful professional knowledge

The public administrators were also technocratic in the decision-making process within the An'Yang stream restoration governance.

They had to create consensus-building processes in analysis and understanding of the scientific data to avoid following conflicts. In particular, water quality improvement was a hot topic of discerning other stakeholders' interests in stream restoration. The water quality improvement was primarily aimed for in the stream restoration process. Social factors like culture, education, and history were not the major agenda to the stakeholders. (PA08)

In particular, professional interviewees agreed that An'Yang Stream was struggling because of serious contamination of domestic sewage inflow. The strong will of the government groups who wrote the Master Plan faced the challenges of domestic sewage pipeline maintenance and the need to improve the processes and augment the deficient urban sewage treatment facility. Consequently, professionals' perspectives were supported by other groups to consider water quality improvement as the most important and primary concern during the stream restoration process.

Hydrologists and water resource experts began to study innovative approaches for designing energy efficient and sustainable technologies. Because each local government had appointed a water specialist or an environmental the professional advisory committee had to resolve multiple conflicts to determine which scientific professional information to share and how the information could most usefully be shared. (PS 02)

There was a prevalent misunderstanding in South Korean society regarding the functions and roles of urban planners because public administrators are not trained in participatory processes. However, most Korean public administrators seemed to understand the significance of the role of planners who held strong responsibilities for successful public participation in frequent occasions of stream restoration, but they did 
not consider participatory decision-making processes to be a primary agenda in the An'Yang Stream restoration. The public administrators were not ready to embrace the values of civic participation and develop a system for it. In fact, they had more influence and professional information in the process of the decision-making of An'Yang Stream restoration.

Consequently, the An'Yang Stream's decision-making process was not the best choice to embrace values, because most stakeholders from the governments were engineers and hydrologists who influenced and participated in the technocratic decisionmaking. In other words, the decision-makers in the process did not adequately value the consideration of different stakeholder values.

\subsubsection{Non-governmental organizations (NGO)}

Private sector groups such as NGOs and citizen groups had different viewpoints on the water quality restoration for the stream. Even though they felt less influential in the agenda setting and policy decision-making processes, they could put their idea into practice through a community movement for water quality improvement. NGOs held various educational and cultural events that attracted voluntary participation and public support for water quality enhancement activities, as well as addressed the importance of increasing water quality. Citizen groups organized frequent riverfront cleaning activities.

The Master Plan addressed the importance of collaboration with non-governmental organizations (NGOs) and their contributions. The group of NGOs was composed of the An'Yang YMCA, the Gunpo YMCA, the Federation of Environmental Movement of 
An'Yang Gunpo Euiwang, the Gunpo Agenda 21, the Gwangmyong Agenda 21, the Gunpo Environmental Governing Citizens Association, the Euiwang Agenda 21, the An'Yang Agenda 21, the Dorim Stream Protection Citizens Association, the Open Society Citizens Federation, Citizens' Solidarity of An'Yang, the Shihwanet, and the Federation of Environmental Movement of Seoul.

These groups were expected to represent the diverse values and interests of ordinary citizens. NGOs demonstrated a strong political agenda in their goal setting, and were generally united in their opposition to the technocratic perspective of the government's agenda. In some cases, NGOs reported that their minor role was not satisfactory.

The advisory committee was composed of scientists and hydrologic engineers. They did not care for non-scientific values such as culture, education, and history. Our group of YMCA had a blueprint of education and cultural events in the stream restoration with communities, but it was very hard to persuade the advisory committee members in the decision-making processes. I have left the An'Yang Stream Project because it was a big challenge for us, and the An'Yang Stream Restoration Project is still focusing on scientific innovation based on hydrologic engineering. (NGO 01)

Other NGOs held a strong political viewpoint against the central government. The activists of the environmental NGOs were politically very liberal and their activities were a part of a political stance. Their involvement in the An'Yang Stream restoration gave them influence in political decision-making regarding environmental issues. It was shaped and planned on purpose. (PA 04)

In fact, the NGOs' group was rarely cohesive. Each NGO had a different a point of view on specific values. Some NGOs such as the YMCA and An'Yang, Gunpo, Euiwang Federation for Environmental Movement played key roles in leading the An'Yang Stream Protection Network, as well as the An'Yang Stream restoration governance network. At the onset, NGOs could collaborate based on a strongly 
constructed trust during their cooperation, conflict resolution, and vision sharing.

However, this bond was dissolved over the An'Yang YMCA's desire for more educational opportunities for young leaders and students in the stream restoration while other NGO stakeholders chose to solely focus on technocratic solutions. Applying scientific technology strengthened political competition for grants, assuring that technocratic goals would lead the way.

The representatives of most NGOs were environmental scientists or civil engineers because it would be hard to fight against politically powerful governments and organizations if they didn't interpret and understand knowledge and information about professional scientific water resource management.... Stream restoration projects assuring technocratic agendas received high priority in the budget allocations supported by the governments. (NGO 03)

To sum up, for NGOs, building participatory, collaborative, and adaptive governance was a great opportunity to address their preference for various interests. Unfortunately, most NGO representatives did not develop a specific strategy for incorporating diverse values, nor build mutual agreements during the An'Yang Stream planning. The NGOs individually held different priorities and did not have appropriate levels of skills to initiate collaboration.

Consequently, according to NGO interviewees, despite the involvement of different groups and their alleged values, ecological factors continued to remain the highest priorities.

\subsubsection{Advisory water resource professionals}

The An'Yang Stream Restoration advisory committee was composed of many professional water experts, researchers, hydrologists, and professors from diverse 
institutes, governments, and NGOs as explained in the Master Plan. In 2000, the An'Yang Stream restoration advisory committee was established to support the stakeholders to seek rational and sustainable solutions in the restoration process (City of An'Yang, 2001). The advisory body provided specific direction for the stream restoration with professional expertise to develop wise decision-making. In this decision-making process, these professionals advised the stakeholders with professional data, and interpreted information on water quality indicators and ecological evaluation reports. One interviewee (PA 01) mentioned that most stakeholders of the An'Yang Stream restoration project were engineers who understood professional water data. The stakeholders of the An'Yang Stream governance began to rely on the information from these advisory professionals. The advisory committee also sometimes assisted citizen groups in the governance debates. As planned and addressed in the Master Plan, there were periodic different workshops to share the professional findings with participants.

As PA 01 said above, the advisory committee was mostly composed of water resource experts from the engineering field. The hydrologists and civil engineers in the advisory board cared about water quality improvement and ecological conservation in stream restoration. In order to justify the primary values of the hydrologists and civil engineers in the An'Yang Stream restoration, they worked closely with politicians and public administrators, because the stakeholders had to understand specific data based on scientific information from field surveys and relevant water-quality data. This was so the scientific information could be used in their reports proposing effective solutions for alleviating the contamination after evaluating indicators determined by scientific and engineering investigations. 
NGOs and citizen groups cannot have appropriate levels of abilities and data to collect and analyze them by themselves. So, our professional advisory committee plays roles of the most important and influential actor in the center of the final decision-making as well as agenda setting of the An'Yang Stream restoration. The stakeholders are still prone to rely on our research and technical documents on the stream systems. (PS 03)

The interviews explained a strong reliance and alliance between public administrators and advisory committee members. Both the stakeholders from the private sector and the government participants needed advice and assistance in analyzing and understanding the professional scientific indicators. Since members of the advisory group set the agenda for the An'Yang Stream restoration, they exerted a strong influence of expert power within the governance.

...the advisory committee was composed of scientists and hydrologic engineers. They did not care for non-scientific values such as culture, education, and history. Our group of YMCA had a blueprint of education and cultural events in the stream restoration with communities, but it was very hard to persuade the advisory committee members in the decision-making processes. I have left the An'Yang Stream project because it was a big challenge for us, and the An'Yang Stream restoration project is still focusing on scientific innovation based on hydrologic engineering. (NGO 01)

Again, however, the members of the advisory body could not address non-scientific interests without bias because engineers and scientists were prone to underestimate values such as society, culture, education, and history. In reviewing their interviews, this work found that non-scientific values were not considered properly during their advisory processes. It was hard to have discussions with them to ask why the nonscientific values should have been included in stream restoration in the long term because they were working within the technocratic frame of the An'Yang Stream restoration. 


\subsubsection{Citizens}

The six citizen representatives who were interviewed tended to be pro-

environment, because there had been serious water contamination from sewage and

industrial effluents.

Of course, the water quality of the An'Yang Stream was very poor. The smell was awful in the waterfront area. The citizens did not want to go to the waterfront area. Some thoughtless people illegally threw away domestic trash. The water quality improvement was the most important value. (CO 05)

Another interviewee expanded

The mayor of the city of An'Yang made a great step in the An'Yang Stream restoration. The water quality was improved and citizen events were frequently held for promoting stream restoration activities. In fact, ordinary citizens could not know what was happening in the stream restoration process without updates by the governments...The decision-making processes were not open to everyone in the public. However, we supported their decisions because the water quality and ecological systems of An'Yang Stream became better. Floods were another big concern to the citizens. The An'Yang Stream restoration project provided solutions for the floods in the riverside renovation process. The mayor did these things, so most citizens were very happy with his policies. ( $\mathrm{CO} 03)$

A large number of citizen interviewees wanted to have clean water instead of sustainable policy-making and amendment of environmental regulations for a river management system, such as canal construction.

Some citizens wanted to have civic open recreational facilities in the waterfront area after stream restoration construction because An'Yang stream was located in an urban area. During the field research, many people were observed enjoying the recreational parks and sports exercise facilities along An'Yang Stream's waterfront spaces.

Also, others valued the educational, historical, and cultural revitalization resulting from the An'Yang Stream restoration. 
Water quality improvement and ecological restoration were successfully achieved by our efforts. It is the time to consider non-scientific factors such as social restoration including culture, education, history, and social integrity. (CO 05)

Citizens were also were determined to have a seat at the table. Citizen groups who actively participated in the decision-making were interested in sharing their interests about the lifestyle and recreational use near the watershed. The citizen interviewees stated that they could not directly recognize what was happening in the decision-making processes of An'Yang Stream restoration if the government groups did not hold participatory events, such as public hearings and open discussions.

The governments held many public events such as public hearings and open discussions. However, most citizens did not precisely know why or how they could improve the water quality. Not many citizens could understand the scientific data of water quality. People saw the surface of the tangible changes through the stream restoration. They thought of stream restoration cases that build many banks and dikes for flood prevention, and that planted reed for ecological restoration in the waterfront area were examples of good stream restoration. Hence, it seems that the governments ignored other values. (CO 04)

The government groups also recognized the value of citizen input. They established task-forces to determine the public's complaints and requests because the governments had to communicate with and reflect the public about the An'Yang Stream management that was polluted and needed a well-planned restoration strategy. In addition, the An'Yang's residents showed political attitude and a postive stance toward stream management.

Some citizens often made complaints, so public administrators had to consider their complaints in policy making so that the politicians, the mayors who had human resource authority, would be looked upon favorably in upcoming elections. The water quality issues were more serious for the citizens than the politicians. Successful stream restoration brought an increase in real property values in the region. Hence, the mayor sided with the citizens...the citizen groups and NGOs held political power because their influence on specific political parties was more 
powerful in the An'Yang Stream restoration decision-making. Ordinary citizens had weaker power comparing with environmental NGOs ... (CO 05)

The values of potential flood prevention and stream-flow management were major issues in the agenda-setting process because the An'Yang Stream had to overcome flood damage mitigation and drought. Many interviewees argued for the importance of natural disaster control and prevention in the An'Yang Stream restoration. Among the natural disasters in the An'Yang Watershed, floods were a serious and significant topic for the stakeholders. For flood control, the An'Yang Stream governance recommended that additional banks and artificial recharge systems be created near the river basin regions. However, many NGOs did not agree with some stakeholders who supported human-made artificial constructions of dikes and banks in the An'Yang Watershed, which caused conflicts due to holding different opinions on flood prevention. Some NGOs members and citizens wanted to focus on deliberative and participatory decisionmaking processes based on strong collaborative governance structure.

In addition to NGOs, the citizen participants discussed their concerns about annual severe flooding. The majority of the citizen interviewees believed that the An'Yang Stream governance needed to consider constructing more dikes and banks to prevent floods in monsoon season.

The An'Yang Stream needed more dikes and banks to prevent floods during the monsoon season. Most households are very vulnerable to floods. When there is flooding, commoners like us experience severe damage. Water quality improvement and flood management are important values of the stream restoration. (CO 05)

According to interviewees who represented the local governments, the An'Yang Stream restoration was designed for and targeted to flood prevention and stream-flow 
control for water quality management. During the stream restoration, government groups set goals and established strategies by using conventional civil and environmental engineering technologies. In other words, stream restoration was accomplished by increasing scientific indicators that could evaluate water quality as well as use quantitative information of engineering technological principles.

The environmental scientists, hydrologists, and civil engineers who were interviewed argued for the benefits of stream-flow management and flood control as their primary goals, and relied on scientific innovation in the An'Yang Stream management. They had the same opinion that water quality improvement could not happen without stream flow control and flood management. In addition, when asked about roles of participatory decision-making processes in measuring and evaluating water quality improvement, they mentioned that after reaching ideal conditions, the An'Yang Stream restoration would need participatory decision-making processes and plans and strategies to address flood management and stream-flow control.

Most interviewees noted that the citizens were willing to participate in any available citizen participation activity. The value of civic participation in this stream restoration was not the primary goal when the citizens considered ecological restoration, landscape beautification, and water quality improvement. However, the improvement of the recent living conditions motivated the citizens to participate in the governance of the An'Yang Stream restoration.

The An'Yang Stream restoration project was 100\% aimed at scientific methods oriented water quality improvement. Citizen participation was not the major goal, but it was considered more when compared to other Korean stream restoration cases. (PS 01) 
Another benefit of the participatory processes of the An'Yang Stream restoration governance was the establishment of the An'Yang River Ecological Story Hall (An'Yang River Visitor Center) by the government:

The An'Yang Stream restoration partnership could play a role of community educator for local citizens and students, as well as a participation activity. The various values of the citizens can be easily reviewed and recognized through the educational activities in the An'Yang River Visitor Center. (PA 06)

The citizen interviewees were very interested in a participatory process of decisionmaking for the An'Yang Stream restoration. This showed the changed and increased interests of citizens in terms of democratic governance. The An'Yang Stream governance held more public supported self-governing and operating systems when compared to other South Korean river restoration governance cases because it made diverse efforts to handle voluntary participation from the citizens and demonstrated democratic river management.

During the interviews, it was found that the NGOs and citizen participants preferred participating in the An'Yang watershed association in private partnerships, such as the Association of People Loving the An'Yang Stream, because the public sector did not address any realizable or reliable participatory programs, such as periodic meetings and field surveys with citizens and NGO members in the river basin regions of An'Yang Stream. Civic participation was not properly driven in terms of the reality and condition of existing governance situations of An'Yang Stream. It seemed to fail to embrace diverse values of socio-cultural, education, and historical factors. The interviewed public administrators and the professional advisory committee tended to be noncommittal in supporting the value of civic participation moreso than supporting 
water quality improvement and ecological restoration using scientific engineering technologies. Unfortunately, more than a few interviewees were unconcerned with the thought of the value of civic participation during the An'Yang Stream restoration.

The interview excerpts above demonstrate how much the interviewees considered solutions to mitigate risks that result from stream-flow devastation and floods. Furthermore, the content analysis of the interview transcripts let us understand how much the An'Yang Stream restoration was a technocratic revitalization project that relied upon scientific and technological innovation.

The citizens had the opportunity to promote their values through collective activities involved in environmental groups or NGOs. They considered not only cultural, educational, and public events, but water quality investigation activities. Fortunately, the An'Yang Stream restoration task force conducted citizen surveys before writing the Master Plan in 2001. Also, according to interview transcripts conducted in 2015, citizen participation was recognized by some stakeholders (mostly citizens) as one key factor in making successful stream restoration, because the success would not be able to be possible without participatory processes in reaching and realizing diverse agendas.

\subsubsection{Enterprise (Engineering companies)}

One stakeholder group within the An'Yang Stream restoration governance that might have held different values in this stream restoration process, compared to others was the group of engineers representing engineering companies that participated in the physical construction and spatial renovation (such as landscaping, river-basin 
maintenance projects, and regional development). As the An'Yang Stream Restoration Master Plan addressed this enterprise group before, regarding scientific and engineering applications, private engineers in the enterprise group were well trained, had professional expertise and field experience with stream management, and obtained economic benefits as a result of their scientific consulting. First of all, these engineers acted to make more money through construction contracts and spatial renovation projects from the An'Yang Stream restoration work.

The contractors and consulting engineers at the private engineering companies had backgrounds in engineering and scientific technologies. Most of them held the idea that advanced technologies would change the world as a top value in ecological and environmental development. They were also prone to look to the visible outcomes and calculable results in evaluating the An'Yang Stream restoration. Hence, the engineers in the private sector did not consider improving the social integrity and social value in the revitalization.

During the stream restoration work, private engineers developed relevant data sets and hydraulic modeling tools that could be implemented in the short term and were concerned with water quality changes and stream-flow levels based on advanced engineering technologies and skilled field experience below.

I had an experience with waterfront renovation construction. My company focused on efficiency and higher profits from the project. My company had a leading engineering technology in the stream restoration projects. The opportunity was a very innovative case for us and the community. (EN 01)

The private engineers drew upon their data and their in-depth knowledge of many other stream restorations. In spite of their extensive professional knowledge, the 
interviewees representing these engineers and contractors noted their limited influence in the decision-making processes of the stream restoration.

I think stream restoration needs to be primarily considered by environmental and engineering standards. It is very challenging without available technologies. (EN 03)

My engineering corporation focused only on environmental engineering improvement with advanced technologies, but did not include any other goals like non-scientific values such as social, cultural, educational, and historical values. Korean civil engineering culture is not ready to accept those additional values in water resource management. (EN 05)

Even so, they sought economic profit based on technical innovation, and financial revenue was their most important concern. In other words, the values of the private engineers might have focused more on regional development and spatial renovation construction than on stream restoration. To sum up, the engineers in the private sector focused only on scientific improvement with advanced technologies, but did not consider non-scientific values such as social, cultural, educational, and historical values.

\subsection{SUMMARY}

This chapter focused on the voices of water professionals, engineers, NGO representatives and local citizens to gather their knowledge of planning and implementation of the An'Yang Stream Restoration Master Plan Based on the research design.

The primary goal of the An'Yang Stream Restoration Master Plan published in 2001 was water quality improvement. In reviewing the interview transcripts and mapping the diverse values within the governance, it became clear that stakeholder groups held a variety of goals and values, but most interviewees adopted the primary 
value of the scientific and engineering factors as compared to other non-scientific values within the governance.

This research recognized how the stakeholders within this An'Yang Stream restoration decision-making from 2001 until 2015 accepted concepts about nonscientific, engineering values during the governance establishment. Also, it drew how these non-scientific engineering values were integrated into the governance agendasetting process, along with technocratic values in order to define the specific values which would be asked in AHP analysis. Thus, we can understand and review which values were more and less considered during their decision-making and the stream restoration governance network, and how those values were shaped and viewed by the stakeholders during the restoration progress.

Unfortunately, as this interview analysis has driven and affected the researcher to infer that the implementation of the Master Plan did not perfectly guide the stakeholders in finding the right direction to understand various interests raised by the stakeholders, governmental visions and institutional guidelines, including regulations of water use and conservation of aquatic ecological systems of the An'Yang Stream. The Master Plan did not properly address a strategy for incorporating the network of NGOs into the An'Yang Stream planning because the governmental groups who wrote the Master Plan did not consider that a harmonious partnership among the NGOs or citizen groups would increase the potential for long-lasting success. 


\section{Chapter 6}

\section{Understanding Values of Stakeholders (AHP Analysis)}

This chapter reports the relative importance among the values of the stakeholders who participated in the restoration project during the post-Master Plan stage of the An’Yang Stream Restoration Master Plan. More specifically, an analysis using the Analytic Hierarchical Process (AHP) was conducted to quantitatively answer the question, 'what factors are considered to be the most important by the stakeholders?' and 'what is the relative value (or ranking) the stakeholders assign these different factors in the restoration of An'Yang Stream?' AHP provides an appropriate analytic tool of multi-criteria decision-making processes, which can compare values, preferences, and interests across groups of stakeholders (Chung and Lee, 2007). The use of qualitative data analysis from interviews and quantitative analysis of data using AHP analysis strengthens the power of this research.

Also, this author sought to look at the temporal process of the stream restoration governance from viewpoint of the citizens. Before recognizing and addressing some potential keys for long-lasting sustainable stream management integrating participatory, transparent, and rigorous conditions, this research sought to understand and review the temporal changes of the patterns and trends of the stakeholders (Ellen et al., 2016). The groups of respondents were selected since much depends on how they reflect and accept the policies, strategies, and plans on stream restoration (Esaiasson et al., 2016). Thus, the citizens' values of An'Yang Stream restoration in 2015 (Hong and Chung, 2016) are compared with the random citizen AHP results of 2005 conducted by Chung and Lee 
(2007) to understand the effect of technocratic decision-making processes and citizen movements led by engineers and scientists.

\subsection{QUANTITATIVE ANALYSIS BY AHP}

AHP is recognized as a systematic multiple-criteria decision making (MCDM) method for comparing and weighting multiple alternatives held by stakeholders (Hong and Chung, 2016). As the first step, this research modeled the hierarchy structure to set main agendas of the An'Yang Stream restoration before the field survey. Second, the criteria were selected from a set of values that stood for the interests of the stakeholders through the Nominal Group Technique (NGT) (Hiligsmann et al., 2013). This step identified and chose three criteria for calculating the relative importance weights through pairwise comparisons between the criteria (values in content analysis or categories in Grounded Theory). The third step, the consistency index (CI) was calculated to test the consistency of the weights through the pairwise comparisons. Finally, the results were analyzed after filtered by using the standard $(\mathrm{CI}<0.1)$ as suggested by Saaty (1980). Thus, if the CI level is 0, the pairwise model can be regarded as a good level of consistency.

$$
C I=\frac{\lambda_{\max }-n}{n-1}
$$

The CI was calculated where the $\lambda_{\max }$ is the principal eigenvalue which is known that the changes between values imply the possible range of the changes. The model can be evaluated in terms of the $\lambda_{\max }$, with the difference between this $\lambda_{\max }$ and $n$ being a good measure of consistency (Saaty, 1980; Alonso and Lamata, 2006). 
These stakeholders also must recognize the various options to solve and address the problem. AHP requires evaluating these alternatives and the predetermined priorities by calculation of the relative weights of the each criterion in making a decision (Saaty, 1980; Hirayama et al., 2011; Hong and Chung, 2016). In particular, this AHP analysis helps to define the pairwise relative importance in the environmental problem for the stakeholders who must ensure that they understand what it should be considered (Hong and Chung, 2016).

One common method for determining relative weights between the various alternative options is through a process of analyzing each pairwise comparison process (Chow and Sadler, 2010; Hirayama et al., 2011; Hong and Chung, 2016). This pairwise comparison is the main part of this chapter because the results can be directly discussed and compared with the results of the content analyses written in the previous chapters. Thus, benefits of the AHP methodology come from the determination of the respective weights between the criteria and sub-criteria (Hong and Chung, 2016).

According to Hong and Chung (2016) and Stefanidis and Stathis (2013), AHP helps researchers to effectively compare each factor as well as to elucidate the relative interrelations between the factors by using quantitative sources such as pairwise comparisons and reliability of the obtained relative weights. All stakeholders directly or indirectly involved in the decision-making process might make their final decisions based on the extensive investigation of each related interest and goal (Hong and Chung, 2016). In short, this researcher considers AHP an appropriate method to understand and reflect accurately the relative priorities of the stakeholders who participated in the multi-dimensional decision-making in the field of stream restoration. Thus, this study 
uses AHP to precisely recognize the stakeholders' values regarding the An'Yang Stream Restoration (Hong and Chung, 2016).

\subsection{USING NGT TO SELECT SURVEY ITEMS FOR AHP}

Before AHP survey, this research used Nominal Group Technique (NGT) in order to identify the top three prioritized values in general cases of stream restoration. The AHP survey form was designed based on an application of the NGT, which concluded and indicated ecological restoration (ER), social restoration (SR), and landscape revitalization (LR), as the top three values. The AHP survey form was designed to exam pairwise relative importance between the values (criteria) rated in the NGT.

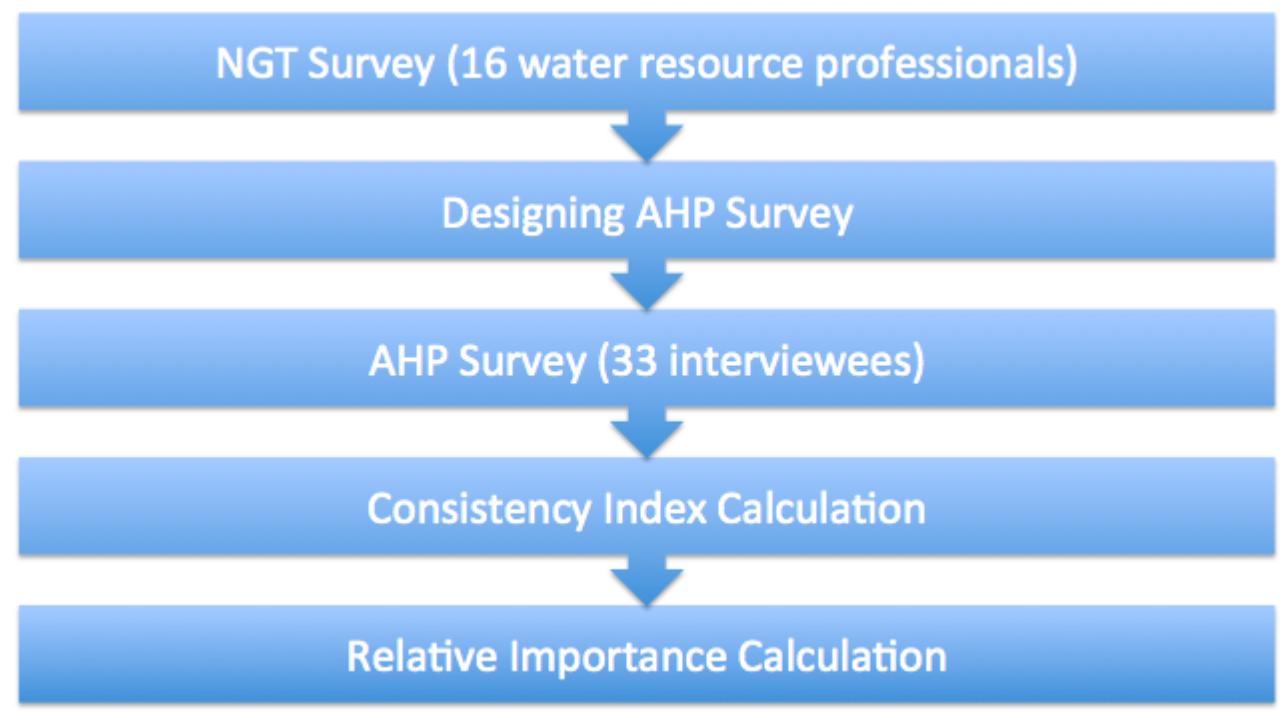

Figure 12. AHP process flowchart

NGT process was utilized in order to identify sets of values in the AHP. In this research, NGT survey participants were selected based on their experience and professional knowledge in the projects of An'Yang Stream restoration. 
According to a general NGT process modeled and originated by Totikidis (2010), this research designed the NGT survey process before the AHP was conducted. The first stage of the NGT survey was to generate and record ideas as well as to introduce the significance of this work through email interviews or Skype phone calls. Second, the corresponding email was sent to ask them to discuss and clarify their ideas about the An'Yang Stream restoration. The third stage was to ask them to vote and rate the values (ideas). The interviewees rated their top three responses to the An'Yang Stream Restoration Project. The last stage was to calculate and sum the ratings.

Before the field trip to Korea, the nominal group technique (NGT) was conducted with water resource professionals who worked for and participated in the An'Yang Stream restoration project. Sixteen NGT interviewees of An'Yang Stream restoration, who requested anonymity, were asked to rank their top three important values. These NGT interviews included 16 well-reputed respondents from various prestigious water resource management organizations, which were composed of water professionals, public administrators, NGO representatives and engineering contractors (private engineering companies). Their names were collected and found in the advisory committee directory of the Korean Water Resources Corporation (K-water). These NGT interviewees were not the same as the respondents for AHP and semi-structured interviews.

In order to calculate the total score of their priorities in comparing values, the first place was scored as 3 points, the second place was scored 2 points, and the third place was scored as 1 point. After calculating the results of NGT analysis, the survey format and items for AHP could be confirmed. As the respondents of the NGT analysis 
requested, a close-ended survey was conducted for approximately 30 minutes; it was designed so that they did not know others who participated in the NGT analysis survey. The results are described in Table 12 below and Appendix 3.

After reviewing and reflecting on the results, the AHP survey was consequently designed to reflect the priority among the values of Ecological Restoration (ER), Social Restoration (SR), and Landscape Revitalization (Flood Prevention + Spatial Regeneration) (LR). Each interviewee who was chosen for AHP gave his or her preferences among those three values (criteria).

Table 12. The survey results of NGT: priorities among diverse values

\begin{tabular}{ccc}
\hline $\begin{array}{c}\text { Value in Stream } \\
\text { Restoration }\end{array}$ & Priority rank & $\begin{array}{c}\text { Summed score of priority } \\
\text { value }\end{array}$ \\
\hline Ecological Restoration & 1 & 31 \\
\hline Social Restoration & 2 & 10 \\
\hline Flood prevention & 3 & 9 \\
\hline Spatial regeneration & 3 & 9 \\
\hline
\end{tabular}

\subsection{AHP RESULTS}

After the semi-structured interviews (33 participants), this researcher asked the interviewees to complete one additional AHP survey. The pairwise comparisons were calculated by pairing (1)ER and SR, (2)ER and LR, and (3)SR and LR. These comparisons indicated relative significance between the criteria (values). The AHP relative significance tests between two criteria helped to calculate relative significance among the three criteria. In order to maintain reliability, the AHP results were calculated under the condition of CI $<0.1$ (Table 13). With the results illustrated in Table 13, this research could discuss and conclude that one criterion is relatively more 
important, pairwise, compared to the other two criteria. In addition, the calculations revealed that specific stakeholder groups demonstrated preferences in agenda setting for stream restoration.

Table 13. The relative importance test results of AHP with stakeholders' value

\begin{tabular}{|c|c|c|c|c|c|c|c|c|c|}
\hline \multirow[t]{3}{*}{ Group } & \multirow{3}{*}{$\begin{array}{l}\text { Num } \\
\text { ber of } \\
\text { data }\end{array}$} & \multirow{3}{*}{$\begin{array}{l}\text { Numb } \\
\text { er of } \\
\text { availa } \\
\text { ble } \\
\text { data }\end{array}$} & \multicolumn{7}{|c|}{ Weighted values } \\
\hline & & & \multicolumn{2}{|c|}{$\begin{array}{l}\text { Ecological } \\
\text { restoration } \\
\quad(\mathrm{ER})\end{array}$} & \multicolumn{2}{|c|}{$\begin{array}{l}\text { Social } \\
\text { restoration } \\
(\mathrm{SR})\end{array}$} & \multicolumn{2}{|c|}{$\begin{array}{l}\text { Landscaping } \\
\text { revitalization } \\
\text { (LR) }\end{array}$} & \multirow[t]{2}{*}{$\begin{array}{l}\text { Avera } \\
\text { ge CV }\end{array}$} \\
\hline & & & $\begin{array}{l}\text { Weight } \\
\text { ed } \\
\text { value }\end{array}$ & $\mathrm{CV}$ & $\begin{array}{l}\text { Weight } \\
\text { ed } \\
\text { value }\end{array}$ & $\mathrm{CV}$ & $\begin{array}{l}\text { Weight } \\
\text { ed } \\
\text { value }\end{array}$ & $\mathrm{CV}$ & \\
\hline NGO & 6 & 6 & 0.577 & $\begin{array}{c}0.26 \\
5\end{array}$ & 0.309 & $\begin{array}{c}0.36 \\
3\end{array}$ & 0.112 & $\begin{array}{c}0.66 \\
4\end{array}$ & 0.430 \\
\hline $\begin{array}{l}\text { Public } \\
\text { Admin } \\
- \\
\text { istrator } \\
\quad \mathrm{s}\end{array}$ & 9 & 9 & 0.488 & $\begin{array}{c}0.40 \\
4\end{array}$ & 0.322 & $\begin{array}{c}0.42 \\
9\end{array}$ & 0.189 & $\begin{array}{c}0.59 \\
2\end{array}$ & 0.475 \\
\hline $\begin{array}{l}\text { Water } \\
\text { Profess } \\
\text {-ionals }\end{array}$ & 6 & 6 & 0.577 & $\begin{array}{c}0.31 \\
5\end{array}$ & 0.232 & $\begin{array}{c}0.99 \\
8\end{array}$ & 0.189 & $\begin{array}{c}0.37 \\
8\end{array}$ & 0.564 \\
\hline $\begin{array}{c}\text { Citizen } \\
\text { s } \\
\text { (partici } \\
\text { p-ants) }\end{array}$ & 7 & 6 & 0.499 & $\begin{array}{c}0.42 \\
1\end{array}$ & 0.172 & $\begin{array}{c}0.88 \\
1\end{array}$ & 0.327 & $\begin{array}{c}0.59 \\
1\end{array}$ & 0.631 \\
\hline $\begin{array}{c}\text { Engine } \\
\text { ers }\end{array}$ & 5 & 4 & 0.298 & $\begin{array}{c}0.70 \\
0 \\
\end{array}$ & 0.120 & $\begin{array}{c}1.01 \\
1 \\
\end{array}$ & 0.580 & $\begin{array}{c}0.56 \\
6 \\
\end{array}$ & 0.759 \\
\hline $\begin{array}{c}\text { Averag } \\
\mathrm{e}\end{array}$ & 6.6 & 6.2 & 0.487 & $\begin{array}{c}0.42 \\
1\end{array}$ & 0.231 & $\begin{array}{c}0.73 \\
6\end{array}$ & 0.279 & $\begin{array}{c}0.55 \\
8\end{array}$ & 0.571 \\
\hline
\end{tabular}

*CV: Coefficient of Variation

As shown in Table 13, the relative weighted values (measuring pairwise relative importance) in the five groups of professional and citizen participants within the An’Yang Stream Restoration decision-making network varied in priorities for stream restoration. In particular, most respondents valued ecological restoration as the most 
important factor $(0.487(48.7 \%))$. The interest in SR and LR measured lower than ER, reflecting the same results as the content analysis discussed earlier. The weighted value of SR and LR is $0.231(23.1 \%)$ and $0.279(27.9 \%)$, respectively. The value of Landscaping Revitalization was the third value (ranked as the second) examined in this AHP analysis. The results showed that the respondents in the survey were more concerned about ecological restoration (ER), based on scientific management in watershed restoration, than they were about SR and LR. Further, the value of SR was regarded as the least important factor in stream restoration.

Figure 12 provides information about primary preferences among ER, SR, and LR. Water professionals, such as civil engineers and environmental scientists, held the highest priority on ER (58 \%; 0.577799) compared to other values. The NGOs (58\%; 0.577699), public administrators (49\%), and citizens (50\%) also considered ER as the most important agenda. On the other hand, engineers who worked at private engineering enterprises and participated in the construction project had different views, with low values for ecological restoration in stream restoration $(0.298(29.8 \%))$. They valued the landscaping revitalization as the primary value $(0.581(58 \%))$. Citizens ranked landscaping revitalization higher than any other group - 32.8\%. Also, SR was ranked by three stakeholder groups — NGOs, water professionals, and public administrators as the second critical value, whereas it was ranked as the least important by the citizens and private engineers. Across the board, all groups except private contractors (engineers), place a high value on ecological restoration using innovative engineering technologies. 

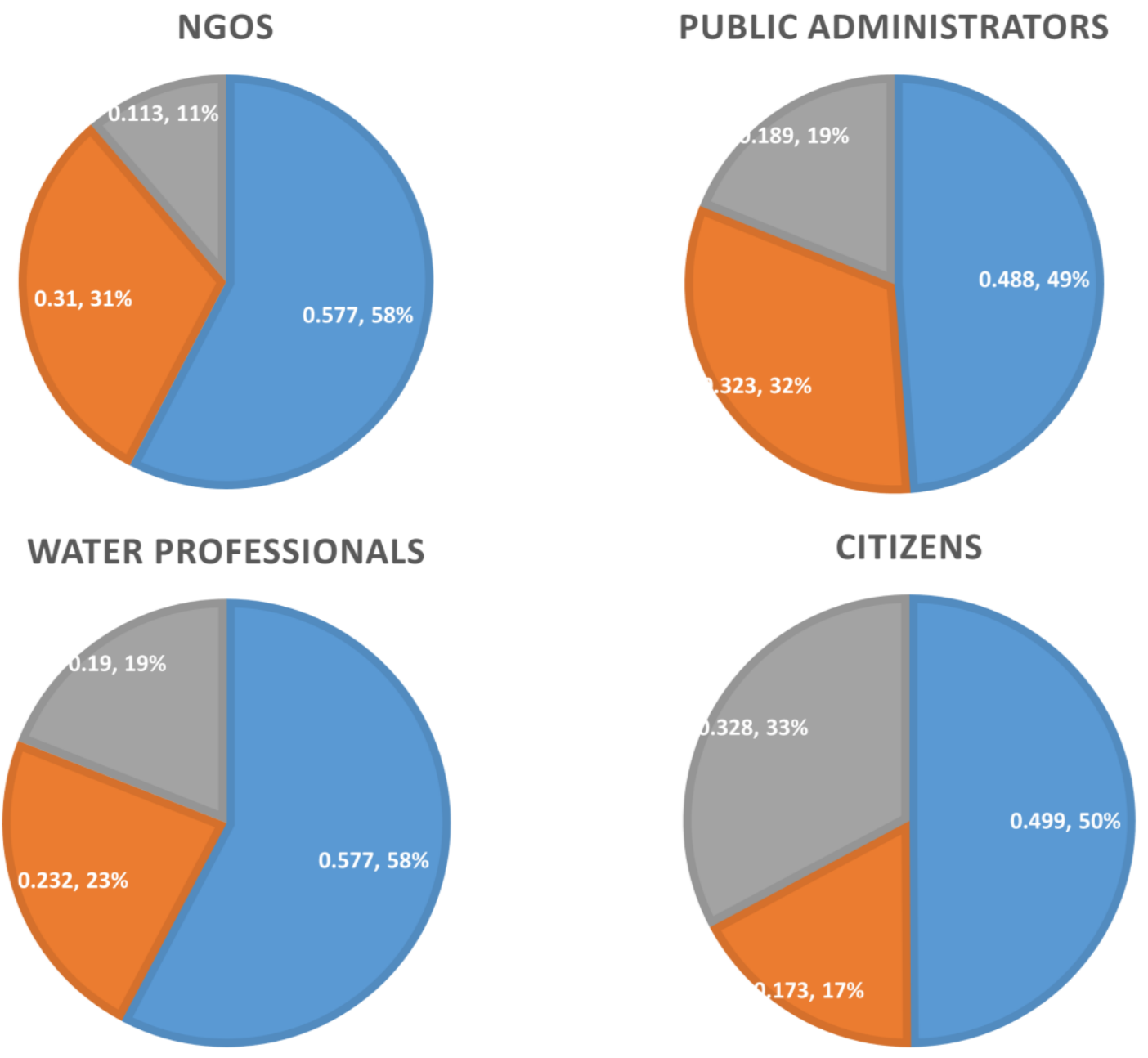

\section{ENGINEERS OF PRIVATE CORPORATIONS}

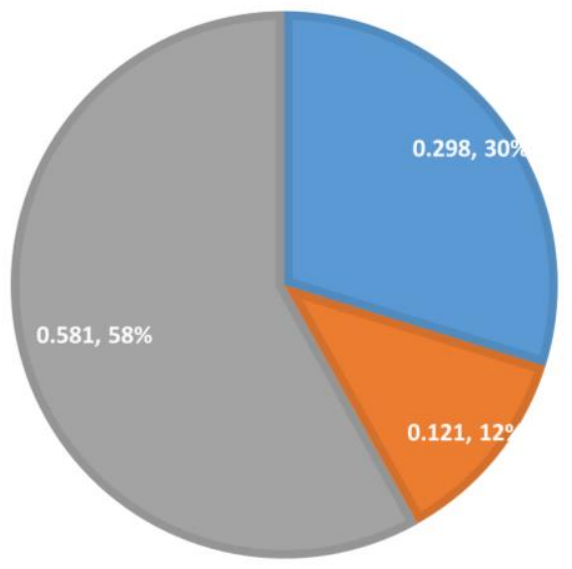

- Ecological Restoration

- Social Restoration

- Landscaping Revitalization

Figure 13. Distribution diagrams of the stakeholders' preferences in agenda setting of stream restoration 
As shown in Table 13, the results indicated different levels of the coefficient of variation $(\mathrm{CV})$ of ER (0.421), SR (0.736), and LR (0.558), similar to the preceding results in the content analysis. $\mathrm{CV}$ was defined as the ratio of the standard deviation to the mean, allowed comparison of the degree of variation from each data set of the stakeholders to one another. When the overall results of the AHP analysis are examined, the groups of non-governmental organizations (NGO) representatives and water resource professionals maintained intensely consistent attention to ecological restoration, including water quality enhancement in stream restoration (Table 13 and Figure 13). Including the group of engineers in the private sector (0.759), most CVs of the stakeholder groups indicated various levels. Moreover, CVs show how consistently the respondents of each group recognize the specific values on the An'Yang Stream restoration. The group of NGOs was prone to be more consistent as held the lowest level of CV (0.43) because the NGOs aimed at one focused value about the stream restoration. On the other hand, the citizen groups $(0.63)$ and private engineers $(0.75)$ were less consistent, compared to other stakeholder groups.

This AHP results illustrated that ecological restoration (49\%) held the highest value in decision-making as well as the agenda-setting process of stream restoration Especially, both water resource professionals (engineers and scientists) and NGO representatives valued most the agenda of ecological restoration in both decisionmaking and goal-setting. The following section will discuss the quantitative research result to answer the questions: to what extent and how the values were prioritized by the An'Yang Stream restoration stakeholders. 


\subsection{DISCUSSIONS}

The results provided information about the comparatively weighted values of ER, SR, and LR among stakeholders. When examining the data from the 2015 survey overall, most stakeholders were still likely to pay consistent attention to the value of ecological restoration in stream restoration. At this point, this research had one question: "Why do the stakeholders of the An'Yang Stream restoration still consider ER to be the most important value, after it has already accomplished greatly improved ecological revitalization compared to water quality in the 1990s?" According to the results in Table 13 above, we could imagine the future direction suggested by the participants would allow the decision-makers and policy-makers to pay more attention to ER, like the results from the early stages of restoration. Regarding ER, the gap between the average and the calculated values from the answer sets of the individual respondents choosing that value was smaller than for respondents' rating of other values. As shown in Table 13, the respondents' constant and wholehearted priority for ecological restoration (ER) could be examined and explained by these strong numerical data.

This quantitative analysis method, AHP, provided insights by which to this researcher examined the relative weighted importance between the values (criteria) by pairwise comparisons in one conflicting issue. First, this work could analyze the quantitatively calculated relative priorities among the three values (criteria). Second, this work found which stakeholder group valued most ecological restoration compared to others. Third, the CVs of the AHP results indicated how consistent the value of ecological restoration in stream restoration among stakeholders was. 
Similar to the findings in the previous chapters, SR was recorded as the lowest score because most stakeholder groups underestimated the value of the SR in the An'Yang Stream restoration project. The NGO members $(0.310$ (31.0\%) and public administrators $(0.323(32.3 \%)$ were prone to value SR more than other participant groups (Figures 13). At this point, even public administrators who were engineers had to take social factors into consideration, which would lead them to investigate and research the An'Yang Stream project. Also, the public administrators and the NGOs do not play a role of facilitators or mediators in those conflicts, which mitigate confrontation of opinions. As a result, both the representatives of NGOs and public administrators marked a higher level for the weighted value of SR. Also, engineers who value scientific methods in stream restoration did not give high marks in examining SR $(0.121(12.1 \%))$.

Figure 13 also provides information about the coefficient of variation (CV) of the weighted values among the stakeholder groups, in terms of the social restoration category. This figure showed that the levels of $\mathrm{CV}$ of the groups of NGO representatives (0.363) and public administrators (0.429) were lower than others. Social restoration was not a primary value for the stakeholders in the An'Yang Stream restoration governance. Some representatives of NGO groups valued social factors, such as educational, cultural, and historic approaches in the master plan, and they prioritized the value of social restoration of An'Yang Stream. Except for the groups of NGOs and public administrators, the CVs of other participant groups on SR showed very high levels. This implied that the participants' values survey provided a good example of a trend to value less invisible social factors in stream restoration in South 
Korean society. For the CV levels of representatives of engineers (1.011) and water resource professionals, including hydrologists (0.998), the gap between the average level and the calculated values from the answer sets of the individual respondents was much larger than those of the respondents' choosing other values. In other words, the fact that the technocratic participants, such as engineers and water professionals, did not intensely disagree on the interests and values of social restoration, such as socio-cultural recuperation and educational program development, was shown in the digitized CV numbers through pairwise comparison of the values. In addition, the CV level of citizens $(0.881)$ was also quite high because individual citizen respondents held a wide range of answers about the social restoration of An'Yang Stream, compared to other stakeholder groups.

For the value of ER, the gap between the average level and the calculated values from the answer sets was smaller than in the respondents' who chose other values. In other words, the participants' constant and wholehearted interests and value of ER (scientific restoration of ecological recuperation and water quality control) have been examined and explained by this numerical data, based on a quantitative analysis performed by evaluating and measuring their priorities and comparing the values. For the CV value of SR (0.736), the gap between the average level and the calculated values from the answer sets was notably larger than for the respondents who chose other values. In other words, they had different interests and priorities in the stream restoration work. This explained how the participants place little value on social restoration such as social integrity, cultural revitalization, and building of sustainable governance, as has been explained by these numerical results. 

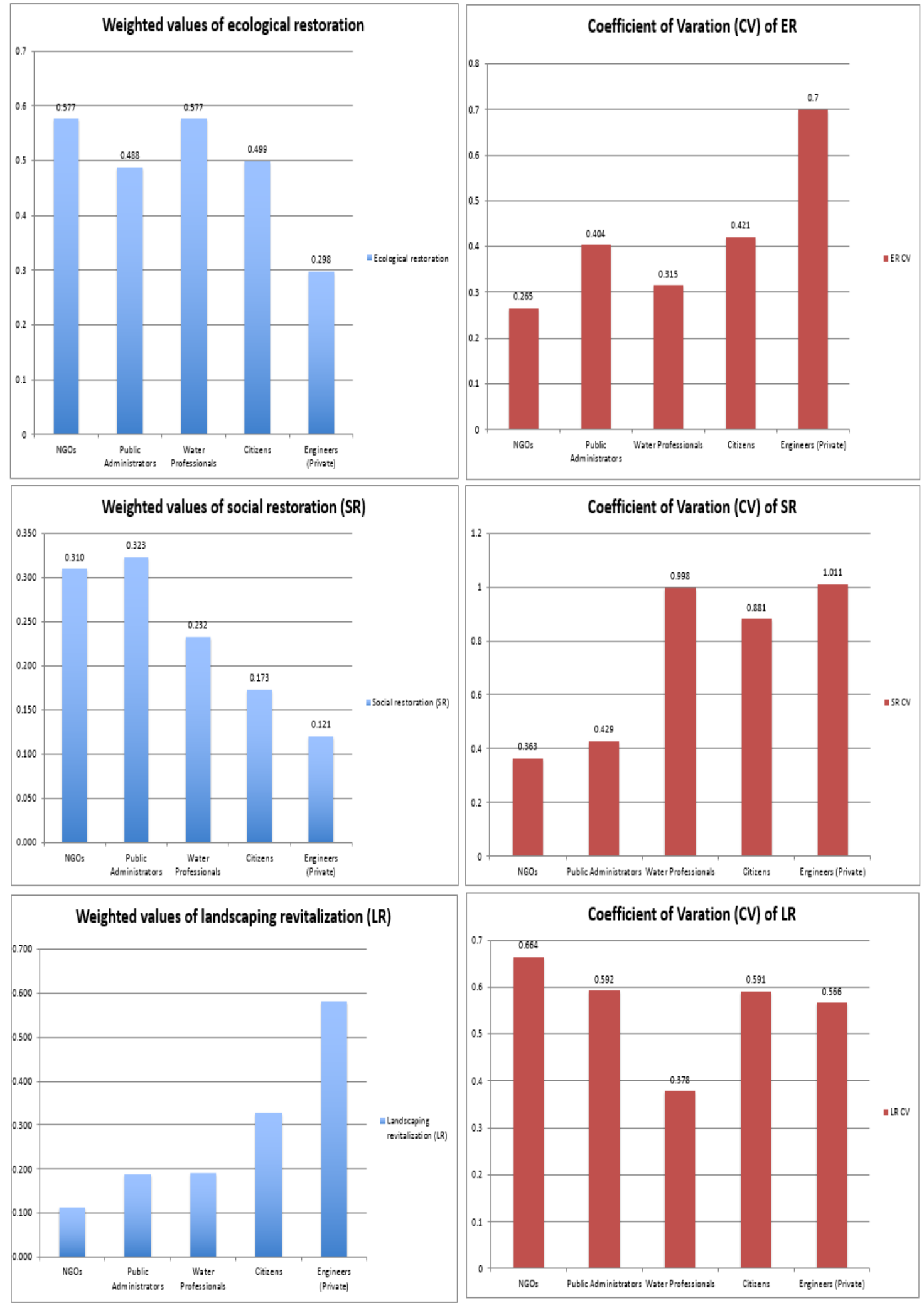

Figure 14. Weighted value of relative importance and CVs of the criteria on An'Yang Stream Restoration 
The results also provided information about the $\mathrm{CV}$ of the weighted values among the participant groups. An overall look at the results table showed that the groups of NGO representatives and water resource professionals are prone to give intensely high and consistent value on ecological restoration, including water quality enhancement in stream restoration (Table 13 and Figure 14). Except for the group of engineers in the private sector (0.700), most CVs of ER were indicated as low level. The participants' values survey indicated the stream restoration authority should pay attention to working on scientific ecological restoration, similar to the results of the content analysis of the master plan document. For the values prioritized by representatives of NGOs, the gap between the average level and the calculated values from the answer sets was smaller than in the respondents who chose other values. In other words, our APH analysis results on evaluating and measuring priorities and comparing values show that the NGO members intensely support the interests and values of scientific restoration for ecological recuperation and water quality control. For the values prioritized by engineers of private engineering corporations, the gap between the average level and the calculated values from the answer sets was much larger than in the respondents who chose other values, because they sought profit from the stream restoration as found in Chapter 5. In other words, the fact that they are profit-driven might change their values, depending on each strategy designed for the stream restoration goals.

According to the interviews with citizens, the citizens believed once they have a well-organized civic space and green space in the watershed, diverse benefits from An'Yang Stream can be realized, such as outdoor appreciation and economic synergy. Meanwhile, according to Figure 14, representatives of NGOs (0.113 (11.3\%)), public 
administrators $(0.189(18.9 \%))$, and water resource professionals $(0.190(19 \%))$ did not award high priorities to LR. The NGOs did not want to have economic developmentoriented stream restoration through landscaping beautification, but rather through natural stream restoration for both humans and nature.

The result set showed the coefficient of variation $(\mathrm{CV})$ of the weighted value of each of the participant groups within the landscaping revitalization (LR). According to the results table, water professionals $(0.378)$ had a very narrow variance in opposing civic gardens and waterfront beautification projects. In other words, more respondents of the water professional group were prone to maintain consistent attention to the values of ER and SR, rather than LR in stream restoration (Table 13). Interestingly, the participants from NGOs showed very wide variance, even though they had the lowest level of the weighted value $(11.3 \%)$. This indicated that members of the NGOs could have diverse interests in evaluating their values in stream restoration. Some NGOs, who were working for local citizens, couldn't help addressing the high priorities on LR of the people for whom they advocated. Except for the group of water resource professionals (0.378), most CVs of the participant groups on LR indicated a high level of variance. This implies that the scope of the participants' values might be very dispersed and diverse in considering and adopting the concept of landscaping and spatial renovation in the An'Yang Watershed.

Summing up, this study analyzed the results collected from surveys with participants of the An'Yang Stream decision-making. The results indicated that stakeholders with different values and from diverse backgrounds variously held the weighted values of ecological restoration (ER), social restoration (SR), and landscaping 
and spatial restoration (LR). In particular, most respondents rated ecological restoration, which was composed of ecological revitalization and water quality, as the most important factor. The interests in SR and LR were valued less than ER, similarly to the survey results of content analysis shown previously. The results showed that the respondents in this survey were concerned about LR.

Thus, this researcher could conclude that the responses of AHP survey participants were coherent in reflecting and valuing the three criteria in this An'Yang Stream project as similar results occurred from document review and a semi-structured interview.

\subsection{CHANGES OF CITIZENS’ VALUES, 2005 - 2015}

Among the AHP survey, this researcher wanted to see whether citizens' views on the An'Yang stream restoration have changed. Chung and Lee (2007) researched citizens' views and preferences in the stream restoration project in 2005 , which could be compared the results with new citizen survey results conducted in 2015. As Esaiasson et al. (2016) state, the groups of citizens may be the best one to evaluate responsive actions and preference fulfillment on policy decision in local debates. This work discusses changes of citizens' preference across time. In addition, this temporal comparison can help us meaningfully understand to what extent the decision-making of this stream restoration project was comprehensive and participatory.

Using AHP could help us clearly evaluate citizens' values regarding the An'Yang Stream restoration. First, interests of the citizens who live near the An'Yang Stream were analyzed because they were tax-payers and immediate users of the resources of the stream. This research showed the primary values of the stakeholders who participated in 
the decision-making process at the early stage of the stream restoration of An'Yang Stream.

In both chapters 4 and 5, this research found that citizens participating in An'Yang Restoration Project were most motivated by water pollution, so that this group preferred technological solutions for addressing technical water issues. These reasons were able to explain through the previously conducted and published works (Chung and Lee, 2007; Hong and Chung, 2016).

The awareness of stakeholders about the An'Yang Stream showed that landscaping revitalization values, including the flood prevention and beautification management, were more important due to flood risk and an increase of leisure activities in 2015, compared with the data gathered by the citizen survey in 2005. In terms of the citizens' preference survey of 2005, streamflow control was considered less important than the other preferences such as the water quality issue. For citizens, streamflow management was not considered a primary preference because it was difficult for citizens to recognize droughts or wet seasons. Again, water quality and ecological revitalization were considered more crucial for the stakeholders of the An'Yang Stream restoration governance.

Citizen groups were prone to be very sensitive to the water quality enhancement because they use the riverfront space every day. According to previous researchers, the water quality as a factor of ecological restoration interests was rated as the most important value among the three major values in the stream restoration by the citizen surveys conducted in 2005 (Chung and Lee, 2007) and 2015 (Hong and Chung, 2016). The results were 50.6\% in 2005 and $51.8 \%$ in 2015 . This researcher could interpret this 
finding from two perspectives: 1) public sharing with citizens concerning the importance of water quality enhancement in the An'Yang Stream worked well and established a cooperative bond with the An'Yang Stream restoration governance; and 2) stream restoration efforts failed to result in the citizens considering and supporting other values after achieving successful water quality improvement, due to the lack of participatory citizen involvement in a constructive fashion which can inform citizens of the importance of other values. The various governance activities and processes of the An'Yang Stream led to improved water quality based on collaboration, but it relied too much on the use of innovative scientific and engineering technologies. This excessive reliance might have hindered communication about the values and interests of the citizens of the An'Yang Stream. Scientific indicators of the water quality level were the most tangible, but not the most inclusive, a method to evaluate the success of stream restoration. In other words, the citizens still wanted better water quality, although the water quality level has been recorded as optimal by survey respondents. Thus, it was very important to recognize the citizens' preferences to plan strategies and to establish agendas for the An'Yang Stream restoration.

There were no significant statistical differences in weighted values between water quality and the other preferences when comparing the AHP results of 2015 with those of 2005. Some citizen's concerns on stream flow management vary considerably in each season or time. In other words, they did not feel the threat of floods or droughts when the season was mild, and no risk was apparent because they did not have appropriate outreach education activities about the impact of other influential factors as well as stream flow changes into the stream. The roles of participants and planners from 
the An'Yang Stream restoration governance should have included educating the citizens about diverse ways to consider and embrace new values in agenda-setting for sustainable stream restoration. In the case of the An'Yang Stream, citizens tended to adopt opinions published by the government or by prestigious organizations because they did not have sufficient experience or knowledge to understand the complex scientific studies and indicators.

Similarly, the AHP results from research about preferences of stakeholders including citizen groups conducted in this dissertation research also showed that most An'Yang Stream regions have a similar pattern of increased preference for water quality improvement and a decreased preference for other interests. In addition, this research could assume that most regions in the An'Yang Stream basin have been experiencing an enormous impact from regional redevelopment since the 2000s, which needed to provide more affordable housing for the increased population as found in the script of interviews with the citizens and private engineers. These social and spatial changes still continued to influence the stream restoration goal setting by the scientific evaluation parameters of water quality despite the successful technocratic water quality improvement activities of the An'Yang Stream restoration governance.

Hence, these significant findings on the An'Yang Stream regions recommend the redrafting of current policies and regulations on stream restoration and urban planning by participatory process-oriented decision-making which can earnestly pay attention to non-scientific values about the An'Yang Stream restoration.

Within the stream restoration process, the private consulting engineers (contractors) usually valued LR because they participated in the engineering consulting 
construction of An'Yang Stream in order to make an economic profit, such as from regional redevelopment or spatial renovation projects of the waterfront facilities like sustainable land-use planning and stream-flow control by dredging sediment. Most construction projects made the engineering companies produce profits from these projects in the watershed regions along An'Yang Stream. The engineers believed in the technocratic power of stream restoration. Also, they believed that successful stream restoration could be evaluated as a place physically and spatially shaped by innovative spatial engineering technologies such as ecological corridor solution and stone-net engineering technique (City of An'Yang, 2001; Choo, 2013; Hong and Chung, 2016). The sub-watersheds of An'Yang Stream had two major construction projects: a waterfront area renovation and a natural stream restoration project that were completed around 2010. Through these major works, the regions near An'Yang Stream could see a benefit in the form of a rise in real property value (Lee, 2014).

This study tested whether the stream restoration authorities and professional experts within the decision-making processes of the governance have given preference to ecological restoration. In other words, the stream restoration strategies were determined, influenced, and reflected by their strong ecological values about the An'Yang Stream restoration.

The policies and programs implemented by the An'Yang Stream restoration stakeholders were prone to drive the restoration strategies only toward ecological restoration, including ecological luxuriance and water quality improvement, as the primary value. In addition, the policies and programs of stream restoration were formed based on top-down decision-making processes because the decision-making aimed to 
achieve an efficient restoration based on quantifiable figures and scientific indicators in measuring water quality and ecological diversity in the short term. Hence, this research found that the stakeholders' individual values on the An'Yang Stream were seriously indicated as one pattern of the trend such as the collective push for ER. Also, these findings provided a solid foundation for policy-making and governance development in the future of stream restoration in the An'Yang Watershed.

\subsection{SUMMARY}

In this chapter, AHP guided us to further evaluate stakeholders' values about the An'Yang Stream restoration. The An'Yang Stream restoration decision-making included various collaborative stakeholder partnerships consisting of governmental groups, private groups, and private citizens, which value ER. Water quality as one indicator of ecological restoration measurement of the An'Yang Stream has improved since 2000 because of the collaborative partnership efforts. This work might guardedly conclude that most respondents rated ecological restoration as the most important factor due to the policies and public campaign about water quality improvement as well as serious water pollution since the late 1990s. In addition, this research discussed the changes and implications of the citizens' interests on An'Yang Stream between 2005 and 2015. The citizens' preferences appeared to have changed very little. 


\section{Chapter 7}

\section{Evaluating and Comparing Values of Stakeholders}

The earlier chapters helped explain the results this research found - that despite the identified social values, even the citizens prioritized the ecological restoration of the An'Yang Stream. This chapter includes Grounded Theory analysis which describes an overall cause and effect storyline, as well as a brief discussion of findings and the implication of the content analysis after interviews, and AHP analysis of the preference survey in order to understand and recognize how the different values and goals of citizens and other stakeholders influenced and shaped the restoration process within the An’Yang Stream Restoration governance. This analysis uses the axial coding process established by Strauss and Corbin (1998).

“This Grounded Theory is inductively derived from discovering and developing the phenomenon it represents." (Strauss and Corbin, 1998) Based on the results of the previous analyses, each finding is considered and integrated into a conceptual map of Grounded Theory. In particular, one of the major coding methods of the Grounded Theory, axial coding puts the data together in new ways by making connections between a category and its keywords (Strauss and Corbin, 1998).

\subsection{AXIAL CODING PROCESS}

In order to systematically compare the strengths and weaknesses of the An'Yang Stream restoration decision-making up to the present, the axial coding process of Grounded Theory was used. Again, this research aimed to ascertain the primary value 
within the An'Yang Stream restoration decision-making and determine the critical success factors of water quality enhancement. In previous chapters, key concepts of the stakeholders' values within the An'Yang Stream restoration were reviewed and categorized through open coding. Also, these key concepts of values could be categorized into 'core categories' (ER, SR, and LR) that were used in AHP analysis (Chapter 6). The axial coding process was conducted in order to define each core category. First, the core categories are defined and scoped, then this research addresses the causal condition, the contextual condition, the intervening condition and strategy, and the consequence category based on the core categories.

\subsubsection{Main three values of stakeholders (Core category)}

"Axial coding: a set of procedures whereby data are put back together in new ways after open coding, by making connections between categories." (Strauss and Corbin, 1990)

This section aims to address the research questions using Grounded Theory. After reviewing content review analysis of interview scripts and the public documents published by the government, core categories (main values such as ER, SR, and LR) and each keyword of the An'Yang Stream restoration were set and defined (Table 14). For each category, multiple keywords which were most frequently tagged in the interview scripts were analyzed in the coding process. 
Table 14. Core categories (main values of stakeholders)

\begin{tabular}{|c|c|c|c|}
\hline Core Category & Keyword & Definition & Content from Interviews \\
\hline \multirow[t]{3}{*}{$\begin{array}{l}\text { Ecological } \\
\text { restoration }\end{array}$} & $\begin{array}{l}\text { Improvement of } \\
\text { ecosystem and } \\
\text { increase in } \\
\text { resilience }\end{array}$ & $\begin{array}{l}\text { Ecological } \\
\text { resilience } \\
\text { improvement } \\
\text { and species } \\
\text { diversity } \\
\text { increase }\end{array}$ & $\begin{array}{c}\text { "An'Yang Stream } \\
\text { restoration should get fry, } \\
\text { water snails, snakes, } \\
\text { crawfishes, king crabs back } \\
\text { to the stream and BOD and } \\
\text { DO level control, } \\
\text { and provide strategies for } \\
\text { protection and restoration of } \\
\text { native species, } \\
\text { endangered species, and } \\
\text { ecosystem health recovery } \\
\text { through the restored } \\
\text { protection." }\end{array}$ \\
\hline & $\begin{array}{l}\text { Water quality } \\
\text { enhancement }\end{array}$ & $\begin{array}{l}\text { Pollutants } \\
\text { removing and } \\
\text { purifying }\end{array}$ & $\begin{array}{l}\text { "The stream restoration } \\
\text { project has to provide a } \\
\text { stable supply of clean water } \\
\text { and solutions to increase } \\
\text { sewage treatment capacity - } \\
2009 \text { sewer penetration } \\
\text { objective criterion An'Yang } \\
\text { is } 100 \% \text {. Since the } 2003 \\
\text { sewer penetration was } \\
\text { continued, locations can } \\
\text { successfully achieve the } \\
\text { target of } 100 \% \text { in } 2009 . "\end{array}$ \\
\hline & $\begin{array}{l}\text { Innovative } \\
\text { engineering } \\
\text { system }\end{array}$ & $\begin{array}{l}\text { Real-time } \\
\text { hydraulic } \\
\text { monitoring } \\
\text { system }\end{array}$ & $\begin{array}{l}\text { "Through eco-friendly } \\
\text { maintenance, primer } \\
\text { formulations, and the } \\
\text { introduction of state-of-the- } \\
\text { art techniques can enable a } \\
\text { return to optimal conditions } \\
\text { of water quality and wetland } \\
\text { area." }\end{array}$ \\
\hline $\begin{array}{c}\text { Social } \\
\text { restoration }\end{array}$ & Social integrity & $\begin{array}{l}\text { Sustainable } \\
\text { leadership, } \\
\text { utilizing the } \\
\text { stream } \\
\text { restoration with } \\
\text { a sustainable } \\
\text { governance } \\
\text { building }\end{array}$ & $\begin{array}{l}\text { "To maximize citizen } \\
\text { participation and } \\
\text { cooperation, to constitute an } \\
\text { An'Yang Stream basin } \\
\text { environmental } \\
\text { administration council, we } \\
\text { must be able to pursue social } \\
\text { integration." }\end{array}$ \\
\hline
\end{tabular}




\begin{tabular}{|c|c|c|c|}
\hline & $\begin{array}{c}\text { Social } \\
\text { revitalization }\end{array}$ & $\begin{array}{l}\text { Cultural, } \\
\text { educational, } \\
\text { historical, and } \\
\text { social } \\
\text { revitalization of } \\
\text { the community }\end{array}$ & $\begin{array}{l}\text { "An'Yang Stream will need } \\
\text { to be restored to develop in } \\
\text { the near civil favorite } \\
\text { historical, cultural, and } \\
\text { hydrophilic space." }\end{array}$ \\
\hline \multirow[t]{3}{*}{$\begin{array}{c}\text { Spatial } \\
\text { renovation } \\
\text { (Landscape } \\
\text { revitalization) }\end{array}$} & $\begin{array}{l}\text { Flood } \\
\text { prevention and } \\
\text { stream flow } \\
\text { management }\end{array}$ & $\begin{array}{l}\text { Wastewater } \\
\text { control facility }\end{array}$ & $\begin{array}{c}\text { "Natural stream restoration } \\
\text { should be aimed for to } \\
\text { prevent floods and } \\
\text { droughts." }\end{array}$ \\
\hline & $\begin{array}{l}\text { Economic } \\
\text { development } \\
\text { and property } \\
\text { value increase }\end{array}$ & $\begin{array}{l}\text { Local economic } \\
\text { vitalization } \\
\text { through } \\
\text { environmental } \\
\text { improvement } \\
\text { near the } \\
\text { waterfront areas }\end{array}$ & $\begin{array}{l}\text { "We want citizens to live in } \\
\text { the town, and set a target of } \\
\text { An'Yang Stream to restore a } \\
\text { livable city; also, we can } \\
\text { motivate and activate the } \\
\text { sluggish regional economy } \\
\text { and real estate market." }\end{array}$ \\
\hline & $\begin{array}{l}\text { Recreational } \\
\text { amenities }\end{array}$ & $\begin{array}{l}\text { Places for } \\
\text { leisure and civic } \\
\text { activities for the } \\
\text { community }\end{array}$ & $\begin{array}{l}\text { "Local culture must also be } \\
\text { activated to create a space in } \\
\text { which citizens enjoy a } \\
\text { nearby in the water front } \\
\text { space of the An'Yang } \\
\text { Stream." }\end{array}$ \\
\hline
\end{tabular}

7.1.2 Influential background (causal conditions)

"Causal conditions: Events, incidents, happenings that lead to the occurrence or development of a phenomenon." (Strauss and Corbin, 1990)

The causal conditions result in the phenomenon that influenced the core categories during policy-making processes such as stream restoration process (Strauss and Corbin, 1998; Chae, 2012). Also, the causal conditions determine the contextual phenomenon before forming the core categories, such as having a stream restoration task-force team led by the strong and efficient leadership of local political leaders who value ecological restoration, including the natural system's revitalization and water quality enhancement, and the various efforts hosted by cutting-edge engineering technological and scientific 
innovation. At the same time, the causal factors of large and small conflicts resulted from these factors (Chae, 2012).

In previous chapters, the value that was supported by most stakeholders was ecological restoration (such as water quality improvement and ecological conditions' enhancement) by technocratic operations. The respondents except for citizen groups in this survey mostly had backgrounds in environmental science or engineering technology. From their interview answers, it seemed that they trusted epistemological and positivistic evidence based on scientific exams and experiments. Thus, other values formed by social, cultural, educational, and historical interests seemed to be ignored and not a priority in the An'Yang Stream restoration.

Stakeholders' reliance on science and engineering-technology for ecological restoration, as can be seen in interviews and document review, was a priority over other values since many citizens near An'Yang Stream had been struggling to mitigate serious water contamination for a long time (Table 15). Hence, the citizens wanted to elect a leader who would improve their stream with firm leadership in environmental policy-making, as found in previous chapters. Based on the bond of sympathy from the citizens, the elected politicians fully supported and cooperated with water quality improvement projects, with full financial support. For instance, as the mayor of the City of An'Yang, Mr. Jongdae Shin's leadership contributed to building successful, efficient, and sustainable stream restoration strategies. Mr. Shin invited many experts who had been studying stream restoration and hydrological engineering for a long time into the governance network. Thus, the primary interests and values of the local residents and citizens were consistent with the stream ecologists and engineers. 
The politics in the local area of An'Yang Stream have influenced the decisionmaking processes within the An'Yang Stream governance. The local politicians (city mayor and congressmen, etc.) paid attention to the local stream management because the citizens who wanted a clean and organized river in their region would fully support a candidate who made that a priority. The elected politicians were prone to increase the budget for An'Yang Stream restoration. These politicians were also prone to opt for a conspicuous short term improvement in anticipation of elections every four years.

The An'Yang Stream restoration decision-making board was composed of various stakeholders and professional groups. Through weekly gatherings and monthly professional workshops, this group later formed a large and strong foundation in building multilateral partnership systems for finding good solutions for water quality improvement. However, within these decision-making processes, many conflicts among the stakeholders could not be avoided. These conflicts came from political issues, different levels of access to and understanding of the professional scientific engineering information on stream restoration, and diverse individual interests.

Table 15. Causal conditions (influential background)

\begin{tabular}{|c|c|c|c|}
\hline $\begin{array}{c}\text { Causal } \\
\text { condition }\end{array}$ & Keyword & Definitions & Content from Interviews \\
\hline $\begin{array}{c}\text { Engineering } \\
\text { technology } \\
\text { oriented SR }\end{array}$ & $\begin{array}{l}\text { Establishing a } \\
\text { systematic and } \\
\text { advanced hydro } \\
\text { data system for } \\
\text { An'Yang } \\
\text { Stream } \\
\text { management }\end{array}$ & $\begin{array}{l}\text { Construction of } \\
\text { additional } \\
\text { An’Yang Stream } \\
\text { sewage treatment } \\
\text { plants and } \\
\text { additional } \\
\text { network } \\
\text { mapping of the } \\
\text { drainage and } \\
\text { stream flow }\end{array}$ & $\begin{array}{c}\text { 'Both upstream and } \\
\text { downstream in An'Yang } \\
\text { Stream were struggling due } \\
\text { to urbanization and } \\
\text { industrialization, which } \\
\text { directly caused the pollution, } \\
\text { and the pollution was } \\
\text { becoming more serious as it } \\
\text { goes downstream. } \\
\text { Thus, the An'Yang Stream } \\
\text { Governance leaders planned } \\
\text { to build additional sewage }\end{array}$ \\
\hline
\end{tabular}




\begin{tabular}{|c|c|c|c|}
\hline & & & $\begin{array}{l}\text { treatment plants that could } \\
\text { treat such a problem. In } \\
\text { addition, groundwater } \\
\text { recharge technology and } \\
\text { rainwater storage and } \\
\text { management systems have } \\
\text { been developed, and located } \\
\text { in the stage of application." }\end{array}$ \\
\hline \multirow[t]{2}{*}{ Leadership } & $\begin{array}{c}\text { Willingness and } \\
\text { policy strategy } \\
\text { of politicians }\end{array}$ & $\begin{array}{c}\text { Participation and } \\
\text { efforts of } \\
\text { politicians }\end{array}$ & $\begin{array}{l}\text { "The City of Seoul and } \\
\text { Kyonggi Province provided } \\
\text { and supported this stream } \\
\text { restoration project with full } \\
\text { confidence, so a task-force } \\
\text { of An'Yang Stream } \\
\text { management could be } \\
\text { established." }\end{array}$ \\
\hline & & $\begin{array}{c}\text { Leaders' } \\
\text { willingness to } \\
\text { restore water } \\
\text { quality }\end{array}$ & $\begin{array}{l}\text { "A version of An'Yang } \\
\text { Stream water quality } \\
\text { improvement network, based } \\
\text { on specialized human and } \\
\text { material resources, could be } \\
\text { established due to } \\
\text { governmental agencies" } \\
\text { sincere support of activities." }\end{array}$ \\
\hline Politics & $\begin{array}{l}\text { Political } \\
\text { interests and } \\
\text { volition in } \\
\text { An'Yang } \\
\text { Stream } \\
\text { restoration } \\
\text { project }\end{array}$ & $\begin{array}{l}\text { Governmental } \\
\text { planning group } \\
\text { for supporting } \\
\text { the An'Yang } \\
\text { Stream } \\
\text { restoration } \\
\text { agenda setting }\end{array}$ & $\begin{array}{l}\text { "The elected politicians were } \\
\text { very enthusiastic in restoring } \\
\text { An'Yang Stream. The } \\
\text { governmental partnership led } \\
\text { by the politicians was } \\
\text { established and set the } \\
\text { agenda in the An'Yang } \\
\text { Stream Restoration } \\
\text { Masterplan. Also, they } \\
\text { allocated a huge budget for } \\
\text { this restoration project. Their } \\
\text { efforts ensured ecological } \\
\text { space development of } \\
\text { An'Yang Stream as well as } \\
\text { water quality enhancement." }\end{array}$ \\
\hline $\begin{array}{l}\text { Resource } \\
\text { distribution in } \\
\text { the governance } \\
\text { network }\end{array}$ & $\begin{array}{l}\text { Partnership } \\
\text { network within } \\
\text { the decision- } \\
\text { making }\end{array}$ & $\begin{array}{l}\text { Interdependence } \\
\text { and information } \\
\text { sharing among } \\
\text { the stakeholders } \\
\text { guided by } \\
\text { An'Yang Stream }\end{array}$ & $\begin{array}{l}\text { "The private and public } \\
\text { organizational partnership, } \\
\text { 'The Always Green } \\
\text { An'Yang 21' contributed to } \\
\text { scientific information } \\
\text { sharing and guiding the }\end{array}$ \\
\hline
\end{tabular}




$\begin{array}{cc}\text { Protection } & \text { agenda of the An'Yang } \\ \text { Masterplan } & \begin{array}{c}\text { Stream Restoration } \\ \text { Masterplan." }\end{array}\end{array}$

7.1.3 Preconditions- public opinion and media (contexts)

"Context: The specific set of properties that pertain to a phenomenon. A context represents the particular set of conditions within which the action/interactional strategies are taken." (Strauss and Corbin, 1990)

Contexts can be defined as specific conditions and key factors that directly impact setting a core category (Strauss and Corbin, 1998; Chae, 2012). The contexts may also be a set of conditions that makes the actors establish specific strategies or central phenomena happen within a decision-making system. These contexts within the An'Yang Stream decision-making system were composed of the stakeholders' public opinions, active support, the prioritization of water quality improvement, the forming of a social consensus, and the involvement of the media. Contexts in the An'Yang Stream's ecological restoration project are presented as follows in Table 16.

Table 16. Contextual condition (preconditions of decision-making)

\begin{tabular}{cccc}
\hline $\begin{array}{c}\text { Contextual } \\
\text { condition }\end{array}$ & Keyword & Definitions & Content from Interviews \\
\hline Public opinion & $\begin{array}{c}\text { Water quality } \\
\text { enhancement }\end{array}$ & $\begin{array}{c}\text { Severe water } \\
\text { contamination } \\
\text { due to } \\
\text { industrialization } \\
\text { and urbanization } \\
\text { in the upstream } \\
\text { and downstream }\end{array}$ & $\begin{array}{c}\text { "The upstream of An'Yang } \\
\text { Stream is located near big } \\
\text { cities such as Gunpo and } \\
\text { Euiwang, so the upstream is } \\
\text { exposed to a non-point } \\
\text { pollution source and point } \\
\text { pollution source from the } \\
\text { urbanized region. The } \\
\text { downstream is located near } \\
\text { the largest South Korean } \\
\text { city, Seoul. Of course, water } \\
\text { quality improvement was the } \\
\text { main issue in both upstream } \\
\text { and downstream. The }\end{array}$ \\
& & \\
& &
\end{tabular}


An'Yang Stream restoration was a very complicated process that reflects the diverse geographical factors in terms of water quality enhancement."

\begin{tabular}{cc}
\hline Citizens' & Increased \\
aspiration for & interests of \\
environmental & citizens in using \\
improvement & the waterfront \\
& spaces for \\
& recreational \\
& purposes
\end{tabular}

"For a long time, the waterfront space existed to play a very important role, providing space for civic and recreational purposes since it is very close to urbanized regions in which many people live. Thus, the urban stream felt pressure to provide for citizen activities and amenities. The sense of duty put great pressure on the stream."

$\begin{array}{cc}\text { Various spatial } & \text { Ecological parks } \\ \text { uses through } & \text { and gardens for } \\ \text { stream } & \text { citizen activities } \\ \text { restoration } & \end{array}$

"While providing public space, by addressing the nature of the ecosystem in the restoration project of An'Yang Stream, this project can enhance the diversity that was determined to be one of the most important targets. From this process, the agenda of the An'Yang Stream restoration was set. Here, because I mean everyone should agree with the citizens and the government.

Here, the agenda setting seemed to address everyone (citizens, NGOs, and governments)'s interest. There was no disagreement. It was the easiest topic on which to achieve collaboration."

\begin{tabular}{cccc}
\hline Media & $\begin{array}{c}\text { Media's } \\
\text { contribution }\end{array}$ & $\begin{array}{c}\text { Public sharing } \\
\text { and announcing } \\
\text { of stream }\end{array}$ & $\begin{array}{c}\text { "Seoul Broadcasting } \\
\text { one TV show 'Water is the }\end{array}$ \\
\hline
\end{tabular}




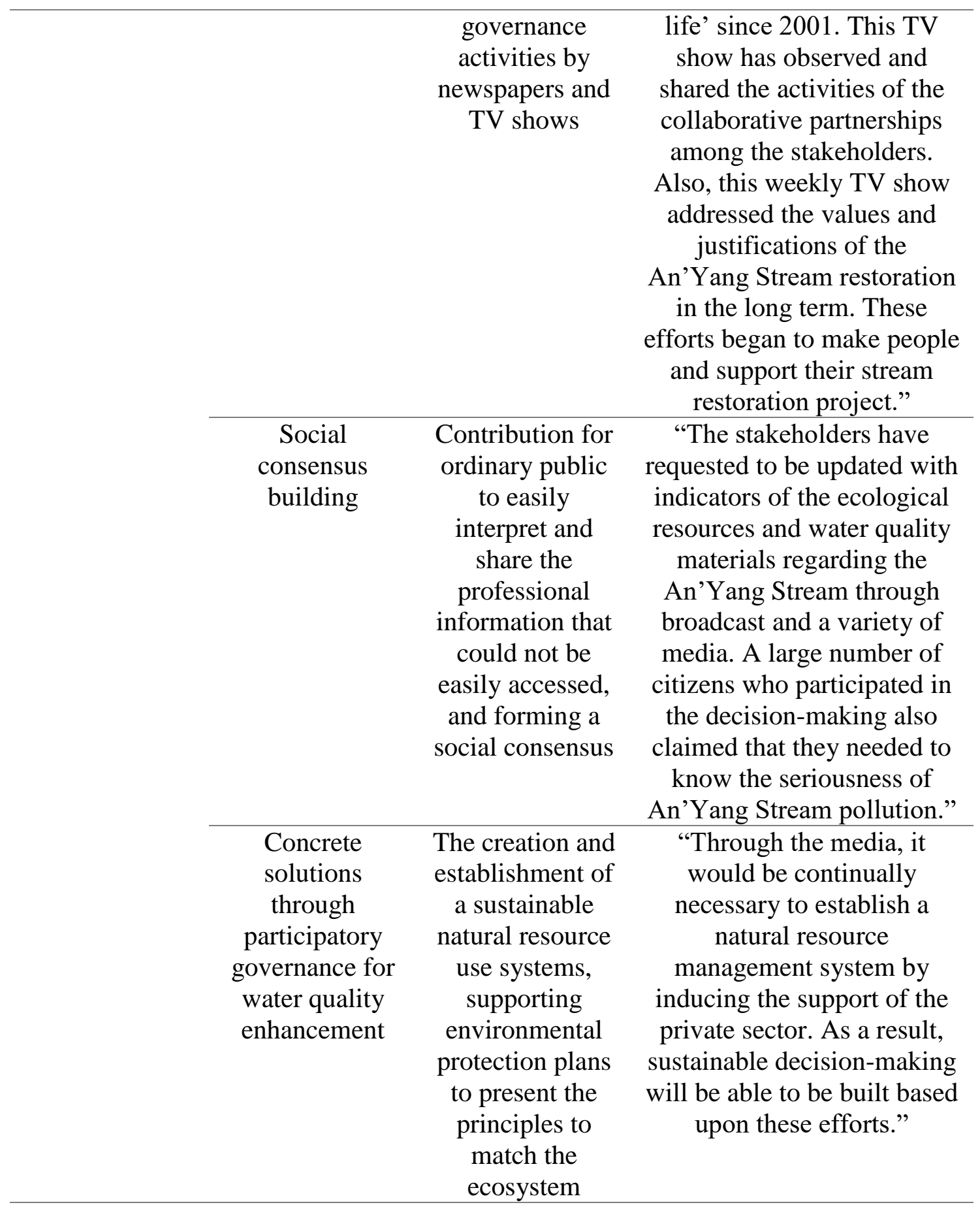

7.1.4 Interactive motivation (intervening conditions)

"Intervening conditions: The structural conditions bearing on action/ interactional strategies that pertain to a phenomenon. They facilitate or constrain the strategies taken within a specific context." (Strauss and Corbin, 1990) 
The intervening condition explains one structural and strategic condition which can solve conflicts over interdependent situations among stakeholders (Strauss and Corbin, 1998; Chae, 2012). There was limited trust among the stakeholders of the collaborative governance, due to a strong commitment to the technocratic restoration and institutional arbitration by upper governmental groups. In addition, political activities such as lobbies and elections affected the decision-making of the governance.

The stakeholders held strong responsibility and obligation for the ecological restoration. The citizens' real-time monitoring contributed to developing this sense of strong responsibility and obligation. The An'Yang Stream task-force could receive feedback about any issue on the stream from the ordinary citizen watchdog group which was expanded into ecological outreach education programs for citizens. According to the interviews with the stakeholders, the An'Yang Stream water quality improvement advisory committee held frequent and periodic workshops as well as public hearing sessions to share professional hydraulic data with the stakeholders. These efforts promoted the public understanding of the professional scientific information (Table 17). The An'Yang Stream Water Quality Improvement Council provided the stakeholders with global workshops to learn from other countries' successful stream restoration cases for more efficient understanding and sharing of integrated and common scientific knowledge of stream restoration. Through discussions at the monthly council meetings, the stakeholders established scientific standards of stream restoration. When the leaders of the organization could not attend the meeting, public administrators who were in charge of stream management hosted the meetings to share others' 
activities and update additional information on the An'Yang Stream with the professional advisors.

The citizens could display control by voting in political elections as another interacting option. After citizens confirmed the commitment of each political party to the An'Yang Stream restoration process, they would vote in the local elections. In addition,

Table 17. Intervening conditions (solutions for interactive situation)

\begin{tabular}{|c|c|c|c|}
\hline $\begin{array}{l}\text { Intervening } \\
\text { conditions }\end{array}$ & Keyword & Definitions & Content from Interviews \\
\hline \multirow[t]{3}{*}{$\begin{array}{l}\text { Trust building } \\
\text { based on } \\
\text { ecological } \\
\text { restoration }\end{array}$} & Fact-finding & $\begin{array}{l}\text { Trust building } \\
\text { through } \\
\text { outreach } \\
\text { education and } \\
\text { citizen } \\
\text { movements }\end{array}$ & $\begin{array}{l}\text { "Considerable trust building } \\
\text { among the stakeholders } \\
\text { contributed to the An'Yang } \\
\text { Stream restoration network. } \\
\text { Public administrators and } \\
\text { citizens had a large } \\
\text { consensus of mutual } \\
\text { collaboration and } \\
\text { cooperation as well as a } \\
\text { concession for water quality } \\
\text { improvement and ecological } \\
\text { restoration through citizen } \\
\text { education programs and } \\
\text { community movements for } \\
\text { An'Yang Stream." }\end{array}$ \\
\hline & $\begin{array}{c}\text { Deliberative } \\
\text { processes }\end{array}$ & $\begin{array}{l}\text { Sharing mutual } \\
\text { agreements }\end{array}$ & $\begin{array}{l}\text { "The method of citizen } \\
\text { participation was not } \\
\text { completely ideal, but } \\
\text { citizen-oriented and } \\
\text { government-motivated } \\
\text { stream restoration aimed at } \\
\text { deliberative decision- } \\
\text { making to reach a mutual } \\
\text { agreement." }\end{array}$ \\
\hline & $\begin{array}{c}\text { Frequent } \\
\text { communication }\end{array}$ & $\begin{array}{l}\text { Building a } \\
\text { relationship of } \\
\text { mutual trust } \\
\text { through frank }\end{array}$ & $\begin{array}{c}\text { "There were many frequent } \\
\text { both private and public } \\
\text { communication } \\
\text { opportunities among the }\end{array}$ \\
\hline
\end{tabular}




\begin{tabular}{|c|c|c|c|}
\hline & & $\begin{array}{l}\text { and deep } \\
\text { dialogue }\end{array}$ & $\begin{array}{l}\text { stakeholders. Through such } \\
\text { communication, they } \\
\text { learned others' interests and } \\
\text { values on the An'Yang } \\
\text { Stream restoration. People } \\
\text { say love grows as they } \\
\text { fight? The stakeholders also } \\
\text { got closer while having } \\
\text { many conflicts and } \\
\text { debates." }\end{array}$ \\
\hline \multirow[t]{4}{*}{$\begin{array}{l}\text { Deep commitment } \\
\text { and responsibility } \\
\text { of the stakeholders }\end{array}$} & $\begin{array}{c}\text { Efforts and } \\
\text { enthusiasm of } \\
\text { the } \\
\text { stakeholders }\end{array}$ & $\begin{array}{l}\text { Synergistic } \\
\text { effects of } \\
\text { various } \\
\text { activities and } \\
\text { government } \\
\text { level of support } \\
\text { among } \\
\text { stakeholders } \\
\text { within the } \\
\text { governance for } \\
\text { the water } \\
\text { quality } \\
\text { improvement }\end{array}$ & $\begin{array}{l}\text { "The stakeholders had a } \\
\text { strong sense of } \\
\text { responsibility in their } \\
\text { positions and deep interests } \\
\text { in the An'Yang Stream } \\
\text { restoration. To receive the } \\
\text { support of the government, } \\
\text { it seems that there was a } \\
\text { wide variety of activities } \\
\text { and cooperation. In } \\
\text { addition, it took a very long } \\
\text { period of time." }\end{array}$ \\
\hline & $\begin{array}{l}\text { Active } \\
\text { participation of } \\
\text { civic society }\end{array}$ & $\begin{array}{l}\text { Self-motivated } \\
\text { and } \\
\text { collaborative } \\
\text { activities of } \\
\text { citizen groups }\end{array}$ & $\begin{array}{l}\text { “The NGOs and citizen } \\
\text { groups in the regions of } \\
\text { An'Yang, Gunpo, Euiwang, } \\
\text { Guro, and Keumcheon got } \\
\text { together very often to have } \\
\text { discussions and mutual } \\
\text { learning of stream } \\
\text { restoration knowledge. } \\
\text { During this process, they } \\
\text { could build a strong } \\
\text { friendship." }\end{array}$ \\
\hline & $\begin{array}{l}\text { Citizens' real- } \\
\text { time } \\
\text { monitoring }\end{array}$ & $\begin{array}{l}\text { Self-motivated } \\
\text { citizen } \\
\text { partnerships }\end{array}$ & $\begin{array}{l}\text { "Various communications } \\
\text { of vision-sharing within the } \\
\text { An'Yang Stream Protection } \\
\text { Network led by citizens } \\
\text { resulted in a strong } \\
\text { partnership and trust- } \\
\text { building among the private } \\
\text { stakeholders." }\end{array}$ \\
\hline & $\begin{array}{l}\text { Private-public } \\
\text { partnership }\end{array}$ & $\begin{array}{l}\text { Sustainable and } \\
\text { interactive } \\
\text { collaboration }\end{array}$ & $\begin{array}{c}\text { "Governmental } \\
\text { administrators also } \\
\text { maintained support for the }\end{array}$ \\
\hline
\end{tabular}




\begin{tabular}{|c|c|c|c|}
\hline & & $\begin{array}{l}\text { through the } \\
\text { An'Yang } \\
\text { Stream } \\
\text { decision- } \\
\text { making }\end{array}$ & $\begin{array}{l}\text { An'Yang Stream Protection } \\
\text { Network of NGOs and } \\
\text { citizen groups after the } \\
\text { successful partnership } \\
\text { building. Collaborative } \\
\text { decision-making within the } \\
\text { An'Yang Stream restoration } \\
\text { governance could be } \\
\text { established based on this } \\
\text { collaboration between } \\
\text { public and private sectors." }\end{array}$ \\
\hline \multirow[t]{3}{*}{$\begin{array}{l}\text { Mediation of the } \\
\text { third party }\end{array}$} & $\begin{array}{l}\text { Professional } \\
\text { information } \\
\text { sharing among } \\
\text { the internal } \\
\text { stakeholders }\end{array}$ & $\begin{array}{l}\text { Advice by } \\
\text { professional } \\
\text { advisory } \\
\text { committee }\end{array}$ & $\begin{array}{l}\text { "The An'Yang Stream } \\
\text { water quality improvement } \\
\text { advisory committee } \\
\text { provided frequent and } \\
\text { periodic workshops to share } \\
\text { professional hydraulic data } \\
\text { with the stakeholders. These } \\
\text { efforts promoted the public } \\
\text { understanding of the } \\
\text { professional scientific data." }\end{array}$ \\
\hline & $\begin{array}{c}\text { Objective } \\
\text { evaluation } \\
\text { based on } \\
\text { scientific facts }\end{array}$ & $\begin{array}{l}\text { Finding } \\
\text { comprehensive } \\
\text { and objective } \\
\text { factors through } \\
\text { the workshops } \\
\text { and advanced } \\
\text { cases } \\
\text { observation in } \\
\text { consultation } \\
\text { body }\end{array}$ & $\begin{array}{l}\text { "The An'Yang Stream } \\
\text { Water Quality Improvement } \\
\text { Council provided the } \\
\text { stakeholders with field } \\
\text { survey trips of successful } \\
\text { stream restoration cases for } \\
\text { efficient understanding and } \\
\text { sharing of integrated and } \\
\text { common scientific } \\
\text { knowledge of stream } \\
\text { restoration. They } \\
\text { established scientific } \\
\text { standards of stream } \\
\text { restoration by discussions." }\end{array}$ \\
\hline & $\begin{array}{c}\text { Advisory } \\
\text { Committee } \\
\text { held frequently }\end{array}$ & $\begin{array}{l}\text { Governance } \\
\text { councils held } \\
\text { every month }\end{array}$ & $\begin{array}{l}\text { "The An'Yang Stream } \\
\text { Water Quality Improvement } \\
\text { Council held meetings } \\
\text { every month. When the } \\
\text { head of the organization } \\
\text { could not attend the } \\
\text { meeting, the person who } \\
\text { was in charge of stream } \\
\text { management participated in } \\
\text { the meetings to share }\end{array}$ \\
\hline
\end{tabular}




\begin{tabular}{|c|c|c|c|}
\hline & & & $\begin{array}{l}\text { others' activities and update } \\
\text { additional information on } \\
\text { the An'Yang Stream with } \\
\text { the professional advisors." }\end{array}$ \\
\hline \multirow[t]{3}{*}{$\begin{array}{l}\text { Political } \\
\text { evaluation } \\
\text { (Election) }\end{array}$} & Elections & $\begin{array}{l}\text { Evaluation of } \\
\text { the leadership } \\
\text { of the local } \\
\text { politicians }\end{array}$ & $\begin{array}{l}\text { The efforts and } \\
\text { achievements of political } \\
\text { campaign pledges on } \\
\text { An'Yang Stream restoration } \\
\text { by each politician who was } \\
\text { the leader of the local } \\
\text { government were evaluated } \\
\text { and judged through } \\
\text { elections. The political } \\
\text { election played a role in } \\
\text { evaluating if the politician } \\
\text { was a good leader in the } \\
\text { An'Yang Stream } \\
\text { restoration. It prevented the } \\
\text { re-election of incompetent } \\
\text { politicians." }\end{array}$ \\
\hline & $\begin{array}{l}\text { Giving a voice } \\
\text { to the less- } \\
\text { empowered }\end{array}$ & $\begin{array}{c}\text { Ecological } \\
\text { education } \\
\text { program for the } \\
\text { unrepresented }\end{array}$ & $\begin{array}{c}\text { “The An'Yang ecological } \\
\text { environment continuing } \\
\text { education center was } \\
\text { installed for community } \\
\text { education about An'Yang } \\
\text { Stream, and this education } \\
\text { program has shared the } \\
\text { importance and the value of } \\
\text { An'Yang restoration.” }\end{array}$ \\
\hline & Lobby & $\begin{array}{c}\text { Political } \\
\text { competitions } \\
\text { and activities }\end{array}$ & $\begin{array}{l}\text { “At election time, } \\
\text { environmental organizations } \\
\text { and citizen groups } \\
\text { participated in heated } \\
\text { debates on politicians' } \\
\text { election pledges regarding } \\
\text { the An'Yang Stream } \\
\text { restoration. Through the } \\
\text { processes, the candidates } \\
\text { addressed their visions and } \\
\text { agenda on the An'Yang } \\
\text { Stream management. Many } \\
\text { stakeholder groups from the } \\
\text { private sector made efforts } \\
\text { to appeal their interests to } \\
\text { the political candidates in }\end{array}$ \\
\hline
\end{tabular}


various routes such as private meetings and using social media."

environmental organizations and citizen groups participated in public debates on politicians' election pledges regarding the An'Yang Stream restoration. Through the processes, the candidates addressed their visions and agendas for the An'Yang Stream management. Social media also played an important role to share with the stakeholders and appeal their interests to the political candidates.

\subsection{TACTICAL POSITIONING FOR SHORT-TERM GOALS (STRATEGIES)}

"Action/Interaction: Strategies devised to manage, handle, carry out, respond to a phenomenon under a specific set of perceived conditions." (Strauss and Corbin, 1990)

In Grounded Theory, these interaction strategies were intentionally designed to respond and adjust to the empirical phenomena that happened during underrecognized specific conditions. According to Strauss and Corbin (1998), these strategies (interaction or confrontational strategies) are solutions to deal with and reflect that the phenomenon existed within the context or under certain conditions.

Table 18. Strategies (tactical positioning for short-term goals)

\begin{tabular}{cccc}
\hline Strategy & Keyword & Definitions & Content from Interviews \\
\hline $\begin{array}{c}\text { Master plan for } \\
\text { effective water } \\
\text { quality } \\
\text { improvement }\end{array}$ & $\begin{array}{c}\text { Sustainable } \\
\text { sewage } \\
\text { treatment plant } \\
\text { and waste-water } \\
\text { reduce }\end{array}$ & $\begin{array}{c}\text { Constructing } \\
\text { additional } \\
\text { sewage } \\
\text { treatment plants }\end{array}$ & $\begin{array}{c}\text { "In 1992 and 2002, } \\
\text { wastewater treatment } \\
\text { facilities were constructed in } \\
\text { the An'Yang Stream regions, } \\
\text { and facilities were built in to } \\
\text { reprocess to purify and } \\
\end{array}$ \\
& & & $\begin{array}{c}\text { recycle domestic wastewater } \\
\text { and industrial wastewater." }\end{array}$ \\
\hline
\end{tabular}




\begin{tabular}{|c|c|c|c|}
\hline & $\begin{array}{l}\text { Integrated water } \\
\text { resources } \\
\text { management } \\
\text { system }\end{array}$ & $\begin{array}{c}\text { Integrated } \\
\text { An'Yang } \\
\text { Watershed } \\
\text { Management } \\
\text { Strategy and } \\
\text { sustainable } \\
\text { decision-making } \\
\text { system by } \\
\text { comprehensive } \\
\text { water data } \\
\text { modeling }\end{array}$ & $\begin{array}{l}\text { "The decision-making board } \\
\text { decided to develop an } \\
\text { optimized and future- } \\
\text { oriented method based on } \\
\text { evaluating and understanding } \\
\text { the scientific indicators of } \\
\text { stream-flow, water quality, } \\
\text { and integrated water balance } \\
\text { analytical model..." }\end{array}$ \\
\hline & $\begin{array}{l}\text { Treated sewage } \\
\text { water recycling }\end{array}$ & $\begin{array}{l}\text { Discharging into } \\
\text { the stream after } \\
\text { using advanced } \\
\text { wastewater } \\
\text { treatment } \\
\text { technology }\end{array}$ & $\begin{array}{l}\text { "While pursuing a water } \\
\text { purification soundness in the } \\
\text { process of the water cycle, it } \\
\text { would be the main goal that } \\
\text { this new An'Yang Stream } \\
\text { restoration needs to address } \\
\text { pro-environmental waste } \\
\text { treatment that can oversee } \\
\text { both the reprocessing and the } \\
\text { discharge to the stream of the } \\
\text { main source of } \\
\text { contamination drainage." }\end{array}$ \\
\hline \multirow[t]{2}{*}{$\begin{array}{l}\text { Technocratic } \\
\text { governance } \\
\text { building }\end{array}$} & $\begin{array}{l}\text { Governmental } \\
\text { committee for } \\
\text { water quality } \\
\text { improvement }\end{array}$ & $\begin{array}{c}\text { Stream } \\
\text { restoration } \\
\text { committee led } \\
\text { by water quality } \\
\text { engineering } \\
\text { specialists }\end{array}$ & $\begin{array}{l}\text { "Well-trained public } \\
\text { administrators in each central } \\
\text { governmental ministry } \\
\text { (Ministry of Environment } \\
\text { and Ministry of Construction } \\
\text { and Transportation), who } \\
\text { held professional civil } \\
\text { engineering and hydraulic } \\
\text { contributed to improving the } \\
\text { water quality of the stream } \\
\text { restoration process by their } \\
\text { collaboration and } \\
\text { cooperation with } \\
\text { complementary research } \\
\text { works. Moreover, the } \\
\text { network among them built a } \\
\text { strong decision-making } \\
\text { structure." }\end{array}$ \\
\hline & $\begin{array}{l}\text { Professional } \\
\text { advisory body } \\
\text { for water }\end{array}$ & $\begin{array}{l}\text { Objective and } \\
\text { collaborative } \\
\text { monitoring }\end{array}$ & $\begin{array}{l}\text { "The water quality of the } \\
\text { An'Yang Stream has } \\
\text { gradually changed and } \\
\text { improved by the }\end{array}$ \\
\hline
\end{tabular}




\begin{tabular}{|c|c|c|c|}
\hline & $\begin{array}{l}\text { resource } \\
\text { planning }\end{array}$ & $\begin{array}{c}\text { system of water } \\
\text { data }\end{array}$ & $\begin{array}{l}\text { collaborative monitoring by } \\
\text { the partnership. In addition, } \\
\text { the stakeholders commonly } \\
\text { recognized and investigated } \\
\text { environmental issues on } \\
\text { An'Yang Stream, along with } \\
\text { the activities of the } \\
\text { professional advisory } \\
\text { committee." }\end{array}$ \\
\hline & $\begin{array}{l}\text { Governance } \\
\text { network } \\
\text { configuration } \\
\text { for An'Yang } \\
\text { Stream } \\
\text { ecological } \\
\text { protection }\end{array}$ & $\begin{array}{l}\text { Development of } \\
\text { small } \\
\text { watershed-based } \\
\text { water resources } \\
\text { diagnostic } \\
\text { system using } \\
\text { landscape } \\
\text { ecological } \\
\text { principles }\end{array}$ & $\begin{array}{l}\text { "In the An'Yang Stream } \\
\text { restoration advisory } \\
\text { committee, many } \\
\text { hydrologists and aqua- } \\
\text { environmental scientists } \\
\text { joined, and landscaping } \\
\text { architects who held different } \\
\text { values in stream management } \\
\text { were invited to contribute to } \\
\text { the governance network. } \\
\text { Sometimes, the various } \\
\text { values of the participants in } \\
\text { the advisory committee } \\
\text { caused conflicts due to } \\
\text { different frames and goals for } \\
\text { understanding the scientific } \\
\text { measuring indicators. } \\
\text { Fundamentally, each stream } \\
\text { of local regions needed to } \\
\text { establish its own water } \\
\text { quality diagnostic } \\
\text { management system because } \\
\text { each stream had very } \\
\text { different issues that had to be } \\
\text { solved by different scientific } \\
\text { solutions and different } \\
\text { experts of different } \\
\text { specialties." }\end{array}$ \\
\hline $\begin{array}{l}\text { Profit-seeking } \\
\text { motivation of } \\
\text { private } \\
\text { engineering } \\
\text { consultants }\end{array}$ & $\begin{array}{l}\text { Advanced } \\
\text { engineering } \\
\text { technology }\end{array}$ & $\begin{array}{l}\text { Strong reliance } \\
\text { on engineering } \\
\text { and scientific } \\
\text { technologies }\end{array}$ & $\begin{array}{l}\text { "I think the An'Yang Stream } \\
\text { needed only engineering- } \\
\text { oriented water quality } \\
\text { improvement rather than } \\
\text { other values, so hydrologists } \\
\text { and water resource engineers } \\
\text { were the major stakeholders }\end{array}$ \\
\hline
\end{tabular}




\begin{tabular}{|c|c|c|}
\hline & & $\begin{array}{l}\text { and leaders of the } \\
\text { governance." }\end{array}$ \\
\hline $\begin{array}{c}\text { Economic profit } \\
\text { based on } \\
\text { technical } \\
\text { innovation }\end{array}$ & $\begin{array}{c}\text { Aiming at } \\
\text { spatial } \\
\text { efficiency based } \\
\text { on economic } \\
\text { benefit }\end{array}$ & $\begin{array}{l}\text { "Our company aimed at more } \\
\text { efficient stream restoration } \\
\text { from our projects, as well as } \\
\text { making profits. Engineering } \\
\text { companies had to consider } \\
\text { how much we can profit } \\
\text { from major construction. } \\
\text { Good efficiency made us } \\
\text { more money." }\end{array}$ \\
\hline
\end{tabular}

In the An'Yang Stream restoration case, the interactive strategies were collaborative governance building and a sustainable Master Plan. Although the strategies were quite effective in improving water quality and ecological standards, they could not adequately address concrete solutions that deal with social values such as social integrity, civic participation, and embracing other various interests.

The stakeholders and their governance of the An'Yang Stream restoration had three strategies. The first one was about plan-making prior to 2002 and the other two strategies regarded implementation from 2002 to 2015.

The first strategy indicated a sustainable Master Plan which aimed at both planmaking and the establishment of strategies as well as an advanced innovative water quality management system. The Master Plan guided stakeholders and their decisionmaking within the governance to sustainably develop an optimized and future-oriented method based on evaluating and understanding the scientific standards of stream-flow, and water quality. In particular, the Master Plan explained the available methods and the importance of the soundness of water purification in the process of stream restoration. Also, it addressed that the new sustainable An'Yang Stream restoration 
strategies would need to ensure pro-environmental waste treatment that supervised both the reprocessing and the discharge to the stream of the main source of contamination drainage.

Second, they considered effective ways to achieve short-term successful outcomes. These effective ways emphatically opted for a technocratic and objective decisionmaking system under the engineering technology-oriented governance. In the An'Yang Stream restoration advisory committee, many hydrologists and aqua-environmental scientists, as well as landscaping architects, were included to develop and extend a scope of the technocratic governance network. Sometimes, the various values of the stakeholders in the advisory committee caused conflicts due to different frames and goals for understanding the scientific measuring indicators. Also, the public administrators who held professional civil engineering and hydraulic backgrounds contributed to emphasizing and building the agenda of ecological restoration by collaborating and cooperating with professional complementary research.

In addition, engineering consultants of private engineering companies influenced the decision-making process with profit-seeking motivations of engineering innovation. Due to this trend during the engineering consulting, waterfront beautification landscaping for economic development and spatial efficiency for flood prevention became an influential value of An'Yang Stream in the agenda setting. The engineering consultants believed that the stream needed only advanced engineering-oriented ecological restoration rather than other values, so hydrologists and water resource engineers should lead the decision-making. Therefore, the network among the 
engineering consultants influenced other stakeholders based on a goal-oriented,

effective, empirical, and professional technocratic knowledge.

\subsection{IMPLEMENTATION OF MASTER PLAN (CONSEQUENCES)}

“Consequences: Outcomes or results of action and interaction." (Strauss and Corbin, 1990)

The consequences are defined as an outcome directly stemming from the adoption of interactive strategies to deal with a specific phenomenon (Strauss and Corbin, 1998; Chae, 2012). The consequences should be analyzed and reviewed when evaluating the strategies, even though they cannot be well-addressed or lead to results as they were designed and intended. This process is the main analytic process of the Grounded Theory (Strauss \& Corbin, 1998). In this analysis, based on governance building by central phenomena such as private-public partnerships and the firm leadership of the stakeholders, the professional advisory committee played a key role in achieving water quality improvement and ecological revitalization.

Table 19. Consequence (Implementation of Master Plan)

\begin{tabular}{cccc}
\hline Consequence & Keyword & Definitions & Content from Interviews \\
\hline $\begin{array}{c}\text { Technocratic } \\
\text { stream }\end{array}$ & Water quality & Total pollution & "The water quality \\
restoration & & amounts in & enhancement strategies and \\
& & 2010 were & programs led by the \\
& reduced by & governance changed the \\
& & $60.4 \%$ on & stream. For example, water \\
& average, & quality level was \\
& compared to & impressively increased and \\
& that of 2002. & improved." \\
& Ecological & Fish increased & "Stream restoration project \\
& (Chinese & brought king crabs and \\
& minnow) and & Chinese minnows back to \\
& & other plant & An'Yang Stream." (Second \\
& & species diversity & river grade) \\
& increased & \\
& &
\end{tabular}




\begin{tabular}{|c|c|c|c|}
\hline \multirow[t]{2}{*}{$\begin{array}{l}\text { Incomplete } \\
\text { participatory } \\
\text { process }\end{array}$} & $\begin{array}{c}\text { Negligence of } \\
\text { social, cultural, } \\
\text { educational, and } \\
\text { historical values }\end{array}$ & $\begin{array}{l}\text { Technocratic } \\
\text { decision- } \\
\text { making and } \\
\text { stream } \\
\text { restoration } \\
\text { strategies }\end{array}$ & $\begin{array}{l}\text { 'It was very limited and } \\
\text { impossible to address } \\
\text { nonscientific factors and } \\
\text { social values about An'Yang } \\
\text { Stream, since the } \\
\text { stakeholders viewed the } \\
\text { importance of scientific } \\
\text { indicators in evaluating the } \\
\text { stream restoration results." }\end{array}$ \\
\hline & $\begin{array}{l}\text { Lack of } \\
\text { governance } \\
\text { resiliency }\end{array}$ & $\begin{array}{l}\text { Professional } \\
\text { mediators were } \\
\text { absent, so many } \\
\text { great and small } \\
\text { conflicts } \\
\text { happened }\end{array}$ & $\begin{array}{l}\text { "When facing conflicts } \\
\text { among the stakeholders in } \\
\text { the governance, they did not } \\
\text { have any effective solutions } \\
\text { to resolve the conflicts. } \\
\text { Moreover, the An'Yang } \\
\text { Stream decision-making did } \\
\text { not include any trained } \\
\text { professionals who could } \\
\text { coordinate these conflicts. In } \\
\text { fact, some stakeholder } \\
\text { groups who held more } \\
\text { detailed and professional } \\
\text { resources of scientific } \\
\text { knowledge tended to occupy } \\
\text { the governance decision- } \\
\text { making system. These } \\
\text { conflicts caused political } \\
\text { debates regarding policy- } \\
\text { making for An'Yang Stream } \\
\text { restoration even after } \\
\text { successful water quality } \\
\text { enhancement." }\end{array}$ \\
\hline
\end{tabular}

Also, a cutting edge engineering technology-oriented decision-making system was established within the An'Yang Stream governance, as we observed in the document review that most evaluation indicators of stream restoration relied on scientific information, such as water quality levels and fluvial diversity. However, through reviewing the consequences, it was hard to find accomplishments or improvement in the social, cultural, educational, or historical restoration of An’Yang Stream. 
In reviewing the Master Plan, it was found that policymaking on environmental issues offered only limited procedures, such as public hearings. In comparison to other general stream restoration cases, having these public hearings was cursory, so the civic participation for successful decision-making was not satisfied as much as the Master Plan had outlined.

In other words, those values were almost neglected as the interviewees confirmed. Limited functions of the civic participation programs and the lack of the governance's flexibility to reflect citizens' interests might have concentrated only on technocratic stream restoration.

\subsection{OVERALL STORYLINE OF STREAM RESTORATION GOVERNANCE (PARADIGM BUILDING)}

In previous chapters, analytic coding through categorization and conceptualization with interview scripts and content of public documents was conducted. Connecting and mapping the categories allowed us to recognize the causes of successes and failures in the storyline of the An'Yang Stream restoration project, as described in Figure 15.

First, it is critical that the contextual conditions indicated a common interest of all of the stakeholders; particularly citizens. The common interest that originated from water contamination in the stream brought about citizen movement, because the problem of water contamination made the public and the government consider and set strengthening of water quality standards. The promoting role of the media regarding private citizens' interests in the An'Yang Stream restoration catalyzed devoted support 
and active involvement of local governments and NGOs to mitigate the water quality pollution and aqua ecological devastation.

Local citizen groups and NGOs could not be involved in the decision-making board. The major avenue of communication was public hearings hosted by the governments. Citizen participation was not the primary value in the stream restoration because water quality improvement was more urgent and important for everyone, including the citizens and NGOs. However, after the conspicuous water quality enhancement, the citizens and NGOs began to hold different opinions and visions for longlasting success in stream restoration. These long-term visions included social restoration and cultural revitalization in the watershed to achieve sustainable and longterm success. However, the governments and politicians who led the stream restoration project did not pay attention to these different voices. They placed a higher value on the scientific efficiency and engineering innovation developed through technocratic decision-making. This research tried to find the negative social phenomenon of technocratic decisionmaking by continuous application of a professional expertise that was built on cuttingedge engineering technology. There was an imbalance among the stakeholders in evaluating and reviewing the initial conditions such as political structure, knowledge, information related to river restoration, and budget allocation. In addition, the water quality in An'Yang Stream has now been gradually deteriorating since 2010 due to indiscriminately adhering to the technocratic value-oriented decision-making process. In addition, social factors have changed the results of the stream restoration since a new mayor was elected in 2007, who held different opinions and values about the stream. 
At the early stage of the stream restoration, based on interests and support of local societies, the An'Yang Stream Protection Network was established in order to develop and meet the goals of ecological restoration, social restoration, and spatial renovation (beautification). The ecological restoration was successfully achieved through scientific innovation and engineering technology-oriented governance building, specifically decision-making. However, social restoration, such as social integrity based on participatory stream restoration decision-making, cultural revitalization, education development, and historical re-illumination (re-exploration) was not properly considered in the stream restoration governance's decision-making processes. Also, spatial renovation and waterfront beautification projects were frequently requested by citizens, but this value was not the primary one of the decision-making board, because the citizen groups had less influence and power in the decision-making of the governance than civil engineers, environmental scientists, and hydrologists.

Strategically, the An'Yang Stream restoration decision-making board developed 1) frequent communicative workshops among the stakeholders, 2) interdependent and interactive networks, and 3) an integrated Master Plan. However, these strategic approaches faced various challenges due to internal conflicts among the stakeholders, because top-down and unilateral river restoration agenda-setting based on science and engineering technology impeded the progress in pursuit of diverse values. Still, there were delicate and subtle internal conflicts among the stakeholders because experts of conflict and collective mediation were absent within the decision-making of the governance until now. 


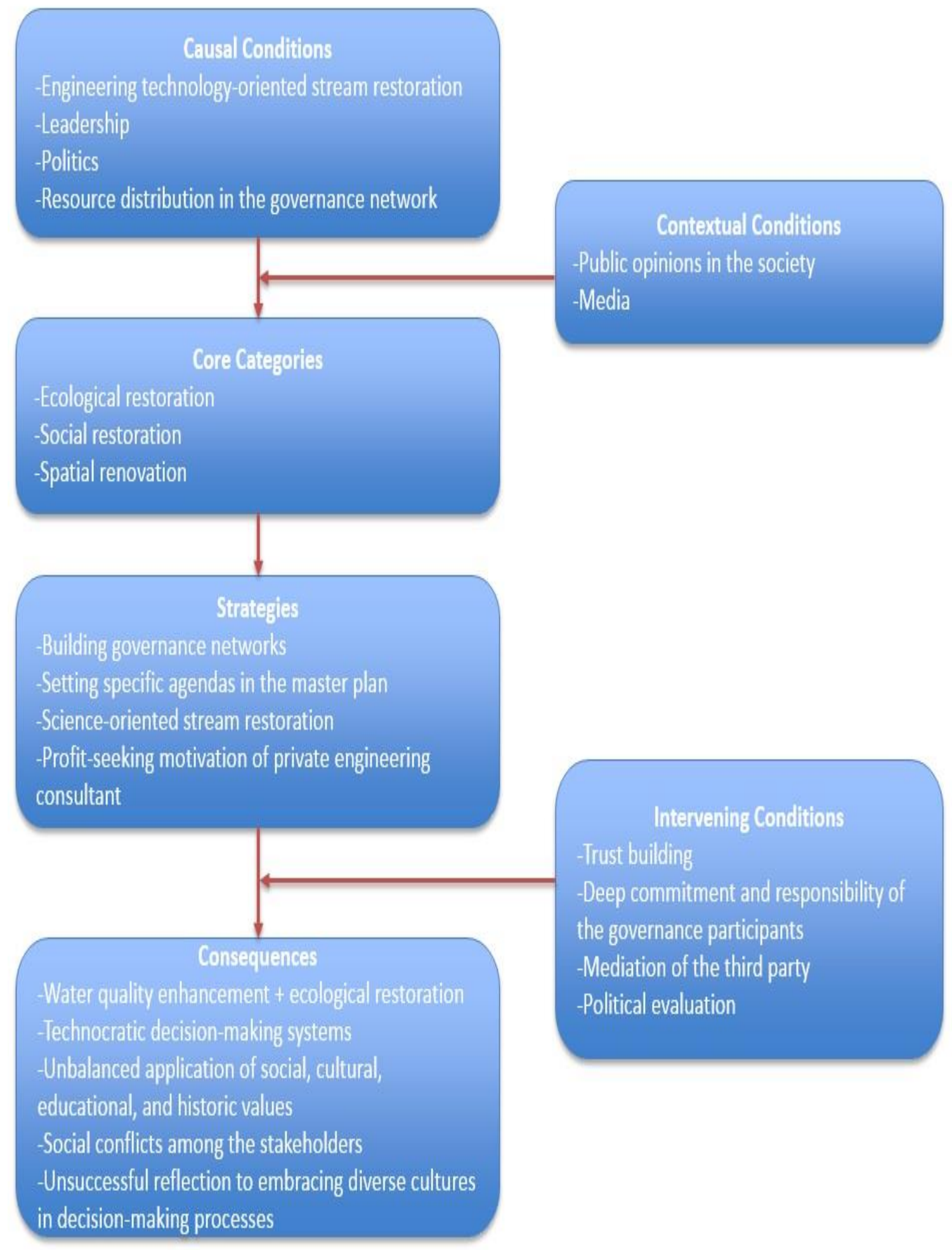

Figure 15. Paradigm building of An'Yang Stream case 
Intervening conditions are composed of trust building among stakeholders, and commitment and responsibility of the stakeholders accumulated over a long period of time. Trust-building could be the driving force among many groups gathered to aim for a big goal; water quality enhancement of An'Yang Stream restoration as the common denominator. Interview transcripts (PA 01, CO 03, and NGO 04) showed evidence of their trust-building efforts through monthly and other periodic meetings. In addition, the individual responsibility of each stakeholder contributed to catalyzing and maximizing water quality enhancement and ecological improvement. However, these intervening conditions were also shaped by very technocratic and top-down oriented decisionmaking processes, so were not successfully able to reflect and satisfy non-scientific and social values on An'Yang Stream restoration.

\subsubsection{Leadership in decision-making}

I strongly think that the leadership of the former city mayor of An'Yang, Mr. Shin contributed to this successful water quality improvement in An'Yang Stream restoration. (CO 03)

Leadership was one factor of successful water quality improvement in the short term of the An'Yang Stream Restoration Project, as Yosie and Herbst (1998) argue. Governance leaders and stakeholders aimed for water quality improvement as the primary goal. Based on their leadership, an administrative system and private-public partnerships were established. The interviewees contended that the leadership was mainly motivated by building, operating, and sustaining the decision-making process. Before conducting the interviews with the stakeholders and decision-makers, the researcher did not initially expect to find the shape of and how leadership worked 
within the decision-making. However, this research realized leadership as an important factor.

The stream restoration results could be distinguished by the spatial renovation and updates, depending on who the leading participants in local governance were in the stream management department. The citizen interviewees responded that the ability and efforts of the leaders impacted the successful results of the stream restoration. For instance, the leadership of the former mayor of the City of An'Yang, Mr. Shin JungDae, who originally initiated the An'Yang Stream restoration project and established the public-private partnership, was positively evaluated and reviewed. His leadership and insight into the stream restoration led to the formation of the stream restoration task-force and persuaded other local government leaders to join the collaborative stream restoration decision-making.

The decision-making system based on its strong leadership, motivated collaborative and cooperative discussions (despite conflicts based on different understandings of professional information), and on holding different individual values in dealing with the disciplines. Also, the decision-making board faced various frictions among the participants, such as accepting citizens' interests and budget distribution.

Under the leadership of Professor Choi (professional advisory committee member) and Mr. Shin (mayor), all of the stakeholders could be good colleagues and friends even though they had very different backgrounds and interests. However, they held a strong passion for successful stream restoration in the project. (PS 02)

Professor Choi helped participants work through conflicts when they occurred among the stakeholder groups as well as the advisory committee members. According to the stated transcripts of NGO03 and PA05 as well as Professor Choi, the stakeholders 
began to listen to others and open their minds to understanding the different interests of other participants, after promoting amity through the processes of consensus and trust building. Still, some stakeholders got along with each other like close friends.

Officially, the decision-making system and procedures did not have a mediator or facilitator, but some participants played those roles, and the An'Yang Stream decisionmaking board could improve water quality in the short term. The interviewees had the common idea that the strong leadership of Professor Choi helped to catalyze and motivate active sharing of professional information, and changed the attitude of citizens who were against the government groups.

Generally speaking, citizen groups and NGOs in South Korea tended to distrust professional advisory groups in environmental planning because those groups were mostly appointed by the government. As one leader of the professional advisory committee, Professor Choi established flexible communication channels that helped citizen representatives and NGOs understand the abstruse professional data on water quality and ecological management of the An'Yang Stream through participatory workshops with other stakeholders. According to his interview transcript conducted in 2015, sometimes Dr. Choi had to assist and advocate for the underrepresented in the decision-making and conveyed the values held by private sector participants. Based on the active communication and interaction among the stakeholders, some solutions and mutual agreements on the issues of conflicts of understanding and interpreting the scientific data were found.

The stakeholders who were involved in conflicts regarding scientific disagreements and conflicting interests among stakeholders had an open communication channel with 
Professor Choi. In particular, Dr. Choi could contribute to finding a solution to seek mutually agreed common scientific efficiency. However, his leadership was limited to play the functions of a convener, a negotiation process manager or a translator.

Also, during political conflicts within the decision-making, the professional advisory committee led by Dr. Choi played the crucial role of mediator among the stakeholders and advisory committee members with their professional expertise on water quality and ecological standards of An'Yang Stream. Besides, local government leaders were in positions that were elected quadrennially, so they had strong political prisms in controlling the policy-making and administrating systems. These political viewpoints might have caused conflicts within the decision-making of the An'Yang Stream restoration because the politicians considered their political interests preferentially. Thus, successful leadership of some stakeholders was not established in an available mediating official systematic or institutional device, because nobody considered the roles and functions of mediators who would make the decision-making work better.

\subsubsection{The media and its influence}

This work had not set out to examine the role of the media, but through the interviews the researcher learned how important its role was. This section describes findings based on simple observations regarding the media's influence. As Kratzig and Warren-Kretzschmar (2014) mention and analyze the functions of media that catalyze public involvement and expand public awareness, this research found that the media such as TV stations and Facebook indirectly mediated the relationships by providing 
information to educate the residents and non-experts on the technical issues and served to amplify the concerns and views of the residents because their interviews and interactions with citizens showed successful citizen initiatives.

In particular, the researcher met producers who filmed documentary TV shows on environmental issues. The producers contributed to and participated in the governance network and partnerships, and their influence must be reckoned with in this analysis and interviews, even though they were not directly stakeholders. Citizens and NGO leaders acknowledged the contributions of these TV producers and staff.

'Water is life' (the Seoul Broadcasting Station (SBS) TV show) is a social contribution that has played on SBS since 2001 to protect our environment and ecological systems, as well as to restore water quality in the river basin. This SBS TV show introduced many behind-the-scenes stories on governance activities and successful outcomes of river management through citizen movements, as well as innovative scientific and engineering technologies in South Korea. Also, it dealt with accepting and sharing diverse values of stakeholders. In many episodes of 'Water is Life' citizens were introduced to new paradigms and various values within the An'Yang Stream restoration governance, which could not be found nor observed in the government documents. Comparing the different values of the stakeholders of An'Yang Stream restoration, the TV show drew the priorities based on public opinion and described the conflicts among the values by addressing the strengths and weaknesses of the present An'Yang Stream restoration decision-making system. Also, it tried to interpret the abstruse and complicated scientific indicators and convey the information to the ordinary citizens in easy language. 
Additionally, the An'Yang Federation of Environmental Movement began to pay attention to the function of media such as SBS and MBC. It filmed an educational DVD to announce and advocate for the various values from the underrepresented and ordinary citizen groups. The function of the media to facilitate information exchange, especially about values, was verified again through the interviews in this research.

The documentary TV shows covered many stories on citizens' efforts and contributions that could not be well addressed in the governance activities led by the public administrators. The citizens could hear of the successful contribution of citizen groups and NGOs in the stream restoration project. Some NGOs filmed DVD movies of their activities on An'Yang Stream restoration for the purpose of educational and cultural prosperity. (CO 04)

The citizen values for An'Yang Stream described by the media were much different from the values of water resource professionals (specifically civil engineers). First of all, the citizens valued usable waterfront and recreational spaces and aesthetic spatial beautification, as well as An'Yang Stream's cultural and historical revitalization.

The SBS TV show also introduced An'Yang Stream educational and cultural programs based on citizen activities. One example was An'Yang Stream Water Ecological Specialist Education Program, which was open to the local community. In this program, the participants could learn about ecological water systems and professional information on the stream ecological systems. The media catalyzed and assisted the governance network based on citizens' involvement. The SBS TV show introduced their innovative efforts through educational programs about the An'Yang stream restoration. The public in An'Yang society could see some positive signals toward the successful civic participation from the educational program. 
The strengths of the TV documentaries were to compare and convey others' values and impact key stakeholders within the stream restoration governance. Also, the stream contamination processes and human impacts in the ecology of An'Yang Stream were explained to citizens. Shaping public opinion through the media was one of the effective ways to announce information and receive a fervent response by citizens to the vision. The episodes filmed regarding An'Yang Stream successfully carried the legitimacy of the stream restoration project and its agenda, as well as the stakeholders' interests. In this process, the media integrated their common ideas and analyzed conflicting points. Through the TV documentaries, various values could be mapped and categorized into the specific values' groups like 'ecological restoration', 'collaborative governance building', and 'waterfront gardening'. After watching the SBS documentaries, groups who had seen water quality improvement as the primary value tended to expand their agenda to include ecological restoration.

The SBS TV show helped both sides share and accept different values to seek the best solution. One episode of 'Water is life' dealt with the entire story of the An'Yang Stream governance's activities since the beginning stage of the An'Yang Stream restoration movement. The episode addressed that the An'Yang Stream restoration governance concentrated its energy on enhancing water quality and ecological restoration. Meanwhile, it showed a conflict between private stakeholders and the government because the government and water resource managers were considered the most important, ignoring citizens' diverse interests in restoring the stream's resources. In selecting one method of participatory communication, the public administrators held simple one-way processes, such as public hearings or policy introduction presentations, 
but the stakeholders such as citizens, NGOs, and environmental groups wanted to be deeply engaged in the decision-making process.

Furthermore, the interests, support, and field activities of the private stakeholders could be evaluated and gain recognition. This SBS TV show had a position that could share invisible and underrepresented values of ignored stakeholders regarding collaborative governance.

The chief producer of the documentary TV show, 'Water is life' recorded and observed the process of the An'Yang Stream restoration through the camera lens. The team later joined our volunteering group for the ecological restoration and became one part of our jobs. They were very enthusiastic about working with community members and NGOs because the SBS headquarters was located in the downstream region of the An'Yang Stream. In other words, they knew the seriousness of the water pollution very well before. (NGO 02)

Also, the TV shows criticized the irresponsible leadership of some public administrators who did not know the nature of and did not frequently visit the An'Yang Stream. The show suggested that the managers needed to rotate their positions every three to four years. In fact, many academic articles and public documents on the An'Yang Stream restoration were written by water professionals who had never been to the An'Yang Stream. According to the producers who filmed the documentary TV shows, they observed these things when they met the water experts during interviews.

The TV shows showed citizens' efforts and support of some private stakeholders such as NGOs (namely, the Environmental Conservation Institution and An'Yang Euiwang Federation of Environmental Movement and An'Yang YMCA). The shows introduced some cases that the private network based on these efforts and support of citizens. The NGOs finally established the 'Water Ecology Citizen Expert Training Program' to overcome the lack of understanding of professional knowledge and access 
to relevant data by citizens, due to a limitation in collecting water quality data and ecological measuring indicators, and in analyzing such information.

The TV media conveyed enthusiastic efforts to embrace diverse interests in An'Yang Stream. From his testimony, one TV show producer mentioned that the value of non-scientific issues tended to be weakened in their influence, power, and legitimacy against technocratic values within the An'Yang Stream restoration governance. Hence, the roles of broadcasting, newspaper, and social media since 2001 have played an important role that reflects and advocates for the interests of ordinary citizens and disadvantaged groups in the An'Yang Stream restoration, and lets the policy-makers and stakeholders of the stream restoration recognize their various interests.

Documentary DVDs recorded and published by the An'Yang Stream Protection Network described the diverse interests of the stakeholders who were concerned about agenda setting and the directions of the An'Yang Stream restoration. The DVD documentary produced by the NGO network (the An'Yang Stream Protection Network) showed the associated stakeholders' diverse interests and values on stream restoration. The documentary shared the values on An'Yang Stream, and the visions and opinions of various An'Yang Stream specialists in each subject. Contrary to the previous Master Plan and strategies of the An'Yang Stream restoration, most government documentaries and public materials did address historical and cultural issues.

The waterfront bike path is connected from the Han River to upstream An'Yang Stream. The rest areas and amenities for the bikers need to be maintained well for their sake of convenience. ( $\mathrm{CO} 01)$

The An'Yang Stream Protection Network dealt with new interests and values that had been introduced in previous documents. In the movie, diverse viewpoints on the 
scientific stream restoration were available to compare as an opportunity for social learning and an educational outreach program for the public. To sum up, the roles of the broadcast media contributed to promoting the various efforts and challenges within the governance of the An'Yang Stream restoration, and sometimes conveyed different opinions among the stakeholders as a communication route. This research could answer one newly arisen research question, "How can the media contribute to collaborative planning processes?”

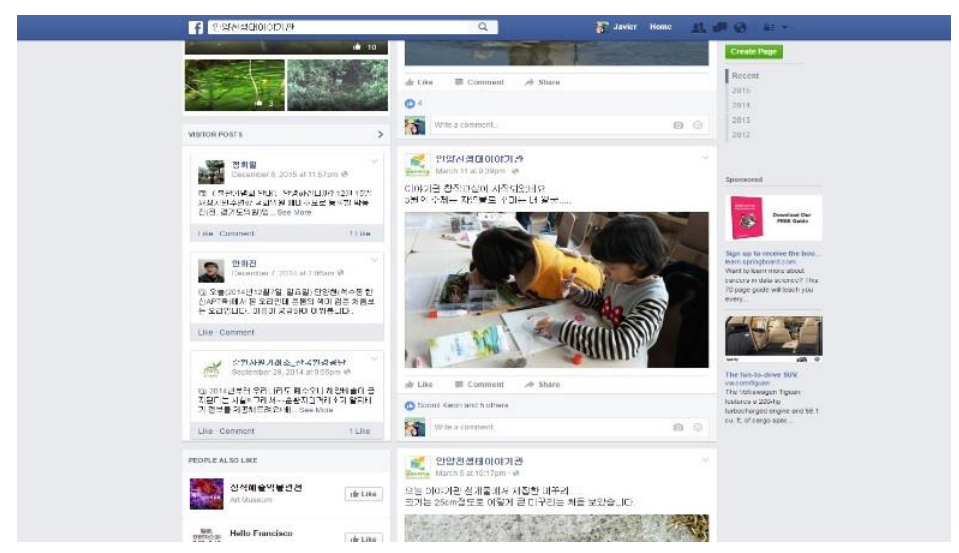

Figure 16. An'Yang Stream Restoration Story Hall (Visitor Center) Facebook (1): communicating with citizens and announcing their events

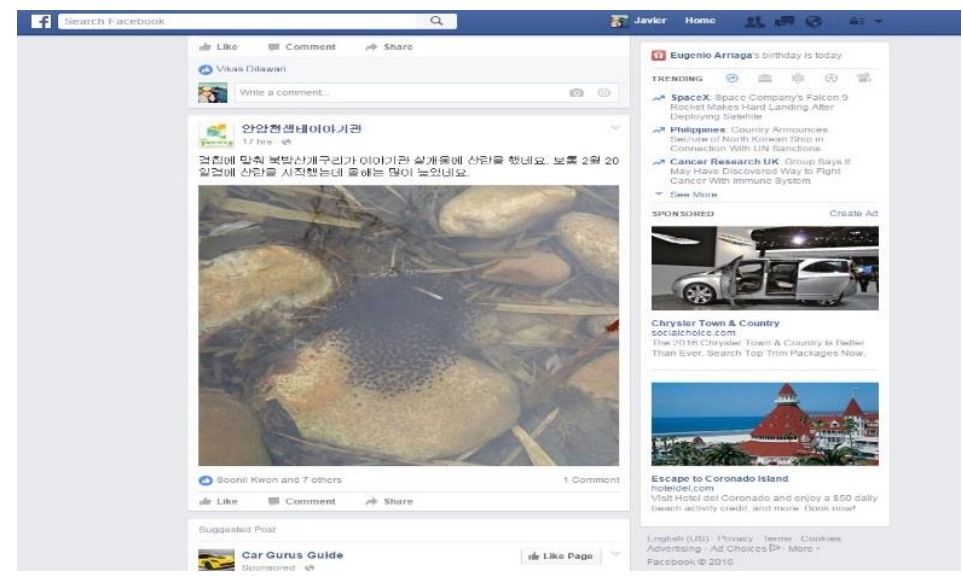

Figure 17. An'Yang Stream Visitor Center Facebook (2): updating on An'Yang Stream on the social media 
Since 2012, Social media (Figures 16 and 17), such as Facebook and Twitter, has also played a new role in exchanging information and forming public opinion on the An'Yang Stream restoration. The citizens were introduced to the processes, results, and conflicts within the governance. However, social media was only available for specific groups who could connect through digital devices, and many of those citizens did not want to check the updates on An'Yang Stream restoration everyday or every week.

The An'Yang Stream Ecological Education Center has provided updated hydrologic information and environmental activities and changes of ecological systems of the An'Yang Stream through Facebook and Twitter. (PA04)

\subsubsection{Joint-fact-finding}

According to Herman et al. (2007), Joint-Fact-Finding (JFF) refers to a procedure or process of best practices that ensure science and politics are appropriately incorporated in environmental decision-making through shared learning at different levels. The concept of joint fact-finding is new in South Korean society. In particular, urban planning and environmental planning scholars in South Korea did not consider the idea of joint-fact-finding to be important because the public officials, scholars, and researchers who worked in the planning field were civil engineers or environmental scientists. In other words, they did not view local and cultural knowledge or 'planning' as a part of engineering technological processes, as Herman et al. (2007) have stated.

Joint-fact-finding provides multiple benefits (Schultz, 2003). First, it promotes conflicting parties to have an opportunity to better understand scientific and technical issues together. In particular, non-experts can learn a great deal about technical issues and experts can better understand the non-technical factors. Second, through 
independent representation and voice, the parties can come to agreement on potential ways to solve problems. The third benefit of joint-fact-finding is an improved relationship, based on mutual trust, between the conflicting parties.

This An'Yang Stream task-force held frequent workshops to share newly found scientific indicators and ecological test results within the active networks and strong partnerships among the stakeholders. During these processes, scientific and engineering experts gave presentations on the restoration outcomes and explained the scientific and engineering changes in An'Yang Stream in simplified language. The citizen groups noted that these workshops helped them understand the scientific knowledge, such as water quality indicators and ecological index. These activities of the An'Yang Stream decision-making system were more akin to an outreach educational program, rather than joint-fact-finding. Non-technical stakeholders were not involved in designing the research; they were not asked simple questions such as what is important to know before making decisions or agreeing on data collection methods and analytical protocols.

Even though the An'Yang Stream restoration project did not include the benefits of joint-fact-finding, it is a still great example of active interactions among stakeholders in exchanging professional expertise and knowledge in communicative workshops as an educational outreach program. Thus, even though the An'Yang Stream decision-making process did not exhibit the core concepts of joint-fact-finding, it did achieve successful water quality improvement through private-public partnerships based on the active interactions among stakeholders. 


\subsubsection{Conflicts and power dynamics}

There are still many unsolved conflicts between stakeholders with diverse values within the An'Yang decision-making process, and these conflicting values have been a stumbling block to long-term successful stream restoration.

\section{Conflicts}

Within the An'Yang Stream decision-making, the NGOs and citizen groups experienced conflicts because of different interests. These included social restoration as well as ecological restoration, rather than technocratic stream restoration. The politicians were prone to rely on the consulting advice of professional advisory groups of An'Yang Stream to show their short-term accomplishments in the restoration job. The public administrators did not handle the variety of complaints.

There were several types of conflicts in the An'Yang Stream decision-making system. First, we can view conflicts among the different values. The public administrators and citizens had entirely different backgrounds and values in approaching successful stream restoration. These conflicts were very general, typical types of discord in environmental governance building and processes (Cortner and Moote, 1999). Also, when considering collaborative decision-making, the relations and communications among the values are most important in evaluating the success of the governance and having the best solutions for conflicts, which are not easy (Cotner and Moote, 1999). The citizens and NGOs wanted to have more communication channels to share their values with other stakeholders, but there was no arbitration committee or any conflict resolution committee that could deal with these challenges. The only available institutional solution for conflict resolution was the Environmental Conflict Arbitration 
Committee, established by the Ministry of Environment of Korea, but it focused on finding solutions for major conflicts between governments and organizations.

Moreover, the stakeholders could not help facing complicated conflicts due to different academic backgrounds and applications. The researchers and engineers held highly the value of technocratic stream restoration. In particular, environmental scientists focused on restoring the ecological systems of the An'Yang Stream through water quality improvement, but civil engineers argued for using and applying new technologies and innovative construction systems of wastewater purifying facilities and sewage treatment plants for An'Yang Stream's restoration. This was an excellent example of a conflict stemming from different epistemological values that were held by the professional stream management experts. In other words, the environmental researchers and civil engineers held differences of opinion on how to approach the search for solutions to process water quality improvement, and the stakeholders tended to rely on their technocratic viewpoints in the policy-making. Thus, the influence of the scientific groups had a large impact in shaping the diverse values within the An'Yang Stream decision-making, which might have caused various debates. The conflicts between technocrats within the stream decision-making system were not easy to resolve due to the distinctive scopes and frames rooted in their different backgrounds.

Scientific water quality standard data functioned as a useful tool to evaluate the environmental water systems based on objective standards defined by prestigious international institutions, but they might have been misunderstood or interpreted differently (Yosie and Herbst, 1998). 
Our NGO has been working for monitoring the BOD and DO since 1998, and we have scientist members who can advise An'Yang Stream restoration activities. However, the government committee had different levels of standards of BOD and DO based on the engineering textbook. It would be a far-reaching issue for local ecological systems because the government committee had the river survey results from the universities or institutes, which did not know the An'Yang Stream ecological systems. I am sure we had more experience than they did. (NGO 02)

Decision-makers of the governments also relied on these scientific data when announcing their achievements in the restoration job, but the private sector stakeholders were careful to announce and commend the success because there was a broad range of stream restoration standard levels regulated by different institutes. Sometimes, participants within even the advisory committee had different standards in evaluating the stream restoration processes. Some parties assessed based on the water quality standards of Europe and others by those of the United States or Japan. These disagreements in their findings resulted in conflicts.

Sometimes, the public documents issued by the AGWQC addressed disagreements due to the scientific indicators and construction of wastewater purification facilities of each stream region of the An'Yang Stream. In fact, the success of water quality improvement and stable stream-flow was caused by the wastewater purification facilities in the stream regions. In this process, people in the upstream region, such as Gunpo and Eui-wang, were not happy with these facilities because they wanted to keep natural-style stream regions, and the water quality in the upstream region was much better than where the downstream region joined the Han-River. In addition, the citizens had concerns that new constructions in the stream basin would result in higher taxes.

Second, the citizen groups of the decision-making system also experienced conflicts due to debating of values. These groups participated in the decision-making to 
support and share various values on the An'Yang Stream restoration. Comparing other participant groups, the citizen groups held a wider range of values because the citizens utilized the stream resources for different purposes. For example, the citizens in the upper stream prized natural stream restoration, but the citizens in the downstream focused on spatial beautification and landscaping. The citizens in the upstream regions (natural stream) did not want human-made structures while the citizens in the urbanized downstream regions (urban stream) favored efficient spatial utilization for recreational purposes. All of the citizen groups held the standard value of water quality improvement, but the citizens in each stream region viewed the process and the benefit from the stream restoration differently. Regarding building water structures such as recreational facilities and wastewater treatment facilities, some citizen groups showed support where others did not because of the potential for additional environmental devastation. Some interviewees did address those conflicts from different interests in how to use the restored An'Yang Stream. Also, groups addressed benefits of participatory decision-making systems to the stakeholders in the governance to avoid inappropriate construction in the watershed regions through an institutional democratic and deliberative process. Due to the lack of a deliberative system, there were small and large conflicts between the citizens.

Third, the conflicts among the citizens were not addressed in the proper way, because of a lack of professionally trained mediators, who assist conflicting parties through communication and negotiation techniques, and facilitators, who have duties to share the relevant information with stakeholders to reach a jointly agreed upon consensus following negotiation, so the conflicts grew worse and more complicated. 
Many citizen groups left the decision-making board and some existing citizen groups were struggling to find solutions for unsolved conflicts. In terms of social, cultural, educational, and historical values, some residents established a system for addressing them, because they thought that the present stakeholders ignored those values in the agenda setting. Meanwhile, some citizen groups still supported technocratic factors as the primary value in the agenda setting. Also, there was complicated political interest led and manipulated by some political citizen groups that resulted in complex issues about environmental policy-making processes. These conflicts were harder to resolve through the reframing of their different views and interests again because of a lack of the right leadership or mediator.

Fourth, the local governments faced challenges in distributing the financial resources and available information on the An'Yang Stream. The An'Yang Stream decision-making board included 13 local governments. Geographically, these were distributed from upstream to downstream in the watershed. Thus, they had different viewpoints on stream restoration. The City of Gwangmyong under the Kyonggi Province and the Guro District under the City of Seoul shared the same region of the An'Yang Stream and needed to cooperate and collaborate in managing the stream, but they could not avoid conflicts due to different levels of budget allocation. For example, they had different interests in constructing new recreational and sports facilities for the citizens, and neither party wanted to pay due to budget reductions. In this conflict, the higher government like the City of Seoul or Kyonggi Province might have had the power to mediate, but they did not pay attention to the conflict, and thus did not have a professional mediator. Another issue came from the nonprofessional mediating and 
advocating of the public administrators because they cycled positions every other year within the government. Consequently, the unstable leadership of the public officials in charge of the An'Yang Stream restoration was not helpful for conflict resolutions between the governments, and even had the potential to bring about new conflicts.

Lastly, the An'Yang Stream stakeholders experienced various conflicts due to different political interests and social values. These conflicting interests and values were expanded to collective political conflicts among the participants within policy-making processes of the governance. In these political battles, the stakeholders were sometimes adversarial against each other. Among the local governments, political conflicts happened because each leader of the local government, who was elected by the people, was involved in a specific political party that had a different political background and agenda in environmental policy-making. Also, some NGOs and citizen groups viewed the An'Yang Stream restoration in a political frame in the decision-making system. Some were liberal and others conservative; these political preferences influenced individual agenda setting in the An'Yang Stream restoration decision-making system. The stakeholders holding conservative political views did not want a large change in the stream restoration, but others aligned with a liberal political view tended to be willing to accept a challenge based on innovative policy-making. For instance, one of the most important key persons in the An'Yang Stream restoration, Mr. Joong-Dae Shin was involved with the conservative party. After his term as a mayor of the City of An'Yang, his successor rose from the liberal party, which held a different political frame in stream restoration. The new local government leader from the liberal party had a goal of process-oriented restoration while Mr. Shin seemed to have had a goal-oriented 
restoration process. Mr. Shin's government had tremendous achievement in the An'Yang Stream restoration, but could not smoothly solve the conflicts with many NGOs and citizen groups. The new mayor repealed the An'Yang Stream restoration task-force to reduce the budget in the stream restoration project and expanded the social-welfare budget based on different political values. Due to this, it was more difficult to solve the conflicts among the stakeholders. As a result, the An'Yang Stream decision-making system including the AGCWQ and ASPN has since been inactive, without any motivator or driver following the water quality improvement.

Most participants answered that the best solutions that they had selected for finding mutual agreement would be scientific information based on professional knowledge and statistical data. In An'Yang Stream's case, because of the absence of professional mediators, participants wanted to use more updated and rational scientific data such as ecological indicators and water quality data in conflicts. To sum-up, these various types of conflicts on An'Yang Stream tended to be viewed and resolved with scientific research and technocratic feasibility evaluations. In this process, the power and control within the decision-making process came from better understanding and having professional knowledge of scientific stream restoration.

\section{Power dynamics within decision-making}

The interviews revealed different opinions about power in An'Yang Stream decision-making process. One government representative contended that power was shared. This was a kind of 'conditioned power' defined by Galbraith (1983) and 'network power' asserted by Booher and Innes (2002). This conditioned power can be 
explained as one exercise rationally influenced by changing belief through scientific education and social commitment (Galbraith, 1998). Booher and Innes (2002) argue that network power can be a pattern of shared power which is shaped by the participating parties in a collaborative network. The governments wanted to believe and convince that the stakeholders equally exerted their power through the stream restoration participatory governance established by the top-down decision-making structure.

However, the interviewees from NGOs and citizen groups had different opinions on power dynamics in sharing scientific information. The citizen groups and environmental NGOs described their difficulties in obtaining the appropriate scientific information and requesting professional consulting, and they felt the public administrators and water resource professionals were stronger than themselves. The public administrators, civil engineers, and hydrologists tended to have a system and the legal authority to collect and analyze the necessary data and knowledge, while other private stakeholders (NGOs and citizen groups) were at a disadvantage in accessing relevant water resource data on An'Yang Stream.

\subsection{DICUSSION AND SUMMARY}

"Selective coding: The process of selecting the core category, systematically relating it to other categories, validating those relationships, and filling in categories that need further refinement and development." (Strauss and Corbin, 1990)

Again, this chapter addresses a summary of the analytical process after field survey through the Grounded Theory concept. According to Strauss and Corbin (1990), selective coding played a role in the process of choosing one category to be the core 
category, and then relating all other categories to that category. The essential idea was to develop a single storyline around which everything else was focused. After field research, the researcher applied Grounded Theory to draw from the literary analysis as seen in this chapter. Also, this selective coding was about finding the driver that compels the story forward. The storyline under the guidance of selective coding provided a categorized analytic system that can help us connect the core categories with other available variables. First, open coding was conducted to analyze the individual value of the stakeholders, and then the paradigm model was drawn through the axial coding. Also, the selective coding process helped to define the core categories and to both describe power dynamics among the stakeholders and evaluate priorities among their values.

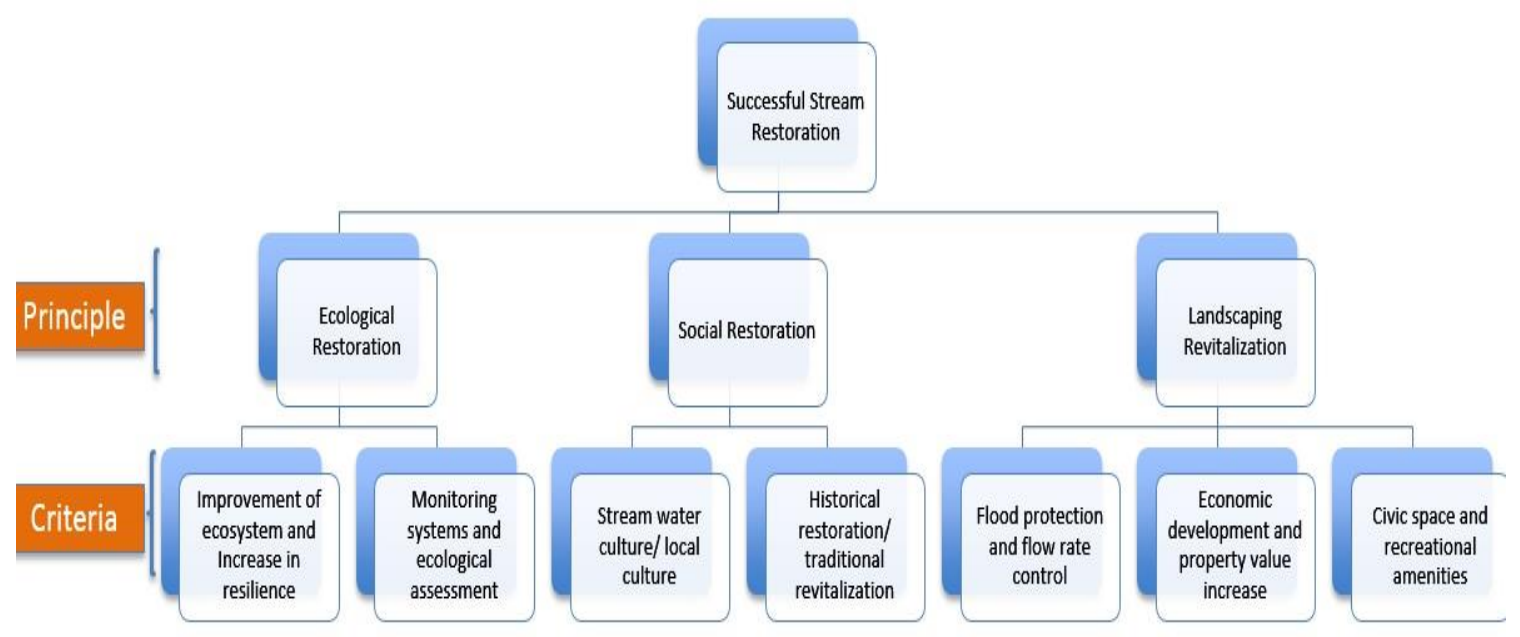

Figure 18. Hierarchical structure of stream restoration

Figure 18 shows the values (principles) and criteria of the stakeholders, as used in AHP analysis. ER stood for ecological improvement based on technocratic innovation 
and social restoration included water culture and history through developing social systems. Lastly, landscaping revitalization was aimed by some stakeholder groups by reason of establishing flood prevention and increasing spatial efficiency for the community and providing economic profits for the construction companies and landlords.

Ultimately, serious ecological dilapidation of the An'Yang Stream induced ordinary citizen groups to work together for the stream restoration. In the past, watershed management tended to focus on flood and streamflow control by the authorities, which was aimed at rapid industrialization and urbanization; thus causing water quality deterioration and indiscreet channelization in the An'Yang watershed (Lee and Chung, 2011; Yang et al., 2012). In the late 1990s, many public debates about the local river or stream restoration occurred as a result of the self-governing capacity of South Korean local autonomous systems and citizens' increasing demands. Local governments and citizen groups in the An'Yang watershed wanted to find an efficient solution to streamflow contamination.

Technocratic stream restoration came about as a good system to successfully achieve water quality improvement and ecological enhancement within a short time, but the government and other players lacked the capacity to integrate social values and therefore defaulted to the scientific/technical orientation. These neglected values and interests became a cause of discord among conflicting stakeholders within the decisionmaking. The An'Yang Stream decision-making board did not have a professional who could mediate these conflicts. Consequently, it prevented the establishment of a sustainable long-term decision-making system for stream restoration. 
The An'Yang Stream restoration case, as well as other South Korean stream restoration cases, had several common limitations in building a decision-making system. In particular, according to Hong and Chung (2016), although the stakeholders of the An'Yang Stream governance were more active than other cases, they did not reflect and overcome some of the challenges and obstacles. First, the An'Yang Stream restoration decision-making board could not break from conventional paradigms of environmental and ecological stream restoration based on technocratic information and knowledge. As a result, it only aimed at specific ecological restoration goals for standardized and uniform scientific promotion.

Second, there was an imbalance of power dynamics among the stakeholders, and any institutional innovation for conflict resolution was absent within the decisionmaking. Participatory processes to achieve an equally balanced power structure could not be aptly realized because of unbalanced power relations among the stakeholders. These varied stakeholders' influences on the decision-making process arose from differences in the capacity to understand professional expertise and the access to relevant information on An'Yang Stream. The decision-making board did not properly address institutional devices to mitigate unequal power distribution, and did not provide opportunities such as 'joint-fact-finding' for the stakeholders, although participatory programs were designed in the Master Plan. The participatory programs were nominally established by nonprofessionals who did not appropriately understand the field of participatory decision-making and civic participation. Consequently, they failed to solve the harmful effects of the lopsided power distribution pattern because the contents of addressed participatory programs were limited and impractical. Citizen groups and 
environmental NGOs were not prepared to analyze or evaluate the professional indicators of stream restoration, while most public officials and administrators had established professional experience in stream restoration. Hence, the participatory program of An'Yang Stream decision-making was mostly shaped and determined by the public administrators who led the top-down decision-making systems, in embracing other non-scientific values and interests about the An'Yang Stream restoration. This process resulted in technocratic stream restoration in the An'Yang Stream management project.

Citizens and environmental groups also believed that appropriate river restoration needed to enhance and improve scientific indicators such as water quality and ecological standards regarding stream restoration. Finally, scientific indicators that are quantifying and evaluating water quality, as well as aqua ecology, were improved. However, the decision-making agendas could not meet the requests of various values and interests held by the citizens and environmental groups; rather they faced even more conflicts among the stakeholders.

Third, prevalent political stakes in the An'Yang Stream decision-making tended to value political profit more than productive decision-making driven by deliberative and participatory governance activities for the river restoration. Political leaders focused on water quality improvement and ecological system promotion in the short term because they needed to show the success of their leadership during their term of office. In other words, they wanted to achieve political success and a successful reputation. They also wanted to strengthen their political position through the technocratic restoration of 
An'Yang Stream based on top-down driven decision-making, such as engineering technological renovation.

Furthermore, political conflicts influenced the governing relations among the stakeholders. During agenda setting, those political conflicts directly affected differing values on stream restoration. These conflicts within the decision-making process caused power imbalances and struggles that negated partnerships. Some stakeholders unconditionally opposed values of others who were competing with them to gain more political power, regardless of the legitimacy and necessity of the value. Because the An'Yang Stream restoration decision-making board could not overcome these limitations, it still remains unsolved and complicates conflicts among the stakeholders, and many participants have left the decision-making board.

Lastly, public administrators' performance-oriented bureaucracy prevailed in the short-term and was the biggest obstacle in the decision-making. Because public administrators generally moved to a new position each year or every two to three years, their professionalism could not be developed. To overcome and avoid this issue, the Mayor, Mr. Shin of the City of An'Yang established a task-force that focused on the An'Yang Stream restoration. The members of the An'Yang Stream restoration taskforce stayed and worked on the team for more than three years, and their professionalism contributed to water quality improvement in the short term. The task force made an effort to build an active and sustainable decision-making system by supporting various programs. Unfortunately, however, after a new mayor was elected and the administration changed, the An'Yang Stream management task force team was abolished, and the traditional circulating public administrative system returned. Thus, 
the public administrators who were newly assigned to the stream restoration department began An'Yang Stream restoration work without relevant professional knowledge about the stream.

Other government agencies, as well as the City of An'Yang, also had newly changed political leaders. Hence, the public administrators and officers on the team under new leadership managing the An'Yang Stream restoration aimed at a short-term outcome, rather than long-term enhanced efficiency. Severe bureaucracy and top-down decision-making systems again prevailed and became widespread in the An'Yang Stream restoration. The bureaucracy created administrative and political friction among the stream restoration stakeholders regarding financial decisions and budget allocation. Ultimately, addressing and mitigating conflicts and disagreements became more complicated to solve. 


\section{Chapter 8}

\section{Conclusions}

This chapter reviews the findings and provides solutions and suggestions for future research. Based on the results, each research finding is reviewed and evaluated along with previous studies and their meanings. Prior empirical and theoretical implications of the research process are provided in depth. Future practical implications of possible solutions in the case of An'Yang Stream restoration are described to address each element of the strengths and weaknesses of the present stream restoration trend and culture in South Korea. The limitations of this study and guidelines for future research are provided.

This dissertation research addresses how and to what extent environmental decision-making processes incorporated different values and visions of the stakeholders. Chapter 1 introduced the goals and motivations of this research. It included an overall summary of the dissertation and the following chapters and the linkages among the chapters.

Chapter 2 provided a comprehensive overview of an interdisciplinary literature which explains complex and critical issues, environmental decision-making in governance. To answer the research questions, it found some relevant theories and cases to argue for balanced interaction and coordination between scientific knowledge and societal contexts (non-scientific values) in stream restoration.

Chapter 3 introduced the framework of this research that can meet the primary goal and designed research plan. Data collection and analysis for the stream restoration case occurred in four steps: (1) examination of an initial document to understand agendas of 
the early stage of stream restoration before 2001, (2) interviews with governance participants to recognize the impact of the document from 2001 until 2015 after published, (3) Analytic Hierarchic Process (AHP) method to evaluate the impact of the document, and (4) grounded theory quantitatively.

Chapter 4 identified and analyzed the goals and agendas of the early period of the An'Yang Stream restoration through content analysis with the Master Plan published in 2001. The chapter let the readers understand what was planned regarding the governance structure and key agendas of the restoration process as presented in the An'Yang Stream Restoration Master Plan at the initial stages (before 2001).

Chapter 5 discussed findings and the implications of interviews with key participants of the An'Yang Stream restoration governance after the Master Plan was published in public, through content analysis, to recognize and analyze the values and goals of each participant within the An'Yang Stream restoration governance. This chapter helped to understand directly how the Master Plan has been implemented in the restoration process from 2001 up to 2015.

Chapter 6 indicated the discussion of findings and the implications of Analytic Hierarchy Process (AHP) analysis, to support my findings in Chapter 5 by quantitatively recognizing and analyzing the relative priorities (comparative importance) among the values of the key participant within the An'Yang Stream restoration governance from 2001 up to 2015.

Chapter 7 covered comprehensive discussion of findings and the implication of content analysis after interviews and AHP analysis of the preference survey to integratedly understand and emphasize not the only various values and goals of each 
decision-maker but also their causal relationships based on inductive thinking, within the An'Yang Stream restoration decision-making governance along with the Axial Coding of Grounded Theory. Lastly, this Chapter 8 draws the conclusions after discussions of findings and the implications of available solutions that can be found through this dissertation research.

Due to the complexity and uncertainty during the decision-making process of the stream management, the decision-makers as well as the stakeholders had to solve many conflicting and different problems when each stakeholder of the governance had different views based on distinct values. This study found the technocratic values and interests of the decision-makers and governance participants can remarkably influence and impact a process to revitalize river systems. Based on the technocratic value finding of water quality and ecological restoration, An'Yang Stream project may be one of the best cases of Korean stream restoration, one that could successfully meet the goals of water quality improvement and increased ecological diversity. Conventional stream restoration can provide a good short-term solution from ecological and environmental pollution.

However, this conventional approach does not appear to address intangible elements or values, such as social conflicts among stakeholders in stream management, which may be necessary for more sustainable solutions. The An'Yang Stream restoration process was also designed by natural scientists and technocratic leaders who valued scientific information rather than non-scientific factors such as culture, education, social integrity, and waterfront beautification based on a participatory 
process. An'Yang Stream tended to be viewed and resolved through scientific research and technocratic feasibility evaluations.

This research has a different significance than the currently published articles or research papers because it is based on mixed-methods research into the stakeholders' preference surveys and in-depth interviews conducted in 2015. This mixed-methods analysis is essential to reflect the newly updated stakeholders' (governance participants) preference patterns in rating the specific values of the An'Yang watershed. In 2015, many citizens were concerned about ecological restoration such as water quality issues with An'Yang Stream. They valued water quality enhancement as the main goal more than other values, such as culture or history, as some stakeholders of the An'Yang Stream restoration partnership considered.

Some citizens seemed to be concerned about the physical and spatial renovation, as well as the ecological devastation in the An'Yang watershed. In particular, citizens who live in frequently flooded regions were inclined to hold higher concerns about flooding than citizens in other regions. The citizens in regions that recorded low stream-flow levels responded that the An'Yang Stream restoration strategies should solve the stream-flow issues in tandem with water quality enhancement. 


\section{Technical definition of SR}

A SR process of returning river sections to a near-natural state through improved hydrologic, geomorphic, and ecological processes (Wohl et al. 2005 and Woolsey et al., 2007)
Interdisciplinary definition of SR

A SR process by sustainable governance (Henriksen et al., 2009), for socioeconomic enhancement and local economy revitalization (Riley, 1998)

A participatory SR process embracing diverse feedback from ecological (scientific knowledge) and social factors (cultures and values) (MacDonald et al., 2004)

\begin{tabular}{|l|}
\hline Ecological Restoration \\
\hline - Improvement of ecosystem and \\
increase in resilience \\
(NIH, 2003; NSF, 2010, Palmer \\
et al., 2005) \\
- Ecological monitoring systems \\
(BOD, DO, FD level) (Lacoul, \\
2006, Piwowar et al. 2008a; \\
2008b) \\
\hline
\end{tabular}

\section{Social Restoration}

- Social values and culture (Rogers, 2006)

- Local and Historical restoration (McDonald et al., 2004) - Democratic collaboration (Henriksen et al., 2009) - Conflict resolution (Dutcher et al., 2004)

\section{Landscape Revitaliz.}

- Landscape beautification - Flood protection Flow rate control (Wohl et al., 2005) - Recreational space (Kondolf and Yang, 2008)

- Easy access (NRCS, 2007)

- Modern landscaping (Olden and Poff, 2006)

Figure 19. Various definitions of stream restoration

Therefore, the decision-makers of the An'Yang Stream governance need to establish a participatory and flexible river management system by accepting the unique regional features and the stakeholders' interests in planning a long-term river management strategy (Figure 19). The integrated river management strategy by wellorganized participatory processes would potentially be able to satisfy the diverse interests and values with respect to social restoration as well as river spatial renovation, landscaping, floods, the flow-rate problem and water quality problems.

\subsection{MOTIVATION IN RESEARCH}

The main objective of this research was to examine whether a collaborative approach to governance incorporates different values and visions of stakeholders within 
the context of an environmental decision-making governance structure. This research studied a case from South Korea to examine how decision-making systems are shaped in stream restoration collaboratives. This research concentrated on observing and reviewing the values and interests of each stakeholder representing diverse interests regarding the stream restoration, to fundamentally adopt rational stream restoration decision-making processes based upon a participatory system in the future. It is going to eventually help the decision-makers achieve a core vision of an integrated decisionmaking process between social and scientific factors.

This research reviewed and analyzed the decision-makers' behaviors and opinions in order to elucidate why the decision-makers representing the stakeholders think of scientific information as the significant factor influencing the decision-making process within stream restoration management.

\subsection{SUMMARY OF FINDINGS}

Since science-oriented technocratic stream restoration tends to be more common and taken for granted, as well as to be predominated in the stream restoration process, investigating and reviewing diverse preferences are not often seen as primary goals. In this regard, the study may be valuable. Some people hold the prejudice that scientists plan and lead the decision-making in agenda setting for stream restoration. In reality, many stream restoration cases experienced iterative social conflicts and they were evaluated as incomplete stream restorations as reviewed by a third party. Thus, this study provides an opportunity to find and suggest feasible alternative solutions, as well as to find out the decision-makers, including governance participants, who considers 
scientific information as the primary value in evaluating stream restoration. Also, this researcher addressed the contextual conditions of decision-making processes and agenda setting in the stream restoration.

The main objective of this research is investigating to what extent non-technocratic values are integrated into stream restoration cases through governance processes of stream restoration in South Korea. As the data collection and analysis for the research occurred in four steps, the findings are conducted in four categories: (1) Nominal Group Technique (NGT) and Initial document review of the An'Yang Stream Restoration Master Plan reflecting agendas and values before 2001, (2) Content analysis of interviews with governance participants qualitatively describing implementation of the Master Plan strategies, (3) The Analytic Hierarchic Process (AHP) method quantitatively showing the implementation of the Master Plan, and (4) Axial Coding Analysis by Grounded Theory.

The first step of NGT analysis and initial document review was conducted and defined the three key values (ER, SR, and LR) of stream restoration. The initial document review of the An'Yang Stream Restoration Master Plan found the restoration agendas and strategies as well as plan-making in the early stages were aimed at only scientific stream restoration, rather than holistic and comprehensive stream restoration. It also included and accepted various kinds of scientific and non-scientific values in the stream restoration. In particular, the governmental groups and water resource engineers who work at water and environmental institutes still had more predominant control and power within the governance. This researcher concludes that many governance participants had a strong motivation due to their backgrounds in environmental or civil 
engineering. The stakeholders who valued the factors of humanities and socio-cultural development could not be adequately included in the decision-making processes because of a lack of access to the network and technocratic top-down oriented structures.

After reviewing and analyzing the document An'Yang Stream Restoration Master Plan published in 2001, this researcher addressed what values were mentioned and considered during their governance building processes and agenda setting of the Master Plan. As a result of the analysis, it was evident the An'Yang Stream governance aimed to accomplish values such as water quality enhancement, ecological revitalization, waterfront space renovation and landscaping, after the water resource experts scrutinized the monitoring process.

In addition, the An'Yang Stream governance was limited with being able to introduce the concept of political and administrative application regarding citizen participation in the An'Yang Stream, and affirmatively influenced the reactions of its citizens. Furthermore, it prompted politicians to support their political interests and values in the restoration work, which in turn induced citizen participation.

"Water quality improvement" was the most frequently mentioned term in the content analysis with the Master Plan (48 times). "Ecological city planning” was the second-most mentioned term in the plan. Meanwhile, codes representing the value of civic participation were recorded as lower than those representing scientific values. The results showed that civic participation was not as important compared to water quality and ecological restoration. This was determined by recording the frequency of the usage of terms such as collaborative governance (only 13 times) and participation (only 10 
times). Consequently, I posit that this master plan was successful in only addressing the importance of scientific water quality improvement based on technocratic values.

Second, after understanding the values and agendas of the early stage of the stream restoration through the content analysis with the An'Yang Stream Restoration Master Plan (City of An'Yang, 2001), interview sessions were held to recognize the implementations since 2001 after the Master Plan. This interview process was challenging. Finding stakeholders to interview was difficult, because most key stakeholders of the governance had retired or moved to new jobs. Stakeholders were contacted for in-person interviews and then a snowball sampling method was conducted to seek other associated stakeholders. Many stakeholders were reluctant to do interviews because of concerns about revealing their individual interests to the public. After several attempts of interview requests, some of the hesitant participants joined these semi-structured interviews and survey.

The interviews indicated limited ways to take in the different values of the stakeholders who had been experiencing scientific disagreements, conflicts, and power imbalance. The An'Yang Stream restoration decision-making board could not reflect the diverse values and different preferences of the stakeholders in the agenda setting because most decision-making happened based on technocratic efficiency and scientific knowledge. This research may carefully predict one potential reason, such as lack of joint-fact-finding and trained facilitators as well as technocratic knowledge-oriented culture.

This study was able to interview television broadcasting producers who made environmental issues-related documentary programs for Seoul Broadcasting Systems 
(SBS) and Mun'hwa Broadcasting Corporation (MBC). It was a rare opportunity because producers do not usually want to be involved in any public interview sessions and governance conflicts, and the An'Yang Stream restoration was a very sensitive issue in the region and local society. Through the interviews with these producers, this researcher learned about the roles and contributions of the media, and reviewed transcripts of their objective observations on the An'Yang Stream restoration.

A huge finding from these interview processes was the importance of the role the media has as a catalyst and facilitator. As noted in the previous sections in quotations from interviewees, the media helped the public understand what was happening in the An'Yang Stream restoration project. Documentary TV shows also helped demonstrate how resident involvement could help restore the An'Yang Stream. An exemplary case of this is the environmental documentary TV show, 'Water is life' produced by SBS.

Citizens learned about the successful process of An'Yang Stream restoration through the TV show, 'Water is life' filmed by SBS. It contributed to the sharing of public visions and policy agendas at the same time. Also, it provided a chance to display the big picture of the master plan, and the strengths and weaknesses of precedence cases. ( $\mathrm{CO} 01)$

During the stream restoration process, despite the high interests and enthusiasm of the stakeholders, they did not favorably or think it was important with regards to the value of non-scientific interests and only valued technocratic information, primarily addressed through decision-making processes and negotiation for collective decisionmaking and agenda-setting. The reason that the stakeholders needed technocratic information in the environmental debates was because they thought accurate and wellprepared technocratic information would be a most potent tool in negotiations and political debates. For instance, the values focusing on ecological restoration were the 
most important in agenda-setting, even after successful water quality improvement. The decision-making board did not adequately reflect and take diverse values, but ignored the role of professional mediators in conflicts, and are still political in the decisionmaking activities.

After the interviews with the stakeholders, such as citizen groups and NGOs, this study concludes that the An'Yang Stream restoration governance included the diverse values of the stakeholders, but conflicts and power dynamics arose because of the high interests and enthusiasm of the stakeholders. During the stream restoration process, these active stakeholders researched and collected technocratic information and addressed it through diverse governance networking and negotiations for collective decision-making and agenda-setting.

"Our organization invited professional researchers and professors in the field of hydrology and environmental engineering because they can help us with gaining professional information and build an ability to understand the relevant data........ This federation of environmental movement had to persuade the public administrators in the policy-making about An'Yang Stream waterfront renovation projects in the upstream." (NGO 03)

"Mayor Shin did a good job in stream restoration process, but the citizens could not be involved in the decision-making. They had more control because the citizens do not know how to evaluate and what is the major reason for the natural disasters and water pollution...... I attended one public hearing session hosted by City of An'Yang circa 2008. I gave them some questions about bike lane construction and landscaping because these projects would not be helpful to increase water quality in the stream. However, the public administrators mentioned they already researched the efficiency and feasibility and conducted relevant experiments. I am not a specialist in the water resource management field, and I could not refute their arguments." (CO 06)

Values focusing on water quality enhancement were the most important in agenda setting, after successful water quality improvement, because the governance did not 
embrace diverse values, ignored the importance of professional mediators in conflicts, and was overly political in governance activities.

The values and goals of interviewees originated from different backgrounds and priorities of preference. This content analysis delved into how much emphasis the governance participants put on technocratic performance, which is based on improvement by adopting scientific knowledge. Hence, this researcher looked at interview transcripts in a new way: by evaluating the agenda setting in terms of theories of both interdisciplinary analyses and urban planning. In particular, these interviews addressed who the key participants and leading decision-makers were, and how their values were drawn through mixed methods. The results provide the importance of the role of mixed methods in value findings within governance. Also, the results of content analysis through interviews guided the scope of the Analytic Hierarchy Process (AHP) by Nominal Group Technique (NGT).

The urban stream in An'Yang was almost the only ecological passage in a city surrounded by concrete. It was important to accommodate the migratory birds that come to the An'Yang watershed as well as to conduct a preliminary evaluation to protect the public space and provide a relaxing space for citizens. On the other hand, using certain sections for ecological parks could limit public access and certain sections near the downtown region had been designed as civic spaces for public activities. "The An'Yang Stream requires a strategic master plan for watershed protection and conservation, such as a strategy of natural stream restoration for all sectors." In addition, the An'Yang Stream needed consistent goals and plans that would generally cover characteristics about the entire regions of the watershed. Specifically, the differences between the 
upstream and the downstream regions were significant regarding stream flow management, flood prevention management, and water quality.

Third, according to the results of this AHP analysis, the weighted values of the five groups of decision-makers and stakeholders within the An'Yang Stream restoration governance network reflected the different priorities during strategic implementation of stream restoration, which each participant group had various standards as well as preferences and interests in evaluating the values in the stream restoration. These results show how the representatives of each participant group variously weighted the values of ecological restoration (ER), social restoration (SR) and landscaping revitalization (LR). In particular, most respondents tended to value ecological restoration as the most important factor (48.7\%). The interests in SR and LR measured lower than ER, reflecting the same results as the content analysis mentioned earlier. The weighted value of SR was $0.231(23.1 \%)$ and the weighted value of LR was $0.279(27.9 \%)$. The results show that the respondents in the survey were slightly more concerned about ecological restoration (ER) based on scientific management in the watershed than in SR and LR. The value of SR was regarded as the least important factor in the stream restoration. As a result, the value of ER was found to be the most important value among the various values held by the participants.

\subsection{DISCUSSION OF FINDING 1: STRENGTHS OF TECHNOCRATIC STREAM RESTORATION}

The predominance of technocratic approaches to stream restoration might be explained by framing the power and influence of the participants, which contributed to 
the power dynamics within the governance. In the An'Yang Stream Restoration governance, understanding and access to expertise led to influence and power or domination of decision making. Hence, citizen groups and non-governmental organizations needed to seek assistance from water resource professionals and environmental engineers, but these participants had limited access to the water resource data. 'Expert power' based on hydrologic engineering technology was preferred by the powerful participant groups in the governance.

There were benefits of hydrologic engineering technology-oriented stream restoration. Most decision-makers primarily preferred technocratic stream restoration due to the benefits. The first benefit was that improvement of the hydrologic and environmental indicators in the short-term could be highlighted and evaluated as a success of the entire river restoration process. Thus, the decision-makers took advantage of scientific indicators, and relied heavily upon them as most of the decision-makers were engineers. Additionally, methods other than scientific approaches were not preferentially considered because the preference for scientific approaches. To achieve interest politically and for the purpose of influencing the stream restoration decisionmaking, it was necessary to obtain a justification through a comparison of the scientific indicators from expert analysis that could be achieved in a short period. Politicians, the governance leaders, also used these scientific indicators to win the election and to obtain 'the legitimate power' in governance by securing specialized scientific knowledge.

Second, the use of scientific information in the power competition of the governance presented a very favorable condition: 'the expert power.' In other words, 
scientific data was the essential requirement that could win the power struggle; as Francis Bacon (1879) stated, "Knowledge is power." The participants in the governance did their best to first establish their own value in the An'Yang Stream restoration. Also, they tried to take the initiative in the power struggle by holding more extensive professional and hydrological data on the An'Yang Stream than the others obtained. As also appeared in the AHP analysis, the power dynamics reflected the technocratic stream restoration pattern well. The governance participants thought that ecological restoration based on science and technology should enable them to have more influence on the governance. That was why the governance participants wanted to hold accurate information and collect more reliable data. The structure of the decision making itself looked democratically equal; but on the other hand, the personal collective power structures were relative, interactive, and complementary to each other. The politicians used this technocratic professional resource as both a political tool externally, and a system to obtain administrative efficiency internally. The result is an eternal quandary for political actors. The efforts and passion of the politicians and governance leaders could achieve the water quality improvement in a short-term, but their support of technocratic stream restoration might be exposed to criticism for imprudently ignoring non-scientific values.

Third, the ecological discipline-oriented stream restoration strategy led by environmental scientists and engineers tended to take credit for the achievement of desired benefits and interests, as well as to reduce a backlash from other stakeholders. The decision-making process within the An'Yang Stream governance seemed to be topdown relying on technocratic knowledge, and the opponents who valued social 
restoration in the process of An'Yang Stream restoration could not overcome the attacks based on the scientific effectiveness of ecological stream restoration. Hence, the engineers and environmental scientists were easily key decision-makers in the governance. For instance, the public administrators or officials who represented the government and were the main key-decision makers had a background in environmental science or civil engineering, while representatives of the NGOs and citizen groups held diverse backgrounds and specialties, such as history, psychology, etc. Thus, these governance participants of NGOs and citizen groups did not have enough experience with river management regarding either data collection or expert analysis, and their ability to analyze was not developed. Accordingly, their influence on the governance was less powerful than the public administrators. It was also easy to convince the other opposing stakeholders by discussing the interpretations of professional and specialized scientific indicators. Therefore, the ecological stream restoration strategy addressed by governmental officials tended to be smoothly achieved in a short period.

Lastly, technocratic stream restoration provided cutting edge and innovative engineering technological methods to actively improve the scientific indicators. According to the An'Yang Stream Restoration Masterplan, scientific indicators and knowledge allowed decision-makers and governance participants to define problems with precision and then to precisely measure outcomes. The An'Yang Stream Restoration Project governance, which incorporated natural scientists and civil engineers, could quickly acquire advanced scientific knowledge and information from strong stream management cases overseas, and they adopted locally-processed knowledge in the An'Yang Stream restoration process. During interviews, participants 
testified about their sense of accomplishment and pride for their achievements. However, this research revealed that there was an insufficiency in the ecological scientific stream restoration that should be corrected.

\subsection{DISCUSSION OF FINDING 2: WEAKNESSES OF TECHNOCRATIC STREAM RESTORATION}

The ecological scientific stream restoration had many challenges and limitations. First, the technocratic restoration's weakness resulted from the lack of understanding of socio-cultural attention in the long-term, so the governance based on technocratic ecological stream restoration required ongoing supplements to carefully reflect the agenda changes in the river restoration and to meet citizens' demands. Moreover, citizens' participation was not always open and not continuous, so it was very limited in reflecting citizen opinion in their decision-making. This weakness undermined the longterm planned strategy of stream restoration.

Second, the response to non-scientific factors was significantly low. Non-scientific values such as socio-cultural factors did not interest the technocratic participants.

Instead, participants in the governance pursued ecological water quality enhancement of the An'Yang Stream as the primary value, and they did not significantly look at the values of social integrity, cultural revitalization, historical education, and sustainable governance building based upon stakeholder diversity. The ecological technocratic stream restoration only for ecological water quality enhancement did not properly cover cultural, political, and economic values. 
The third weakness of technocratic science-oriented stream restoration was the hegemony of the powerful participants who held professional scientific knowledge on the stream restoration process. Hydrologists especially had great control in governance processes, such as agenda setting of the stream restoration. Holding a wide range of professional hydrology knowledge seemed to be 'coercive power' as well as 'expert power.' The citizen groups and NGOs who were not water engineering professionals, could not understand or analyze the raw data regarding the water environment of the stream. Also, they could not persuade or refute the professional groups when discussing the pros and cons of the present stream restoration policy, or the process and results of scientific stream restoration. Thus, the key agenda of the An'Yang Stream restoration has been designed by the participants who could analyze the water data and have more access to it. Within the governance, the participants who did not hold sufficient professional knowledge on stream management might be eliminated in the course of the final decision-making, because their relative power and dominant influence were reduced and weakened.

Fourth, when they could not find an absolute scientific standard, the governance participants had serious conflicts and debates in understanding the scientific phenomenon. Hydraulic data based on the scientific phenomenon in the water environment varied depending on the organization that collected, analyzed, and perhaps manipulated it. In these cases, the participating stakeholders in the governance had different understandings of the same changes in scientific indicators, which led to conflicts. When there were obscure and subjective interpretations of data, governance participants were occupied in dealing with endless environmental debates. In this 
An'Yang Stream restoration case, there were frequent debates between environmental scientists and civil engineers because both parties had different disciplines and target levels in setting the water quality agenda. Also, the participants who represented various regions, such as upstream and downstream, had different environmental interests and values in the stream restoration. Thus, all participants needed to collaborate and cooperate before they could reach mutual consent. This complex paradigm within the governance structure caused constant competitions among the participants, but once the scientific indicators such as water quality level were based on absolute and objective standards, solutions were more straightforward.

Fifth, most non-scientific values in stream restoration were ignored, without indepth consideration. Most of the participants who made the major decisions about An'Yang Stream restoration were environmental scientists and civil engineers. Therefore, social restoration dealing with social integrity, cultural revitalization, historic research, etc. was excluded from the primary values. In the last 15 years, this weakness of technocratic stream restoration became noticeably worse in reflecting social factors. Collaboration among the participants who actively participated in the governance in the early stages started to lag after successful improvement of the water quality and environmental conditions through the technocratic stream restoration strategy. Looking at this change, we could conclude the fundamental value of An'Yang Stream restoration was to improve water quality and the ecosystem by accepting technocratic disciplines, but other elements were not considered significant. The findings of this research showed that most interviewees did not fully comprehend the importance of social restoration in the An'Yang project because of the predominance of the technocratic 
discipline of stream restoration within the governance. In particular, interdisciplinary theories such as the SESs (Ostrom, 2009) could help to explain the weakness of technocratic stream restoration because the equally balanced consideration and interdependence between social and ecological systems assist in creating sustainable environmental management in natural resource planning.

Sixth, the goals for citizen participation and social community benefits were disregarded when the technocratic stream restoration process proceeded for short-term success. Projects valuing citizen participation establish long-range processes, but the An'Yang Stream Restoration leaders did not plan for the necessary duration in establishing a well-organized civic participation system. Although a public participation system was described as one goal in the An'Yang Stream Restoration Master Plan (2001), no expert for governance management or civic participation practice was part of the planning process. Mediating mechanisms such as a conflict resolution committee or citizen watchdog group were peripheral in a technocratic stream restoration paradigm. The An'Yang Stream Restoration case illustrates the difficulty to institutionalize civic participation and sustainable governance building in a stream restoration project by focusing on short timelines and scientific innovation.

Lastly, key stakeholders' backgrounds and interests were crucial in setting the agenda of the stream restoration. In the An'Yang Stream case, we found that the key persons of the governance were environmental scientists and civil engineers, and they valued less social values of An'Yang Stream restoration in terms of humanities and socio-cultural disciplines. The water resource professionals and engineers who worked in the governmental organizations and research institutes had easy access to in-depth 
professional and scientific information. Thus, it was not easy to widely address the value of social factors of stream restoration.

Some stakeholders who valued social restoration had a hard time in sharing their visions and values through governance activities. In other words, the governance configuration comprised of scientists and engineers prevented expansion of diversity in the decision-making process of the An'Yang Stream restoration. The stakeholder group who belonged to a prestigious research institute that dealt with professional hydraulic data and who had researched many technocratic stream restorations previously were prone to have a strong and dominant influence in the An'Yang Stream restoration governance. Citizen groups and NGOs who were in pursuit of a variety of values were prescinded from the governance configuration. Although the An'Yang Stream governance aspired toward a democratic, collaborative, and deliberative governance that aimed at diversity regarding primary interests of participants in designing its structural configuration, it developed a very top-down structure as it ended up meeting the goal of technocratic stream restoration. Both unbalanced levels of professional knowledge in understanding hydraulic and ecological indicators, and incomplete citizen participation made a noticeable difference of the interactive power and influence within the governance among the participants.

The citizens have been positive about the results of the An'Yang Stream restoration and have evaluated the project as an effective South Korean urban river restoration. In order for the river restoration to be successful, the values and lifestyles of the citizens had to be reflected in a democratic and participatory way. 


\subsection{LIMITATIONS OF THIS RESEARCH}

This research used one stream restoration case from South Korea in the early 21 st century. As such, this case is a snapshot in time from a very specific social culture. The stream restoration case had indigenous societal elements. In addition, the researcher was part of the social context - a native of South Korea — creating concerns about subjective research outcomes resulting from distinct local knowledge and history.

While this research tried to address any possible limitations involved in the research processes, a few limitations remain. The primary limitation is that the complex, contradictory, and fluctuating nature of each factor within the stream restoration governance system made direct application of general and universal concepts in the case difficult.

The second limitation arises from miscommunications between the interviewees and this researcher in using certain terms, especially 'joint-fact-finding.' "Joint-factfinding' is a Western concept grounded in mutual trust and acknowledgment of the right to participate regardless of educational background. Future research may study the benefits and contributions of systematic constructing of joint-fact-finding within the stream restoration governance.

Lastly, the sampling strategy might have limited the findings. There was a discrepancy between the governance participants originally included in 2001 and those interviewed in this research in 2015. The interviews and surveys was planned to recruit an equal number of participants in each stakeholder group that took part in the An'Yang Stream governance in 2001. However, the stratified sampling strategy with the equal allocation method in each group did not work well because of the inaccuracy of the 
membership lists. To mitigate the impact of this limitation, a snowballing sampling method was used.

Communicative and participatory decision-making systems are not common concepts in South Korea (Lee and Choi, 2011). Due to cultural characteristics and their political nature, most South Korean water conflict cases are solved by lawsuits and litigation. However, recent research shows a potential challenge to find solutions for conflicts in Korea with Western-style communicative discourses (Cho, 2010, Bamba, 2011, and Kataoka, 2011).

This case from South Korea represents governance building through an iterative and collaborative partnership among a variety of stakeholders; the case documented conflicts due to their different frames or interests.

\subsection{GUIDELINES FOR FUTURE RESEARCH}

This section provides guidelines for future studies based on the findings of this research. Future research could (1) investigate the efficiency of each system within the network of interdisciplinary concepts considered in this research; Socio Hydrology (SH) or Socio-Ecological Systems (SESs) with some of the methodologies of AHP and content analysis employed in this research, (2) examine political theories in stream restoration, and (3) compare the findings of this research with the governance activities of other stream restoration cases.

First, future research in stakeholders' values on stream restoration should expand upon the governance activities addressed in this research, through the frames of systems of SESs or socio-hydrology. This will be a great contribution for stream restoration 
scholars who aim to design a sustainable concept within the stream restoration field. As this research found, accepting various stakeholders' interests within a stream restoration process can be a promoter that provides a foundation for building adaptive management tools for sustainable stream restoration governance (Ostrom, 2009). Also, Ostrom (2009) explains the sub-factors such as government organizations, NGOs, network structure, property-rights systems, operational rules, collective-choice rules, constitutional rules, and monitoring and sanctioning processes of the governance systems. These sub-factors in the governance system need to be examined and evaluated by the AHP and content analysis used in this research.

Second, future research might test how political theories can be applied to stream restoration processes. Scientific expertise regarding stream restoration garnered a political advantage. Applying political theory and a study of political dynamics could deepen understanding of multiple influences in decision-making.

Finally, comparative studies of other stream restoration cases, in South Korea, and other regions of the world would offer insights into the role of culture understanding diversity in decision-making processes. Future studies would benefit from accepting the standards of interdisciplinary theories such as SESs or SH.

\subsection{SYNERGISTIC PATHWAYS FOR WATERWAY RESTORATION (SPWR)}

South Korea is a dynamic and technologically advanced nation, but the challenges for safe water, effective stream flows, and recreation will expand due to new development projects. Knowing the limitations faced in the next decade in South Korean stream restoration, collaborative and participatory governance that rely on 
contemporary communications and professional expertise can offer guidelines for the future.

As noted by Ko (2008), the policies of the stream restoration decision-making board in charge of IWRM in Korea appear insufficient to include processes that will sufficiently satisfy citizen groups and social scientists. Consequently, engineers play a role as public administrators (sometimes planners) and establish the IWRM system they describe as innovative IWRM, but it is neither a fit nor effective in building sustainable and long-term decision-making of stream restoration.

This research addresses one modified decision-making model of water governance, which is named Synergistic Pathways for Waterway Restoration (SPWR) (Figure 20). This model is based on the primary findings from this dissertation. It includes the characteristics as noted below.

First, it has to be able to address and reflect diverse values of the stakeholders. The diverse participants in collaborative planning enterprises rely on their background of experience and training more than the subject for which they are planning. Each value and goal of stakeholders originate from different social and ecological priorities.

In this study, stakeholders rarely shared perspectives because they represented a variety of constituents. In this case, a group of stakeholders representing broad constituencies (engineers, government professionals, non-governmental organizations, etc.) was expected to collaborate in making decisions about planning and implementing only water quality improvements surrounding the An'Yang Stream.

As stakeholders varied in educational background, technological and scientific sophistication, life experiences, etc., the SPWR will need to establish and develop an 
interdependent decision-making system to embrace and adjust those differences and ignored agendas, such as social values, with others.

Second, the SPWR aims to build a balanced power structure among the groups. In particular, technocratic power dominated by specific groups should be sublated in the decision-making. One finding in this research was that data and perspectives based in natural science or engineering hold disproportionate power in collaborative planning. In this case, the originating problem was presented as a scientific problem: the An'Yang River system has been changed and its original ecological balance has been lost. Therefore, it may be helpful to consider and apply the concept of socio-hydrology and SESs to avoid the side effects of unilateral technocratic dominance. Once the SPWR can provide an ideal stage of participatory decision-making model, the participants in this Restoration Project may have been more willing to understand others' interests and give preference to synergistic solutions offered by whomever.

The third characteristic is to reduce potential concerns regarding communication. This research found three challenges in terms of communication. One is a lack of mediating professionals that can exacerbate communication. Lacking a workforce specialized in urban planning left collaborative planning efforts with no trained "middle-men." Participants in this case were in distinct categories without bridging structures. Hydrologists and water engineers were specialized in their own specific academic background; NGOs focused on building capacity for communities, and citizens sought pleasant landscapes for recreation and safe water. The second form of evidence about communication was the salience of non-traditional modalities like social media, texting and internet web-pages. This SPWR includes and utilizes the functions 
of advanced communication technologies. A third challenge in communication is the lack of mediating careers. The labor markets in the water resource management field have not yet acknowledged the essential role of mediating mechanisms such as urban planners. Thus, this SPWR is operated and designed by planners who can bridge various factors including non-scientific value.

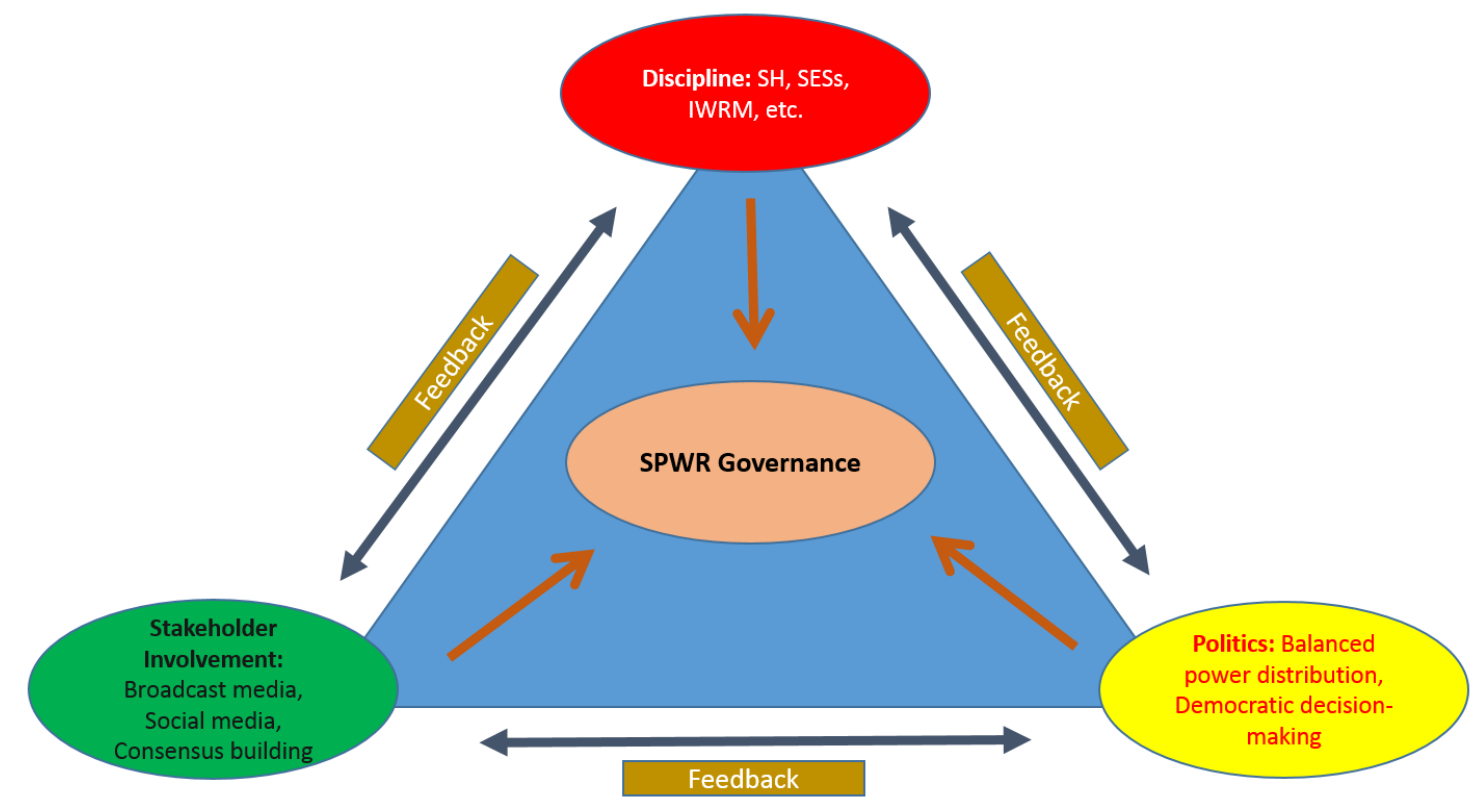

Figure 20. Synergetic pathways for waterway restoration (SPWR)

\subsection{CONCLUSION}

In South Korean society, the An'Yang Stream governance made the first great step in promoting participatory processes in stream management, but achieved only limited success in moving from technological solutions to improved living for residents. By expanding training for mediators, such as what in the West are called "urban planners," future projects can bridge power and knowledge gaps among potentials. 
This research presented an overview of the major strengths and weaknesses in decision-making processes during both development of a plan and its implementation in Korean stream restoration management, with a focus on its attempts to incorporate social and ecological factors and water policy aspects into existing water quality management systems.

Also, the research results can help us create complementary systems for seeking better research findings, as well as demonstrate the importance of the role of mixed methods in value findings within decision-making of stream restoration.

In particular, this study combined surveys, interviews, document review using analytic tools including NGT, AHP, content analysis, and grounded theory to observe and review stream restoration process. While this combined format created a by definition sometimes complex process, it contributed to answering questions about stream restoration governance that encompasses stakeholders with multiple perspectives. In this case, the combination of data collection and data analysis methods allowed the researcher to gain confidence in these findings.

After this research, the values and future direction of the An'Yang Stream restoration will be received by the key decision-makers and politicians and hopefully will be considered, reviewed and accepted into the decision-making. Now is the best time to think about serious solutions and implications for sound stream restoration in the An'Yang Stream region, because conditions of the stream have been continuously changing. The present stream restoration aims mostly for ecological management, such as wastewater treatment and ecosystem revitalization, rather than socio-cultural restoration. This causes many problems that confuse stakeholders and governance 
participants in dealing with complex social issues resulting from the stream restoration process. Thus, the stream restoration paradigm should be redirected to newly established and functioning participatory systems that emphasize various values and beneficent functions, such as the benefits of embracing non-scientific approaches and technocratic advantages. Importantly, a new An'Yang Stream restoration with wellorganized participation must contribute with social restoration and environmental revitalization as a pioneering role in the region.

The Synergistic Pathway for Waterway Restoration (SPWR) model builds on what has been learned from the An'Yang Stream Restoration Project. The SPWR model offers the potential to build an informed class of citizens who gain experience in "speaking truth to power" (Wildavsky, 1979) for water quality as well as confronting top-down bureaucratic decision making.

The SPWR offers the potential for a stream of informed and active citizens gaining experience through stream restoration. 


\section{References}

Adams, W.M. (2006). "The Future of Sustainability: Re-thinking Environment and Development in the Twenty-first Century." Report of the IUCN Renowned Thinkers Meeting, 29-31 January 2006. Retrieved on: 2009-02-16.

ADB (2012). "The Saemaul Undong Movement in the Republic of Korea: Sharing Knowledge on Community-Driven Development”, published by Asian Development Bank.

Allan, J. and Castillo, M. (2007). Stream Ecology. Dordrecht: Springer Netherlands.

Alexander, G. (2007). Ecological Success in Stream Restoration: Case Studies from the Midwestern United States. Environmental Management, (2), 245-255.

Allmendinger, P., \& Tewdwr-Jones, Mark. (2002). Planning futures : New directions for planning theory. London; New York: Routledge.

Alonso, J., \& Lamata, M. (2006). Consistency in the Analytic Hierarchy Process: a new approach. International Journal of Uncertainty, Fuzziness and Knowledge-Based Systems, 14(04), 445-459.

Amy, D. (1987). The politics of environmental mediation. New York: Columbia University Press.

Anderson, J. L., R. W. Hilborn, R. T. Lackey, and D. Ludwig. (2003). Chapter 9:

Watershed restoration-adaptive decision making in the face of uncertainty. Pages 203-232 in RC Wissmar and PA Bisson, editors. Strategies for restoring river ecosystems: sources of variability and uncertainty in natural and managed systems. American Fisheries Society, Bethesda, Maryland. 
Ansell, C., \& Gash, A. (2007). Collaborative Governance in Theory and Practice. Journal of Public Administration Research and Theory, 18(4), 543-571. Bae, C. (1998). Korea's greenbelts: impacts and options for change, Pacific Rim Law Journal, 7 (3), 479-502

Bacon, F. (1879). The Works of Francis Bacon. Ed. James Spedding, R. L. Ellis, and D. D. Heath. N.p.: Longon, 1879.

Bamba, Y. (2011). Integrated basin management in the Lake Biwa and Yodo River Basin. Lakes and Reservoirs: Research and Management, 16, 2, 149-152.

Berner, M., Amos, J., \& Morse, R. (2011). What Constitutes Effective Citizen Participation In Local Government? Views From City Stakeholders. Public Administration Quarterly, 35(1), 128-163.

Berkes, F., Folke, C., \& Colding, J. (1998). Linking social and ecological systems: Management practices and social mechanisms for building resilience. Cambridge, U.K: Cambridge University Press.

Berry S, Farquhar LGD, Roderick ML. 2005. Co-evolution of Climate, Soil and Vegetation. Chapter 12 In Encyclopedia of Hydrological Sciences, Anderson MG (ed.). John Wiley: London.

Bilec, M. (2007). A Hybrid Life Cycle Assessment Model for *construction Processes, ProQuest Dissertations and Theses.

Booher, D. E., \& Innes, J. E. (2002). Network power in collaborative planning. Journal of Planning Education and Research, 21(3), 221-236.

Booher, D., \& Innes, J. (2003). Network power in collaborative planning. Sage Urban Studies 
Abstracts: Trends in Urbanization and Urban Society, 31, 2.)

Bourget, L. (2011). Converging waters : Integrating collaborative modeling with participatory processes to make water resources decisions (IWR Maass-White series). Alexandria, VA: IWR Press.

Bras, R. \& Eagleson, P.S. (1987) Hydrology, the forgotten earth science. Eos 68, 287. City of An'Yang (2001). An'Yang Stream Restoration Project.

Bromley, Daniel W.(2008). "sustainability", "The New Palgrave Dictionary of Economics", Eds. Steven N. Durlauf and Lawrence E. Blume, Palgrave Macmillan, 2008, The New Palgrave Dictionary of Economics Online, Palgrave Macmillan. 26 March 2016, DOI:10.1057/9780230226203.1656

Brunner, R., Steelman, Toddi A, \& Coe-Juell, Lindy. (2005). Adaptive Governance Integrating Science, Policy, and Decision Making. New York: Columbia University Press.

Burger, J., Gochfeld, M., Kosson, D., Powers, C., Friedlander, W., Eichelberger, B., . . . Volz, S. (2005). Science, Policy, and Stakeholders: Developing a Consensus Science Plan Science Plan for Amchitka Island, Aleutians, Alaska. Environmental Management, 35(5), 557-568.

Burgess, G. and Burgess, H. (1994). Environmental mediation: beyond the limits applying dispute resolution principles to intractable environmental conflicts, Conflict Research Consortium working paper, University of Colorado, Boulder. Castells, M. (1983). The city and the grassroots: A cross-cultural theory of urban social movements. Berkeley and Los Angeles: The University of California Press. 
Chae, J. (2012). 환경 갈등 해결을 위한 협력적 거버넌스의 성공요인에 관한 연구

(Analysis on successful factors of collaborative governance for environmental conflicts), the Korea Institute of Public Administration, Seoul, Korea.

Chang, H. (2008). Spatial analysis of water quality trends in the Han River basin, South Korea. Water Research, (13), 3285-3304.

Cheng, A. (2003). Examining the interaction between geographic scale and ways of knowing in ecosystem management: A case study of place-based collaborative planning. Forest Science, (6), 841-854.

Christopher Moore, The Mediation Process: Practical Strategies for Resolving Conflict, 2nd ed., (San Francisco: Jossey-Bass Publishers, 1996).

Cho, Myung-Rae. (2010). The politics of urban nature restoration: The case of Cheonggyecheon restoration in Seoul, Korea.(Report). International Development Planning Review, (2), 145.

Cho, C., \& Jang, M. (2011). A Study on Collaborative Governance Model for Conflict Resolutions, Journal of Urban Administration, 24, 2, 23-47.

Cho, Y. et al. (2011). 사람과 자연이 바라는 지속가능한 물 관리 (Sustainable water resource management for human and nature), Goyang, Kyonggi, Korea.

Choi, J. (2015). 안양천 살리기 20002010 2020, An’Yang Stream Environmental College published by City of An'Yang (2015).

Choo, N. (2013). 한국의 환경 복원 사례 (Korean Stream Restoration); presentation slide. 
City of An'Yang (2001) An'Yang Stream Restoration Master Plan

City of An'Yang (2004). Rehabilitation of the Hydrologic Cycle for the An'Yangcheon Basin, Technical report.

City of An'Yang (2009). Environmental Master Plan of An'Yang

Comin, F. A., Menendez, M., Pedrocchi, C., Moreno, S., Sorando, R., Cabezas, A., Garcia, M., Rosas, V., Moreno, D., Gonzalez, E., Gallardo, B., Herrera, J. A., \& Ciancarelli, C. (2005). Wetland restoration: Integrating scientific-technical, economic, and social perspectives. Ecological Restoration, 23(3), 182-186.

Comín, F. A. (2010). Ecological restoration: A global challenge. Cambridge, U.K: Cambridge University Press.

Conley, A., \& Moote, M. (2003). Evaluating Collaborative Natural Resource Management. Society \& Natural Resources, 16(5), 371-386.

Corbin, J., \& Strauss, Anselm L. (2015). Basics of qualitative research : Techniques and procedures for developing grounded theory (Fourth ed.). Los Angeles: SAGE.

Cortner, H., \& Moote, M. (1999). The politics of ecosystem management. Washington, DC: Island Press.

Cvitanovic, C., Hobday, A., Van Kerkhoff, L., Wilson, S., Dobbs, K., \& Marshall, N. (2015). Improving knowledge exchange among scientists and decision-makers to 
facilitate the adaptive governance of marine resources: A review of knowledge and research needs. Ocean and Coastal Management, 112, 25.

Daejeon Daily (2011). 민.관 손잡고 안양천 살리기 23 개 단체. 13 개 지자체 합심

자연 하천정비.생태복원 앞장 [대전일보](2011-10-13) 16 면

DeSteiguer et al. (2003) The Analytic Hierarchy Process as a Means for Integrated Watershed Management.

Díaz, S., Lavorel, S., de, B. F., Quétier, F., Grigulis, K., \& Robson, T. M. (December 26, 2007). Incorporating Plant Functional Diversity Effects in Ecosystem Service Assessments. Proceedings of the National Academy of Sciences of the United States of America, 104, 52, 20684-20689.

Dredge, D. (2006) Policy networks and the local organisation of tourism. Tourism Management 27 (2), 269-80

Dryzek, J. S. (1990). Discursive democracy: Politics, policy, and political science. Cambridge: Cambridge University Press.

Dutcher, D. (2004). Landowner perceptions of protecting and establishing riparian forests: A qualitative analysis. Society \& Natural Resources, (4), 329-342.

Edelstein, M. R. (2003). Contaminated communities: coping with residential toxic exposure (2nd ed.). Boulder, CO: Westview Press.

Ellen, I., Yager, J., Hanson, M., and Bosher, L. (2016). Planning for an Uncertain Future: Can Multicriteria Analysis Support Better Decision Making in Climate Planning? Journal of Planning Education and Research, September 2016; vol. 36: pp. 349-362 
Esaiasson, P., Gilljam, M., and Persson, M. (2016). Responsiveness Beyond Policy Satisfaction: Does It Matter to Citizens?, Comparative Political Studies, January 2016.

Falkenmark, M. (January 01, 1979). Main Problems of Water Use and Transfer of Technology. Geojournal, 3, 5, 435-443.

Fisher, R. and Ury, W. (1991). Getting to Yes, Negotiating Agreement Without Giving In. New York : Penguin Books.

Flyvbjerg, B. (1998). Rationality and power: Democracy in practice. Chicago: University of Chicago Press.

Flügel, W. (2007). The adaptive integrated data information system (AIDIS) for global water research. Water Resources Management, 21(1), 199-210.

Folke, C., Hahn, T., Olsson, P., and Norberg, J. (2005) Adaptive Governance of SocialEcological Systems. Annual Review of Environment and Resources 30: 441-73.

Folke, C. (2006). Resilience: The emergence of a perspective for social-ecological systems analyses. Global Environmental Change, 16(3), 253-267.

Friedmann, J. (1987). Planning in the public domain: From knowledge to action. Princeton, N.J: Princeton University Press.

Galbraith, J. K. (1983). The anatomy of power. Challenge, 26(3), 26-33.

Giebels, D., Buuren, A. \& Edelenbos, H. (2015). Using knowledge in a complex decision-making process - Evidence and principles from the Danish Houting project's ecosystem-based management approach. Environmental Science and Policy, 47, 53-67. 
Giorgos Somarakis, \& Anastasia Stratigea. (2014). Public Involvement in Taking Legislative Action as to the Spatial Development of the Tourist Sector in GreeceThe "OpenGov" Platform Experience. Future Internet, 6(4), 735-759.

Gober, P. \& Wheater, H. (2014). Socio-hydrology and the science\&ndash;policy interface: A case study of the Saskatchewan River basin. Hydrology and Earth System Sciences, 18(4), 1413-1422.

Goodland, R. (1997). Environmental sustainability in the hydro industry:

Disaggregating the debate. In Large dams: Learning from the past looking at the future, ed. Tony Dorcey. IUCN/The World Bank Group.

Gough, J. (1997). Environmental decision making and risk management for groundwater systems. Risk: Health, Safety \& Environment, 8, 155-172.

Gregory, R. (2000). Using Stakeholder Values to Make Smarter Environmental Decisions. Environment: Science and Policy for Sustainable Development, 42(5), $34-44$.

Graham, E. (2003). Reforming Korea's industrial conglomerates.

Gregory, R., \& Keeney, R. (2002). MAKING SMARTER ENVIRONMENTAL MANAGEMENT DECISIONS 1. JAWRA Journal of the American Water Resources Association, 38(6), 1601-1612.

Gregory, \& Wellman. (2001). Bringing stakeholder values into environmental policy choices: A community-based estuary case study. Ecological Economics, 39(1), 3752.

Habermas, J. (1984). The theory of communicative action. Boston: Beacon Press. 
Hammond, J., \& Keeney, R. (1999). Making smart choices in engineering. Spectrum, IEEE, 36(11), 71-76.

Han'guk Haengjŏng Yŏn'guwŏn. (2015). The Korean government : Policies and administration, 1948-2013. Seoul: Daeyoung Moonhwasa Publishing Co.

Harding, R., Hendriks, Carolyn M, \& Faruqi, Mehreen. (2013).Environmental Decision-Making: Exploring Complexity and Context. Federation Press.

Hatton, T. J., Salvucci, G. D., \& Wu, H. I. (1997). Eagleson's optimality theory of an ecohydrological equilibrium: quo vadis? Functional Ecology, 11(6), 665-674. doi:10.1046/j.1365-2435.1997.00159.x

Haferkamp, H., \& Smelser, Neil J. (1992). Social change and modernity. Berkeley: University of California Press.

Herringshaw, C. (2009). Stream ecosystems in human-dominated landscapes: Investigating land use impacts and integrating public participation, restoration, and research. ProQuest, UMI Dissertations Publishing.

Healey, P. (2003). Collaborative Planning in Perspective. Planning Theory, 2, 2, 101 123.

Healey, P. (2006). Collaborative planning: Shaping places in fragmented societies. Basingstoke, Hampshire: Palgrave Macmillan.

Heathcote, I. W. (1998). Integrated watershed management: Principles and practice. New York: Wiley.

Henriksen, H., Refsgaard, J., Højberg, J., Ferrand, C., Gijsbers, A., \& Scholten, L. (2009). Harmonised principles for public participation in quality assurance of 
integrated water resources modelling. Water Resources Management, 23(12), 2539-2554.

Herman, K., Susskind, L., \& Wallace, K. (2007). A dialogue not a diatribe: Effective integration of science and policy through joint fact finding. Environment: Science and Policy for Sustainable Development, 49(1), 20-34.

Hersha, D. (2012). A conceptual model of the citizen stream stewardship decision process in an urbanising Midwestern United States watershed. Journal of Environmental Planning and Management, (2), 253-270.

Herringshaw, C. (2009). Stream ecosystems in human-dominated landscapes: Investigating land use impacts and integrating public participation, restoration, and research. (Vol. 48, p. 137).

Hiligsmann M, et al. (2013). Health technology assessment in osteoporosis. Calcif Tissue Int. 2013;93(1):1-14.

Hobbes, T. (1969). Leviathan, 1651. Menston: Scolar P.

Hoch, C. (1994). What planners do: Power, politics, and persuasion. Chicago, Ill: Planners Press.

Hong, C. and Chung, E. (2016). Temporal variations of citizens' demands on flood damage mitigation, streamflow quantity and quality in the Korean urban watershed. Sustainability, 8(4), 370.

Hooper B (2003) Integrated Water Resources Management and River Basin Governance. Water Resources Update 126, Universities Council on Water Resources, 12-20 
Houston, J., Hawthorne, J., Perreault, M., Park, E., Goldstein Hode, M., Halliwell, M., . . Griffith, S. (2015). Social media and disasters: A functional framework for social media use in disaster planning, response, and research. Disasters, 39(1), 122.

Howarth, \& Monasterolo. (2016). Understanding barriers to decision making in the UK energy-food-water nexus: The added value of interdisciplinary approaches. Environmental Science and Policy, 61, 53-60.

Innes, J., \& Booher, D. (2004). Reframing public participation: Strategies for the 21st century. Planning Theory \& Practice, 5(4), 419-436.

Innes, J. E., \& Booher, D. E. (2010). Planning with complexity: An introduction to collaborative rationality for public policy. Milton Park, Abingdon, Oxon: Routledge.

Irazábal, C. (2009). Realizing Planning's Emancipatory Promise: Learning From Regime Theory To Strengthen Communicative Action. Planning Theory, 8(2), 115-139.

Fainstein, S. S. (2012). Readings in planning theory (3rd ed.). Malden, MA: WileyBlackwell.

Franzén, F., Hammer, M. \& Balfors, B. (2015). Institutional development for stakeholder participation in local water management-An analysis of two Swedish catchments. Land Use Policy, 43, 217-227.

Hatton, T. J., Salvucci, G. D., \& Wu, H. I. (1997). Eagleson's optimality theory of an ecohydrological equilibrium: quo vadis? Functional Ecology, 11(6), 665-674. doi:10.1046/j.1365-2435.1997.00159.x 
Herringshaw, C. (2009). Stream ecosystems in human-dominated landscapes:

Investigating land use impacts and integrating public participation, restoration, and research. (Vol. 48, p. 137).

Jaeger, W. K., Plantinga, A. J., Chang, H., Dello, K., Grant, G., Hulse, D., ... Wu, J. (2013). Toward a formal definition of water scarcity in natural-human systems: Opinion. Water Resources Research, 49(7), 4506-4517. doi:10.1002/wrcr.20249

Joo, J. (2004). Local governance and self-governing system: A case of An'Yang Stream

Jung, C. (2004). Invitation to Urban Engineering, 도시공학에의 초대, http://blog.naver.com/cityplanner7/40001790133

Jung, S. (2014). Oswald Nagler, HURPI, and the Formation of Urban Planning and Design in South Korea. Journal of Urban History, 40(3), 585-605.

Kang, L. (2014). "South Korea's Sustainable Urban Planning and Environmental Technology." Discussions, 10(1). Retrieved from http://www.inquiriesjournal.com/a?id=844

Karl, H., Susskind, L., \& Wallace, K. (2007). A Dialogue, Not a Diatribe: Effective Integration of Science and Policy through Joint Fact Finding. Environment: Science and Policy for Sustainable Development, 49(1), 20-34.

Kataoka, Y. (2011). Water Quality Management in Japan: Recent Developments and Challenges for Integration: Water Quality Management in Japan. Environmental Policy and Governance, 21(5), 338-350. doi:10.1002/eet.591

Kim, Y. and Woo, H. (2004). Introduction to Ecohydrology, the Journal of Korean Water Resource, 37 (5), pp.78 81. 
Kitagawa, Z. (2011). Measures for the conservation of water quality in Lake Biwa and the Akanoi Bay initiative. Lakes \& Reservoirs: Research \& Management, (3), 211-214.

Kitchin, R., \& Thrift, N. (Eds.). (2009). International encyclopedia of human geography, Elsevier Science.

Ko, Ik-Hwan (2008). Integrated Water Resource Management, presentation slides on Korean cases

Koh, G. W. (2005). Groundwater Occurrence on Jeju Island, Korea, the Jeju Development Institute, Jeju, Korea.

Kondolf, M. (2006). River Restoration and Meanders. Ecology and Society, 11(2), 42.

Krätzig, S. \& Warren-Kretzschmar, B. (2014). Using Interactive Web Tools in Environmental Planning to Improve Communication about Sustainable Development. Sustainability, 6(1), 236-250.

Lave, R. (2012). Fields and streams stream restoration, neoliberalism, and the future of environmental science. Athens: University of Georgia Press.

Lee, A. (2014). Measuring Positive Externalities from Water Quality Improvements :The Case of the River An'Yang, Journal of Korea Water Resources Association, Vol. 5.

Lee, H. (2012), 증거기반정부 (EBG) 관점에서의 합리적 갈등관리, 한국 행정 학회 하계학술대회. 
Lee, J., Kim, J., Kim, T., Ji, Y. (2010). 물환경 거버넌스를 위한 의사결정체계 구축, KEI 연구보고서 2010-12.

Lee, K.; Chung, E. (2007). Development of integrated watershed management schemes for an intensively urbanized region in Korea. Journal of Hydro-Environment Research, 1(2), 95-109.

Lee, K., Chung, E., Kim, Y. (2005). Integrated Approach for Rehabilitating the Hydrologic Cycle in the An’Yangcheon Watershed(II): Prefeasibility Study

Lee, S., \& Choi, G.-W. (2012). Governance in a River Restoration Project in South Korea: The Case of Incheon. Water Resources Management, 26, 5, 1165-1182.

Lee, Y., Yoo, S., Choi, J., \& Kang, M. (2014). Considering changes in river operations and management in the river environment, IHP report.

Lindblom, C. (1959). The Science of "Muddling Through" Public Administration Review, 19(2), 79-88. doi:1. Retrieved from http://www.jstor.org/stable/973677 doi:1

MacDonald, L.H., Anderson, D.M., \& Dietrich, W.E. (1997). Paradise threatened: Land use and erosion on St. John, US Virgin Islands. Environmental Management, 21(6), 851-863.

McCarthy, D. (2006). A critical systems approach to socio-ecological systems: Implications for social learning and governance. ProQuest, UMI Dissertations Publishing. 
McCreary, S., Gamman, J., \& Brooks, B. (2001). Refining and testing joint fact-finding for environmental dispute resolution: Ten years of success. Mediation Quarterly, 18(4), 329-348.

McDonald, A. \& Kay, D. (1988). Water Resources: Issues and Strategies. Water Resources Issues and Strategies Series, Longman Scientific and Technical, Essex, England. 1988. 284p.

Min, Y., Song, T., and Kim, Y. (2014). Study on river restoration plan through a case of An'Yang Stream. Water for Future, 47(3), 105-114.

Moran, E. (2010). Environmental Decision Making. In Environmental Social Science (pp. 126-142). Oxford, UK: Wiley-Blackwell.

Morandi, B., Piegay, H., Lamouroux, N., \& Vaudor, L. (2014). How is success or failure in river restoration projects evaluated? Feedback from French restoration projects. Journal Of Environmental Management, 137, 178-188.

NRC (National Research Council) (2005) Decision Making for the Environment: Social and Behavioral Science Research Priorities. Washington, DC: National Academy Press.

Nakamura, K., Tockner, K., \& Amano, K. (2006). River and Wetland Restoration: Lessons from Japan. BioScience, 56(5), 419-429.

Natural Resources Conservation Service (NRCS). (2007). National Engineering Handbook, Part 654, Stream Restoration Design, U.S. Dep. of Agric., Washington, D. C. 
Nelson, R., Howden, M., \& Smith, M. (2008). Using adaptive governance to rethink the way science supports Australian drought policy. Environmental Science and Policy, 11(7), 588-601.

Olden, J. (2006). Life-history strategies predict fish invasions and extirpations in the Colorado River Basin. Ecological Monographs, (1), 25-40.

O'Leary, R., \& Bingham, Lisa. (2003). The promise and performance of environmental conflict resolution. Washington, DC: Resources for the Future.

Ostrom, E. (1990). Governing the commons: The evolution of institutions for collective action (Political economy of institutions and decisions). Cambridge: Cambridge University Press.

Ozawa, Connie P. (1996). Science in environmental conflicts. (Special Issue: Environmental Conflict). Sociological Perspectives, 39(2), 219.

Ozawa, C. (2006). Science and intractable conflict. Conflict Resolution Quarterly, 24(2), 197-205.

Pahl-Wostl, C. (2008). The importance of social learning and culture for sustainable water management. Ecological Economics, (3), 484-495.

Palmer, M. A., Bernhardt, E. S., Allan, J. D., Lake, P. S., Alexander, G., Brooks, S., Carr, J., Clayton, S., Dahm, C. N., Shah, J. F., Galat, D. L., Loss, S. G., Goodwin, P., Hart, D. D., Hassett, B., Jenkinson, R., Kondolf, G. M., Lave, R., Meyer, J. L., O'Donnell, T. K., Pagano, L., \& Sudduth, E. (2005). Standards for ecologically successful river restoration: Ecological success in river restoration. Journal of Applied Ecology, 42(2), 208-217. 
Park, S. \& Choi, J. (1998). 21 세기의 물관리 정책방향, Water for future, v.31 no.1,

pp. 104-114.

Park, S., \& Grigg, Neil S. (2004). Water Policy in South Korea: Towards a New Paradigm, ProQuest Dissertations and Theses.

Park, M.S.; Lee, H. (2016). Legal Opportunities for Public Participation in Forest Management in the Republic of Korea. Sustainability 2016, 8, 369.

Pearse, P. (1985). Currents of change; final report, inquiry on Federal Water Policy. Ottawa, ON: Environ. Can.

Phillips, G. (2003). Success and benefits of stream restoration, Watershed Update, 1(6)

Pieraccini, Margherita. (2015). Rethinking participation in environmental decisionmaking: Epistemologies of marine conservation in South-East England. Journal of Environmental Law, 27(1), 45-67.

Pinto, J. (1998). The Project Management Institute : Project management handbook (1st ed., Jossey-Bass business \& management series). San Francisco: JosseyBass.

Priscoli, J. (2001). Participation, consensus building, and conflict management training course (tools for achieving PCCP), UNESCO, Technical Documents in Hydrology.

Private-public partnership for An'Yang Stream Restoration by 23 NGOs and 13 local governments. (2011, October, 13). Daejeon Ilbo Newspaper. Retrieved July 12, 2015, from http://www.daejonilbo.com/news/newsitem.asp?pk_no=973867 
Purcell, A. (2002). An assessment of a small urban stream restoration project in northern California. Restoration Ecology,(4), 685-694.

Reed, M. (2008). Stakeholder participation for environmental management: A literature review. Biological Conservation, 141(10), 2417-2431.

Reese, Laura A., \& Rosenfeld, Raymond A. (2004). Local economic development in the United States and Canada: Institutionalizing policy approaches. American Review of Public Administration, 34(3), 277-292.

Rich, R., Edelstein, M., Hallman, W. K., \& Wandersman, A. H. (1995). Citizen participation and empowerment: The case of local environmental hazards. American Journal of Community Psychology, 23(5), 657-676.Pande, S. and Sivapalan, M. (2016), Progress in socio-hydrology: a meta-analysis of challenges and opportunities. WIREs Water. doi:10.1002/wat2.1193

Rosenthal, J., \& Brandt-Rauf, P. (2006). Environmental planning and urban health. Annals of the Academy of Medicine, Singapore, 35(8), 517-22.

Roy, A. (2008). Impediments and Solutions to Sustainable, Watershed-Scale Urban Stormwater Management: Lessons from Australia and the United States. Environmental Management, (2), 344-359.

Ruskin, William A. (1993). The use of "principled negotiation" in resolving environmental disputes. American Journal of Trial Advocacy, 17(1), 225-244.

Salka, William M. (2001). Urban-rural conflict over environmental policy in the western United States. American Review of Public Administration, 31(1), 33-48.

Sandercock, Leonie. (1998). Making the Invisible Visible: A Multicultural Planning History. Berkeley, CA: U of California P. 
Sato, Y. (2012). New Challenge of Citizen Participation for Environmental Conservation, edited by Kawanabe, H. et al. (2012) Lake Biwa: Interactions between nature and humans. Springer. New York.

Schmoldt, D., Peterson, D., and Smith, R. (1994). The analytic Hierarchy Process and Participatory Decision-making, Proceedings of 17th Annual Geographic Information Seminar and the Resource Technology '94 Symposium-Toronto, Ontario.

Schön, D. A., \& Rein, M. (1994). Frame reflection: toward the resolution of intractable policy controversies. New York: BasicBooks.

Schultz, N. (2003). "Joint Fact-Finding." Beyond Intractability. Eds. Guy Burgess and Heidi Burgess. Conflict Information Consortium, University of Colorado, Boulder. Posted: July 2003 <http://www.beyondintractability.org/essay/jointfact-finding>.

Schymanski, S. J., Sivapalan, M., Roderick, M. L., Hutley, L. B., \& Beringer, J. (2009). An optimality-based model of the dynamic feedbacks between natural vegetation and the water balance: VEGETATION OPTIMALITY. Water Resources Research, 45(1), n/a-n/a. doi:10.1029/2008WR006841

Seoul Metropolitan Government. (2006). the White Paper of Cheonggyecheon Restoration

Project. Seoul: Seoul Public Relations Planning Bureau

Sevaly, S. (2001). Involving stakeholders in aquaculture policy-making, planning and management. In R.P. Subasinghe, P. Bueno, M.J. Phillips, C. Hough, S.E. McGladdery \& J.R. Arthur, eds. Aquaculture in the Third Millennium. 
Technical Proceedings of the Conference on Aquaculture in the Third Millennium, Bangkok, Thailand, 20-25 February 2000. pp.83-93. NACA, Bangkok and FAO, Rome.

Shiga Prefecture Government. 1997. Lake Biwa:Conservation of Aquatic Environment. Otsu, Japan

Simon, A. (2011). Stream restoration in dynamic fluvial systems: Scientific approaches, analyses, and tools. Washington, DC: American Geophysical Union.

Simon, Herbert A. (1990). Invariants of human behavior. Annual Review of Psychology, 41, 1.

Sivakumar, B. (2012). Socio-hydrology: Not a new science, but a recycled and reworded hydrosociology. Hydrological Processes, 26, 24, 3788-3790.

Sivapalan M. (2009). The secret to 'doing better hydrological science': change the question! Hydrological Processes 23: 1391-1396.

Sivapalan, M., Savenije, H. H. G., \& Bloschl, G. (2011). Socio-hydrology: A new science of people and water. Hydrological Processes, 26, 8, 1270-1276.

Slovic, P., and Gregory, R. (1999) Risk Analysis, Decision Analysis and the Social Context for Risk Decision Making. In J. Shanteau, B. A. Mellers and D. A. Schultz, N. (2003). "Joint Fact-Finding." Beyond Intractability. Eds. Guy Burgess and Heidi Burgess. Conflict Information Consortium, University of Colorado, Boulder. Posted: July 2003 <http://www.beyondintractability.org/essay/jointfact-finding >.

Schum (eds.), Decision Science and Technology: Reflections on the Contributions of Ward Edwards. Boston, MA: Kluwer Academic. 
Smith, N. (1982). Gentrification and uneven development. Economic Geography, 58(2), $139-155$.

Smith, S. (2012). Planning and Management in Eastern Ontario's Protected Spaces: How Do Science and Public Participation Guide Policy?, ProQuest Dissertations and Theses.

Song, B., \& Kang, S. (2016). A Method of Assigning Weights Using a Ranking and Nonhierarchy Comparison. Advances in Decision Sciences, 2016, 9.

Strang, V. (2006). Social Ecohydrology: integrating the social and natural sciences. Research Paper prepared for Scientific Advisory Committee, UNESCO International Ecohydrology Programme.

Strauss, A., \& Corbin, J. (1998). Basics of qualitative research: Techniques and procedures for developing grounded theory (2nd ed.). Thousand Oaks: Sage Publications.

Susskind, L. (2005). Resource planning, dispute resolution, and adaptive governance, edited by

Scholz, J. and Stifel, B (2005) Adaptive Governance and Water Conflict: New Institutions for Collaborative Planning. Resources for the future. Washington, DC, USA.

Susskind, L., \& Cruikshank, Jeffrey L. (1987). Breaking the impasse : Consensual approaches to resolving public disputes. New York: Basic Books.

Susskind, L., McKearnan, Sarah, \& Thomas-Larmer, Jennifer. (1999). The consensus building handbook: A comprehensive guide to reaching agreement. Thousand Oaks, Calif.: Sage Publications. 
Susskind, L. (2010). Collaborative rationality, http://theconsensusbuildingapproach.blogspot.com/2010/02/collaborativerationality.html

Tenhunen, J.(1), \& Members of the TERRECO Project(2). (2010). A South Korean case study of social-ecologically-based management of ecosystem services: Global change impacts on agricultural production versus water quality in mountain landscapes. Symposcience - Éditions Quae.

Thengane, Hoadley, Bhattacharya, Mitra, \& Bandyopadhyay. (2014). Cost-benefit analysis of different hydrogen production technologies using AHP and Fuzzy AHP. International Journal of Hydrogen Energy, 39(28), 15293-15306.

Totikidis, V. (2010). Applying the Nominal Group Technique (NGT) in Community Based Action Research for Health Promotion and Disease Prevention, The Australian Community Psychologist, 22 (1), 18-29.

Trachtenberg, Z., \& Focht, W. (2005). Legitimacy and watershed collaborations: The role of public participation. In P. A. Sabatier, M. Lubell, A. Vedlitz, W. Focht, Z. Trachtenberg, \& M. Madock (Eds.), Swimming upstream: Collaborative approaches to watershed management (pp. 85-135). Cambridge, MA: MIT Press.

Trowbridge, J., Botan, Carl H., Farnsworth, Stephen, Rowan, Katherine, \& Villagran, Melinda. (2012). Structuration and Intractability in Environmental Public Participation and Decision Making: An International Case Study, ProQuest Dissertations and Theses. 
Tuladhar, Anita. (2005). Governance Structures and Decision-Making Roles in Inflation-Targeting Central Banks. 05/183.

UC Denver (2016). IAD; Institutional Analysis and Development Framework: http://www.ucdenver.edu/academics/colleges/SPA/researchandoutreach/Buechn er\%20Institute\%20for\%20Governance/Centers/WOPPR/IAD/Pages/default.asp $\underline{\mathbf{x}}$

Umemoto, K. (2001). Walking in Another's Shoes: Epistemological Challenges in Participatory Planning. Journal of Planning Education and Research, 21(1), 1731. doi:10.1177/0739456X0102100102

Upton, R., Forester, J., Hajer, M., Huxley, M., Albrechts, L., O'Neill, J., \& Campbell, H. (2009). Patsy Healey: In Theory and in Practice How Lucky We Are: A Glimpse at Patsy Healey's Contributions From Oxford onwards Theoretical Debates, Planning Practice and Spatial Processes From Strategic Spatial Plans to Spatial Strategies Some Presidential Reflections on Patsy Healey Learning about Scholarship...on a Red London Omnibus. Planning Theory \& Practice, 10(1), 133-149.

Van De Ven, A., \& Delbecq, A. (1974). The Effectiveness of Nominal, Delphi, and Interacting Group Decision Making Processes. The Academy of Management Journal, 17(4), 605-621.

Vorkinn, M. and Riese, H. (2001). Environmental concern in a local context: The significance of place attachment. Environment and Behavior, 33(2), 249-263. 
Wagner, H. (2003). Improving the performance of US Environmental Protection Agency Method 300.1 for monitoring drinking water compliance. Journal of Chromatography A, (1), 89-97.

Waley, P. (2000). Following the flow of Japan's river culture. Japan Forum, 12(2), 199217.

Wang, Y., Lee, K., Byrne, J., Smith, W., Wozniak, S., Scozzafava, M., \& Lee, J. (2003). An Institutional Approach to River Basin Management: Conflict Resolution in the U. S. and South Korea, Korean Journal of Environmental Studies, v.41: 139-155.

Wang, Y.\& He, B. (2010). Sustainable lake water resource management through integrated ecological models and community participation. World Lake Database.

Warner, J. (2007). Multi-Stakeholder Platforms for Integrated Water Management (Ashgate Studies in Environmental Policy and Practice). Farnham: Ashgate Publishing.

Watanabe, S. (2007). Comparative History of Urban Planning in Japan, Korea and Taiwan: A Challenge from Machizukuri, ACP2007 Research Paper.

Wildavsky, A. (1979). Speaking truth to power: The art and craft of policy analysis. Boston: Little, Brown.

Wilkes, D., (1975). Water supply regulation. In: Chatham House Study Group (Ed.), Regional Management of the Rhine, London.

Willson, R. (2001). Assessing communicative rationality as a transportation planning paradigm. Transportation, 28(1), 1-31. 
Winterfeldt, D. V. (2013). Bridging the gap between science and decision making. Proceedings of the National Academy of Sciences of the United States of America, 14055.

Wohl E, Angermeier P, Bledsoe B, Kondolf M, MacDonnell L, Merritt D, Palmer M, Poff N, Tarboton D (2005) River restoration. Water Resour Res 41:1-12

Wohl, E., Gerlak, A., Poff, K., \& Chin, N. (2014). Common Core Themes in Geomorphic, Ecological, and Social Systems. Environmental Management, 53(1), 14-27.

Woolsey S, Capelli F, Gonser T, Hoehn E, Hostmann M, Junker B, Paetzold A, Roulier C, Schweizer S, Tiegs D, Tockner K, Weber C, Peter A (2007) A strategy to assess river restoration success. Freshwat Biol 52:752-769

Wyant, J., Meganck, G., \& Ham, R. (1995). A planning and decision-making framework for ecological restoration. Environmental Management, 19(6), 789796.

Yosie, T. and Herbst, T. (1998). Using Stakeholder Processes in Environmental Decisionmaking: An Evaluation of Lessons Learned, Key Issues, and Future Challenges (www.riskworld.com/Nreports/1998/ STAKEHOLD/HTML/nr98aao1.htm, accessed 20 June 2001)

You, J., Gong, K., Song, Y., \& Lee, K. (2011). Developing Cooperative Framework for Integrated Watershed Management, Technical Report Sponsored by Sustainable Water Resources Research Center

Zahedi, F. (1986). The Analytic Hierarchy Process: A Survey of the Method and Its Applications. Interfaces, 16, 4, 96-108. 
Zalewski, M., Janauer, G. A., Jolankai, G., Fournier, Frederique, \& Pypaert, Philippe. (1997). Technical Documents in Hydrology, Technical Documents in Hydrology - Documents Techniques en Hydrologie. 
Appendix A. Codes of the content analysis of the An'Yang Stream Master Plan
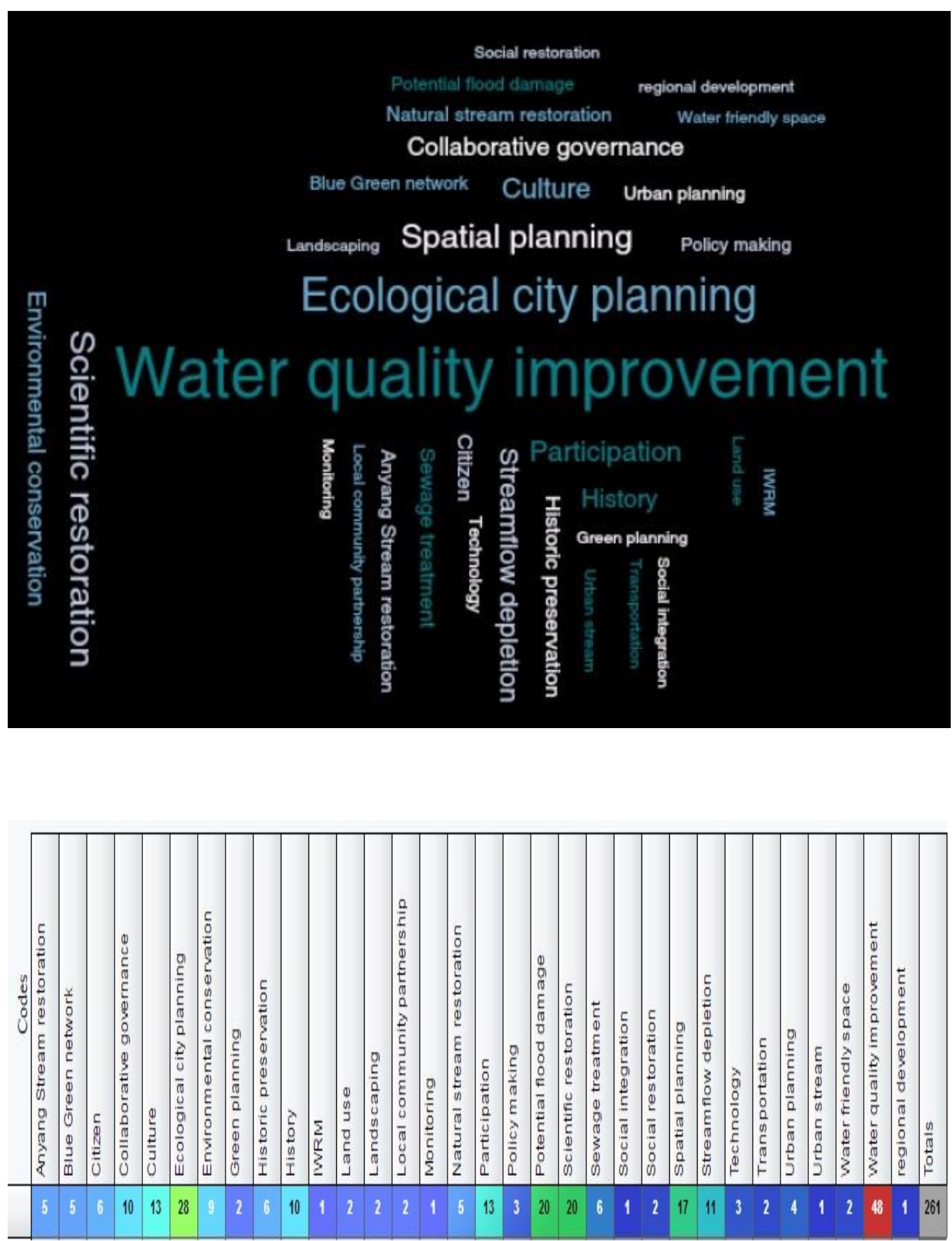
Appendix B. Codes of the content analysis of the interview

\begin{tabular}{|c|c|}
\hline Code & $\begin{array}{l}\text { Totals of } \\
\text { quotation } \\
\text { frequency }\end{array}$ \\
\hline Water quality improvement & 63 \\
\hline Ecological restoration & 61 \\
\hline Limited functions of the governance & 59 \\
\hline Civic participation & 49 \\
\hline Scientific restoration & 42 \\
\hline Conflicts & 39 \\
\hline Flood damage prevention & 35 \\
\hline Recreational use & 27 \\
\hline Professional knowledge & 19 \\
\hline Media & 17 \\
\hline Economic development & 17 \\
\hline Politics & 16 \\
\hline Cultural restoration & 15 \\
\hline Natural stream restoration & 15 \\
\hline Citizen groups & 14 \\
\hline Educational value & 13 \\
\hline Landscaping & 11 \\
\hline Community partnership & 10 \\
\hline Diversity & 10 \\
\hline Joint fact-finding & 10 \\
\hline
\end{tabular}




\begin{tabular}{|c|c|}
\hline Social integration & 10 \\
\hline Social restoration & 10 \\
\hline Water-friendly space & 10 \\
\hline Communication & 9 \\
\hline Leadership & 9 \\
\hline Democratic way & 8 \\
\hline Transportation & 8 \\
\hline An'Yang stream restoration task-force & 7 \\
\hline Historic preservation & 7 \\
\hline Power dynamics & 6 \\
\hline Trust building & 6 \\
\hline Citizen monitoring & 5 \\
\hline Environmental restoration & 5 \\
\hline Sewage treatment & 5 \\
\hline Stream-flow control & 5 \\
\hline Technocratic stream restoration & 5 \\
\hline Absence of mediator & 4 \\
\hline Urban stream & 4 \\
\hline Budget distribution & 3 \\
\hline Lack of understanding social values & 3 \\
\hline Sustainable stream restoration & 3 \\
\hline Civil complaints & 2 \\
\hline
\end{tabular}




\begin{tabular}{|c|c|}
\hline Policy-making & 2 \\
\hline Volunteering & 2 \\
\hline Agenda setting & 1 \\
\hline Enthusiasm & 1 \\
\hline Top-down participation & 1 \\
\hline Totals & 683 \\
\hline
\end{tabular}

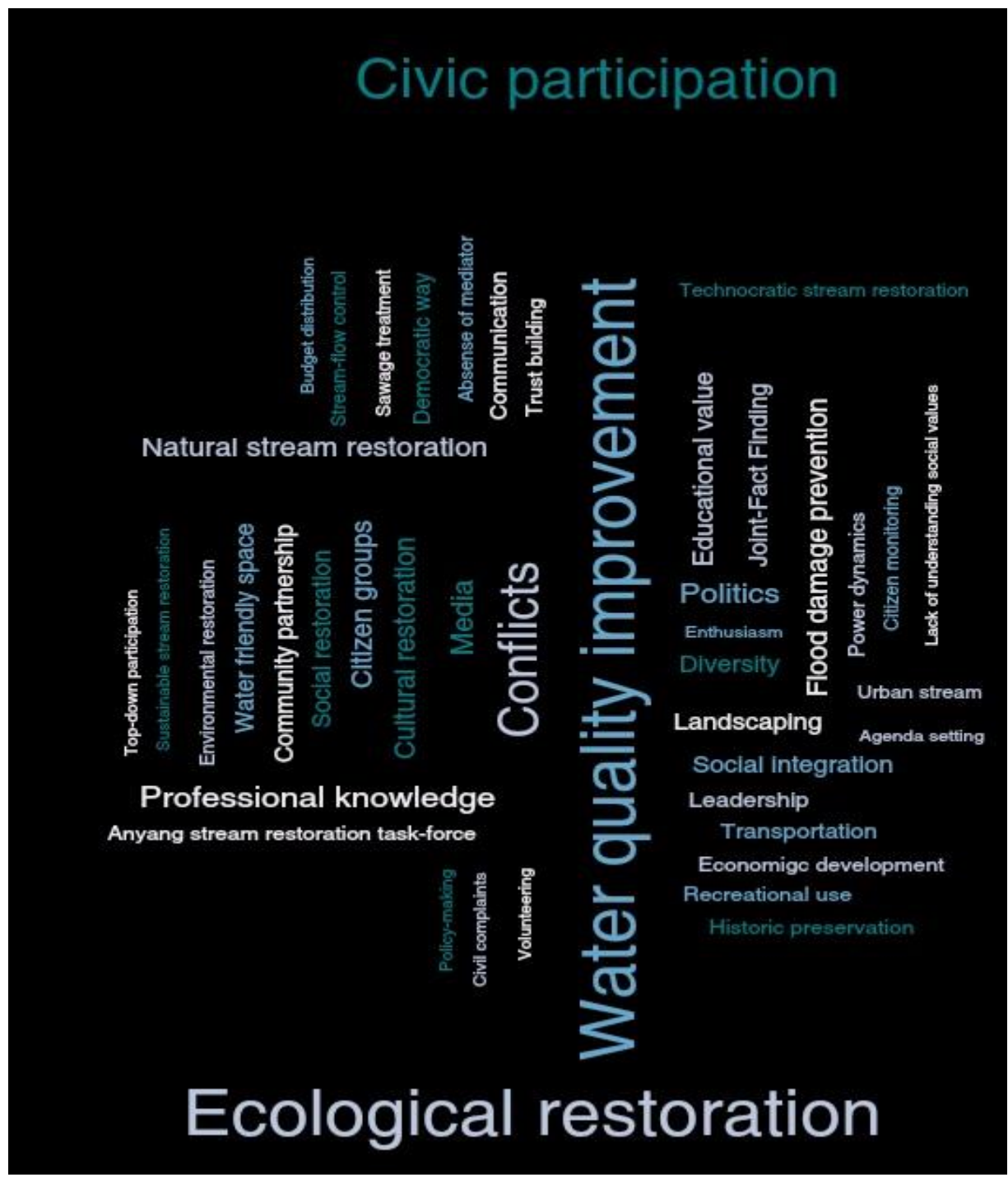


Appendix C. Top three values on An'Yang stream restoration of water professionals

\begin{tabular}{|c|c|c|c|}
\hline \multirow[t]{2}{*}{ Respondent } & \multicolumn{3}{|c|}{ Top 3 values in An'Yang Stream restoration } \\
\hline & Top 1 (3points) & Top 2 (2points) & Top 3 (1point) \\
\hline $\begin{array}{c}\text { NGT } \\
\text { Respondent } 1\end{array}$ & $\begin{array}{l}\text { Water quality } \\
\text { enhancement }\end{array}$ & $\begin{array}{l}\text { Ecological } \\
\text { restoration }\end{array}$ & Flood prevention \\
\hline $\begin{array}{c}\text { NGT } \\
\text { Respondent } 2\end{array}$ & $\begin{array}{l}\text { Water quality } \\
\text { enhancement }\end{array}$ & $\begin{array}{l}\text { Waterfront space } \\
\text { renovation }\end{array}$ & $\begin{array}{c}\text { Cultural } \\
\text { revitalization }\end{array}$ \\
\hline $\begin{array}{c}\text { NGT } \\
\text { Respondent } 3\end{array}$ & $\begin{array}{l}\text { Water quality } \\
\text { enhancement }\end{array}$ & Streamflow control & Flood prevention \\
\hline $\begin{array}{c}\text { NGT } \\
\text { Respondent } 4\end{array}$ & $\begin{array}{l}\text { Water quality } \\
\text { enhancement }\end{array}$ & $\begin{array}{l}\text { Governance } \\
\text { building }\end{array}$ & $\begin{array}{c}\text { Educational } \\
\text { programs }\end{array}$ \\
\hline $\begin{array}{c}\text { NGT } \\
\text { Respondent } 5\end{array}$ & $\begin{array}{l}\text { Water quality } \\
\text { enhancement }\end{array}$ & $\begin{array}{l}\text { Engineering } \\
\text { technology } \\
\text { innovation }\end{array}$ & $\begin{array}{c}\text { Economic } \\
\text { development }\end{array}$ \\
\hline $\begin{array}{c}\text { NGT } \\
\text { Respondent } 6\end{array}$ & $\begin{array}{l}\text { Water quality } \\
\text { enhancement }\end{array}$ & Civic participation & Social integrity \\
\hline $\begin{array}{c}\text { NGT } \\
\text { Respondent } 7\end{array}$ & $\begin{array}{l}\text { Water quality } \\
\text { enhancement }\end{array}$ & $\begin{array}{l}\text { Ecological } \\
\text { restoration }\end{array}$ & $\begin{array}{c}\text { Spatial } \\
\text { regeneration }\end{array}$ \\
\hline $\begin{array}{c}\text { NGT } \\
\text { Respondent } 8\end{array}$ & $\begin{array}{l}\text { Water quality } \\
\text { enhancement }\end{array}$ & $\begin{array}{c}\text { Cultural } \\
\text { revitalization }\end{array}$ & $\begin{array}{c}\text { Historic } \\
\text { preservation }\end{array}$ \\
\hline $\begin{array}{c}\text { NGT } \\
\text { Respondent } 9\end{array}$ & $\begin{array}{l}\text { Water quality } \\
\text { enhancement }\end{array}$ & Spatial regeneration & $\begin{array}{c}\text { Economic } \\
\text { development }\end{array}$ \\
\hline $\begin{array}{c}\text { NGT } \\
\text { Respondent } 10\end{array}$ & $\begin{array}{l}\text { Water quality } \\
\text { enhancement }\end{array}$ & Flood prevention & Social integrity \\
\hline $\begin{array}{c}\text { NGT } \\
\text { Respondent } 11\end{array}$ & Civic participation & $\begin{array}{l}\text { Governance } \\
\text { building }\end{array}$ & Water quality \\
\hline $\begin{array}{c}\text { NGT } \\
\text { Respondent } 12\end{array}$ & Spatial regeneration & $\begin{array}{c}\text { Economic } \\
\text { development }\end{array}$ & Flood prevention \\
\hline $\begin{array}{c}\text { NGT } \\
\text { Respondent } 13\end{array}$ & Social integrity & Civic participation & $\begin{array}{l}\text { Ecological } \\
\text { education }\end{array}$ \\
\hline $\begin{array}{c}\text { NGT } \\
\text { Respondent } 14\end{array}$ & Spatial regeneration & $\begin{array}{l}\text { Waterfront space } \\
\text { renovation }\end{array}$ & Flood prevention \\
\hline $\begin{array}{c}\text { NGT } \\
\text { Respondent } 15\end{array}$ & Flood prevention & $\begin{array}{c}\text { Regional } \\
\text { redevelopment }\end{array}$ & $\begin{array}{c}\text { Economic } \\
\text { development }\end{array}$ \\
\hline $\begin{array}{c}\text { NGT } \\
\text { Respondent } 16\end{array}$ & Civic participation & $\begin{array}{l}\text { Ecological } \\
\text { restoration }\end{array}$ & $\begin{array}{c}\text { Spatial } \\
\text { regeneration }\end{array}$ \\
\hline
\end{tabular}


Appendix D. Factors to examine in analysis

a. Who are the stakeholders in collaborative stream restoration governance? (QA)

Hypothesis 1: Decision-making groups that include non-engineers/planners incorporate social values into the decision-making (stream restoration) process.

Hypothesis 2: When information is shared more widely in the participatory decision-making process, social values on the stream restoration are incorporated.

Hypothesis 3: Disagreement among technical experts arise when the decisionmaking group includes non-governmental organizations (private business, residents, environmental groups, etc.)

Factors to examine:

1) Characteristics of the methods of the overall and participatory processes -How is the participatory process shaped and formed?

-Who facilitates the collaborative planning processes of stream restoration (Who has convening authority)?

2) Participants

-How are participants identified? Who is invited?

-Are the participants speaking for themselves or are they representing others?

-How is feedback to the community occurring?

-What resources are available to the stakeholders in order to join the participatory decision-making committee?

-Are the organizers of participation in stream restoration engineers or planners?

-Are external facilitators involved?

3) Agenda setting and problem defining 
-Who sets the initial agenda and how are the problems defined?

-What are the objectives of stream restoration for each stakeholder?

-Is the problem definition reflective of scientific factors, socio-cultural factors, or a combination of both?

4) Community groups

-Is there an opportunity for the community to influence the agenda? How are community members chosen to join?

-What is the role of community groups in convening the participatory decisionmaking process?

-What are the power dynamics and hierarchy within the community groups? Who gets chosen and why?

b. How does the context of the water planning affect the problem definitions and the goal setting in stream restoration?

Hypothesis 1: Decision-making of stream restoration processes in South Korea tends to be shaped in a top-down structure.

Hypothesis 2: Stream restoration strategies with concentrated social and cultural factors are more likely to draw the attention and participation of the citizens. Also, planning activities where the objectives are to achieve cultural and historical preservation on the stream will result in a positive tone for participatory stream restoration including communities.

Factors to examine:

1) Characteristics of the stream restoration process

-The agenda/mission of the existing strategy (Governmental agendas and 
statements)

-Proportion of social factors (e.g., economic, cultural, and historical factors) in stream restoration public documents written by the government

-Types of stakeholders and structure of the stream restoration governance -Breadth and depth of analysis associated with social factors in stream restoration reports

-Scopes of community program in water resource management (e.g., education, public events, and partnerships with private sectors)

-Participants in stream restoration decision-making -Consideration of participants who represent and advocate social interests in stream restoration decision-making

c. To what extent do the stakeholders use scientific knowledge in stream restoration collaborative decision-making? (QA)

Hypothesis 1: The decision makers use scientific knowledge as the most important factor in the decision-making process of stream restoration collaborative governance. Engineering technology provided by professionals and experts is considered to be a more important factor than the socio-cultural factors that citizens consider important in the stream restoration decision-making process.

Hypothesis 2: Engineers and public administrators who understand scientific measurements and evaluations in stream restoration tend to have more powerful positions than do citizen groups who do not understand the professional jargon without assistance and who do not directly participate in the decision-making process. Each 
stakeholder has a different level of power based on the degree to which the stakeholder can access and analyze relevant information, such as scientific sources.

Hypothesis 3: Joint fact-finding through transformative planning systems will reduce collective conflicts between actors representing diverse interests in stream restoration.

Hypothesis 4: Inclusion of the private sector can create more conflicts in stream restoration.

Factors to examine:

1) Control for the educational/professional background of participants.

2) Characteristics of the water management process

-What is the agenda/mission of the existing strategy? (Governmental agendas and statements)

-What is the main factor in setting agendas and goals? What factors do the engineers and public administrators (planners) consider in stream restoration?

-How is the scientific information treated? How are the social factors treated in the stream restoration collaborative partnership? What is the role of scientific information?

-Is the participatory process open for representatives from the private sector who argue for the importance of social factors in stream restoration?

3) Joint fact-finding

-Is joint fact-finding employed?

-Do citizen groups with limited access to resources in privileged scientific or engineering information receive help from planners or anyone? 
d. What factors are considered to be the most important by the stakeholders?

e. What factors are excluded in the decision-making processes? (Water quality, water

culture, historic preservation, regional economic development, ecological

conservation, landscaping, political issues, etc.) (AHP and QA)

Hypothesis 1: Conflicts in stream restoration emerge from contradictions between

diverse interests. The stakeholders in stream restoration collaborative groups argue with other groups who interpret professional/scientific knowledge from different perspectives.

Hypothesis 2: Participants state that water quality evaluated by scientific indicators will be the most important factor in decision-making, among diverse interests on the stream restoration.

(QA and AHP)

Factors to examine:

1) Presence of identified interests, values, and visions of the stakeholders -stream restoration public documents were analyzed for answering these questions

2) Inclusion of citizen groups and NGOs -Are citizen groups and NGOs who advocate social factors such as property value, culture, history, etc. included in the decision-making committee?

3) Conflicts and collaboration

-What kinds of conflicts exist in the stream restoration process among the stakeholders?

-How are they resolved?

-What kinds of collaborative partnerships happen in the stream restoration process? 
-What is the partnership between public and private sectors?

-What are the influences of the partnerships in the decision-making process?

-Were there any actions and influences of stakeholders excluded of the

partnerships?

4) Ranking in the considerable factors of stream restoration

-What is the rank of scientific knowledge in priority of considerable factors in stream restoration? What is the rank of non-scientific knowledge?

-Pairwise comparison between elements below:

-Ecological restoration

(1) Improvement of ecosystem and increase in resilience

(2) Monitoring systems and ecological assessment

-Social restoration (cultural and historical restoration based on democratic way)

(1) Stream water culture/ local culture, such as conventional ways in stream use

(2) Historical restoration/ traditional revitalization

(3) Collaborative partnerships and social networks for stream restoration -Landscaping revitalization (spatial renovation)

(1) Flood protection and flow rate control

(2) River basin renovation for easy access to the stream

(3) Civic space and recreational amenities 
Appendix E. Informed consent information for semi-structured interviews

Dear Participant,

As a PhD student in the School of Urban Studies and Planning at Portland State University, I am researching the factors for successful stream restoration through collaborative governance embracing social and ecological systems. I am formally contacting you based on your association with the integrated stream restoration management strategy. Your response in this interview will help be better understand how collaborative governance can address interactions between social elements and ecological elements.

Your participation is voluntary. You do not have to take part in this project if you do not want to mention your opinion on stream restoration. If you decide to take part in this interview and survey, I will ask you to respond to approximated 30 questions in the interview in person, or if required, over the phone and through email. This semistructured interview will likely take 50 minutes, depending on your responses. Your privacy is very important to me. The information you share with me will be kept confidential through assigning your name a numerical code. The code will be used to identify your interview recording and transcripts and will only be shared with faculties within my dissertation committee (Chair: prof. Connie Ozawa) at Portland State University. In order to make sure I have accurately captured your input, I will send you a written summary of our interview; transcriptions of the interviews will available upon request. All data collected (digitalized files and transcripts) will be identified only by the numerical code. The file containing your numerical code assignment will be kept in a secured filing storage separate from the digitalized files. Electronic digitalized files will only be saved on a Portland State University main server.

If you have any questions, please contact me - ChangYu Hong - at (503)467-8479. If you have questions regarding the use of human subjects in research, please contact the Research and Sponsored Projects Office at 1-503-725-2227.

Your oral consent means:

1) You understand the risks and benefits of participation

2) You are willing to participate in the planned interview

3) You understand that your participation in the interview is voluntary and you can agree at any point to stop and change your mind.

Thank you for your participation and time,

ChangYu Hong

changyu@pdx.edu

This study has been partially sponsored and supported by Sasakawa Young Leaders Fellowship fund (SYLFF) of the Tokyo Foundation, Japan. 
Appendix F. Interview questions

Code:

Case:

Date:

\section{Interview Questions}

1. What is your professional title?

2. What are the years of experience on stream restoration?

3. What was your role in stream restoration project?

4. What were your goals in the SR? What motivated you to be involved in this stream restoration (SR) project?

5. What were the relevant strategies of your group for meeting the goals?

6. How those goals been changed in the stakeholder networking or communicating?

7. Which stakeholder/ party did you think needed to participate in order to make sure social factors of stream restoration with the project could be adequately addressed? Which stakeholder/ party did you think needed to participate in order to make sure ecological factors (scientific information) of stream restoration with the project could be adequately addressed?

8. If you think social factor/scientific factor is more important in SR, do you think scientific information/ social factors had to be considered in setting goals of SR?

9. Were there participants missing in the process of inducing to forming governance structure?

10. Were relevant resources provided and shared to help stakeholder representatives participate in the process?

11. Did you have access to enough resources to fully take part in the stream restoration project?

12. Did you have relationships with the stakeholders before this project? If yes, describe what was the relationship?

13. Describe how SR factors are identified and addressed in this SR project.

14. Were there any disagreement among stakeholders about stream restoration should be addressed? Did you have equal right to speak your interest to other participants? How were the conflicts based upon interest differences resolved?

15. Describe your involvement in providing scientific information and analyzing scientific information associated with stream restoration. Did you have any difficulty in accessing to scientific information and understanding professional scientific information? If you do, did you have professional assistance to understand it? Were there opinion differences among participants about handling scientific information/ social factors which are associated with SR? Urban planners (public administrators) worked to assist the stakeholder who were not able to understand professional knowledge?

16. What kind of social factors such as local culture and history were discussed in stakeholder meetings? 
17. Were there proper ways of joint-fact-finding process on scientific information and social factors on stream restoration? How do you evaluate the joint-factfinding in the SR project? Did it work?

18. Was there a power imbalance among stakeholders resulting from unbalanced resource distribution? Did you experience power imbalance in sharing your interests? Who was the most powerful stakeholder in the council? Why? (Dominated leadership)

19. Do you recall any external events that were important in shaping the direction of SR process?

20. Did collaborative stakeholders group properly reflect your concerns in SR for the project? Did decision-making process reflect your concerns about SR for this project? Do you think there is adaptive governance including relevant stakeholders? Was it democratic? Was it a top-down way? Was it participatory?

21. How was made the decision making process? (ex. consensus, voting, or decided by governmental leaders) Did citizen representatives take part in the decisionmaking process?

22. Are you satisfied with the SR process?

23. What other key participants in the SR process should I interview?

What were main factors that caused water contamination in the stream? (initial document review)

Who was the primary actor that began restoration work? (initial document review) 
Appendix G. Questions for AHP analysis

1. Asking your preference in SR

2. If you compare each of the following pairs of principles for successful stream restoration, which do you think is more significant in SR decision making process? Compare each of the following pairs of principles and mark the place along the segment.

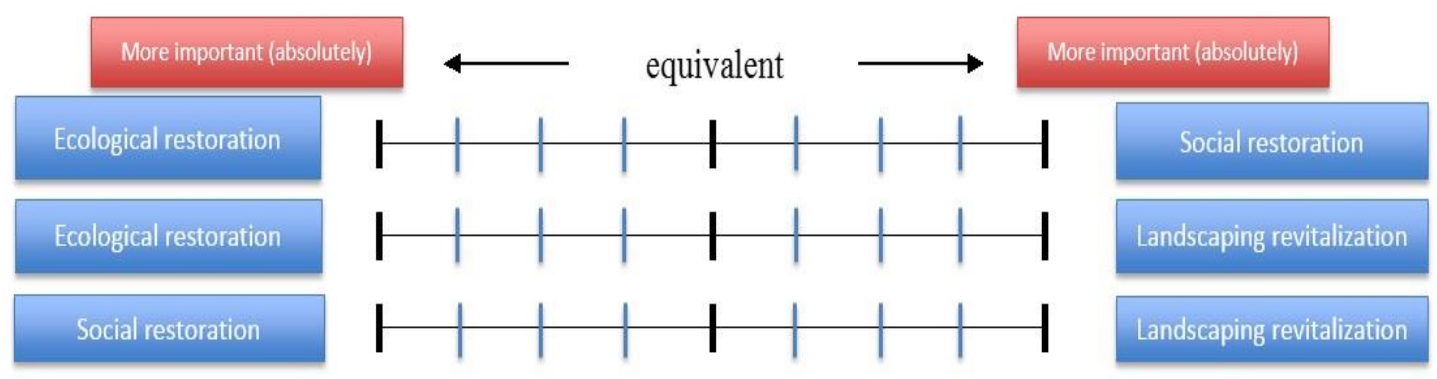

3. If you compare each of the following pairs of criteria for successful stream restoration, which do you think is more significant in SR decision making process? Compare each of the following pairs of criteria and mark the place along the segment.

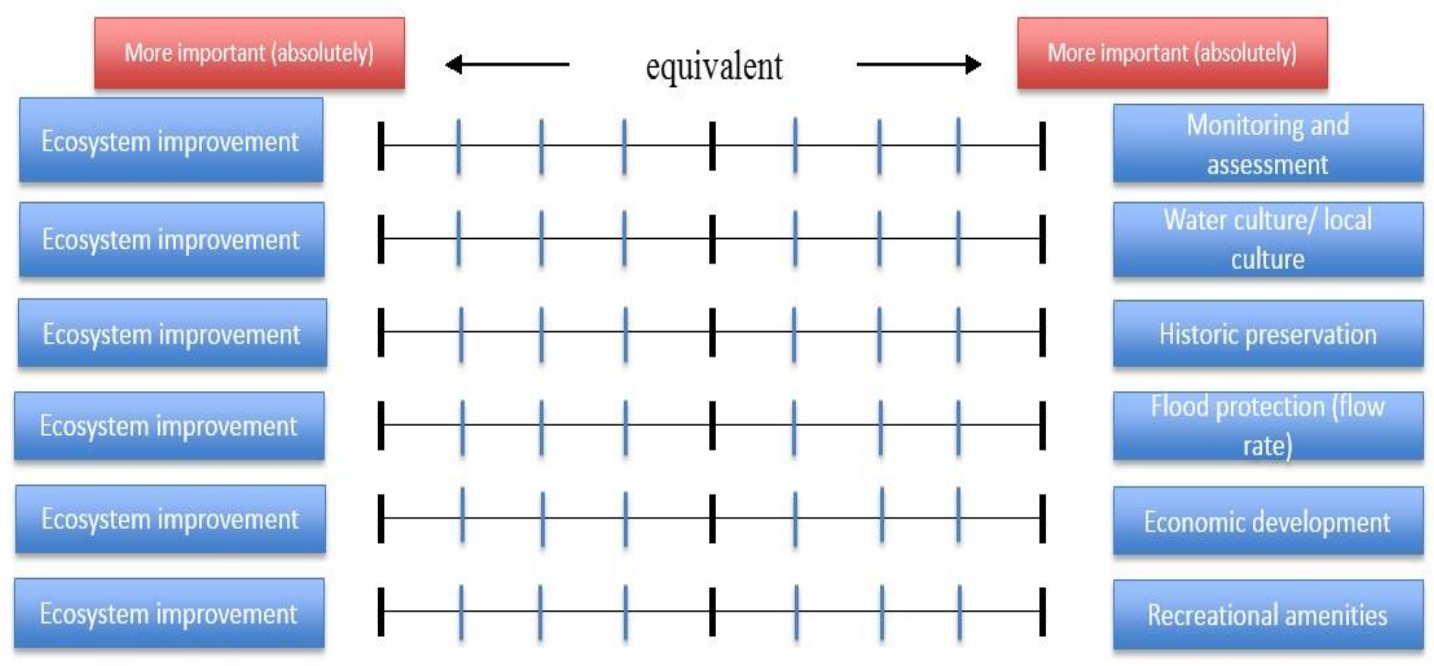




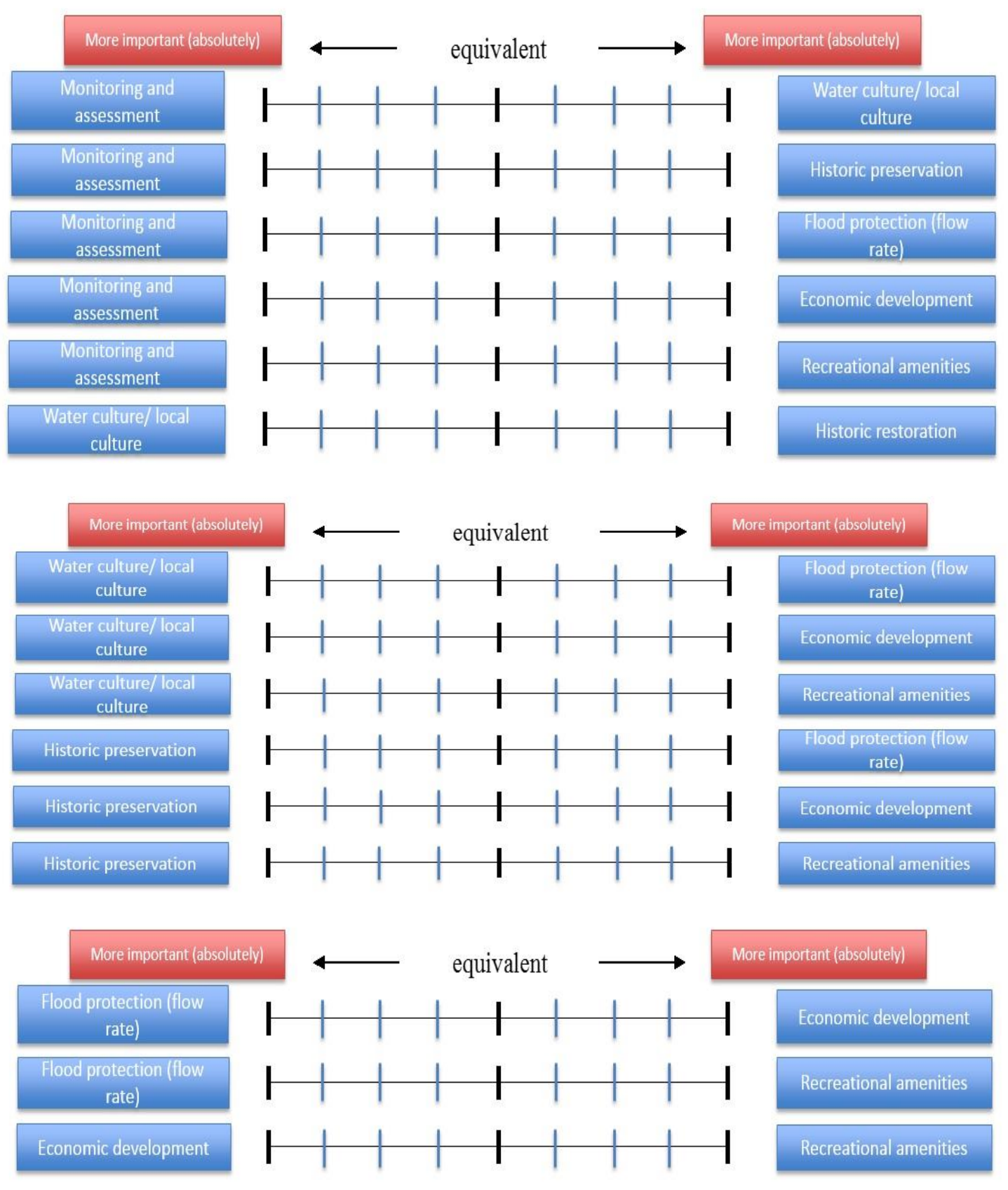


Appendix H. Lists of interviews

\begin{tabular}{|c|c|c|c|c|c|c|}
\hline No. & Group & Organization & Background & $\begin{array}{c}\text { Years of } \\
\text { Participation }\end{array}$ & $\begin{array}{c}\text { ID } \\
\text { Code }\end{array}$ & Sex \\
\hline 1 & Government & $\begin{array}{c}\text { City of } \\
\text { An'Yang }\end{array}$ & $\begin{array}{c}\text { Civil } \\
\text { engineering }\end{array}$ & 1 & PA01 & $\mathrm{M}$ \\
\hline 2 & Government & Guro District & $\begin{array}{l}\text { Environmental } \\
\text { engineering }\end{array}$ & 2 & PA02 & $\mathrm{F}$ \\
\hline 3 & Government & $\begin{array}{l}\text { Yang-cheon } \\
\text { District }\end{array}$ & $\begin{array}{l}\text { Environmental } \\
\text { engineering }\end{array}$ & 2 & PA03 & $\mathrm{F}$ \\
\hline 4 & Government & $\begin{array}{l}\text { Yang-cheon } \\
\text { District }\end{array}$ & $\begin{array}{l}\text { Environmental } \\
\text { engineering }\end{array}$ & 1 & PA04 & $\mathrm{M}$ \\
\hline 5 & Government & $\begin{array}{l}\text { An'Yang } \\
\text { Ecological } \\
\text { Education } \\
\text { Center }\end{array}$ & $\begin{array}{c}\text { Public } \\
\text { administration }\end{array}$ & 1 & PA05 & $\mathrm{F}$ \\
\hline 6 & Government & $\begin{array}{l}\text { An'Yang } \\
\text { Ecological } \\
\text { Education } \\
\text { Center }\end{array}$ & $\begin{array}{c}\text { Business } \\
\text { administration }\end{array}$ & 1.5 & PA06 & $\mathrm{F}$ \\
\hline 7 & Government & $\begin{array}{l}\text { City of } \\
\text { An'Yang }\end{array}$ & $\begin{array}{c}\text { Civil } \\
\text { engineering }\end{array}$ & 3 & PA07 & M \\
\hline 8 & Government & $\begin{array}{l}\text { Ministry of } \\
\text { Land and } \\
\text { Transportation }\end{array}$ & $\begin{array}{c}\text { Civil } \\
\text { engineering }\end{array}$ & 4 & PA08 & $\mathrm{M}$ \\
\hline 9 & Government & City of Seoul & $\begin{array}{c}\text { Civil } \\
\text { engineering }\end{array}$ & 3 & PA09 & M \\
\hline 10 & NGO & $\begin{array}{c}\text { An'Yang } \\
\text { Federation of } \\
\text { Environmental } \\
\text { Movement }\end{array}$ & $\begin{array}{c}\text { Civil } \\
\text { engineering }\end{array}$ & 15 & NGO01 & $\mathrm{M}$ \\
\hline 11 & NGO & $\begin{array}{c}\text { An'Yang } \\
\text { Federation of } \\
\text { Environmental } \\
\text { Movement }\end{array}$ & History & 12 & NGO02 & M \\
\hline 12 & $\mathrm{NGO}$ & $\begin{array}{c}\text { Gunpo } \\
\text { Federation of } \\
\text { Environmental } \\
\text { Movement }\end{array}$ & $\begin{array}{c}\text { Electric } \\
\text { engineering }\end{array}$ & 4 & NGO03 & $\mathrm{M}$ \\
\hline 13 & NGO & YMCA & $\begin{array}{c}\text { Korean } \\
\text { literature }\end{array}$ & 6 & NGO04 & M \\
\hline 14 & $\mathrm{NGO}$ & YMCA & Economics & 13 & NGO05 & $\mathrm{M}$ \\
\hline 15 & $\mathrm{NGO}$ & $\begin{array}{l}\text { Gwangmyong } \\
\text { Protocol }\end{array}$ & $\begin{array}{c}\text { Civil } \\
\text { engineering }\end{array}$ & 10 & NGO06 & $\mathrm{M}$ \\
\hline
\end{tabular}




\begin{tabular}{|c|c|c|c|c|c|c|}
\hline 16 & $\begin{array}{l}\text { Advisory } \\
\text { group }\end{array}$ & $\begin{array}{l}\text { Korea } \\
\text { Research } \\
\text { Institute of } \\
\text { Human } \\
\text { Settlements }\end{array}$ & $\begin{array}{c}\text { Civil } \\
\text { engineering }\end{array}$ & 6 & PS01 & $\mathrm{M}$ \\
\hline 17 & $\begin{array}{l}\text { Advisory } \\
\text { group }\end{array}$ & $\begin{array}{c}\text { Korea } \\
\text { Research } \\
\text { Institute of } \\
\text { Human } \\
\text { Settlements }\end{array}$ & $\begin{array}{c}\text { Urban } \\
\text { engineering }\end{array}$ & 13 & PS02 & $\mathrm{F}$ \\
\hline 18 & $\begin{array}{l}\text { Advisory } \\
\text { group }\end{array}$ & $\begin{array}{l}\text { K-water } \\
\text { Corporation }\end{array}$ & $\begin{array}{l}\text { Regional } \\
\text { economics }\end{array}$ & 5 & $\mathrm{PS} 03$ & M \\
\hline 19 & $\begin{array}{l}\text { Advisory } \\
\text { group }\end{array}$ & $\begin{array}{c}\text { Korea } \\
\text { Institute of } \\
\text { Civil } \\
\text { Engineering } \\
\text { and Building } \\
\text { Technology }\end{array}$ & $\begin{array}{l}\text { Environmental } \\
\text { engineering }\end{array}$ & 13 & PS04 & $\mathrm{M}$ \\
\hline 20 & $\begin{array}{l}\text { Advisory } \\
\text { group }\end{array}$ & Seoul Institute & $\begin{array}{l}\text { Environmental } \\
\text { engineering }\end{array}$ & 3 & PS05 & M \\
\hline 21 & $\begin{array}{l}\text { Advisory } \\
\text { group }\end{array}$ & $\begin{array}{l}\text { Gacheon } \\
\text { University }\end{array}$ & $\begin{array}{l}\text { Landscaping } \\
\text { architecture }\end{array}$ & 13 & PS06 & M \\
\hline 22 & Citizen & Citizen & Business & 8 & $\mathrm{C} 01$ & M \\
\hline 23 & Citizen & Citizen & - & 5 & $\mathrm{C} 02$ & $\mathrm{~F}$ \\
\hline 24 & Citizen & Citizen & - & 16 & $\mathrm{C} 03$ & $\mathrm{M}$ \\
\hline 25 & Citizen & Citizen & - & 30 & $\mathrm{C} 04$ & M \\
\hline 26 & Citizen & Citizen & $\begin{array}{l}\text { Electronic } \\
\text { engineering }\end{array}$ & 19 & $\mathrm{C} 05$ & $\mathrm{M}$ \\
\hline 27 & Citizen & Citizen & $\begin{array}{c}\text { Public } \\
\text { administration }\end{array}$ & 6 & C06 & $\mathrm{F}$ \\
\hline 28 & Citizen & Citizen & - & 4 & C07 & $\mathrm{F}$ \\
\hline 29 & $\begin{array}{l}\text { Private } \\
\text { contractor } \\
\text { (Engineer) }\end{array}$ & $\begin{array}{c}\text { 'D' } \\
\text { Engineering }\end{array}$ & $\begin{array}{c}\text { Civil } \\
\text { engineering }\end{array}$ & 3 & EN01 & $\mathrm{M}$ \\
\hline 30 & $\begin{array}{l}\text { Private } \\
\text { contractor } \\
\text { (Engineer) }\end{array}$ & $\begin{array}{c}\text { 'S' } \\
\text { Engineering }\end{array}$ & $\begin{array}{c}\text { Civil } \\
\text { engineering }\end{array}$ & 1 & EN02 & M \\
\hline 31 & $\begin{array}{l}\text { Private } \\
\text { contractor } \\
\text { (Engineer) }\end{array}$ & $\begin{array}{c}\text { 'D' } \\
\text { Engineering }\end{array}$ & $\begin{array}{c}\text { Civil } \\
\text { engineering }\end{array}$ & 1 & EN03 & M \\
\hline 32 & $\begin{array}{l}\text { Private } \\
\text { contractor } \\
\text { (Engineer) }\end{array}$ & $\begin{array}{c}\text { 'D' } \\
\text { Engineering }\end{array}$ & $\begin{array}{c}\text { Civil } \\
\text { engineering }\end{array}$ & 1 & EN04 & M \\
\hline
\end{tabular}




\begin{tabular}{ccccccc}
\hline 33 & $\begin{array}{c}\text { Private } \\
\text { contractor } \\
\text { (Engineer) }\end{array}$ & $\begin{array}{c}\text { 'K' } \\
\text { Engineering }\end{array}$ & $\begin{array}{c}\text { Chemical } \\
\text { engineering }\end{array}$ & 5 & EN05 & M \\
\hline
\end{tabular}

